\author{
Universidade de São Paulo \\ Escola de Engenharia de São Carlos \\ Departamento de Engenharia de Estruturas
}

Túlio Raunyr Cândido Felipe

\title{
Análise Mecânica e Probabilística de Estruturas Treliçadas Sujeitas ao Colapso Progressivo
}

São Carlos - SP 

Túlio Raunyr Cândido Felipe

\title{
Análise Mecânica e Probabilística de Estruturas Treliçadas Sujeitas ao Colapso Progressivo
}

\author{
VERSÃO CORRIGIDA
}

A versão original encontra-se na Escola de Engenharia de São Carlos

Tese apresentada ao Departamento de Engenharia de Estruturas da Escola de Engenharia de São Carlos, Universidade de São Paulo, como parte dos requisitos necessários para obtenção do título de Doutor em Engenharia Civil (Estruturas).

Orientador: Professor Dr André Teófilo Beck

Coorientador: Professor Dr Vladimir Guilherme Haach

São Carlos - SP

2019 
AUTORIZO A REPRODUÇÃO TOTAL OU PARCIAL DESTE TRABALHO POR QUALQUER MEIO CONVENCIONAL OU ELETRONNICO, PARA FINS DE ESTUDO E PESQUISA, DESDE QUE CITADA A FONTE.

Ficha catalográfica elaborada pela Biblioteca Prof. Dr. Sérgio Rodrigues Fontes da EESC/USP com os dados inseridos pelo(a) autor(a).

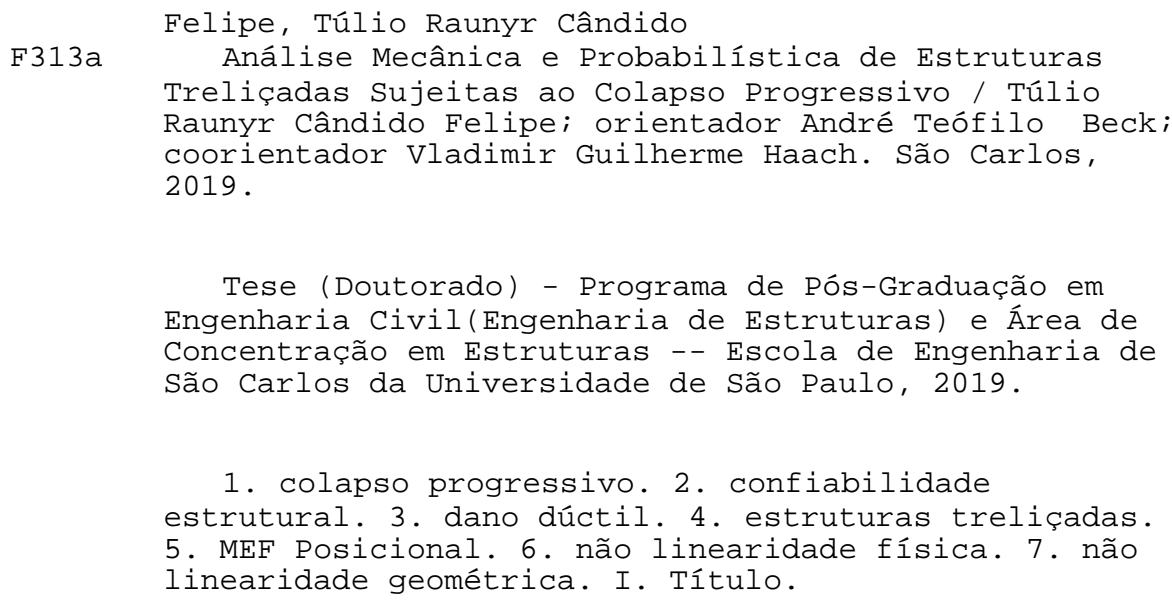

Eduardo Graziosi Silva - CRB - 8/8907 


\section{FOLHA DE JULGAMENTO}

Candidato: Bacharel TÚLIO RAUNYR CÂNDIDO FELIPE.

Título da tese: "Análise mecânica e probabilística de estruturas treliçadas sujeitas ao colapso progressivo".

Data da defesa: 13/09/2019.

Comissão Julgadora:

Resultado:

Prof. Associado André Teófilo Beck

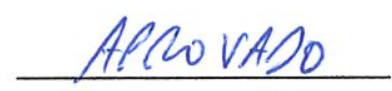

(Orientador)

(Escola de Engenharia de São Carlos/EESC)

Prof. Titular Paulo de Mattos Pimenta

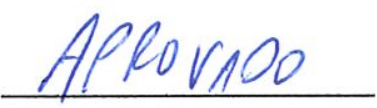

(Escola Politécnica/EP-USP)

Prof. Dr. Julio Flórez-lópez

(Universidade Federal da Integração Latino-Amerciana/UNILA)

Prof. Dr. Marcelo Greco

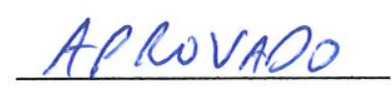

(Universidade Federal de Minas Gerais/UFMG)

Prof. Dr. Luiz Carlos Marcos Vieira Junior

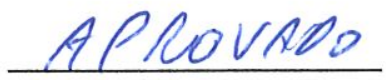

(Universidade Estadual de Campinas/UNICAMP)

Coordenador do Programa de Pós-Graduação em Engenharia Civil (Engenharia de Estruturas):

Prof. Associado Vladimir Guilherme Haach

Presidente da Comissão de Pós-Graduação:

Prof. Titular Murilo Araujo Romero 
Este trabalho é dedicado a Deus,

a minha família, aos meus avós (em memória), aos meus orientadores e amigos. 
A Deus por sempre estar presente na minha vida. Estendo a minha família pelo incentivo e paciência, em especial à minha esposa que está sempre ao meu lado.

Aos professores André T. Beck, Edson D. Leonel e Vladimir G. Haach, pela dose extra de conhecimento e incentivo, que minimizaram as minhas dificuldades na realização desta pesquisa. Aos professores convidados para a defesa pelos comentários valiosos durante suas arguições.

Ao Departamento de Engenharia de Estruturas da Escola de Engenharia de São Carlos e o Departamento de Engenharia Civil da Universidade Estadual da Paraíba, no conjunto de seus professores e funcionários, por proporcionarem um ensino de qualidade e a estrutura necessária para o desenvolvimento de minhas atividades acadêmicas.

Aos meus amigos da Paraíba, bem como meus amigos da cidade de São Carlos/SP. Estendo aos meus irmãos de farda do Curso de Formação de Oficiais 2019 do Centro de Instrução Almirante Wandenkolk, especialmente ao Segundo Pelotão da Terceira Companhia, simplesmente o melhor! Ao Guarda-Marinha Rodrigues pelas relevantes correções gramaticais.

Por fim, ao Conselho Nacional de Desenvolvimento Científico e Tecnológico (CNPq), pela bolsa de estudo a mim concedida. 

A nossa farda é branca

Sou de um corpo especial Marinha do Brasil serei mais um naval Ponte, estrada ou embarcação Estamos aqui pra servir nossa nação Minha missão é projetar Mas pela nossa pátria vou lutar até tombar

(GM EN Serra, 2019) 



\section{RESUMO}

FELIPE, T. R. C. Análise Mecânica e Probabilística de Estruturas Treliçadas Sujeitas ao Colapso Progressivo. 2019. 160 p. Tese de Doutorado (Engenharia de Estruturas) - Escola de Engenharia de São Carlos, Universidade de São Paulo, São Carlos, 2019.

Neste trabalho, um abrangente modelo de dano dúctil é deduzido para a análise não linear estática e dinâmica de estruturas treliçadas. O modelo é acoplado a uma formulação em Elementos Finitos Posicional (MEF Posicional) usando a medida de deformação logarítmica para lidar com grandes deslocamentos e grandes deformações. Ademais, a formulação proposta é combinada à confiabilidade estrutural para avaliar os caminhos de falha das estruturas treliçadas sujeitas ao colapso progressivo. Tal modelo captura a degradação mecânica em termos de variação de porosidade devido ao crescimento e coalescência de microcavidades e microfissuras no material. Usando o modelo proposto, a evolução da degradação mecânica cresce continuamente até que seja alcançado o dano crítico do material, conforme a pressuposição apontada pela comunidade científica. Isso implica que, em aplicações numéricas, a utilização do modelo proposto não acarreta instabilidade numérica na matriz Hessiana, uma vez que o módulo tangente vai tender ao valor obtido via curva experimental, diferentemente dos modelos apresentados na literatura, os quais conduzem a valores de módulo tangente que tendem a zero. A formulação proposta fornece um excelente ajuste para curvas de tensão $v s$. deformação de onze materiais diferentes, registrando o endurecimento, o amolecimento e a falha do material. Nas aplicações ao concreto, o modelo proposto resulta em uma melhor aproximação para os resultados experimentais em comparação com modelos da literatura. Por fim, a formulação proposta apresenta boa convergência dos resultados para a análise da trajetória de equilíbrio de estruturas treliçadas sob colapso progressivo considerando a não linearidade física e geométrica.

Palavras-chave: colapso progressivo; confiabilidade estrutural; dano dúctil; estruturas treliçadas; MEF Posicional; não linearidade física; não linearidade geométrica. 



\section{ABSTRACT}

FELIPE, T. R. C. Mechanical and Probabilistic Analysis of Truss Structures Considering Progressive Collapse. 2019. 160 p. Ph.D’s Thesis (Structural Engineering) - São Carlos School of Engineering, University of São Paulo, São Carlos, 2019.

In this work, a comprehensive ductile damage model is deducted for static and dynamic nonlinear analysis of truss structures. The model is based on the Positional Finite Element Method (Positional FEM) using log-strain measure to deal with large displacements and strains. Furthermore, the proposed formulation combines structural reliability to evaluate failure paths of truss structures subject to progressive collapse. The model captures mechanical degradation in terms of porosity variation due to the growth and coalescence of microcavities and microcracks in the material. According to the proposed model, the mechanical degradation evolves continuously until the critical damage is reached, as indicated by assumptions of the scientific community. This implies that in numerical applications, use of the proposed model does not result in numerical instability of the Hessian matrix, given that the tangent modulus tends to its experimental value, unlike the models presented in the literature, in which the tangent modulus tends to zero. The proposed formulation provides an excellent fit to stress v.s strain curves of eleven different materials, including hardening and softening material failure. When applied to concrete, the proposed model results in a better approximation to experimental results, in comparison with the models indicated in the literature. Finally, the proposed formulation presents good convergence in the results for the analysis of the equilibrium trajectory of truss structures under progressive collapse considering physical and geometric nonlinearities.

Keywords: progressive collapse; structural reliability; ductile damage; truss structures; Positional FEM; physical nonlinearity; geometric nonlinearity. 

Figura 1.1 - Colapso progressivo da ponte I35-W. . . . . . . . . . . . . . . 28

Figura 1.2 - Colapso progressivo do telhado do Centro Cívico, Hartford, 1978. . . . . . 29

Figura 2.1 - Colapso progressivo do edifício Ronan Point, Londres, 1968. . . . . . . . . 36

Figura 2.2 - Colapso progressivo do edifício Murrah, Oklahoma, 1995 . . . . . . . . . . 36

Figura 2.3 - Colapso progressivo do World Trade Center, New York, 2001 . . . . . . . . . 37

Figura 2.4 - Etapas para a ocorrência do colapso progressivo: (a) estruturas não resilientes;

(b) estruturas resilientes. . . . . . . . . . . . . . . . . . 39

Figura 3.1 - Elemento de treliça 3D - cinemática. . . . . . . . . . . . . . 53

Figura 3.2 - Forças externas: a) força externa estática; b) força externa impulsiva; c) força externa aperiódica. . . . . . . . . . . . . . 56 56

Figura 3.3 - a) lei de evolução da porosidade; b) lei de evolução do dano com relação a $\varepsilon_{H}^{p}$. 60 Figura 3.4 - Diagrama de tensão vs. deformação plástica de um material dúctil típico. . . 61

Figura 3.5 - Diagrama de tensão vs. deformação: decomposição da deformação total. . . 62

Figura 3.6 - Algoritmo de solução. . . . . . . . . . . . . . . . . . . 70

Figura 4.1 - Curva tensão vs. deformação do aço doce. . . . . . . . . . . . . . 73

Figura 4.2 - Curva tensão vs. deformação do aço de alta resistência. . . . . . . . . . 73

Figura 4.3 - Curva tensão vs. deformação do cobre $(99 \%)$. . . . . . . . . . . . . . 73

Figura 4.4 - Curva tensão vs. deformação do aço ASTM A36. . . . . . . . . . . . . . 74

Figura 4.5 - Curva tensão vs. deformação da madeira espécie. . . . . . . . . . . . . . 74

Figura 4.6 - Curva tensão vs. deformação do alumínio e do ferro fundido. . . . . . . . . 74

Figura 4.7 - Curva tensão vs. deformação do concreto a tração. . . . . . . . . . . . . 76

Figura 4.8 - Curva tensão vs. deformação do concreto a compressão. . . . . . . . . . . 76

Figura 4.9 - Evolução do dano no concreto. . . . . . . . . . . . . . . . . . 76

Figura 4.10-Curva tensão vs. deformação do UHPFRC a tração. . . . . . . . . . . . . . 78

Figura 4.11-Curva tensão vs. deformação do UHPFRC a compressão. . . . . . . . . . . 78

Figura 4.12-Evolução do dano no UHPFRC . . . . . . . . . . . . . . . . . . . . 78

Figura $4.13-$ Geometria da treliça 2D . . . . . . . . . . . . . . . . . 80

Figura 4.14-Avaliação da treliça 2 D de concreto. . . . . . . . . . . . . . . . . 80

Figura 4.15-Treliça 3D: a) visão de topo; b) visão lateral; c) lei constitutiva. . . . . . . . . 82

Figura 4.16-Curva força $v s$. deslocamento vertical do nó central da treliça 3D. . . . . . . 82

Figura 4.17-Análise da trajetória de equilíbrio da treliça 3D . . . . . . . . . . 83

Figura 4.18-Treliça 3D com 12 barras: (a) dados geométricos; (b) lei constitutiva. . . . . 84

Figura 4.19-Trajetória de equilíbrio para o comportamento do material elástico linear. . . 85 
Figura 4.20-Avaliação da Treliça 3D com 12 barras. . . . . . . . . . . . . . . . 85

Figura 5.1 - Treliça 2D: (a) geometria; (b) força dinâmica. . . . . . . . . . . . . . . 88

Figura 5.2 - Curva deslocamento vs. tempo: sistema conservativo. . . . . . . . . . 88

Figura 5.3 - Curva deslocamento $v s$. tempo: sistema não conservativo. . . . . . . . . . . 89

Figura 5.4 - Razão entre frequências vs. $\xi \ldots$. . . . . . . . . . . . . . . . . . 90

Figura 5.5 - Deslocamentos $v s$. tempo para diferentes $\xi \ldots \ldots$. . . . . . . . . . . 90

Figura 5.6 - Razão entre frequências vs. deformações. . . . . . . . . . . . . . . . . . . 91

Figura 5.7 - Treliça 2D: (a) geometria; (b) relação constitutiva do material. . . . . . . . . 92

Figura 5.8 - Históricos de deslocamento do terremoto Fukushima. . . . . . . . . . . . . 92

Figura 5.9 - Deslocamento $v s$. tempo para $\mathrm{R}=1, \mathrm{R}=2$ e $\mathrm{R}=4 \ldots \ldots$. . . . . . . . 93

Figura 5.10-Evolução das deformações plásticas totais. . . . . . . . . . . . . . . . 94

Figura 5.11-Evolução da força normal. . . . . . . . . . . . . . . . . . . . . 94

Figura 5.12-Torre metálica 2D: (a) posicionamento dos cabos; (b) intensidade da força dinâmica. . . . . . . . . . . . . . . . . 95

Figura 5.13-Análise modal: (a) primeiro, (b) segundo e (c) terceiro modo de vibração. 96

Figura 5.14-Deslocamento $v s$. tempo para o nó 1 com $\xi=0$. . . . . . . . . . . . . 97

Figura 5.15-Deslocamento $v s$. tempo para o nó 1 com $\xi=0,02$. . . . . . . . . . . 98

Figura 5.16-Torre metálica 2D: (a) geometria; (b) relação constitutiva do material. . . . . 99

Figura 5.17-Modo de vibração: (a) primeiro; (b) segundo e (c) terceiro. . . . . . . . . . . 99

Figura 5.18-Deslocamento horizontal do nó 1 vs. tempo: (a) horizontal; (b) vertical. . . . 100

Figura 5.19-Evolução do dano vs. tempo para os elementos E2 e E3. . . . . . . . . . . . 101

Figura 5.20-Deformações plásticas totais $v s$. tempo. . . . . . . . . . . . . . . . . 101

Figura 5.21-Trecho do espectro de deslocamento do terremoto. . . . . . . . . . . . . 102

Figura 5.22-Torre metálica 3D: (a) vista de perspectiva; (b) elevação e posicionamento das antenas; (c) relação constitutiva do material empregado. . . . . . . . . . 103

Figura 5.23-Torre metálica 3D: (a) primeiro e (b) terceiro modo de vibração. . . . . . . . 104

Figura 5.24-Deslocamento $v s$. tempo para o nó 1 com $\xi=0,02$. . . . . . . . . . . . 105

Figura 5.25-Deslocamento $v$ s. tempo para o nó $1 \mathrm{com} \xi=0,05$. . . . . . . . . . . 106

Figura 5.26-Mudança de configuração da torre: (a) inicial; (b) final (aumentado 25 vezes). 107

Figura 6.1 - Treliça de von Mises: (a) geometria; (b) relação constitutiva. . . . . . . . . . 114

Figura 6.2 - Curva $P_{f} v s$. deslocamento vertical do nó central: solução linear elástica. . . 115

Figura 6.3 - Curva força vs. deslocamento vertical do nó central da treliça. . . . . . . . . 116

Figura 6.4 - Curva $P_{f} v s$. deslocamento vertical do nó central: solução não linear elástica. 117

Figura 6.5 - Treliça de von Mises: (a) geometria; (b) relação constitutiva. . . . . . . . . 118

Figura 6.6 - Curva força vs. deslocamento vertical do nó central da treliça. . . . . . . . . 118

Figura 6.7 - Curva $P_{f} v s$. deslocamento vertical do nó central: solução não linear plástica. 119

Figura 6.8 - Comparativos das soluções via FORM. . . . . . . . . . . . . . . . . . 119

Figura 6.9 - Algoritmo do modelo mecano-probabilístico. . . . . . . . . . . . . . 120 
Figura $7.1-P_{f} v s$. deslocamento: comparativo entre as soluções pelo SMC, análise linear elástica. . . . . . . . . . . . . . . . . . 122

Figura $7.2-P_{f} v s$. deslocamento: comparativo entre as soluções pelo SMC, análise não linear elástica. . . . . . . . . . . . . . . . . . . . . . 123

Figura $7.3-P_{f} v s$. deslocamento: comparativo entre os modos de falha pelo SMC. . . . 124 Figura $7.4-P_{f} v s$. deslocamento: comparativo entre as soluções pelo SMC, análise não linear plástica. . . . . . . . . . . . . . . . . . . . . 124

Figura $7.5-P_{f} v s$. deslocamento: comparativo entre os modos de falha pelo SMC. . . . 125

Figura 7.6 - Evolução da probabilidade de falha com o tempo. . . . . . . . . . . . . . 126

Figura 7.7 - Caminhos de carregamentos. . . . . . . . . . . . . . . . . . 128

Figura 7.8 - Evolução da $P_{f}$ com o tempo. . . . . . . . . . . . . . . . . 128

Figura 7.9 - Geometria e lei constitutiva da treliça. . . . . . . . . . . . . . . . . . . . 129

Figura 7.10-Curva Força vs. deslocamento do nó central. . . . . . . . . . . . . . . . . . 129

Figura 7.11-Evolução da $P_{f}$ com o tempo: análise quasi-estática. . . . . . . . . . . . . 131

Figura 7.12-Evolução da $P_{f}$ com o tempo: análise dinâmica. . . . . . . . . . . . . . . . 131

Figura 7.13- $P_{f}$ do sistema $v s$. tempo: comparação entre a análise quasi-estática e dinâmica.132

Figura A.1 - Algoritmo em linguagem Fortran para a determinação de $D$ e $E_{t}$ via curva experimental. . . . . . . . . . . . . . . 155

Figura A.2 - Fit da evolução do dano para o aço doce. . . . . . . . . . . . . . . . . . 156

Figura A.3 - Fit da evolução do dano para o aço alta resistência. . . . . . . . . . . . . . . 156

Figura A.4-Fit da evolução do dano para o cobre (99\%). . . . . . . . . . . . . . . . . 157

Figura A.5 - Fit da evolução do dano para o Aço ASTM A36. . . . . . . . . . . . . . . . 157

Figura A.6-Fit da evolução do dano para a madeira espécie Simarouba amara . . . . . . 158

Figura A.7 - Fit da evolução do dano para o concreto a tração. . . . . . . . . . . . . . . . 158

Figura A.8-Fit da evolução do dano para o concreto a compressão. . . . . . . . . . . . . 159

Figura A.9-Fit da evolução do dano para o UHPFRC a tração. . . . . . . . . . . . . . . . 159

Figura A.10-Fit da evolução do dano para o UHPFRC a compressão. . . . . . . . . . . . 160 

Tabela 2.1 - Abordagens destacadas pelos documentos normativos internacionais e diretrizes. . . . . . . . . . . . . . . . . . 4 45

Tabela 4.1 - Espécimes e dados geométricos do corpo de prova. . . . . . . . . . . 72

Tabela 4.2 - Dados dos materiais obtidos via curva experimental. . . . . . . . . . . . 72

Tabela 6.1 - Comparação das soluções: variáveis normais. . . . . . . . . . . . . . . . . 112

Tabela 6.2 - Comparação das soluções: variáveis log-normais. . . . . . . . . . . . . . . 113

Tabela 6.3 - Estatísticas das variáveis aleatórias da treliça de von Mises. . . . . . . . . 115 

ABNT Associação Brasileira de Normas Técnicas

CNPq Conselho Nacional de Desenvolvimento Científico e Tecnológico

DCR Demand Capacity Ratio

CEGS China Association for Engineering Construction Standardization

DoD Departament of Defense

EESC Escola de Engenharia de São Carlos

FAD Fator de Amplificação Dinâmica

FORM First Order Reliability Method

GSA General Services Adminstration

IS Isolamento por Segmentação

MCCA Método dos Caminhos de Cargas Alternativos

MEF Método dos Elementos Finitos

MRLE Método da Resistência Local Específica

NTSB National Transportation Safety Board

NISTIR National Institute of Standard and Technology

NLF Não Linearidade Física

NLG Não Linearidade Geométrica

RPFA Regras Prescritivas de Forças de Amarração

SMC Simulação de Monte Carlo

SRAPC Systematic Reliability-based Approach to Progressive Collapse

UEPB Universidade Estadual da Paraíba

UHPFRC Ultra-High Performance Fiber-Reinforced Concrete 
Universidade de São Paulo

WASM

Weighted Average Simulation Method 


\section{LISTA DE SÍMBOLOS}

\begin{tabular}{|c|c|}
\hline$\Pi$ & energia mecânica total \\
\hline$\Pi_{0}$ & energia potencial total \\
\hline$Q(t, \vec{Z})$ & energia total dissipada \\
\hline$t$ & instante de tempo \\
\hline$\vec{X}$ & vetor com as posições nodais na configuração inicial \\
\hline$\vec{Y}$ & vetor com as posições nodais na configuração intermediária \\
\hline$\vec{Z}$ & vetor com as posições nodais na configuração atual \\
\hline$K$ & energia cinética \\
\hline$P$ & potencial das forças externas \\
\hline$U$ & energia de deformação \\
\hline$W_{d}$ & energia adicionada ao sistema devido o dano acidental \\
\hline$l_{0}$ & comprimento do elemento de treliça na configuração inicial \\
\hline$l_{p}$ & comprimento do elemento de treliça na configuração intermediária \\
\hline$l$ & comprimento do elemento de treliça na configuração atual \\
\hline$\lambda$ & estiramento de Cauchy-Green \\
\hline$J$ & Jacobiano da transformação \\
\hline$d \varepsilon$ & deformação longitudinal de engenharia instantânea \\
\hline$\varepsilon_{l n}$ & deformação logarítmica \\
\hline$\varepsilon_{l n}^{e}$ & parte elástica da deformação logarítmica \\
\hline$\varepsilon_{l n}^{p}$ & parte plástica da deformação logarítmica \\
\hline$\varepsilon_{l n}^{d}$ & parte de dano da deformação logarítmica \\
\hline & tensor de tensão de Kirchhoff \\
\hline
\end{tabular}




\begin{tabular}{|c|c|}
\hline$\sigma$ & tensor de tensão de Cauchy \\
\hline$\vec{F}^{(e x t)}$ & vetor de forças externas \\
\hline$\delta_{i j}$ & tensor Delta de Kronecker \\
\hline$\Psi$ & potencial da energia livre de Helmholtz \\
\hline$D$ & variável de dano \\
\hline E & módulo de elasticidade do material íntegro \\
\hline א & parâmetro de encruamento isótropo \\
\hline$\Upsilon$ & força termodinâmica conjugada da variável de dano \\
\hline$\chi$ & força termodinâmica conjugada do encruamento \\
\hline$\varpi$ & variável interna de encruamento \\
\hline$\gamma$ & multiplicador plástico \\
\hline$\tau_{y}$ & tensão de escoamento \\
\hline$\vec{F}^{(i n t)}$ & vetor de forças internas \\
\hline$\varepsilon_{l n, d}^{p}$ & limite de dano inicial \\
\hline$\xi$ & extensão plástica \\
\hline tr & operador traço \\
\hline$\varepsilon_{H}^{p}$ & componente hidrostática da deformação plástica \\
\hline$\Re(\xi, D)$ & função de dano \\
\hline$\kappa$ & porosidade \\
\hline$D_{\text {crit }}$ & dano crítico \\
\hline$\tau_{u}$ & tensão última \\
\hline$\tau_{r}$ & tensão de ruptura \\
\hline$P_{f}$ & probabilidade de falha \\
\hline$g(\vec{v})$ & equação de estado limite \\
\hline$\Omega_{s}$ & domínio de falha \\
\hline$\Omega_{s}$ & domínio de sobrevivência \\
\hline$\beta$ & índice de confiabilidade \\
\hline
\end{tabular}


INTRODUÇÃO . . . . . . . . . . . . . . . . . 27

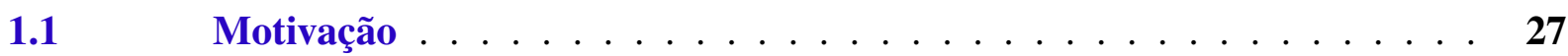

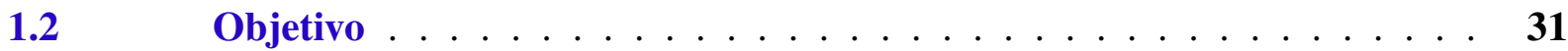

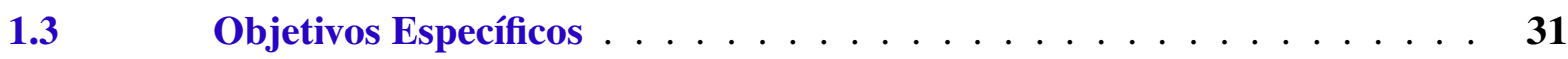

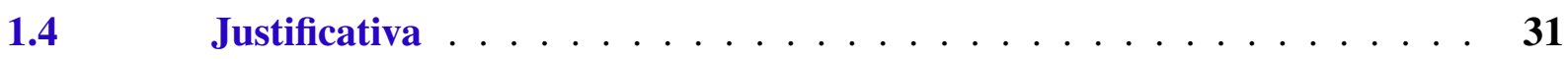

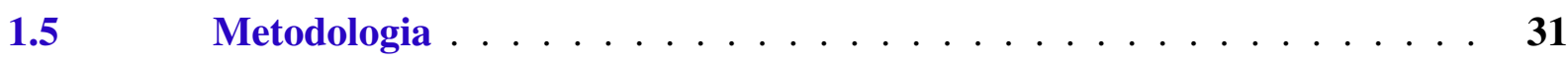

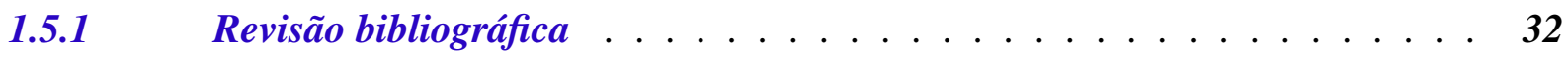

1.5.2 Modelo mecânico . . . . . . . . . . . . . . . . . . . 32

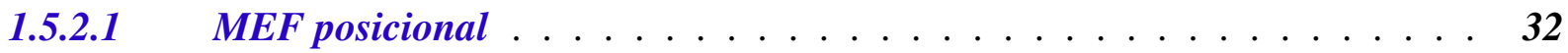

1.5.2.2 Mecânica do dano contínuo . . . . . . . . . . . . . . . 32

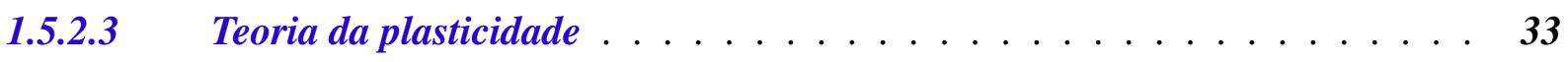

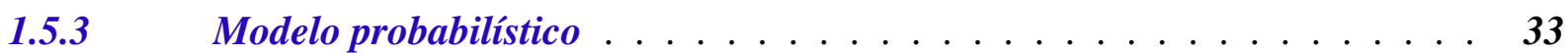

2 MITIGAÇÃO DO RISCO DE DANOS ACIDENTAIS E COLAPSO PROGRESSIVO EM ESTRUTURAS . . . . . . . . . . . . 35

$2.1 \quad$ Generalidades . . . . . . . . . . . . . . . . 35

2.2 Abordagens para a Prevenção de Danos Acidentais e Colapso Progressivo 39

2.2.1 Regras prescritivas de forças de amarração . . . . . . . . . . . . . . . 40

2.2.2 Método dos caminhos de carga alternativos . . . . . . . . . . . 40

2.2.3 Método da resistência local específica . . . . . . . . . . . . . 41

2.2.4 Isolamento por segmentação . . . . . . . . . . . . . . . 41

2.2.5 Abordagem baseada em análise probabilística . . . . . . . . . . . . 42

2.3 Documentos Normativos . . . . . . . . . . . . . . . . . 44

$2.4 \quad$ Pesquisas Atuais $\ldots \ldots \ldots \ldots \ldots \ldots$

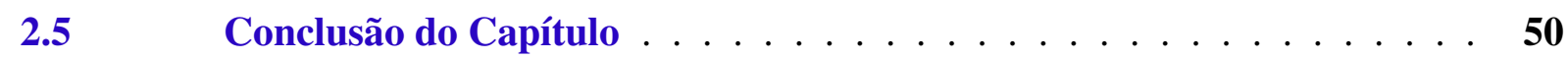

3 MODELO MECÂNICO .................. 51

$3.1 \quad$ Considerações Iniciais $\ldots \ldots \ldots \ldots \ldots \ldots$

3.2 Uma Formulação Lagrangeana Total em Posição Aplicada a Análise Dinâmica não Linear Física e Geométrica de Estruturas Treliçadas . . . 51

3.2.1 Energia mecânica total . . . . . . . . . . . . . . . 52

3.2.2 Cinemática .................... 52

3.2.3 Decomposição multiplicativa do estiramento de Cauchy-Green . . . . . . . 54 
Potencial das forças externas aplicadas . . . . . . . . . . . . . . . 55

3.2.6 Um abrangente modelo de dano dúctil . . . . . . . . . . . . . . . . . . . 59

3.2.7 Energia cinética e forças de inércia . . . . . . . . . . . . . . 63

3.2.8 Energia total dissipativa e força de amortecimento . . . . . . . . . . . . 64

3.3 Procedimento de Solução do Problema . . . . . . . . . . . . 66

$3.4 \quad$ Conclusão do Capítulo $\ldots \ldots \ldots \ldots \ldots \ldots$

4 VALIDAÇÃO DO MODELO MECÂNICO: ANÁLISE ESTÁTICA . . . 71

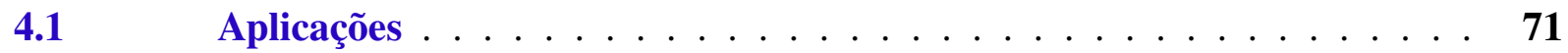

4.1.1 Exemplos experimentais . . . . . . . . . . . . 71

4.1.2 Exemplos numéricos . . . . . . . . . . . . . . . . 79

4.1.2.1 Exemplo 1: treliça $2 D \ldots \ldots \ldots \ldots \ldots$

4.1.2.2 Exemplo 2: cúpula em forma de estrela . . . . . . . . . . . . . . . 81

4.1.2.3 Exemplo 3: treliça 3D com 12 barras . . . . . . . . . . . . . . . . 84

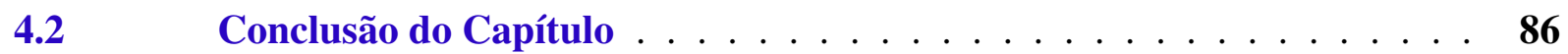

VALIDAÇÃO DO MODELO MECÂNICO: ANÁLISE DINÂMICA . . 87

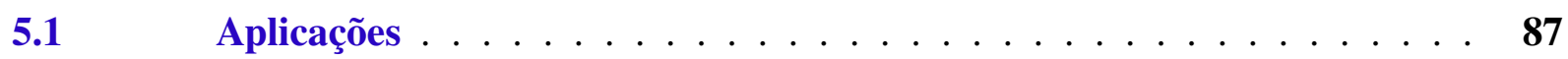

5.1.1 Treliça $2 D$ sob efeito dinâmico sem amortecimento . . . . . . . . . . . . 87

5.1.2 Treliça $2 D$ sob efeito dinâmico com amortecimento . . . . . . . . . . . . . 89

5.1.3 Treliça $2 D$ sob ação de terremoto . . . . . . . . . . . . . . . . . 91

5.1.4 Torre de linhas de transmissão sob a ação dinâmica dos cabos . . . . . . . 95

5.1.5 Torre metálica $2 D$ sob ação de terremoto . . . . . . . . . . . . . . . . . . 98

5.1.6 Torre de telecomunicação submetida ao sismo de El-Centro . . . . . . . . 102

5.2 Conclusão do Capítulo . . . . . . . . . . . . . . . 108

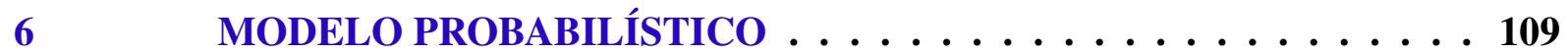

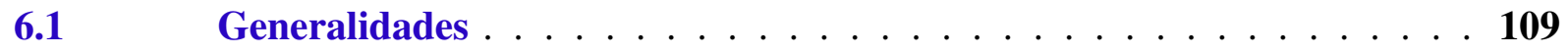

6.2 Simulação de Monte Carlo (SMC) . . . . . . . . . . . . . . 110

$6.3 \quad$ Weighted Average Simulation Method (WASM) . . . . . . . . . . . 110

$6.4 \quad$ First Order Reliability Method (FORM) . . . . . . . . . . . . . . . 111

$6.5 \quad$ Validação do Modelo Probabilístico . . . . . . . . . . . . . . . . 111

6.5.1 Problema fundamental de confiabilidade para variáveis aleatórias normais 112

6.5.2 Problema fundamental de confiabilidade para variáveis aleatórias log-normais 113

6.5.3 Treliça de von Mises: solução analítica linear elástica . . . . . . . . . . . . 114

6.5.4 Treliça de von Mises: solução analítica não linear elástica . . . . . . . . . 116

6.5.5 Treliça de von Mises: solução analítica não linear plástica . . . . . . . . . 117

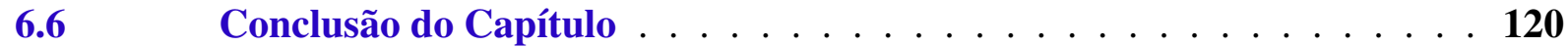


7.2 Avaliação da Treliça de von Mises para Análise de Confiabilidade Independente do Tempo . . . . . . . . . . . . . . . . . . . . . . . . . 121

7.3 Validação da SMC para Análise de Confiabilidade Dependente do Tempo 126

7.4 Dependência do Caminho dos Carregamentos . . . . . . . . . . . . . 127

7.5 Análise Dinâmica não Linear da Treliça de von Mises com Solicitação Dependente do Tempo . . . . . . . . . . . . . . . . . . . . 129

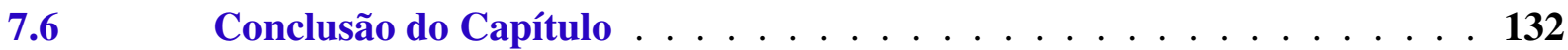

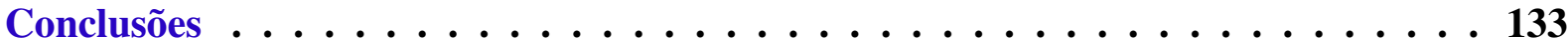

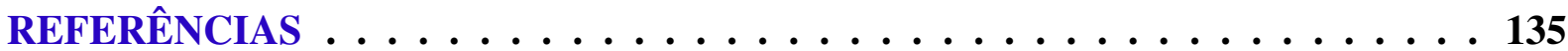

APÊNDICE A DETERMINAÇÃO DOS PARÂMETROS DO MODELO

PROPOSTO ....................... 155

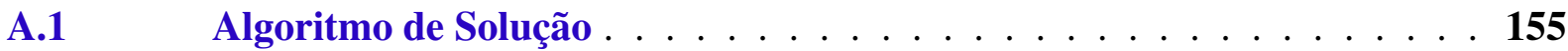

A.2 Determinação de $\alpha_{1}^{p}, \alpha_{2}^{p}$ e $\alpha_{3}^{p}$ para o Aço Doce . . . . . . . . . . . . 156

A.3 Determinação de $\alpha_{1}^{p}, \alpha_{2}^{p}$ e $\alpha_{3}^{p}$ para o Aço de Alta Resistência . . . . . . 156

A.4 Determinação de $\alpha_{1}^{p}, \alpha_{2}^{p}$ e $\alpha_{3}^{p}$ para o Cobre (99\%) . . . . . . . . . . 157

A.5 Determinação de $\alpha_{1}^{p}, \alpha_{2}^{p}$ e $\alpha_{3}^{p}$ para o aço ASTM A36 . . . . . . . . . 157

A.6 Determinação de $\alpha_{1}^{p}, \alpha_{2}^{p}$ e $\alpha_{3}^{p}$ para a Madeira Espécie Simarouba amara em Ensaio de Compressão . . . . . . . . . . . . . . . . . . . . . . 158

A.7 Determinação de $\alpha_{1}^{p}, \alpha_{2}^{p}$ e $\alpha_{3}^{p}$ para o Concreto a Tração . . . . . . . . . 158

A.8 Determinação de $\alpha_{1}^{p}, \alpha_{2}^{p}$ e $\alpha_{3}^{p}$ para o Concreto a Compressão . . . . . . . 159

A.9 Determinação de $\alpha_{1}^{p}, \alpha_{2}^{p}$ e $\alpha_{3}^{p}$ para o UHPFRC a Tração . . . . . . . . 159

A.10 Determinação de $\alpha_{1}^{p}, \alpha_{2}^{p}$ e $\alpha_{3}^{p}$ para o UHPFRC a Compressão . . . . . 160 

CAPÍTULO

\section{1}

INTRODUÇÃO

\subsection{Motivação}

Sistemas estruturais compostos por elementos de treliça são amplamente utilizados em aplicações de engenharia. Esse elemento estrutural permite a rápida montagem de grandes vãos com estruturas leves como observado em sistemas de cobertura, pontes, torres de transmissão e plataformas offshore, por exemplo. Além disso, baixo custo e alta eficiência mecânica tornam as estruturas de treliça altamente atraentes.

A modelagem mecânica de estruturas de treliça 3D é simples sob condições usuais (lineares), para as quais se aplicam as hipóteses clássicas da teoria da elasticidade. No entanto, aplicações modernas de estruturas de treliça muitas vezes exigem análises não linear geométrica e física para a previsão precisa da resposta estrutural.

Essa observação é justificada por recentes falhas estruturais, como o colapso de 2007 das longarinas treliçadas em aço da ponte I-35W sobre o rio Mississippi (Figura 1.1), Minneapolis $[1,2,3,4]$. O colapso progressivo da ponte I-35W resultou em 13 mortes e 145 feridos. Uma investigação do projeto original, pelo National Transportation Safety Board (NTSB) [5], concluiu que a espessura das placas de reforço, a espessura da parede lateral e a análise elástica linear 2D não foram suficientes para caracterizar o comportamento estrutural. Assim, o esforço normal nos elementos nas diagonais da treliça não foi devidamente considerado. Ademais, as ligações entre os membros do tabuleiro e a longarina da treliça foram consideradas inadequadas.

Hao [6] por meio de uma simulação em elementos finitos 3D não linear encontrou que algumas placas de reforço da ponte I-35W atingiram seu limite de escoamento sob condições de carga de projeto. Liao et al. [7] avaliaram a redistribuição de carga após a falha da placa de reforço dessa ponte, usando a análise em elementos finitos não linear 3D. A não linearidade do material foi abordada pelo critério de plastificação de von Mises e pela regra de encruamento isotrópico. A não linearidade geométrica também foi assumida. A análise de Liao et al. [7] revelou que o 
escoamento das placas de reforço resultou em um aumento significativo na força normal nos elementos nas diagonais. Os autores concluíram que a análise não linear, juntamente com a modelagem $3 \mathrm{D}$, forneceu informações essenciais sobre o colapso progressivo das longarinas treliçadas da ponte I-35W.

Figura 1.1 - Colapso progressivo da ponte I35-W.

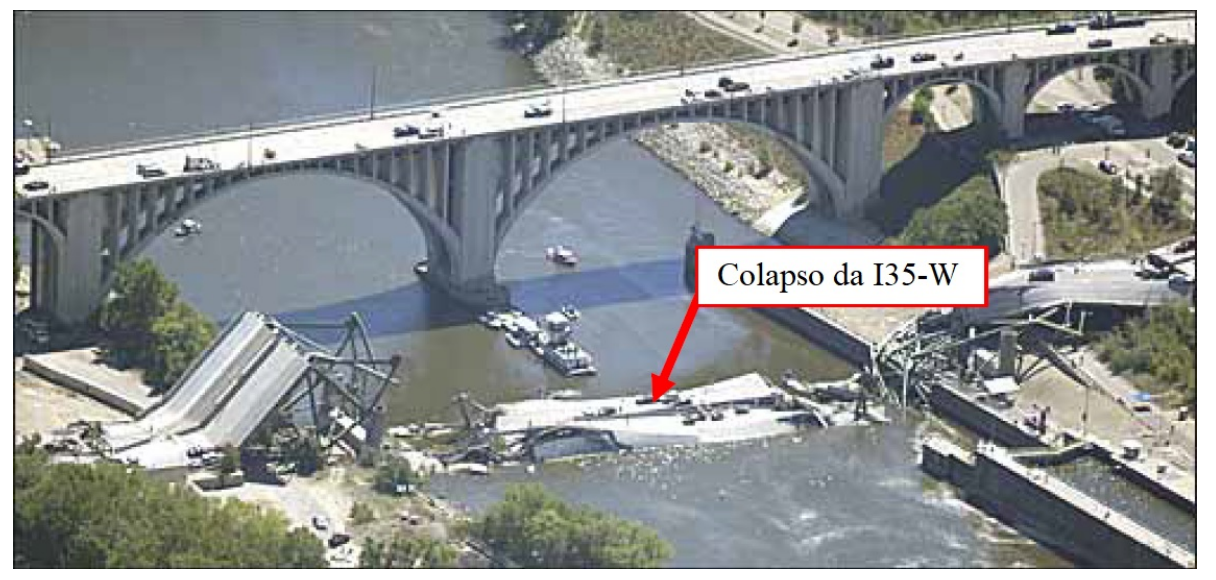

Fonte: National Transportation Safety Board [5].

Portanto, uma estimativa precisa do comportamento mecânico de estruturas treliçadas 3D complexas deve levar em consideração as não linearidades física e geométrica. A não linearidade física surge de alterações na rigidez do material devido ao aumento das deformações, enquanto que a análise não linear geométrica garante o equilíbrio sob grandes deslocamentos [8,9].

A não linearidade geométrica é levada em consideração pela imposição de equações de equilíbrio na configuração atual/deformada. Devido à complexidade envolvida nas alterações de configuração, as análises são simplificadas por meio de métodos numéricos, por exemplo, o Método dos Elementos Finitos (MEF). Muitas formulações do MEF são apresentadas na literatura. Elas diferem quanto à técnica empregada para escrever a equação de equilíbrio mecânico. $\mathrm{Na}$ abordagem clássica do MEF, o funcional de energia é escrito a partir de deslocamentos nodais $[10,11,12]$. Contudo, o funcional de energia também pode ser escrito em termos de posições nodais, em vez de deslocamentos nodais, o que leva ao MEF posicional [13, 14].

Diversos trabalhos que tratam da não linearidade geométrica com a abordagem clássica do MEF são observados na literatura. Meek e Tan [15] analisaram o comportamento geometricamente não linear de pórticos 3D por meio de uma formulação Lagrangeana atualizada para grandes rotações. Oran e Kassimali [16] consideraram uma descrição Euleriana para a análise geometricamente não linear de pórticos 2D sob cargas estáticas e dinâmicas. Torkamani e Shieh [17] empregaram matrizes de rigidez de alta ordem com uma descrição Lagrangeana atualizada para avaliar o comportamento mecânico de estruturas treliçadas 2D. Crisfield [18] e Crisfield e Moita [19] aplicaram a formulação co-rotacional para sólidos, cascas e vigas geometricamente 
não lineares.

A abordagem do MEF posicional foi aplicada em análises estáticas e dinâmicas geometricamente não lineares de cascas [20, 21], placas [22], pórticos [23, 24, 25], vigas [26, 27] e mecanismos [28], sempre com bons resultados. Carrazedo e Coda [29] propuseram um elemento finito prismático de base triangular de alta ordem para analisar vigas, placas e cascas laminadas, usando uma descrição Lagrangeana total com comportamento livre de travamento e distribuição de tensão adequada mesmo para materiais complexos. Greco et al. [30] apresentaram uma formulação posicional para a análise estática de treliças empregando a medida de deformação não linear de engenharia. Todavia, esta é inapropriada para as análises de estruturas sujeitas a grandes deformações, pois permite jacobiano negativo para níveis finito de tensão. Greco e Ferreira [31] propuseram uma formulação posicional usando a deformação logarítmica para a avaliação estática de treliças sob grandes deformações. Greco e Costa [32] apresentaram uma formulação posicional para análise estática de treliça assumindo diferentes medidas de deformação em uma descrição Lagrangeana total.

A descrição precisa das mudanças de configuração é necessária, mas não é suficiente para a modelagem adequada das respostas estruturais. As não linearidades físicas decorrentes do escoamento, encruamento, amolecimento e falha do material também devem ser levadas em conta. A esse respeito, a teoria da plasticidade e a teoria da mecânica do dano contínuo podem ser aplicadas. A teoria da plasticidade foi proposta para modelar falhas de materiais dúcteis $[33,34]$. Já a teoria do dano contínuo foi deduzida para descrever a influência do dano material na rigidez e resistência do material [35, 36, 37, 38, 39].

Figura 1.2 - Colapso progressivo do telhado do Centro Cívico, Hartford, 1978.

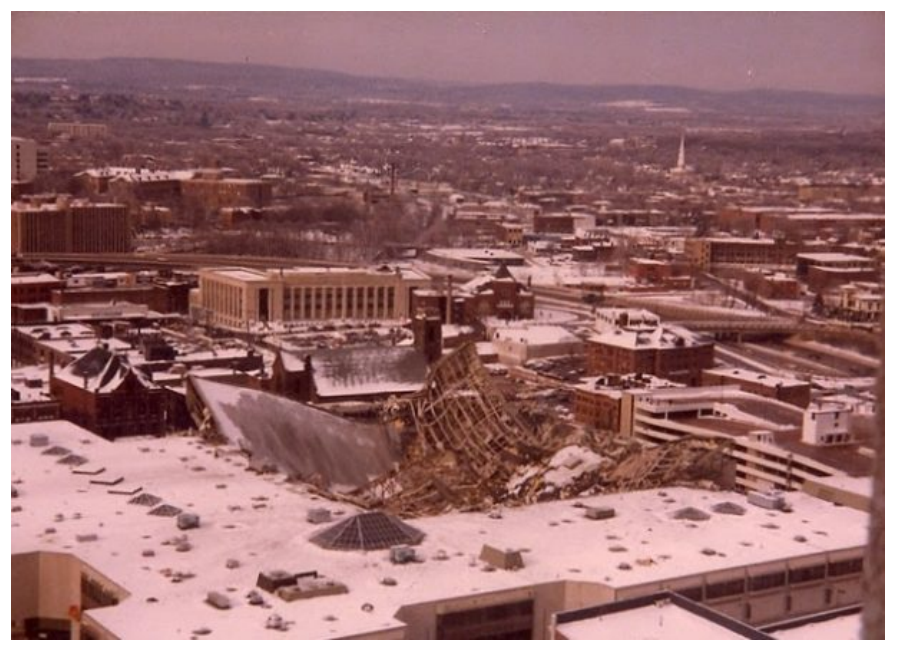

Fonte: Disponível em https://connecticuthistory.org/ civic-center-roof-collapses-today-in-history/. Acesso: 27 novembro de 2018.

Após a falha do telhado do Centro Cívico na cidade Hartford em 1978 (Figura 1.2), 
Connecticut, muitas pesquisas em estruturas treliçadas usaram a teoria da plasticidade para prever o comportamento inelástico pós-escoamento [40, 41, 42, 43, 44, 45, 46]. Não obstante, a degradação mecânica causada por microcavidades e microfissuras não é tratada corretamente pela teoria da plasticidade, porque o comportamento de amolecimento do material precisa ser incluído. Neste contexto, a mecânica do dano contínuo pode ser empregada [47, 48, 49, 50, 51$]$. A mecânica do dano contínuo tem sido amplamente estudada pela comunidade científica [52, 53, $54,55,56]$. Apesar disso, há uma falta de publicações na literatura abordando o acoplamento da não linearidade geométrica, plasticidade e dano para uma análise abrangente das estruturas de treliça.

Nesse contexto, este estudo apresenta uma formulação numérica baseada no MEF posicional utilizando a medida de deformação logarítmica para a modelagem mecânica de estruturas treliçadas 3D sujeitas ao colapso progressivo, levando em consideração a não linearidade física e geométrica. Ademais, a não linearidade do material é modelada pelo acoplamento da plasticidade a mecânica do dano contínuo. Por conseguinte, a formulação proposta inclui um modelo abrangente de dano dúctil acoplado a componente hidrostática das deformações plásticas.

No tocante ao colapso progressivo, todas as estruturas podem estar suscetíveis a esse evento. Esse tipo de colapso pode ser iniciado por danos acidentais, também denominados de eventos de baixa probabilidade e altas consequências, tais como: explosões, colisões de veículos, incêndios, tornados, terremotos, tsunamis, erros humanos de projeto e construção, ataques terroristas, etc.

Os documentos normativos internacionais apresentam recomendações baseadas em leis empíricas de natureza fenomenológica para mitigar a ocorrência do colapso progressivo [57]. Outrossim, a maioria desses códigos não realiza a avaliação da confiabilidade das estruturas perante esse evento, não consegue determinar os elementos mais vulneráveis nem propõe medidas eficientes de resistência ao colapso.

Por outro lado, existem as incertezas presentes, pois tanto as ações como as propriedades físicas relacionadas à resistência dos materiais são variáveis aleatórias. Incertezas são intrínsecas a qualquer problema de engenharia [58]. Elas surgem do conhecimento incompleto da resposta real do problema avaliado [58]. Desta forma, nenhuma construção pode ser projetada e construída para ser absolutamente livre de riscos. O risco é a consequência natural dessas incertezas [59]. Consequentemente, estratégias para a quantificação do risco são essenciais na tomada de decisão para medidas alternativas contra o colapso progressivo das estruturas. Tais estratégias podem ser desenvolvidas usando modelos numéricos robustos acoplados à análise da teoria da confiabilidade estrutural. 


\subsection{Objetivo}

O objetivo deste trabalho é o desenvolvimento e a implementação computacional de uma formulação Lagrangeana total em posição, aplicada a análise estática e dinâmica não linear física e geométrica de estruturas treliçadas 3D sujeitas ao colapso progressivo. Esta formulação é vinculada à teoria da confiabilidade estrutural para a avaliação das incertezas, implicando em uma abordagem robusta para garantir a segurança das estruturas.

\subsection{Objetivos Específicos}

a) utilizar a medida de deformação logarítmica para avaliar o potencial da energia livre de Helmholtz em termos das posições nodais;

b) propor um modelo abrangente de dano dúctil capaz de capturar a degradação do material em função da variação da porosidade;

c) acoplar a formulação proposta ao método de simulação de Monte Carlo para analisar a probabilidade de falha das estruturas treliçadas submetidas ao colapso progressivo.

\subsection{Justificativa}

Os códigos internacionais não têm abordagens para avaliar a probabilidade de colapso das estruturas na ocorrência de um dano acidental. Estes também não apresentam estratégias consistentes para determinar o(s) elemento(s) chave(s) das estruturas. Portanto, constata-se a indispensabilidade por estratégias baseadas na teoria da confiabilidade estrutural.

Outro aspecto relevante nos problemas gerados pelo colapso progressivo é o comportamento não linear da estrutura, que sofre grandes deslocamentos e grandes deformações, fazendo com que uma análise linear não mostre o seu real comportamento. Dessa forma, modelos numéricos robustos devem ser adotados para avaliar a trajetória de equilíbrio da estrutura.

Por fim, com base no levantamento bibliográfico, foi verificado que faltam trabalhos que considerem uma análise não linear conjunta com a confiabilidade estrutural para analisar os efeitos do colapso progressivo nas estruturas.

\subsection{Metodologia}

A seguir, é delineada a metodologia empregada neste trabalho. 


\subsubsection{Revisão bibliográfica}

A revisão bibliográfica é realizada continuamente e compreende conteúdos relativos ao colapso progressivo de estruturas, MEF posicional, mecânica do dano contínuo, teoria da plasticidade e teoria da confiabilidade estrutural, posicionando este trabalho nos desenvolvimentos científicos atuais.

\subsubsection{Modelo mecânico}

Com intuito de representar a trajetória de equilíbrio das estruturas analisadas neste trabalho, o modelo mecânico acopla a análise não linear geométrica e não linear física. A não linearidade geométrica é contemplada pelo MEF posicional, enquanto a não linearidade física pela mecânica do dano contínuo e teoria da plasticidade.

\subsubsection{MEF posicional}

É deduzida e implementada uma formulação posicional estática e dinâmica para estruturas treliçadas 3D em uma versão Lagrangeana Total usando a medida de deformação logarítmica.

Os códigos computacionais são desenvolvidos empregando a linguagem de programação Fortran utilizando o compilador Intel ${ }^{\circledR}$ Visual Fortran em ambiente Windows ${ }^{\circledR}$ de 64 bits, disponível no Departamento de Engenharia de Estruturas da EESC/USP.

\subsubsection{Mecânica do dano contínuo}

É proposto um abrangente modelo de dano dúctil, no qual a lei de evolução do dano é igual a taxa de porosidade do material ocasionada pelo aumento de microcavidades e coalescência de fissuras. O potencial da energia livre de Helmholtz é escrito em função da variável interna de dano desse modelo, da deformação logarítmica e do parâmetro de encruamento isótropo. Esse é o modelo constitutivo assumido na formulação. Para sua validação, são utilizados os resultados experimentais dos seguintes materiais: aço, alumínio, cobre, concreto convencional, ferro, madeira e Ultra-High Performance Fiber-Reinforced Concrete (UHPFRC).

Os parâmetros do modelo de dano dúctil proposto são obtidos via curva experimental para cada material citado no parágrafo anterior. Para isso, primeiramente, por meio do princípio da equivalência das deformações, a deformação total é decomposta em três parcelas: uma parcela elástica, uma parcela de dano e uma parcela plástica. Da parcela plástica é retirada a componente hidrostática $\left(\varepsilon_{H}^{p}\right)$. Em seguida, a variável de dano $(D)$ da curva experimental é determinada para cada nível de deformação, consequentemente, o módulo tangente $\left(E_{t}\right)$ é dado por $E_{t}=(1-D) E$, sendo $E$ o módulo de Young para o material não danificado. Posteriormente, a evolução da degradação mecânica, curva $D v s$. $\left(\varepsilon_{H}^{p}-\varepsilon_{l n, d}^{p}\right)$, sendo $\varepsilon_{l n, d}^{p}$ o limite de dano inicial, é plotada. Por fim, os parâmetros são aferidos por meio de um ajuste polinomial dessa curva, de acordo com as 
hipóteses do modelo proposto. No Apêndice A é apresentado o algoritmo para a determinação de $D$ e $E_{t}$.

\subsubsection{Teoria da plasticidade}

O modelo proposto assume a abordagem de von Mises com encruamento isótropo como critério de plastificação. Consequentemente, aplicando a hipótese do modelo de Gurson, a variação da porosidade ao longo do processo de carregamento é determinada pela componente hidrostática da deformação plástica. Ademais, a deformação plástica e a variável interna de encruamento são atualizadas em cada iteração do procedimento de solução seguindo o algoritmo de mapeamento de retorno proposto por Simo \& Hughes [60].

\subsubsection{Modelo probabilístico}

Após a implementação do modelo mecânico, as análises probabilísticas são realizadas via simulação de Monte Carlo (SMC). A SMC é implementada e agregada ao modelo mecânico para aferir as probabilidades de falha dos elementos estruturais durante a evolução das sequências de falha.

No tocante aos modos de falhas, são escritas equações de estado limites locais para cada elemento e globais em função da trajetória de equilíbrio da estrutura. 

CAPÍtULO

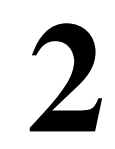

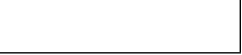

\section{MITIGAÇÃO DO RISCO DE DANOS ACIDENTAIS E COLAPSO PROGRESSIVO EM ESTRUTURAS}

\subsection{Generalidades}

O estudo do colapso progressivo teve seu início durante a Segunda Guerra Mundial, quando Baker [61] analisou o comportamento das construções danificadas por explosões devido aos bombardeios na cidade de Londres. Durante os 20 anos seguintes esse tema ficou sem nenhuma publicação relevante [62].

O colapso progressivo do edifício Ronan Point na cidade de Londres (Figura 2.1), em 1968, retomou o estudo desse tema, sendo o marco inicial da inclusão de recomendações nos documentos normativos da época a respeito do risco desse evento [63, 64]. Todavia, foi somente a partir dos ataques terroristas na cidade de Oklahoma (Figura 2.2) e World Trade Center (Figura 2.3), que foram introduzida novas prescrições nas normas, bem como aumentou a conscientização da comunidade de engenharia estrutural sobre a questão do colapso progressivo e sobre a necessidade de metodologias robustas de projeto [65, 66, 67, 68].

O colapso progressivo de uma estrutura é iniciado pela propagação de um dano estrutural local que resulta em um estado de falha que é desproporcional à intensidade do dano inicial [69]. $\mathrm{Na}$ literatura, outras definições desse evento são apresentadas [70, 71, 72, 73, 74]. Neste trabalho, o colapso progressivo é definido como a propagação de uma falha localizada que conduz um caminho de falha que leva ao colapso parcial ou total de uma estrutura, sendo dependente do dano acidental que o iniciou, do grau de redundância do sistema, do efeito de inércia e da energia cinética.

Danos acidentais tais como explosões, impactos, ataques terroristas, ações excepcionais, 
erros humanos e de construção, frequentemente causam danos locais nas estruturas, os quais podem conceber sérias ameaças quando um ou mais elementos estruturais falham, implicando no colapso progressivo de toda a estrutura ou parte dela [75]. Por conseguinte, o colapso progressivo sempre é acompanhado por graves perdas humanas e materiais [76, 77].

Figura 2.1 - Colapso progressivo do edifício Ronan Point, Londres, 1968.

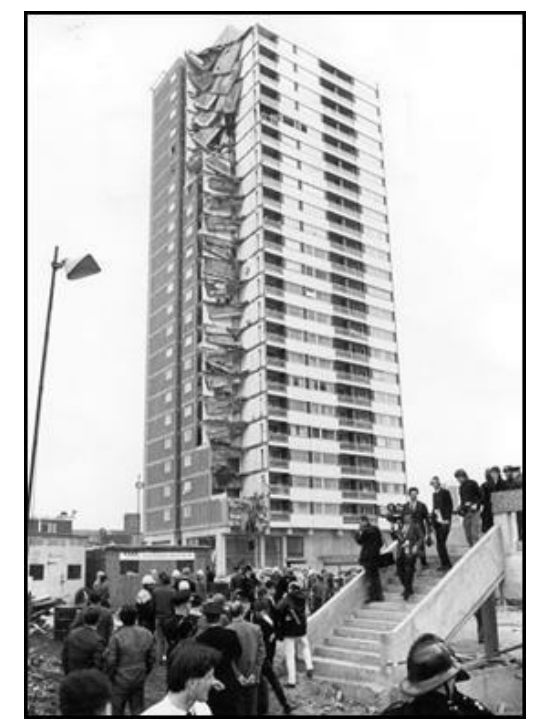

Fonte: National Institute of Standard and Technology (NISTIR) [78].

Figura 2.2 - Colapso progressivo do edifício Murrah, Oklahoma, 1995.

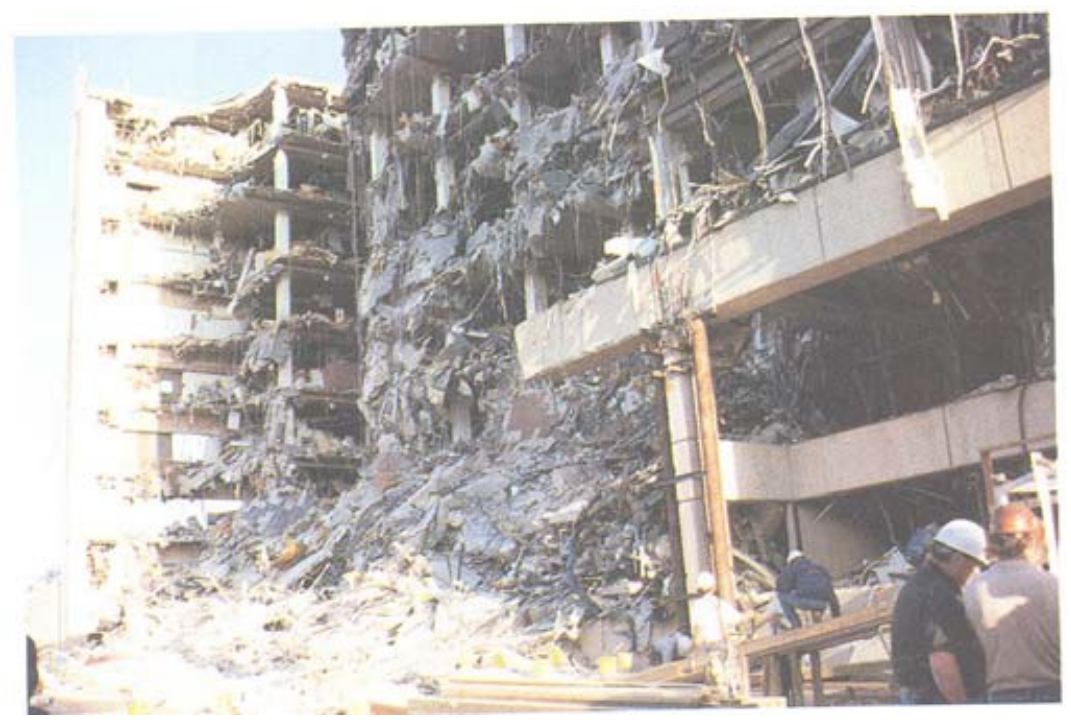

Fonte: NISTIR [78]. 
Figura 2.3 - Colapso progressivo do World Trade Center, New York, 2001.

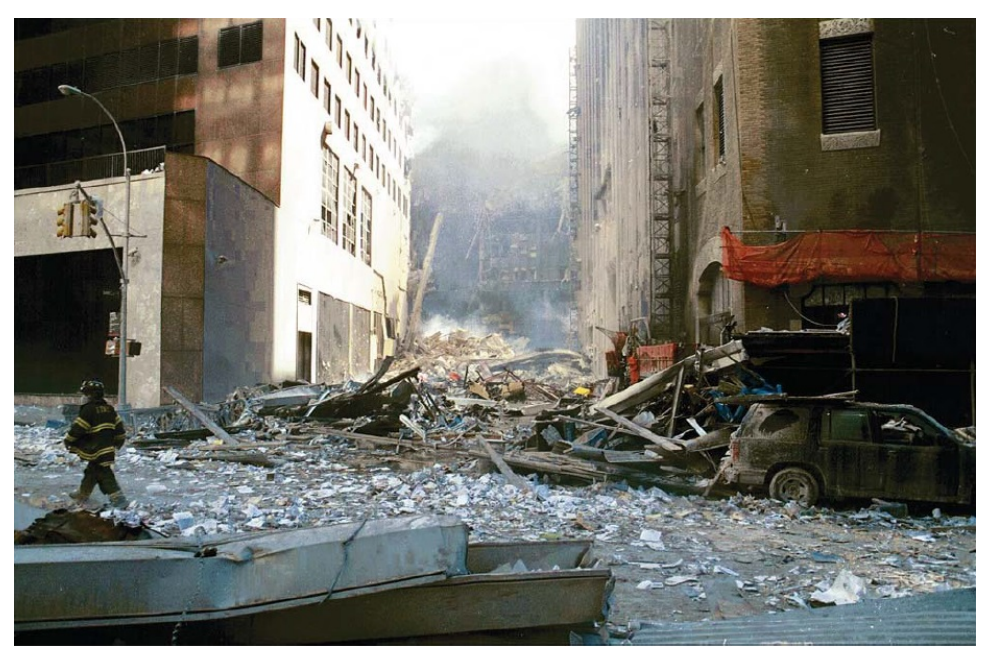

Fonte: Federal Emergency Management Agency (FEMA) [79].

Pela dificuldade de previsão da probabilidade de ocorrência e magnitude dos danos acidentais, não é prático nem possível projetar uma estrutura contra essas ameaças por meio dos métodos tradicionais para cargas convencionais [75, 80, 81]. Consequentemente, danos acidentais são frequentemente abordados de forma qualitativa em códigos de construção [82, 83, 84, 85]. No entanto, abordagens qualitativas são muitas vezes inadequadas para garantir a resistência ao colapso [86, 87]. As baixas probabilidades de ocorrência de eventos extremos não podem ser usadas para justificar sua negligência, porque suas consequências são particularmente severas $[88,89,90]$.

Atualmente, diferentes metodologias são empregadas para avaliar a integridade estrutural de construções sob danos acidentais [91]. Jihong e Liqiang [92] empregaram a teoria da vulnerabilidade estrutural para analisar o mecanismo de colapso de pórticos metálicos. Wolinski [93] analisou a robustez e vulnerabilidade de estruturas de lajes planas sob cargas acidentais. Andre et al. [94] propuseram novos índices de robustez estrutural e fragilidade estrutural baseados em análise de energia de dano para uma dada estrutura e dano acidental. Giuliani [95] desenvolveu dois métodos para avaliar a integridade estrutural, onde as consequências das falhas dos elementos são analisadas, bem como respostas estruturais a eventos extremos específicos. Smith [96] empregou uma analogia de fratura rápida para avaliar o colapso progressivo em edifícios de múltiplos andares em estrutura metálica.

A literatura técnica sobre o tema revela a existência de poucos métodos gerais para descrever quantitativamente falhas progressivas [97, 98, 99, 100]. Essa pesquisa bibliográfica também revela confusão nos principais conceitos e terminologias associados ao problema. As palavras robustez e vulnerabilidade, por exemplo, têm significados bem definidos além da engenharia estrutural (por exemplo, na medicina, ciências sociais ou finanças). Acredita-se que a 
generalidade de tais conceitos deve ser preservada na aplicação à engenharia estrutural.

Em engenharia e em teoria de otimização, em particular, um sistema robusto é um sistema cujo desempenho é insensível a incertezas ou perturbações aleatórias em parâmetros de projeto. Assim, a robustez de um sistema estrutural é definida como uma medida de sua capacidade de sustentar danos localizados, sem propagá-los de maneira desproporcional à intensidade do evento inicial. A teoria de controle define robustez como o grau em que um sistema é insensível a efeitos que não são considerados no projeto [101]. Outras definições de robustez disponível na literatura são fornecidas por [102, 103, 104, 105].

Nas ciências sociais, a vulnerabilidade é uma medida da suscetibilidade de um indivíduo ou grupo social a ser afetado negativamente por eventos como fome, enchentes, secas, desabamentos, doenças, etc. A vulnerabilidade de um sistema estrutural é uma medida de sua suscetibilidade para realizar um determinado grau de perda, após a ocorrência de um evento de ameaça inicial [106]. A vulnerabilidade fornece um mapeamento entre um determinado evento de exposição e consequências resultantes, tipicamente perdas econômicas ou número de fatalidades. Portanto, a vulnerabilidade vincula a fragilidade à consequência [106].

A generalidade das definições acima foi negligenciada por Starossek e Haberland [87], que sugerem interpretações limitadas de vulnerabilidade e robustez. Os autores, no entanto, foram bem sucedidos em identificar algum consenso mínimo em outros termos e definições. Os conceitos de robustez e vulnerabilidade, como dito acima, não são exatamente complementares, como sugerido por Chen et al. [107]. Alguns fatores de vulnerabilidade e importância propostos na literatura são deficientes, pois não levam em conta as consequências de falha [107, 108, 109]. Estudos de vulnerabilidade visando efeitos de tremores sísmicos [110] e redes de oleodutos [111] foram recentemente apresentados, mas esses estudos não apresentam nenhum índice geral de vulnerabilidade. O índice de vulnerabilidade proposto por Jhong e Liqiang [92] relaciona a conectividade estrutural ao potencial de dano, em uma abordagem determinística. Todas essas abordagens podem ser orientadas para sistemas estruturais específicos. Felipe et al. [57, 112] propuseram uma abordagem baseada em confiabilidade para analisar o colapso progressivo. Tal abordagem é probabilística, portanto, também mais difícil de ser implementada na prática.

Índices de robustez foram propostos por vários autores. Incluindo abordagens determinísticas baseadas em energia [87, 91, 94, 113], em confiabilidade [114, 115, 116, 117, 118] e em risco [119].

Atualmente, os documentos normativos encaminham-se para incorporar o conceito de robustez e resistência ao colapso nas suas novas diretrizes [75]. A resistência ao colapso é definida como insensibilidade da estrutura a danos acidentais [86]. Essa é uma propriedade que depende das características do sistema (resistência, ductilidade, redundância e continuidade), mas também dos tipos de danos acidentais que podem ocorrer na estrutura. Por conseguinte, o colapso progressivo pode ser evitado garantindo a resistência ao colapso [103]. 
Como o risco não pode ser eliminado, na prática tem-se buscado metodologias que proporcionem um tempo de resposta para que os usuários das estruturas sejam evacuados antes da ocorrência do mecanismo de reação de falha progressiva dos elementos estruturais. Na Figura 2.4 ilustra-se os estágios da ocorrência desse mecanismo. O tempo $t_{i d}$ representa o estágio inicial de dano, no qual a falha de um elemento estrutural não gera deslocamentos excessivos na estrutura. Entre os tempos $t_{i d}$ e $t_{i c}$ caracteriza-se o estágio de propagação de dano, em que a estrutura apresenta redistribuição dos esforços em uma nova posição de equilíbrio. Caso o equilíbrio não seja alcançado, a partir de $t_{i c}$ até $t_{\text {colapso }}$, inicia-se o mecanismo de falha progressiva de toda a estrutura ou grande parte dela.

Nesse contexto, surgiu o conceito de edifícios resilientes, edifícios capazes de absorver e recuperar-se de um evento extremo [75]. Esse conceito inclui não meramente as propriedades de robustez e resistência ao colapso, mas a capacidade da estrutura de absorver e recuperar-se de um dano acidental.

Figura 2.4 - Etapas para a ocorrência do colapso progressivo: (a) estruturas não resilientes; (b) estruturas resilientes.

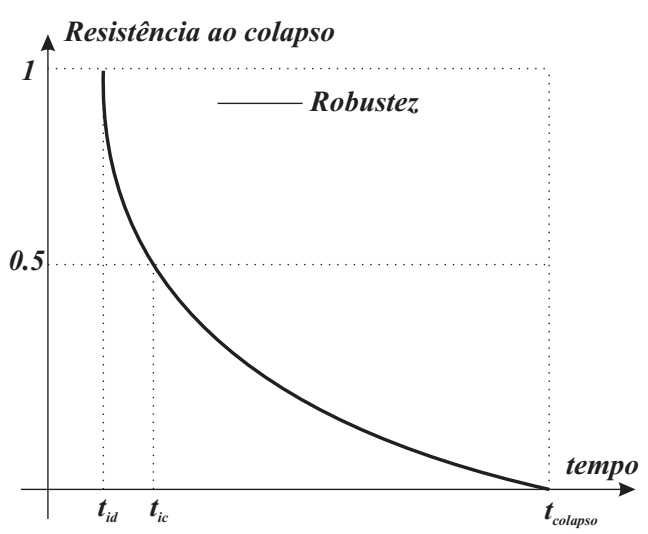

(a)

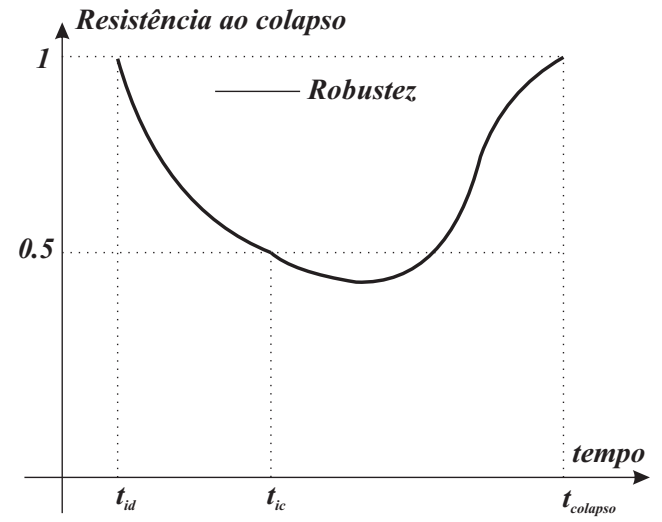

(b)

Fonte: Autor.

A seguir, as abordagens específicas para o projeto resistente ao colapso progressivo são apresentadas.

\subsection{Abordagens para a Prevenção de Danos Acidentais e Co- lapso Progressivo}

Ainda não existem regras específicas para dimensionar uma estrutura contra o colapso progressivo [75, 77, 120]. Não obstante, pode-se apresentar quatro abordagens determinísticas empíricas indicadas pela literatura, as quais são utilizadas para garantir a resistência ao colapso, são elas: $(i)$ regras prescritivas de forças de amarração; $(i i)$ método dos caminhos de cargas 
alternativos; (iii) método da resistência local específica e (iv) isolamento por segmentação. Ademais, a comunidade científica apresenta uma abordagem baseada em análise probabilística. Nos itens a seguir são delineadas tais abordagens.

\subsubsection{Regras prescritivas de forças de amarração}

Os documentos normativos que tratam sobre colapso progressivo comumente focam nas regras prescritivas de forças de amarração (RPFA). Elas visam prover um nível mínimo de redundância, continuidade e ductilidade para a estrutura [121]. As RPFA são fornecidas por meio de tirantes horizontais e verticais obtidos pela prescrição de um requisito mínimo de força de amarração. Tais tirantes são utilizados para prender alguns elementos estruturais pré-selecionados. Como a resistência ao colapso progressivo é abordada implicitamente, as RPFA são consideradas como uma abordagem de projeto indireto [75, 86, 121].

$\mathrm{Na}$ literatura, vários trabalhos sobre a eficiência das RPFA revelaram que, em alguns casos, elas não são eficientes para mitigar o colapso progressivo [122, 123, 124, 125]. Isto porque as rotações necessárias nas ligações para garantir a ação de membrana/catenária são inatingíveis [75]. Por isso, alguns documentos normativos incluem limites de rotações em seus requerimentos para a força de amarração $[78,82]$. Com relação ao comportamento de membrana/catenária de lajes/vigas, esse é o mecanismo capaz de redistribuir as cargas após um dano acidental na estrutura, sendo a última linha de defesa contra o colapso progressivo [75].

\subsubsection{Método dos caminhos de carga alternativos}

A abordagem do método dos caminhos de carga alternativos (MCCA) se concentra na avaliação do comportamento da estrutura após a remoção discricionária de elementos estruturais individuais [69, 121]. Por conseguinte, o sistema estrutural deve ser capaz de suportar os carregamentos usuais na ausência de um elemento. Tal abordagem é também determinística como as RPFA, sendo amplamente aceita pelos documentos normativos internacionais [75].

Na presença de danos locais em um elemento estrutural, o MCCA fornece o mecanismo para que as cargas sejam transferidas de um ponto de aplicação para um ponto de resistência. A redistribuição de carga resultante permite que a estrutura mantenha o equilíbrio global após a falha de um elemento. O MCCA é fornecido por regras de projeto (aumento da rigidez e resistência dos membros), e por análises estruturais explícitas (fornecimento de tirantes e ação catenária). Nesse caso, o ASCE 7-05 [84] propõe combinações de ações reduzidas na análise da propagação de danos, com o entendimento de que um cenário de falha de elementos estruturais é um evento de baixa probabilidade.

Sendo assim, a finalidade do MCCA é verificar explicitamente a robustez do sistema. Esta verificação consiste em avaliar a capacidade de redistribuição de esforços do sistema após a 
remoção de um componente. No entanto, por causa das hipóteses simplificadoras assumidas ${ }^{1}$, usualmente as soluções de projeto do MCCA produzem níveis diferentes de robustez [126]. Desse modo, deve-se aplicar tal abordagem com um nível mínimo de simplificações com o intuito de prover um grau aceitável de resistência ao colapso.

\subsubsection{Método da resistência local específica}

O método da resistência local específica (MRLE), também denominado de abordagem do projeto dos elementos chaves, fornece uma resistência extra à estrutura mediante o dimensionamento de elementos estruturais principais (elementos chaves) para suportar um evento pré-definido. Dessa forma, o engenheiro deve avaliar os esforços solicitantes adicionais impostos pelos efeitos desse evento nas suas combinações de ações, as quais serão utilizadas para projetar a edificação. Sendo assim, a finalidade do MRLE é dimensionar os elementos ditos chaves para resistir a um dano acidental específico. Tal abordagem é o último recurso quando o MCCA é incapaz de corroborar a capacidade de redistribuição de esforços.

Como exemplo, pode-se citar os pilares de edificações que são dimensionados contra colisões de veículos. Nesse caso, o projetista pode utilizar medidas de proteção não estruturais, as quais empregam dispositivos de proteção, ou aplicar o MRLE assumindo como evento o impacto do veículo. Para a última, o Eurocode 1 [127] prescreve uma metodologia para considerar uma força estática equivalente no dimensionamento dos elementos chaves sujeitos ao impacto.

Os elementos chaves são definidos como os elementos estruturais cuja falha ativa um colapso progressivo [127]. De acordo com Felipe et al. [57, 112], o elemento chave de um sistema em paralelo é definido como o membro $E_{i}$ nesse sistema que tem a maior vulnerabilidade no tocante ao colapso progressivo.

A identificação do(s) elemento(s) chave(s) é apresentada nos documentos normativos de modo empírico [57]. Desse modo, alguns elementos estruturais devem ser avaliados, expondo-os a uma carga adicional. No caso de uma explosão de um botijão de gás, tal carga é uma pressão estática de $34 \mathrm{KPa}$ [127, 128, 129]. Esse valor pode prover um certo nível de robustez à estrutura, porém não é capaz isoladamente de prevenir a falha local.

Uma estratégia alternativa para identificar o(s) elemento(s) chave(s) foi proposta por Felipe et al. [57, 112], baseada na teoria da confiabilidade estrutural. Neste trabalho, a confiabilidade estrutural é acoplada ao modelo mecânico proposto no Capítulo 3 para a análise de estruturas treliçadas submetidas ao colapso progressivo.

\subsubsection{Isolamento por segmentação}

O isolamento por segmentação (IS), também denominado compartimentação, é uma abordagem para limitar a extensão de falha local por uma segmentação da estrutura [86, 130]. Tal

1 Análise dinâmica simplificada, linearidade física e geométrica, etc. 
abordagem é análoga à estratégia de dividir uma estrutura em compartimentos para confinar um incêndio ao compartimento de origem [86]. Essa estratégia é sobretudo útil em pontes, todavia, não é explicitamente mencionada nos documentos normativos internacionais que tratam do colapso progressivo [75].

Portanto, o IS é uma técnica que limita fisicamente a extensão da propagação de danos. Isso pode ser alcançado fornecendo: $(i)$ componentes fracos (fusíveis), que desconectam o restante da estrutura; (ii) componentes fortes, que impedem a propagação de danos; e (iii) componentes de alta ductilidade, que dissipam a energia do dano [112].

\subsubsection{Abordagem baseada em análise probabilística}

A análise probabilística do colapso progressivo foi abordada por vários autores [119, 131, 132]. No Eurocode 1 [102] e no NISTIR 7396 [78] tal análise é citada com caráter informativo. Sob múltiplas ameaças, a probabilidade de colapso pode ser avaliada como [69]:

$$
P[\text { colapso }]=\sum_{H} \sum_{D} P[\text { colapso } \mid D, H] P[D \mid H] P[H]
$$

onde $P[H]$ é a probabilidade de ocorrência do evento, $P[D \mid H]$ é a probabilidade condicional de dano local, dada a ocorrência do evento; $P[\operatorname{colapso} \mid D, H]$ é a probabilidade condicional de colapso, dado o dano local $D$ e o evento $H$. Na Equação 2.1, a soma sobre $H$ indica as ameaças as quais a estrutura está exposta, e a soma sobre $D$ representa os diferentes estados iniciais de dano que a estrutura pode experimentar. A probabilidade de ocorrência do evento, $P[H]$, pode eventualmente ser escrita em termos de uma taxa anual de ocorrência $\left(\lambda_{H}\right)$. Nesse caso, a $P[$ colapso $]$ também se torna uma taxa anual [131]. Quando a taxa de ocorrência está abaixo do chamado risco mínimo $\left(\lambda_{H}<10^{-7} /\right.$ ano $)$, o impacto é insignificante e o risco pode ser descartado [133]. Por outro lado, para danos acidentais que possam ocorrer ou quando o projetista quer direcionar o estudo dos outros termos na Equação 2.1, pode-se assumir $\lambda_{H}=1$. Esse é o caso, por exemplo, da remoção discricionária de elementos orientada por códigos estruturais.

Para a análise limitada a um dano acidental específico $E$ e um único estado de dano inicial $D$, a Equação 2.1 pode ser simplificada na Equação 2.2.

$$
P[\text { colapso }]=P[\text { colapso } \mid D, E] P[D \mid E] P[E]
$$

A mitigação de risco contra o colapso progressivo pode ser alcançada trabalhandose em três frentes: $(i)$ controlar ou limitar a probabilidade $\left(P[E]\right.$ ou $\left.\lambda_{H}\right)$ de ocorrência do dano acidental; (ii) controlar ou limitar o dano local (termo $P[D \mid E]$ ) produzido pelo evento de carregamento $E$; e $(i i i)$ controlar ou limitar a propagação de danos (termo $P[\operatorname{colapso} \mid D, E]$ ), que eventualmente podem levar ao colapso estrutural parcial ou total. A prevenção da ocorrência do evento geralmente requer ações não estruturais (sociais ou políticas), que podem incluir a 
proibição de substâncias inflamáveis ou explosivas, a construção de barreiras físicas para deter o impacto do veículo, educação, treinamento e outras.

O controle do termo $P[D \mid E]$ envolve medidas estruturais para fortalecer ou proteger diretamente (com barreiras de segurança, por exemplo) o elemento localmente afetado pelo evento de carregamento $E$. Por outro lado, de acordo com o Eurocode 1 [127], danos localizados devido a ações acidentais podem ser aceitáveis desde que a capacidade da estrutura seja mantida durante a evacuação de emergência. Assim, controlar o termo $P[$ colapso $\mid D, E]$ envolve análise do comportamento do sistema e propagação de danos. Esse termo pode ser controlado fornecendo redundância, caminhos de cargas alternativos ou segmentação.

Controlar o termo $P[$ colapso $\mid D, E]$ tem um duplo objetivo: o mais imediato é permitir a evacuação do edifício, reduzindo o dano potencial e o risco à segurança dos usuários; o segundo é permitir que o dano inicial seja reparado, para que o edifício volte a funcionar. O Eurocode 1 [127], em seu Anexo A, recomenda como limite de danos locais admissíveis para os edifícios, quando sujeitos a uma remoção de um único pilar, $15 \%$ da área do piso do pavimento e não maior que $100 \mathrm{~m}^{2}$. Na direção vertical, os danos localizados devem cobrir não mais do que dois andares adjacentes.

A metodologia para a identificação do elemento chave $(E C)$, por análise de confiabilidade de sistemas, foi proposta por Felipe et al. [57, 112]. O EC é definido como o elemento $E_{i}$ da estrutura que tem a maior vulnerabilidade para o colapso estrutural, i.e.,

$$
E C=\max _{i}\left(C V_{i} \cdot C I C_{i}\right)
$$

sendo $C V_{i}$ o coeficiente de vulnerabilidade, enquanto $C I C_{i}$ o coeficiente de importância para o colapso progressivo. Esses coeficientes são definidos pelas seguintes equações:

$$
\begin{gathered}
C V_{i}=\frac{P\left[f_{i}\right]}{\sum_{j=1}^{n} P\left[f_{j}\right]} \\
C I C_{i}=\frac{P\left[c_{i}\right]}{\max _{j}\left[P\left[c_{j}\right]\right]}
\end{gathered}
$$

onde $P\left[f_{i}\right]$ é a probabilidade de falha do elemento $E_{i}$ dado os distintos modos de falha $(f)$ e $P\left[c_{i}\right]$ é a probabilidade de ocorrência do caminho de falha $c_{i}$.

Códigos que tratam sobre o colapso progressivo fornecem algumas recomendações sobre projeto robusto e prevenção do colapso progressivo [78, 82, 83, 84, 85]. No entanto, a análise probabilística ou de risco do colapso progressivo ainda não foi abordada. Como consequência, os documentos normativos não fornecem maneiras objetivas de identificar elemento(s) chave(s) em uma estrutura, nem medidas quantitativas de sua robustez ou vulnerabilidade. Em vista disso, 
no Capítulo 6 deste trabalho é delineado o modelo probabilístico. Tal modelo é adotado para mensurar a probabilidade de colapso progressivo das estruturas treliçadas aqui analisadas.

\subsection{Documentos Normativos}

A admissão de prescrições em documentos normativos para projetos resistentes ao colapso progressivo foi iniciada no Reino Unido após o colapso do edifício Ronan Point em 1968. Nessa época, o princípio fundamental era proporcionar níveis mínimos de robustez estrutural, a fim de permitir que as estruturas redistribuíssem e suportassem cargas após a perda de um ou mais elementos estruturais. Este conceito de perda de elementos estruturais (remoção discricionária) progrediu com o passar do tempo em diversas abordagens encontradas nos códigos internacionais, sobretudo no método dos caminhos de cargas alternativos.

A maioria desses códigos adotam os requisitos fundamentais de continuidade, ductilidade e redundância nas suas prescrições [82, 83, 85, 134]. Outros especificam as forças mínimas de amarração para alcançar tais requisitos [84, 129, 135]. Alguns prescrevem as combinações de ações para considerar os danos acidentais [84, 127, 136, 137]. Por fim, uns especificam um limite de dano, expresso em termos da área do pavimento, que a estrutura remanescente deve ter para redistribuir os esforços adicionais para os outros elementos estruturais após o dano acidental $[78,127]$.

Na Tabela 2.1 são resumidas as abordagens específicas para o projeto resistente ao colapso progressivo endereçadas nos documentos normativos internacionais. Nota-se que a maioria dos códigos não discutem a abordagem baseada na análise de confiabilidade para a avaliação do colapso progressivo em seu escopo. Entretanto, estratégias mais racionais e práticas para minimizar o risco do colapso progressivo podem ser ordenadas empregando os princípios da teoria da confiabilidade estrutural $[57,69,112]$.

No Brasil, as normas de alvenaria estrutural [138, 139] não têm diretrizes específicas de projeto sobre danos acidentais ou colapso progressivo. Não obstante, elas têm anexos informativos com algumas recomendações gerais sobre esses assuntos.

Em relação às estruturas de concreto, a norma brasileira [140] cita o estado limite último de colapso progressivo como algo a ser verificado para garantir a segurança das estruturas. As seções 19.5 e 20.3 recomendam armadura adicional para lajes, com o propósito de garantir a ductilidade local e, consequentemente, proteção contra o colapso progressivo.

A norma de concreto pré-moldado [141] na seção 5.1.1.4, enfatiza que o engenheiro deve ter um cuidado especial no detalhamento da estrutura para minimizar a ocorrência do colapso progressivo. Em contrapartida, a norma de paredes de concreto [142] não comenta sobre assunto. Ressalta-se que apenas normas brasileiras de alvenaria estrutural [138, 139] indicam a preocupação com danos acidentais e colapso progressivo, embora sem muitas diretrizes para 
auxiliar no projeto de uma estrutura. O histórico de estruturas que sofreram o colapso progressivo no Brasil, como o Edifício da Liberdade no Rio de Janeiro em 2012, com a morte de 22 pessoas, mostra que engenheiros estruturais devem discutir mais esse assunto.

Tabela 2.1 - Abordagens destacadas pelos documentos normativos internacionais e diretrizes.

\begin{tabular}{|c|c|c|c|c|c|c|}
\hline Região & Documento normativo & I) RPFA & II) $\mathrm{MCCA}$ & III) MRLE & IV) IS & V) ABAP \\
\hline EUA & DoD [82] & $\operatorname{sim}$ & $\operatorname{sim}$ & $\operatorname{sim}$ & não & não \\
\hline Rússia & STO [83] & não & $\operatorname{sim}$ & não & não & não \\
\hline EUA & NISTIR [78] & $\operatorname{sim}$ & $\operatorname{sim}$ & $\operatorname{sim}$ & não & não \\
\hline EUA & ASCE/SEI 7-10 [84] & $\operatorname{sim}$ & $\operatorname{sim}$ & $\operatorname{sim}$ & não & não \\
\hline EUA & GSA [85] & não & $\operatorname{sim}$ & não & não & não \\
\hline Europa & Eurocode [127] & $\operatorname{sim}$ & $\operatorname{sim}$ & $\operatorname{sim}$ & não & $\operatorname{sim}$ \\
\hline Reino Unido & BS 5628 [129] & $\operatorname{sim}$ & não & não & não & não \\
\hline Austrália & NCC [136] & não & $\operatorname{sim}$ & $\operatorname{sim}$ & não & $\operatorname{sim}$ \\
\hline Reino Unido & IStructE [130] & $\operatorname{sim}$ & $\operatorname{sim}$ & $\operatorname{sim}$ & $\operatorname{sim}$ & $\operatorname{sim}$ \\
\hline China & CECS [137] & $\operatorname{sim}$ & $\operatorname{sim}$ & $\operatorname{sim}$ & não & não \\
\hline Canadá & NBCC [134] & $\operatorname{sim}$ & $\operatorname{sim}$ & $\operatorname{sim}$ & não & não \\
\hline Brasil & NBR 15812-1 [138] & não & não & não & não & não \\
\hline Brasil & NBR 15961-1 [139] & não & não & não & não & não \\
\hline Brasil & NBR 6118 [140] & não & não & não & não & não \\
\hline Brasil & NBR 9062 [141] & não & $n \tilde{a} o$ & $n \tilde{a} o$ & não & não \\
\hline Brasil & NBR 16055 [142] & $n \tilde{a} o$ & $n \tilde{a} o$ & não & não & não \\
\hline Brasil & NBR 7190 [143] & não & não & não & não & não \\
\hline Brasil & NBR 8800 [144] & não & não & não & não & não \\
\hline
\end{tabular}

Fonte - Autor.

Nota - RPFA $=$ regras prescritivas de forças de amarração; MCCA = método dos caminhos de cargas alternativos; MRLE = método da resistência local específica; IS = isolamento por segmentação; $\mathrm{ABAP}=$ abordagem baseada na análise probabilística.

\subsection{Pesquisas Atuais}

Esta seção apresenta as pesquisas atuais em robustez e colapso progressivo de estruturas com respeito aos ensaios experimentais e análises numéricas propostos pela literatura. Atualmente, há um interesse crescente da comunidade científica com esse assunto [75]. Tal interesse em parte é devido às maiores expectativas dos usuários sobre a segurança dos edifícios projetados com relação aos danos acidentais [75].

Testes experimentais têm sido apresentados por diversos pesquisadores no campo do colapso progressivo. A maioria desses experimentos foram realizados com a utilização de um 
protótipo composto por duas vigas e um ou três pilares [145]. Os experimentos simulam a perda de um pilar, o que serve para evidenciar os mecanismos de resistência ao colapso, como por exemplo, ação catenária das vigas. Esses testes podem ser usados para melhorar as prescrições dos documentos normativos existentes, bem como calibrar as simulações via Método dos Elementos Finitos (MEF).

Com relação aos materiais utilizados, tais experimentos avaliaram protótipos de concreto e aço, enquanto que modelos em alvenaria estrutural e em madeira praticamente ainda não foram estudados.

No tocante aos protótipos de aço, vários pesquisadores analisaram a resistência das ligações viga-pilar sobre um cenário de falha de um pilar [146, 147, 148, 149]. Esses autores examinaram diferentes tipos de ligações, além de diversas seções transversais na conexão viga/pilar.

Liu et al. [150] simularam a falha súbita do pilar $^{2}$ nos experimentos para considerar os efeitos dinâmicos nas ligações. Os estudos experimentais dessas ligações são vitais para garantir a resistência ao colapso de estruturas em pórticos metálicos, pois elas serão essenciais para transpor as cargas adicionais para os outros elementos estruturais não danificados.

Li et al. [151] através da análise via MEF investigaram o comportamento de colapso progressivo de pórticos metálicos sob um cenário de remoção brusca de um pilar. Os autores propuseram um novo índice para quantificar a robustez, o qual leva em conta os efeitos dinâmicos e redistribuição de cargas. Ademais, um fator de amplificação dinâmica para o colapso progressivo foi avaliado. Concluíram que o amortecimento teve maior influência do que a taxa de deformação do material na robustez dos pórticos metálicos analisados.

Parthasarathi et al. [152] averiguaram a sensibilidade de um pórtico 2D metálico com quatro pilares e quatro pavimentos perante a ocorrência do colapso progressivo sob condições de incêndio. Analisaram a estrutura usando o MEF assumindo as não linearidades física e geométrica. Os autores inferiram que os pilares centrais sofrem maiores deslocamentos e deformações do que os outros pilares para temperatura igual ou superior a $800{ }^{\circ} \mathrm{C}$. Nessa temperatura, todos os pilares diminuíram sua resistência mecânica e iniciaram o regime de amolecimento, que culminou na propagação de falhas progressivas.

Lou et al. [153] realizaram um estudo experimental em escala real, sobre o comportamento do colapso progressivo de um pórtico 3D metálico exposto a situação de incêndio. Os autores verificaram que expondo uma face de um pilar externo desse pórtico por 15 minutos a uma temperatura de $1100{ }^{\circ} \mathrm{C}$, acarretou o início da propagação de falhas progressivas dessa estrutura. Averiguaram ainda que as ligações dos pilares de canto no nível da fundação falharam

2 Esta abordagem é conhecida na literatura como cenário independente da ameaça, uma vez que o dano acidental que gera a falha do elemento estrutural não é especificado. Tal estratégia é utilizada pelos códigos normativos, a fim de prover integridade estrutural contra a ocorrência de possíveis danos acidentais. Define-se integridade estrutural como a capacidade da estrutura absorver uma falha local sem o colapso generalizado. 
por intermédio dos grandes giros e grandes deformações que essas sofreram após a falha do pilar externo. Os autores assinalaram que as falhas dessas ligações devem ser evitadas, a fim de mitigarem as propagações das falhas progressivas para os outros compartimentos da estrutura.

Jiang et al. [154] através dos resultados experimentais obtidos por Lou et al. [153] concretizaram uma avaliação quantitativa do processo de colapso progressivo de um pórtico 3D metálico sobre condições de incêndio. As análises foram efetivadas via MEF onde foram calculados deslocamentos críticos em pontos chaves nos elementos estruturais. Os autores concluíram que o processo de colapso progressivo de pórticos 3D metálicos expostos a situações de altas temperaturas pode ser avaliado mediante deslocamentos chaves nos pilares e vigas. Outrossim, eles inferiram que as sequências de falhas dos elementos estruturais e o tempo necessário para o colapso total da estrutura dependem fortemente do cenário de incêndio.

Rezazadeh et al. [155] avaliaram o comportamento de um pórtico 2D metálico com cinco pilares e seis pavimentos sob colapso progressivo, assumindo nas ligações viga/pilar um reforço através de uma chapa de aço conectada aos enrijecedores. Nas análises não lineares os autores utilizaram as combinações de ações preconizadas pela DoD [82]. Averiguaram que a introdução desse reforço modifica o caminho do fluxo das forças internas nas ligações, além de alterar a posição para a formação da rótula plástica na conexão viga/pilar. Os autores ainda mencionaram que esse procedimento pode melhorar a resistência ao colapso progressivo.

Huang et al. [156] realizaram um estudo experimental e numérico da resistência ao colapso progressivo de uma cúpula para um estádio de esportes constituída por elementos de casca que são suportadas por cabos. As análises experimentais foram realizadas em um protótipo em escala reduzida. Já as análises numéricas foram concretizadas via MEF com a utilização do software ANSYS ${ }^{\circledR}$. Os autores verificaram que em ambas as análises o sistema exibiu adequada resistência ao colapso progressivo na ocorrência de falha de um cabo.

Jhong \& Liqiang [92] propuseram um método para avaliar o mecanismo de colapso de um pórtico $2 \mathrm{D}$ metálico com quatro pavimentos, baseado na teoria de vulnerabilidade estrutural. Inferiram que a abordagem proposta identificou corretamente os caminhos de falha do pórtico 2D estudado. Constataram também que a falha de uma ligação viga/pilar provoca nos pilares do pavimento térreo elevados índices de vulnerabilidade. Por outro lado, os autores depreenderam que a falha por formação de rótulas plásticas nas vigas implicam em baixos valores de índices de vulnerabilidade para a estrutura.

Szyniszewski \& Krauthammer [157] preconizaram uma metodologia para a avaliação do colapso progressivo baseado em energia para analisar edifícios metálicos. Os autores concluíram que, diante de um colapso localizado, o edifício atinge uma configuração de equilíbrio estável somente se a energia cinética é completamente dissipada pela estrutura. Caso contrário, a energia cinética remanescente vai causar o colapso progressivo do edifício [157].

Gerasimidis \& Sideri [158] apresentaram um novo método para análise de colapso 
progressivo em estruturas metálicas introduzindo cenários de danos parcialmente distribuídos. Tal método foi aplicado na análise de um pórtico 2D metálico com 15 pavimentos. Eles depreenderam que o método proposto alterou os mecanismos de colapso desse pórtico. Outrossim, os autores inferiram que o método proposto conduz forças de colapso mais baixas e mais críticas do que o método dos caminhos de cargas alternativos.

No que se refere ao concreto, Yu \& Tan [159] analisaram quatro pórticos planos, dos quais três foram dimensionados empregando prescrições dos códigos de sismos. Os autores avaliaram a capacidade da ação catenária das vigas e os pórticos dimensionados para suportar os carregamentos sísmicos. Forquin \& Chen [160] avaliaram a influência das condições de contorno para a redistribuição de esforços em cinco pórticos planos.

Ren et al. [161] e Lu et al. [162] testaram protótipos com e sem a introdução de lajes para mensurar a contribuição delas na resistência ao colapso.

Kang et al. [163] examinaram seis pórticos planos em concreto pré-moldado, onde a ligação viga/pilar e a parte superior da viga eram formadas por compósitos cimentícios modificados. Destacaram que os pórticos foram capazes de desenvolver significante arqueamento das cargas sobre o cenário de remoção de um pilar.

Elsanadedy et al. [164] investigaram através de análises experimentais e numéricas as ligações viga/pilar de três pórticos planos, dois em concreto pré-moldado e um em concreto armado. A partir dessas análises, propuseram novos parâmetros de eficiência das ligações para a avaliação do colapso progressivo.

Lim et al. [165] formularam um modelo analítico para a avaliação de caminhos de cargas alternativos em pórtico $2 \mathrm{D}$ de concreto armado. O modelo considera de forma simplificada a ação catenária das vigas. Os autores apontaram que o modelo proposto fornece previsões razoavelmente conservadoras para os diferentes mecanismos de transferência de carga.

Gowtham et al. [166] realizaram uma análise não linear estática e dinâmica via MEF para avaliar um pórtico $2 \mathrm{D}$ composto por 3 pilares, com cinco pavimentos em concreto armado. Os autores usaram o critério de aceitação DCR (Demand Capacity Ratio), preconizado pela DoD [82] e GSA [85], para examinar as amplificações dos esforços no pórtico após a remoção de um pilar no pavimento térreo, por meio de uma análise estática linear. Os valores dos DCR's de cada elemento foram checados com os resultados obtidos via análise não linear dinâmica. Constataram que as falhas dos pilares de canto acarretam maior vulnerabilidade para a estrutura do que falhas do pilar central.

Zhang \& Li [167] analisaram a resistência ao colapso de um pórtico 3D em concreto armado submetido à falha de um pilar intermediário e deduziram um método analítico para prever a resistência dessa estrutura após a perda do pilar. Os autores testaram a precisão da formulação proposta por meio do MEF com erros menores do que $15 \%$. Inferiram que a curva força $v s$. deslocamento obtida via formulação proposta, foi capaz de capturar as principais características 
dos mecanismos complementares do pórtico avaliado após a falha de um pilar intermediário.

Li et al. [168] propuseram um método analítico para prever a resistência de vigas e lajes mistas de aço/concreto após a perda de um pilar. Os autores realizaram um estudo paramétrico, com a finalidade de investigar o efeito do índice de esbeltez e espessura da laje, além da altura da viga nas curvas de força $v s$. deslocamento. Depreenderam que no estado limite de colapso, a contribuição da laje é influenciada exclusivamente por sua taxa de armadura.

Bredean \& Botez [169] examinaram a influência das vigas e lajes no desenvolvimento de mecanismos resistentes ao colapso progressivo para estruturas de concreto armado. Concluíram que a atuação da laje é expressiva na redistribuição das forças internas entre os elementos estruturais.

Al-Salloum et. al [170] propuseram um procedimento por meio de análises numéricas por meio do MEF, para prever o potencial de colapso progressivo de edifícios de concreto armado expostos às ondas geradas por explosão. Os autores assinalaram que existe uma falta de ferramentas adequadas disponíveis na literatura para simular e antever a resposta de colapso progressivo de estruturas. Averiguaram que o procedimento proposto pode ser usado para situar a localização crítica dos elementos estruturais no interior da área potencial da explosão. Os autores inferiram que as grandes deformações e grandes giros que ocorreram nas conexões viga/laje e viga/pilar nos elementos adjacentes ao componente que falhou, conduziram ao colapso progressivo do edifício avaliado.

Al-Salloum et. al [171] avaliaram a eficiência da introdução de um reforço, por meio de chapas metálicas parafusadas nas faces da ligação viga/pilar de um pórtico de concreto prémoldado, para a mitigação do colapso progressivo. Ensaios experimentais foram concretizados em três protótipos com e sem a estratégia proposta sob um cenário de falha do pilar central. Os autores comprovaram que as ligações usuais (sem o reforço) em concreto pré-moldado têm um potencial muito alto para o colapso progressivo. Isso era esperado, pois essas ligações possuem baixa ou nenhuma redundância para o caminhamento das cargas. Por isso que as estruturas pré-moldadas são mais susceptíveis ao colapso. Os autores depreenderam que a ligação proposta foi eficaz, uma vez que aumentou a carga de colapso do protótipo em referência as ligações usuais diante de um cenário de falha do pilar.

Feng et al. [172] realizaram uma investigação numérica do comportamento das ligações de um pórtico $2 \mathrm{D}$ de concreto pré-moldado com três pilares sob um cenário de falha do pilar central através do MEF. Propuseram um elemento finito 2D para simular a ligação viga/pilar baseado na formulação co-rotacional, com o intuito de incluir grandes deslocamentos. A não linearidade física do concreto foi introduzida por meio do modelo de Feng et al. [173], enquanto a relação constitutiva da armadura via modelo de von Mises com encruamento isótropo linear. Os autores mencionam que a formulação proposta pode capturar os mecanismos complementares de resistência ao colapso progressivo das estruturas de concreto pré-moldado, como por exemplo, a ação catenária. Apontaram ainda que o efeito do deslizamento aço/concreto tem uma influência 
sensível e, consequentemente, precisa ser assumido no modelo numérico. Por outro lado, citam que o efeito de arqueamento foi superestimado pela formulação proposta.

Referente as análises numéricas, o MEF é o mais utilizado para avaliar o colapso progressivo de estruturas, como observado anteriormente. As simulações via MEF apresentadas na literatura são realizadas com distintos níveis de aproximação e complexidade, tais como: $(i)$ modelos 2D ou 3D; (ii) análise linear ou não linear e (iii) comportamento estático ou dinâmico.

Modelos de pórticos 2D foram endereçados por Li et al. [174], Qian \& Li [175], Guo et al. [176] e Shan et al. [177]. O documento normativo DoD [82] não permite que as simulações em modelos 2D sejam utilizadas para dimensionar as estruturas contra o colapso progressivo. Isso porque os mecanismos resistentes ao colapso progressivo não são efetivamente considerados [82]. Dessa forma, modelos 3D são essenciais para verificar a ocorrência desses mecanismos.

A respeito da natureza dinâmica dos danos acidentais, os códigos apresentados na Tabela 2.1 oferecem diferentes ponderações sobre o tipo de avaliação a ser abordada. Os documentos DoD [82], GSA [85] e CECS [137] permitem análises estáticas lineares e não lineares ${ }^{3}$, além de análises não lineares dinâmicas. As vantagens e desvantagens de cada tipo de análise são discutidas por Byfiel et al. [77].

Uma análise estática não linear física e geométrica com o uso de amplificadores dinâmicos para estruturas de concreto e aço foi delineada por Liu et al. [178].

Análises não lineares dinâmicas com a consideração de efeitos de amortecimento e taxa de carregamento são tratados por Olmati et al. [179]. Wang et al. [180] usaram modelos em multi-escala para investigar o desempenho das ligações viga/pilar por meio de análise não linear estática e dinâmica.

\subsection{Conclusão do Capítulo}

O presente capítulo apresentou os conceitos fundamentais, as abordagens de projeto e os principais estudos no campo do colapso progressivo de estruturas. Verificou-se que os documentos normativos internacionais tratam esse assunto através de recomendações implícitas (abordagem indireta) e explícitas (abordagem direta). Todavia, a abordagem baseada na identificação de elementos chave por análise de confiabilidade de sistemas não foi utilizado pela maior parte desses códigos. Desse modo, as perspectivas futuras são inserir essa abordagem nos códigos, de forma a prescrever diretrizes baseadas na redução do risco por meio de uma teoria probabilística. Consequentemente, prover recomendações de projeto que viabilizem aos novos edifícios um nível mínimo de robustez capaz de absorver e suportar os danos acidentais até serem evacuados. 
CAPÍtULO

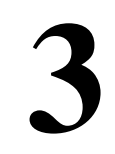

(2)

MODELO MECÂNICO

\subsection{Considerações Iniciais}

$\mathrm{Na}$ ocorrência de um dano acidental, o colapso progressivo ocorre com uma abordagem em termos de energia, se o potencial das forças externas aplicadas for maior do que a energia absorvida pelo sistema [181, 182, 183]. A energia absorvida é constituída pelas parcelas: energia de deformação, energia cinética e energia dissipada [184]. A dissipação inclui o trabalho plástico absorvido pelos elementos que compõem a estrutura, o trabalho ou energia requerida para falhar um elemento e a energia associada ao amortecimento da estrutura [184]. Dessa forma, torna-se fundamental na descrição do comportamento mecânico de uma estrutura em situação de danos acidentais levar em consideração todas essas parcelas de energia. Além disso, de acordo com [185, 186, 187, 188], para tal descrição é essencial a consideração das não-linearidades física e geométrica.

Sendo assim, este capítulo apresenta uma formulação para problemas que envolvam a análise de estruturas treliçadas sujeitas ao colapso progressivo em uma descrição Lagrangeana Total. Baseada na energia mecânica total, a formulação proposta usa as posições nodais ao invés dos deslocamentos nodais para descrever os potenciais de energia. Essa formulação tem a vantagem de utilizar um formalismo matemático mais simples, não requerendo rotação de sistemas de coordenadas, o que implica em fácil implementação numérica e baixo custo computacional [189].

\subsection{Uma Formulação Lagrangeana Total em Posição Apli- cada a Análise Dinâmica não Linear Física e Geométrica de Estruturas Treliçadas}




\subsubsection{Energia mecânica total}

A conservação de energia é assegurada se a energia mecânica total em um sistema isolado permanece constante $[190,191]$. Em um sistema em que atuam somente forças conservativas, a energia mecânica total torna-se independente do tempo [192]. Nesse caso, a soma da energia cinética e potencial é uma constante $\Pi_{0}$ [193]. Entretanto, se no sistema agem forças não conservativas, a energia mecânica total varia ao longo do tempo. Diante disso, a energia mecânica total pode ser expressa pela seguinte equação [193]:

$$
\Pi=\Pi_{0}-Q(t, \mathbf{Z})
$$

em que П é a energia mecânica atual do sistema, $Q(t, \mathbf{Z})$ é a energia total dissipada, $t$ é o instante de tempo considerado e $\mathbf{Z}$ são as posições nodais na configuração atual. A Equação 3.1 pode ser reescrita como [193]:

$$
\Pi_{0}=\Pi+Q(t, \mathbf{Z})=K+P+U+Q(t, \mathbf{Z})
$$

em que $K$ é a energia cinética, $P$ é o potencial das forças externas e $U$ é a energia de deformação.

Diante de um dano acidental em um elemento estrutural a variação na energia mecânica total do sistema deve atender a seguinte inequação [184]:

$$
\delta P \geq \delta K+\delta U+\delta Q(t, \mathbf{Z})
$$

Caso a variação na energia potencial das forças externas seja maior do que o lado direito da Equação 3.3, tem-se a ocorrência do colapso progressivo [184]. Dessa forma, o trabalho ou energia adicionada ao sistema devido ao dano acidental $\left(W_{d}\right)$ pode ser mensurado por [184]:

$$
W_{d}=K+U+Q(t, \mathbf{Z})-P
$$

A Equação 3.4 torna-se uma excelente medida para a avaliação da segurança de uma estrutura na ocorrência de um dano acidental. Portanto, se $W_{d}$ resulta maior ou igual a zero, tem-se que a falha do elemento estrutural não leva o colapso da estrutura; senão, ocorre o colapso progressivo. Desse modo, sua estimativa acoplada a confiabilidade estrutural leva a uma minimização das incertezas atrelada a aleatoriedade dos processos naturais envolvidos. Por consequência, no Capítulo 6 a Equação 3.4 será formulada como a equação de estado limite global para a análise das estruturas treliçadas sujeitas ao colapso progressivo.

\subsubsection{Cinemática}

A descrição do movimento de um elemento de treliça é apresentado na Figura 3.1. Um genérico elemento de treliça na configuração inicial ou de referência $(C R)$, configuração 
intermediária $(C I)$ e configuração atual $(C A)$ é ilustrado. Os eixos de coordenadas representam as coordenadas iniciais $\left(X_{i}^{\alpha}\right)$, intermediárias $\left(Y_{i}^{\alpha}\right)$ e atuais $\left(Z_{i}^{\alpha}\right)$ do elemento. $\mathrm{O}$ índice $i$ indica a direção; $\alpha$ e $\beta$ representam os nós; $l_{0}, l_{p}$ e $l$ são os comprimentos do elemento na $C R, C I$ e $C A$, respectivamente. $\mathrm{O}$ elemento de treliça no tempo $t=t_{1}$ assume uma nova posição no espaço, alterando seu comprimento inicial após a aplicação de forças externas nos seus nós.

Figura 3.1 - Elemento de treliça 3D - cinemática.

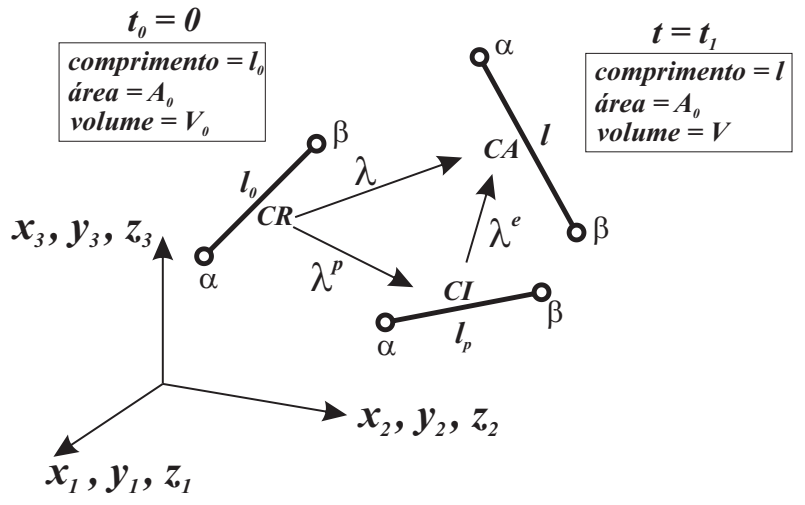

Fonte: Autor.

O comprimento inicial, intermediário e atual do elemento de treliça pode ser escrito com relação as posições nodais, respectivamente, como:

$$
\left\{\begin{array}{l}
l_{0}=\sqrt{\left(X_{1}^{2}-X_{1}^{1}\right)^{2}+\left(X_{2}^{2}-X_{2}^{1}\right)^{2}+\left(X_{3}^{2}-X_{3}^{1}\right)^{2}} \\
l_{p}=\sqrt{\left(Y_{1}^{2}-Y_{1}^{1}\right)^{2}+\left(Y_{2}^{2}-Y_{2}^{1}\right)^{2}+\left(Y_{3}^{2}-Y_{3}^{1}\right)^{2}} \\
l=\sqrt{\left(Z_{1}^{2}-Z_{1}^{1}\right)^{2}+\left(Z_{2}^{2}-Z_{2}^{1}\right)^{2}+\left(Z_{3}^{2}-Z_{3}^{1}\right)^{2}} .
\end{array}\right.
$$

Define-se a grandeza estiramento de Cauchy-Green $(\lambda)$ como a razão entre o comprimento atual e inicial do elemento [194], e o jacobiano da transformação $(J)$ como a relação entre o volume atual $(V)$ e inicial $\left(V_{0}\right)[10]$ :

$$
\begin{aligned}
& \lambda=\frac{l}{l_{0}} \\
& J=\frac{V}{V_{0}} .
\end{aligned}
$$

Para materiais homogêneos e isotrópicos, em estado uniaxial ${ }^{1}$, a Equação 3.7 pode ser reescrita em função do estiramento de Cauchy-Green como:

1 Admitido a hipótese que a área da seção transversal permanece constante durante o processo de carregamento. 


$$
J=\frac{V}{V_{0}}=\frac{A_{0} \cdot l}{A_{0} \cdot l_{0}}=\frac{l}{l_{0}}=\lambda
$$

Na configuração atual, se o elemento sofre um alongamento infinitesimal $d l$, define-se a deformação longitudinal de engenharia instantânea ${ }^{2}$ por [10]:

$$
d \varepsilon=\frac{d l}{l}
$$

Considerando a hipótese de deformação uniforme ao longo do comprimento do elemento de treliça, define-se a medida de deformação de Hencky ou logarítmica ${ }^{3}\left(\varepsilon_{l n}\right)$ pela seguinte equação [11]:

$$
\varepsilon_{l n}=\int_{l_{0}}^{l} d \varepsilon=\int_{l_{0}}^{l} \frac{d l}{l}=\ln (\lambda)
$$

A deformação logarítmica é uma medida de deformação objetiva ${ }^{4}$ e leva em consideração a descrição geometricamente exata do problema [11, 195]. A deformação logarítmica para estado uniaxial, em regime de pequenas deformações, é o conjugado energético da tensão de Cauchy $(\sigma)$, pois a Equação 3.8 resulta aproximadamente igual a 1. Por outro lado, para grandes deformações, o comportamento elastoplástico é mais bem caracterizado usando a tensão de Kirchhoff $(\tau)$ [9], definida como [196]:

$$
\tau=J \sigma
$$

Essa é a medida de tensão utilizada para o desenvolvimento que se segue neste trabalho.

\subsubsection{Decomposição multiplicativa do estiramento de Cauchy-Green}

A avaliação da plasticidade para grandes deformações é melhor representada empregando a decomposição multiplicativa [197, 198, 199, 200]. A decomposição multiplicativa do estiramento de Cauchy-Green é dada por uma componente elástica e plástica de acordo com a Equação 3.12 [10].

$$
\lambda=\lambda^{e} \lambda^{p}
$$

Sendo, $\lambda^{e}$ a parte elástica e $\lambda^{p}$ a parte plástica, respectivamente, do estiramento de Cauchy-Green, as quais são definidos por [10]:

Tendo em vista a descrição Euleriana, a variação da deformação real (conjugada energética da tensão de Cauchy), para o caso uniaxial, é dada pela Equação 3.9 [11, 194].

4 É uma medida de deformação que proporciona valor nulo para movimentos de corpo rígido. 


$$
\begin{aligned}
\lambda^{e} & =\frac{l}{l_{p}} \\
\lambda^{p} & =\frac{l_{p}}{l_{0}} .
\end{aligned}
$$

Substituído a Equação 3.14 e Equação 3.13 na Equação 3.10, resulta a decomposição aditiva da medida de deformação logarítmica [10]:

$$
\varepsilon_{l n}=\ln (\lambda)=\ln \left(\lambda^{e} \lambda^{p}\right)=\ln \left(\lambda^{e}\right)+\ln \left(\lambda^{p}\right)=\varepsilon_{l n}^{e}+\varepsilon_{l n}^{p}
$$

em que, $\varepsilon_{l n}^{e}$ e $\varepsilon_{l n}^{p}$ são, respectivamente, a parte elástica e plástica de $\varepsilon_{l n}$.

\subsubsection{Potencial das forças externas aplicadas}

Uma força é dita conservativa quando sua intensidade, direção e sentido não dependem da posição que ocupa no espaço [20, 21, 26]. Por esse motivo, em um sistema mecânico no qual atuam $n$ forças externas conservativas concentradas, a energia potencial das forças externas $P$ pode ser expressa pela seguinte equação [201]:

$$
P=-F_{i}^{\alpha(e x t)} Z_{i}^{\alpha}
$$

em que, $i=1,2,3$ representa a direção de cada componente de força e $\alpha=1,2, \ldots, n$ indica cada força externa conservativa $\mathbf{F}^{(\text {ext })}$ aplicada no sistema mecânico. Nota-se que $P$ pode não ser nulo na configuração inicial [201].

A derivada da Equação 3.16 em relação as posições nodais resulta nas forças externas aplicadas:

$$
\frac{\partial P}{Z_{k}^{\beta}}=\frac{\partial\left[-F_{i}^{\alpha(e x t)} Z_{i}^{\alpha}\right]}{\partial Z_{k}^{\beta}}=-F_{i}^{\alpha(e x t)} \delta_{\alpha \beta} \delta_{i k}=-F_{k}^{\beta(e x t)}
$$

sendo $\delta_{i j}$ o tensor Delta de Kronecker que é um permutador de índices na notação indicial ou de Einstein. Na seção 3.3 a Equação 3.17 é utilizada para montar as $n$ equações não lineares de equilíbrio.

Como algumas forças externas geram efeitos dinâmicos nas estruturas, para uma análise robusta, torna-se fundamental a consideração de tais efeitos. Desse modo, a Figura 3.2 apresenta os tipos de forças externas que são consideradas neste trabalho. Em a) é ilustrado o comportamento típico da carga devido ao peso próprio da estrutura e ações com variação nula ou quase nula ao longo do tempo. Já em b) mostra-se a força impulsiva, que possui curta duração, mas grande intensidade, como por exemplo, explosões, choques, falha de um elemento estrutural. Finalmente em c), tem-se as forças aperiódicas, que variam de forma arbitrária ao longo do tempo, porém não apresentam curta duração, tais como: vento, terremotos, ondas, construção, etc. As forças 
aperiódicas são as forças externas dinâmicas mais comuns e gerais na engenharia [202, 203, 204].

Figura 3.2 - Forças externas: a) força externa estática; b) força externa impulsiva; c) força externa aperiódica.
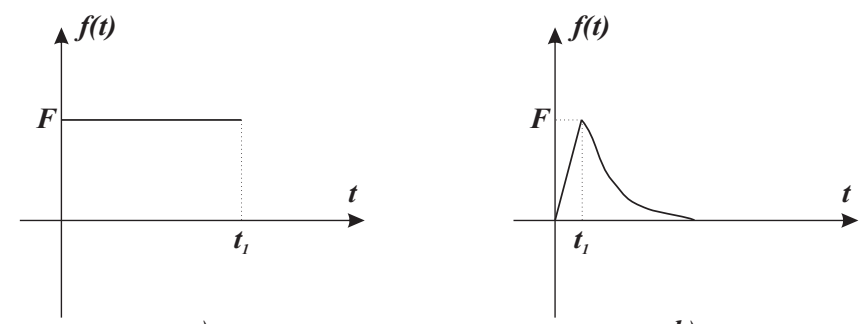

a)

b)

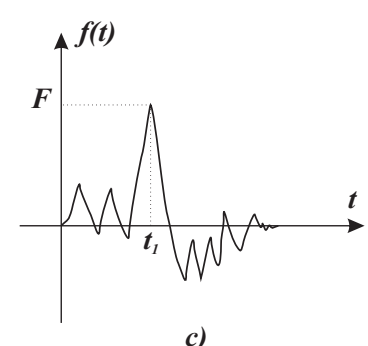

Fonte: Autor.

\subsubsection{Potencial da energia livre de Helmholtz}

Assumindo a hipótese de desacoplamento entre elasticidade-dano e encruamento [205, 206, 207], o potencial da energia livre de Helmholtz ( $\Psi)$, pode ser escrito como:

$$
\Psi\left(\varepsilon_{l n}^{e}, D, \varpi\right)=\frac{1}{2} \varepsilon_{l n}^{e}(1-D) E \varepsilon_{l n}^{e}+\frac{1}{2} \aleph \varpi^{2}
$$

sendo, $D$ a variável de dano, $E$ o módulo de elasticidade do material íntegro e $\mathfrak{\aleph}$ o parâmetro de encruamento isótropo.

Por conseguinte, a tensão de Kichhoff $(\tau)$, que é o conjugado da deformação logarítmica [8]; a força termodinâmica $(\Upsilon)$, que é conjugado da variável interna de dano [36]; e a força termodinâmica $(\chi)$, que é conjugado do encruamento [208, 209] são, respectivamente, definidas pelas seguintes equações:

$$
\begin{gathered}
\tau=\frac{\partial \Psi}{\partial \varepsilon_{l n}^{e}}=(1-D) E \varepsilon_{l n}^{e} \\
\Upsilon=\frac{\partial \Psi}{\partial D}=-\frac{1}{2} \varepsilon_{l n}^{e} E \varepsilon_{l n}^{e} \\
\chi=-\frac{\partial \Psi}{\partial \varpi}=-\aleph \varpi
\end{gathered}
$$


onde o sinal de menos na Equação 3.21 indica que essa parcela é dissipativa.

O parâmetro $\varpi \geq 0$ governa a intensidade do fluxo plástico, que é a variável interna de encruamento [210, 211]. Nesse sentido, o potencial plástico $F(\tau, \chi)$ é definido como segue [60]:

$$
\dot{\varepsilon}_{l n}^{p}=\dot{\gamma} \frac{\partial F(\tau, \chi)}{\partial \tau} \quad e \quad \dot{\varpi}=\dot{\gamma} \frac{\partial F(\tau, \chi)}{\partial \chi}
$$

em que o índice (') denota derivada temporal e $\gamma$ é o multiplicador plástico, que deve satisfazer as clássicas relações KKT [60]:

$$
\dot{\gamma} \geq 0, \quad f(\tau, \chi) \leq 0, \quad \dot{\gamma} f(\tau, \chi)=0
$$

e a condição de consistência [60]:

$$
\text { se } \quad f(\tau, \chi)=0 \quad \Rightarrow \quad \dot{\gamma} \dot{f}(\tau, \chi)=0
$$

sendo que $f(\tau, \chi)$ é o critério de plastificação. O modelo proposto assume a abordagem de von Mises como critério de plastificação. A formulação proposta usa o modelo de encruamento isótropo. Para o caso uniaxial, tal critério é definido por [60]:

$$
f(\tilde{\tau}, \chi)=\|\tilde{\tau}\|-\left(\chi+\tau_{y}\right) \leq 0
$$

em que $\tau_{y}$ é o tamanho inicial da superfície de plastificação; $\|\bullet\|$ é a norma Euclidiana, e $\tilde{\tau}$ é a tensão efetiva dada pela Equação 3.26 [205].

$$
\tilde{\tau}=\frac{\tau}{1-D}=E\left(\varepsilon_{l n}-\varepsilon_{l n}^{p}\right)
$$

A energia de deformação armazenada em um corpo pode ser determinada pela integração da Equação 3.18 no volume do corpo [201]. Caso o volume de referência seja o inicial, tem-se uma descrição Lagrangeana [201], do contrário, resulta em uma descrição Euleriana [201]. Como a formulação que se segue é uma versão Lagrangeana Total, a energia de deformação mais as parcelas de dissipação devido ao dano e a plasticidade, escrita em função das posições nodais, resulta:

$$
U^{j}\left(Z_{k}^{\beta}\right)=\int_{V_{0}^{(j)}} \Psi^{j}\left[\varepsilon_{l n}\left(Z_{k}^{\beta}\right), D, \varpi\right] d V_{0}
$$

sendo $\beta=1,2$ o nó local do elemento de treliça $j$, conforme ilustrado na Figura 3.1, e $k=1,2,3$ a direção. Note que $U$ não depende dos parâmetros $D$ e $\varpi$, devido as suas relações intrínsecas $\operatorname{com} \varepsilon_{l n} \mathrm{e} \tau$.

Apesar de se poder utilizar qualquer medida de deformação para determinar $\Psi[22$, 25], por coerência a subseção 3.2.2, emprega-se a deformação logarítmica. Diante disso, a Equação 3.27 é reescrita da seguinte maneira: 


$$
U^{j}\left(Z_{k}^{\beta}\right)=A_{0}^{(j)} l_{0}^{(j)} \Psi^{j}\left[\varepsilon_{l n}\left(Z_{k}^{\beta}\right), D, \varpi\right]
$$

em que $A_{0}$ é a área inicial do elemento $j$.

Portanto, a energia de deformação de toda a treliça é dada pela soma algébrica das energias de deformação de cada elemento [201], o que resulta:

$$
U=\sum_{j=1}^{n e l} U^{j}\left(Z_{k}^{\beta}\right)
$$

sendo nel o número de elementos que constitui a estrutura da treliça.

Derivando a Equação 3.29 em relação as posições nodais, define-se o seguinte conjugado energético [201]:

$$
F_{i}^{\alpha(i n t)}=\frac{\partial U}{\partial Z_{i}^{\alpha}}=\frac{\partial\left[\sum_{j=1}^{n e l} U^{j}\left(Z_{k}^{\beta}\right)\right]}{\partial Z_{i}^{\alpha}}=\sum_{j=1}^{n e l} \frac{\partial U^{j}\left(Z_{k}^{\beta}\right)}{\partial Z_{i}^{\alpha}}
$$

sendo $F_{i}^{\alpha(i n t)}$ a força interna no nó $\alpha$ e direção $i$ [212].

Da Equação 3.28, procede-se a derivada aplicando-se a regra da cadeia, resultando na Equação 3.31 .

$$
\frac{\partial U^{j}}{\partial Z_{i}^{\alpha}}=A_{0}^{(j)} l_{0}^{(j)} \frac{\partial \Psi^{j}}{\partial \varepsilon_{l n}} \frac{\partial \varepsilon_{l n}}{\partial Z_{i}^{\alpha}}
$$

A primeira derivada do lado direito da Equação 3.31 resulta na tensão de Kirchhoff. Em relação a segunda derivada do lado direito, recordando da Equação 3.5 e Equação 3.10, e utilizando-se das propriedades da função logarítmica, tem-se:

e, portanto,

$$
\varepsilon_{l n}=\frac{1}{2} \ln \left[\frac{\left(Z_{1}^{2}-Z_{1}^{1}\right)^{2}+\left(Z_{2}^{2}-Z_{2}^{1}\right)^{2}+\left(Z_{3}^{2}-Z_{3}^{1}\right)^{2}}{\left(X_{1}^{2}-X_{1}^{1}\right)^{2}+\left(X_{2}^{2}-X_{2}^{1}\right)^{2}+\left(X_{3}^{2}-X_{3}^{1}\right)^{2}}\right]
$$

$$
\frac{\partial \varepsilon_{l n}}{\partial Z_{i}^{\alpha}}=\frac{(-1)^{\alpha}\left(Z_{i}^{2}-Z_{i}^{1}\right)}{l^{2}}
$$

sendo, $\alpha=1,2$ o nó local e $i=1,2(2 D)$ ou $i=1,2,3(3 D)$ a direção.

Destarte, a força interna para um elemento de treliça $j$ fica dada por:

$$
\left[F_{i}^{\alpha(i n t)}\right]^{j}=\frac{\partial U^{j}}{\partial Z_{i}^{\alpha}}=A_{0}^{(j)} l_{0}^{(j)} \tau^{j} \frac{(-1)^{\alpha}\left(Z_{i}^{2}-Z_{i}^{1}\right)}{l^{2}} .
$$

As forças internas globais referem-se às forças locais por acumulação, relacionando os graus de liberdade local dos elementos com os graus de liberdade global da treliça, a saber [201]: 


$$
\left\{\begin{array}{l}
{\left[F_{k}^{(i n t)}\right]^{\text {global }}=\left[F_{k}^{(i n t)}\right]^{\text {global }}+\left[F_{i}^{\alpha(i n t)}\right]^{j}} \\
k=\operatorname{dim}[\operatorname{inc}(j, \alpha)-1]+i
\end{array}\right.
$$

sendo, $\operatorname{dim}$ a dimensão do problema, i.e., $\operatorname{dim}=2$ se $2 D$, ou $\operatorname{dim}=3$ se $3 D$, e inc a matriz de incidência dos nós.

\subsubsection{Um abrangente modelo de dano dúctil}

O abrangente modelo de dano dúctil proposto neste estudo é apresentado nesta seção. Tal modelo é formulado a partir das seguintes hipóteses:

a) o material durante a evolução do dano apresenta comportamento elastoplástico;

b) o dano mecânico ocorre quando há evolução da componente hidrostática da deformação plástica;

c) a variável de dano evolui quando a componente hidrostática da deformação plástica é maior que o limite de dano inicial $\left(\varepsilon_{l n, d}^{p}\right)$;

d) o processo de degradação mecânica é causado pelo crescimento de microcavidades e coalescência de fissuras. A taxa do processo de degradação é assumida como uma função polinomial de segundo grau da componente hidrostática da deformação plástica;

e) presume-se que a lei de evolução do dano é igual à taxa de porosidade do material causado pelo crescimento de microcavidades e coalescência de fissuras;

f) assume-se que o modelo de dano é isotrópico.

À vista disso, a medida de extensão plástica $(\xi)$ é definida como segue:

$$
\begin{cases}\xi=\varepsilon_{H}^{p}=\frac{\operatorname{tr}\left(\varepsilon_{l n}^{p}\right)}{3}, & \text { se } \quad \varepsilon_{l n}^{p} \geq 0 \\ \xi=-\varepsilon_{H}^{p}=-\frac{\operatorname{tr}\left(\varepsilon_{l n}^{p}\right)}{3}, & \text { se } \quad \varepsilon_{l n}^{p}<0\end{cases}
$$

sendo $\varepsilon_{H}^{p}$ a componente hidrostática da deformação plástica e $\operatorname{tr}(\bullet)$ indica o operador traço. Observe que o $\operatorname{tr}(\bullet)$ é usado apenas para o estado de tensão multiaxial. Para um elemento de treliça, tem-se que $\varepsilon_{H}^{p}=\varepsilon_{l n}^{p} / 3$.

A função de dano necessária para identificar a presença ou ausência de dano no material é definida da seguinte forma:

$$
\Re(\xi, D)=\xi-\Phi(D) \leq 0
$$


com $\Phi(0)=\varepsilon_{l n, d}^{p}$ (limite de dano inicial). A Equação 3.37 deve atender as condições de complementaridade, $\dot{D} \Re=0$, e consistência, $\dot{D} \dot{\Re}=0$ [36].

A aplicação do princípio da irreversibilidade de Clausius - Duhem conduz às seguintes inequações [205]:

$$
\left\{\begin{array}{l}
-\Upsilon \dot{D} \geq 0 \\
\dot{D} \geq 0
\end{array}\right.
$$

O processo de degradação mecânica em materiais dúcteis é inicialmente causado pelo deslizamento dos componentes da microestrutura do material, porque o material não é perfeitamente compacto [206]. O deslizamento da microestrutura leva ao desenvolvimento de deformações plásticas [206]. Além disso, esses processos de degradação mecânica modificam a porosidade do material [213]. De acordo com a hipótese do modelo de Gurson [214, 215, 216], a variação da porosidade na mesoescala $(\dot{\kappa})$ é igual a $\dot{\varepsilon}_{H}^{p}$, ou seja:

$$
\dot{\kappa}=\dot{\varepsilon}_{H}^{p}
$$

A Figura 3.3 apresenta a lei de evolução da porosidade assumida no modelo. Vale ressaltar que, na configuração atual, a porosidade do elemento de treliça é modificada pela evolução das deformações plásticas [213]. Nesse caso, a evolução da degradação mecânica da microestrutura do material avaliada pela hipótese do Item d) resultam na porosidade atual $\kappa\left(\varepsilon_{H}^{p}\right)$, que é dada da seguinte forma:

$$
\kappa\left(\varepsilon_{H}^{p}\right)=\kappa_{0}+\alpha_{1}^{p}\left(\varepsilon_{H}^{p}-\varepsilon_{H, u}^{p}\right)^{2}+\alpha_{2}^{p}\left(\varepsilon_{H}^{p}-\varepsilon_{H, u}^{p}\right)+\alpha_{3}^{p}
$$

em que $\kappa_{0}$ é a porosidade inicial do material, $\alpha_{1}^{p}, \alpha_{2}^{p}$ e $\alpha_{3}^{p}$ são parâmetros característicos do material determinados a partir de resultados experimentais e $\varepsilon_{H, u}^{p}$ é a componente hidrostática da deformação plástica última.

Figura 3.3 - a) lei de evolução da porosidade; b) lei de evolução do dano com relação a $\varepsilon_{H}^{p}$.

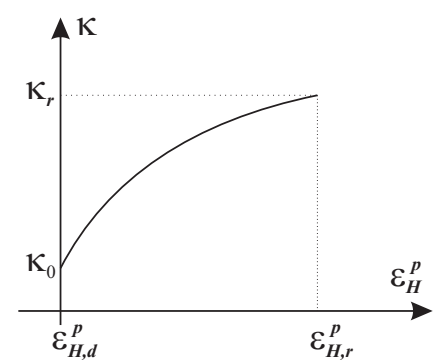

a)

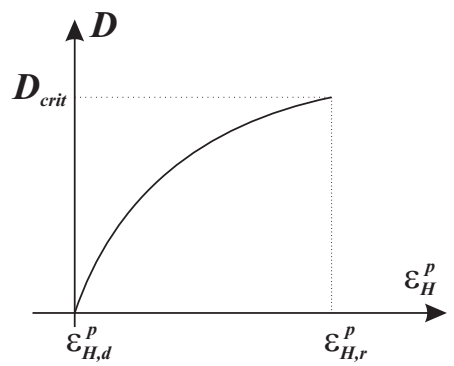

b)

Fonte: Autor. 
Segundo Lemaitre [36], o dano crítico $D_{\text {crit }}$ pode ser relacionado com a tensão última $\left(\tau_{u}\right)$ e ruptura $\left(\tau_{r}\right)$ pela Equação 3.41 .

$$
D_{\text {crit }}=1-\frac{\tau_{r}}{\tau_{u}}
$$

A lei de evolução de dano requerida no modelo proposto é definida pela hipótese do Item e) e considera as medidas de deformação plástica da seguinte forma:

$$
\left\{\begin{array}{l}
D\left(\varepsilon_{H}^{p}\right)=\kappa\left(\varepsilon_{H}^{p}\right)-\kappa_{0}=\alpha_{1}^{p}\left(\varepsilon_{H}^{p}-\varepsilon_{H, u}^{p}\right)^{2}+\alpha_{2}^{p}\left(\varepsilon_{H}^{p}-\varepsilon_{H, u}^{p}\right)+\alpha_{3}^{p} \\
D\left(\varepsilon_{l n}^{p}\right)=\alpha_{1}^{p}\left[\frac{\operatorname{tr}\left(\varepsilon_{l n}^{p}\right)}{3}-\varepsilon_{H, u}^{p}\right]^{2}+\alpha_{2}^{p}\left[\frac{\operatorname{tr}\left(\varepsilon_{l n}^{p}\right)}{3}-\varepsilon_{H, u}^{p}\right]+\alpha_{3}^{p} \\
D(\xi)=\alpha_{1}^{p}\left(\xi-\varepsilon_{H, u}^{p}\right)^{2}+\alpha_{2}^{p}\left(\xi-\varepsilon_{H, u}^{p}\right)+\alpha_{3}^{p} .
\end{array}\right.
$$

A Figura 3.4 ilustra o diagrama tensão-deformação de uma amostra típica de material dúctil. Durante o encruamento, as alterações no volume são desconsideradas, bem estabelecidas na teoria da plasticidade [60]. Portanto, neste caso, as alterações de porosidade são consideradas nulas. Consequentemente, o dano não afeta o mecanismo de encruamento [205]. No ponto da tensão última, a seção transversal deixa a região de plasticidade e inicia o dano em um processo amplamente conhecido como estricção [217]. Nesse ponto, há mudanças significativas na porosidade do material [213]. Então, a porosidade do material cresce até o valor crítico que leva a sua falha [213].

Figura 3.4 - Diagrama de tensão vs. deformação plástica de um material dúctil típico.

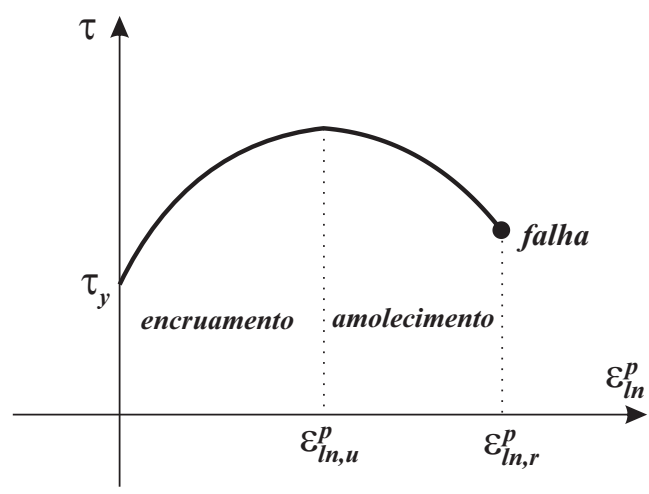

Fonte: Autor.

Vale ressaltar que o dano dúctil ocorre quando o endurecimento por deformação alcança um valor limite [36]. Em vista disso, o limite de dano inicial é assumido como o valor da componente hidrostática da deformação plástica última, i.e.: 


$$
\varepsilon_{l n, d}^{p}=\varepsilon_{H, u}^{p}=\frac{\operatorname{tr}\left(\varepsilon_{l n, u}^{p}\right)}{3}
$$

onde $\varepsilon_{l n, u}^{p}$ é a parte plástica da deformação logarítmica última. Logo, a Equação 3.42 resulta na Equação 3.44.

$$
D(\xi)=\alpha_{1}^{p}\left(\xi-\varepsilon_{l n, d}^{p}\right)^{2}+\alpha_{2}^{p}\left(\xi-\varepsilon_{l n, d}^{p}\right)+\alpha_{3}^{p}
$$

De acordo com a Figura 3.5, e usando o princípio da equivalência das deformações, a deformação total $\left(\varepsilon_{l n}\right)$ pode ser decomposta em três termos; uma parcela elástica $\left(\varepsilon_{l n}^{e}\right)$; uma parcela de dano $\left(\varepsilon_{l n}^{d}\right)$ e, por fim, uma parcela plástica $\left(\varepsilon_{l n}^{p}\right)$, que é avaliada pela Equação 3.45.

$$
\varepsilon_{l n}=\varepsilon_{l n}^{e}+\varepsilon_{l n}^{d}+\varepsilon_{l n}^{p}
$$

Figura 3.5 - Diagrama de tensão vs. deformação: decomposição da deformação total.

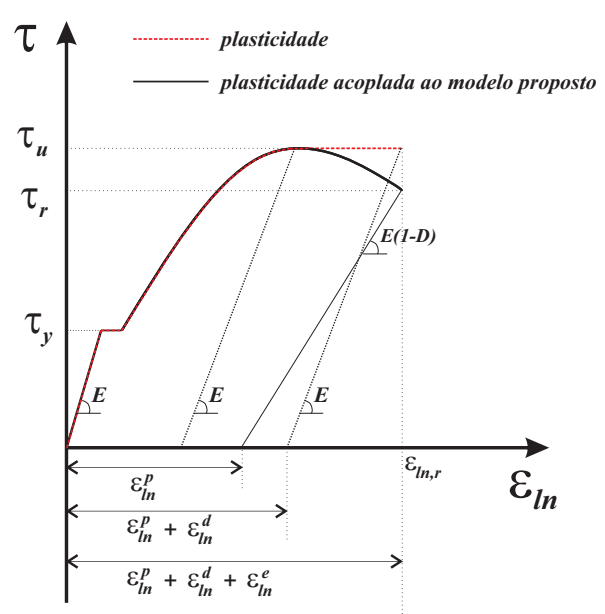

Fonte: Autor.

Observe que o processo de degradação mecânica conduz a uma parcela adicional $\varepsilon_{l n}^{d}$ na decomposição da $\varepsilon_{l n}$, em concordância com a Equação 3.15. Assim, pela hipótese de equivalência das deformações ${ }^{5}, \varepsilon_{l n}^{d}$ é escrita conforme a Equação 3.46 .

$$
\varepsilon_{l n}^{d}=\frac{D \tau}{(1-D) E}=\frac{D \varepsilon_{l n}^{e}}{(1-D)}
$$

Portanto, a tensão no regime de amolecimento em um elemento de treliça fica definida em conformidade com a Equação 3.47.

5 A hipótese de equivalência das deformações afirma que o comportamento de um material danificado pode ser descrito pelas mesmas equações do intacto se $\tau$ for substituída por $\tilde{\tau}$ [205]. 


$$
\tau=(1-D) E \varepsilon_{l n}^{e}=(1-D) E\left(\varepsilon_{l n}-\varepsilon_{l n}^{p}\right)
$$

\subsubsection{Energia cinética e forças de inércia}

A energia associada com o movimento de um corpo é definido como a energia cinética $(K)$ [193]. Essa resulta sempre em um valor positivo e é definida como [203]:

$$
K=\frac{1}{2} \int_{V_{0}} \rho_{0} \dot{\mathbf{u}} \cdot \dot{\mathbf{u}} d V_{0}
$$

sendo, $\mathbf{u}$ a velocidade do corpo e $\rho_{0}$ a massa específica associada à configuração inicial.

Em problemas dinâmicos, assume-se que a massa do elemento de treliça esteja concentrada em seus nós [201]. Desse modo, a Equação 3.48 escrita em termos das posições nodais resulta:

$$
K=\sum_{r=1}^{n} K_{r}=\frac{1}{2} m_{(r)} \dot{Z}_{j}^{r} \dot{Z}_{j}^{r}
$$

em que, $r=1,2, \ldots, n$ são os nós da estrutura, $m_{(r)}$ é a massa do nó $r$ e $\dot{Z}_{j}^{r}$ é a velocidade do nó $r$ na direção $j$.

$\mathrm{O}$ valor de $m_{(r)}$ pode ser dividido em duas partes. A primeira é a massa de cada elemento de treliça concorrente ao nó $r$ [201]. A segunda é a massa que pode ser acrescentada à estrutura, como por exemplo, equipamentos de transmissão, dispositivos de controle de vibração, etc., valores fornecidos como dados de entrada para a análise numérica [201].

Relembrando da Física elementar que o tempo é uma variável independente [190, 191, 192]. Por consequência, a variação da energia cinética pode ser escrita como:

$$
\delta K=\frac{\partial K}{\partial Z_{j}^{r}} \delta Z_{j}^{r}=\frac{d K}{d t} \delta t
$$

logo, substituído a Equação 3.49 na Equação 3.50 e, usando a regra da derivada do produto, tem-se:

$$
\delta K=m_{(r)} \ddot{Z}_{j}^{r} \underbrace{\dot{Z}_{j}^{r} \delta t}_{\delta Z_{j}^{r}}=m_{(r)} \ddot{Z}_{j}^{r} \delta Z_{j}^{r} .
$$

Pelo Princípio de d'Alembert ${ }^{6}$, obtém-se:

$$
F_{j}^{r(\text { iner })}=\frac{\partial K}{\partial Z_{j}^{r}}=m_{(r)} \ddot{Z}_{j}^{r}
$$

6 A resultante das forças aplicadas mais a resultante das forças de inércia, para um sistema dinâmico, é igual a zero. Em outras palavras, um sistema de partículas com massas aceleradas é equivalente a um sistema estático em equilíbrio quando são adicionadas as forças de inércia [203]. 
sendo, $F_{j}^{r(\text { iner })}$ a força de inércia na direção $j$ para o nó $r$. Como resultado, a Equação 3.51, fica dado por:

$$
\delta K=F_{j}^{r(\text { iner })} \delta Z_{j}^{r}
$$

Com relação à matriz de massa de uma treliça $\mathbf{M}$, emprega-se uma matriz diagonalizada, também chamada de matriz de massa concentrada, uma vez que considera-se que a massa de um elemento está concentrada em seus nós [201]. Sendo assim, a matriz de massa de um elemento $k$ é dada por:

$$
\left(M_{\beta \eta}\right)^{k}=\frac{\rho_{0}^{(k)} A_{0}^{(k)} l_{0}^{k}}{2} \delta_{\beta \eta}
$$

$\operatorname{com} \beta=1,2,3$ e $\eta=1,2,3$ são as direções, se o problema é $3 D$, enquanto $\delta_{\beta \eta}$ é o Delta de Kronecker. Portanto, o vetor das forças de inércia fica dado pela Equação 3.55.

$$
\mathbf{F}^{(\text {iner })}(\ddot{\mathbf{Z}})=\mathbf{M} \cdot \ddot{\mathbf{Z}}
$$

\subsubsection{Energia total dissipativa e força de amortecimento}

Os efeitos dinâmicos em uma estrutura sempre estão associados com um processo de dissipação de energia, cujo fenômeno é chamado de amortecimento [218, 219]. Este depende de muitos fatores, tais como: temperatura, frequência, amplitude, histerese, atrito interno, etc. Por estas razões, o amortecimento é o resultado de distintas causas que torna sua avaliação complexa. Portanto, conforme [219], a sua mensuração apresenta a maior incerteza na modelagem de um modelo estrutural que considere os efeitos dinâmicos.

Na literatura específica, o referido fenômeno pode ser idealizado ${ }^{7}$ como uma analogia ao amortecimento viscoso em fluido proposto por Newton [220, 221]. Por isso, a energia total dissipativa $Q(t, \mathbf{Z})$ é proporcional a velocidade [203]. Por conseguinte, a força de amortecimento $\mathbf{F}^{\text {(amort) }}$ correspondente também é assumida proporcional a velocidade [203]. Matematicamente, a $Q(t, \mathbf{Z})$ por ciclo, é definida pela integral de linha ${ }^{8}$ sobre uma curva fechada $\gamma$ [203], a qual pode ser escrita com relação as posições nodais de acordo com a Equação 3.56.

$$
Q(t, \mathbf{Z})=\oint_{\gamma} \mathbf{F}^{(\text {amort })} \cdot d \mathbf{Z}
$$

A variação da energia total dissipativa pode ser escrita conforme a Equação 3.57.

Outras idealizações são: o amortecimento de Coulomb e o amortecimento estrutural. Com relação ao amortecimento de Coulomb, este é amplamente utilizado em dispositivos de dissipação de energia em estruturas sismo-resistentes [219]. O amortecimento estrutural é empregado para modelar a dissipação de energia internamente ao material. Este último também é chamado de amortecimento histerético, pois é obtido pela mensuração da área delimitada pela curva tensão vs. deformação no ciclo de carregamento-descarregamento do material, possui uma forma de um loop histerético, que é proporcional a energia dissipada por ciclo [203].

8 A integral de linha tem muitas aplicações na Física. Quando é realizada sobre uma curva fechada, é conhecida como circuitação. 


$$
\delta Q(t, \mathbf{Z})=\frac{\partial Q(t, \mathbf{Z})}{\partial \mathbf{Z}} \delta \mathbf{Z}
$$

Recordando do Teorema Fundamental do Cálculo (TFC), que na Equação 3.56 a $Q(t, \mathbf{Z})$ é uma primitiva de $\mathbf{F}^{\text {(amort) }}$, o que implica:

$$
F^{(\text {amort })}=\frac{\partial Q(t, \mathbf{Z})}{\partial \mathbf{Z}} .
$$

A força de amortecimento viscoso é definida em referência as posições nodais por [201]:

$$
\mathbf{F}^{(\text {amort })}(\dot{\mathbf{Z}})=\mathbf{C} \cdot \dot{\mathbf{Z}}
$$

em que $\mathbf{C}$ é a matriz de amortecimento viscoso da estrutura.

Combinando a Equação 3.59 na Equação 3.56, tem-se:

$$
Q(t, \mathbf{Z})=\oint_{\gamma} \mathbf{C} \cdot \dot{\mathbf{Z}} d \mathbf{Z}=\oint_{\gamma} \mathbf{C} \cdot \dot{\mathbf{Z}} \frac{d \mathbf{Z}}{d t} d t=\oint_{\gamma} \mathbf{C} \cdot \dot{\mathbf{Z}} \cdot \dot{\mathbf{Z}} d t
$$

Por hipótese, assume-se que todos os elementos que compõe uma treliça estejam sujeitos aos mesmos efeitos de amortecimento. Em vista disso, a montagem da matriz de amortecimento pode ser obtida através da técnica do amortecimento proporcional [203, 204], expresso pela série de Caughey [222]:

$$
\mathbf{C}=\mathbf{M} \sum_{i=0}^{k-1} \varsigma_{i}\left[\mathbf{M}^{-1} \mathbf{H}_{0}^{(e s t)}\right]^{i}
$$

em que $\varsigma_{i}$ são coeficientes arbitrários, e devem satisfazer as condições de ortogonalidade ${ }^{9}$ e, $\mathbf{H}_{0}^{(\text {est })}$ é a matriz Hessiana ${ }^{10}$ estática, i.e., avaliada na configuração inicial $\mathbf{Z}_{0}=\mathbf{X}$.

Para $k=2$, tem-se o método de Rayleigh [223], dessa forma a Equação 3.61 é reescrita conforme a Equação 3.62.

$$
\mathbf{C}=\varsigma_{0} \mathbf{M}+\varsigma_{1} \mathbf{H}_{0}^{(e s t)}
$$

Os coeficientes $\zeta_{0}$ e $\zeta_{1}$ são determinados a partir do fator de amortecimento $\zeta_{j}$ e frequência natural $\omega_{j}$ da estrutura, para o modo de amortecimento $j$, segundo a Equação 3.63 [204]:

$$
\zeta_{j}=\frac{\varsigma_{0}}{2 \omega_{j}}+\frac{\varsigma_{1} \omega_{j}}{2}
$$

9 Uma matriz de amortecimento que é proporcional a matriz de massa e/ou rigidez deve satisfazer às condições de ortogonalidade [203, 204].

10 Para forças externas conservativas e problemas estáticos, a matriz Hessiana $\mathbf{H}$ é dada pela segunda derivada da energia específica de deformação integrada no volume do corpo [201]. Tal matriz será deduzida na seção 3.3. 
No caso de $\varsigma_{0}=0$, tem-se o amortecimento proporcional a rigidez, no qual os modos superiores de $\zeta_{j}$ são fortemente amortecidos de acordo com a Equação 3.64 [204].

$$
\zeta_{j}=\frac{\varsigma_{1} \omega_{j}}{2}
$$

Por outro lado, se $\varsigma_{1}=0$, obtém-se o amortecimento proporcional à massa. Nesse caso, os modos superiores de $\zeta_{j}$ são suavemente amortecidos, em concordância com a Equação 3.65 [204].

$$
\zeta_{j}=\frac{\zeta_{0}}{2 \omega_{j}}
$$

Note que a Equação 3.63 aumenta linearmente com as $\omega_{j}$ da estrutura. Todavia, nem todas as $\omega_{j}$ são bem descritas em um modelo numérico, principalmente as obtidas para modos mais altos [204]. De fato, elevados valores de $\zeta_{j}$ podem levar a instabilidade do modelo numérico. Portanto, segundo [203], não é indicado empregar o método de Rayleigh para avaliar a matriz de amortecimento de modos superiores.

Para o desenvolvimento que se segue, usa-se a matriz de amortecimento proporcional à massa [212, 224], i.e., $\varsigma_{1}=0$. Consequentemente, a Equação 3.63 resulta [203]:

$$
\varsigma_{0}=2 \zeta \omega_{n}
$$

sendo, $\omega_{n}$ a frequência fundamental da estrutura e $\zeta$ o fator de amortecimento, para o qual adota-se valores concedidos na literatura e em normas de projeto [225, 226].

Sendo assim, combinando a Equação 3.66 e Equação 3.62, obtém-se a matriz de amortecimento proporcional à massa da estrutura.

$$
\mathbf{C}=2 \zeta \omega_{n} \mathbf{M}
$$

\subsection{Procedimento de Solução do Problema}

A Equação 3.2 escrita em termos das posições nodais (em vez de deslocamentos), assumindo um modelo constitutivo elastoplástico multilinear acoplado a lei de evolução de dano proposto neste trabalho, é dado pela Equação 3.68.

$$
\begin{array}{r}
\Pi(\mathbf{Z})=U+K+Q(t, \mathbf{Z})+P= \\
=\int_{V_{0}} \Psi\left(\varepsilon_{l n}(\mathbf{Z}), D, \Phi\right) d V_{0}+\frac{1}{2} \int_{V_{0}} \rho_{0} \dot{\mathbf{Z}} \cdot \dot{\mathbf{Z}} d V_{0}+\oint_{\gamma} \mathbf{F}^{(\text {amort })} d \mathbf{Z}-\mathbf{F}^{(\text {ext })} \cdot \mathbf{Z}
\end{array}
$$

Pelo princípio da estacionariedade, tem-se que na condição de equilíbrio a variação de $\Pi(\mathbf{Z})$ é nula [193], i.e.: 


$$
\begin{array}{r}
\frac{\partial \Pi}{\partial \mathbf{Z}} \delta \mathbf{Z}=\frac{\partial U}{\partial \mathbf{Z}} \delta \mathbf{Z}+\frac{\partial K}{\partial \mathbf{Z}} \delta \mathbf{Z}+\frac{\partial Q(t, \mathbf{Z})}{\partial \mathbf{Z}} \delta \mathbf{Z}+\frac{\partial P}{\partial \mathbf{Z}} \delta \mathbf{Z}= \\
=\left[\frac{\partial U}{\partial \mathbf{Z}}+\frac{\partial K}{\partial \mathbf{Z}}+\frac{\partial Q(t, \mathbf{Z})}{\partial \mathbf{Z}}+\frac{\partial P}{\partial \mathbf{Z}}\right] \delta \mathbf{Z}=\overrightarrow{0}
\end{array}
$$

Devido à arbitrariedade do $\delta \mathbf{Z}$ e, substituindo a Equação 3.17, Equação 3.30, Equação 3.52 e Equação 3.58 na Equação 3.69, resultam as $n$ equações não lineares de equilíbrio dinâmico [201], ou de movimento, como:

$$
\vec{g}(\mathbf{Z})=\mathbf{F}^{(\text {int })}(\mathbf{Z})+\mathbf{F}^{(\text {iner })}(\ddot{\mathbf{Z}})+\mathbf{F}^{(\text {amort })}(\dot{\mathbf{Z}})-\mathbf{F}^{(\text {ext })}(t)=\overrightarrow{0}
$$

em que, $\vec{g}(\mathbf{Z})$ é o vetor de desbalanceamento mecânico [201] e $\mathbf{Z}$ é o vetor das posições atuais, incógnitas do problema.

A avaliação da Equação 3.70 demanda um algoritmo que admita a integração no tempo [201]. Outrossim, a solução numérica estabelece que o tempo seja analisado como uma variável discreta, i.e.:

$$
t_{s+1}=t_{s}+\Delta t
$$

sendo, $\Delta t$ o passo de tempo, $t_{s}$ e $t_{s+1}$ o instante anterior e atual, respectivamente. Nas deduções que seguem, por simplicidade, suprime-se o índice $t$.

$\mathrm{Na}$ literatura várias aproximações temporais são apresentadas para a integração numérica da Equação 3.70. Dentre essas, a mais empregada para problemas que utilizam a formulação Lagrangeana total é o algoritmo de Newmark implícito [227]. Por conseguinte, as aproximações de Newmark acerca das posições nodais, podem ser escritas como [201]:

$$
\begin{gathered}
\dot{\mathbf{Z}}_{s+1}=\left[\mathbf{R}_{s}-\gamma_{n} \Delta t \mathbf{Q}_{s}+\frac{\gamma_{n} \mathbf{Z}_{s+1}}{\beta_{n} \Delta t}\right] \\
\ddot{\mathbf{Z}}_{s+1}=\left[\frac{\mathbf{Z}_{s+1}}{\beta_{n} \Delta t^{2}}-\mathbf{Q}_{s}\right] \\
\mathbf{Q}_{s}=\left[\frac{\mathbf{Z}_{s}}{\beta_{n} \Delta t^{2}}+\frac{\dot{\mathbf{Z}}_{s}}{\beta_{n} \Delta t}+\left(\frac{1}{2 \beta_{n}}-1\right) \ddot{\mathbf{Z}}_{s}\right] \\
\mathbf{R}_{s}=\left[\dot{\mathbf{Z}}_{s}+\Delta t\left(1-\gamma_{n}\right) \ddot{\mathbf{Z}}_{s}\right]
\end{gathered}
$$

em que $\beta_{n}$ e $\gamma_{n}$ são os parâmetros livres do método de Newmark. Se $\beta_{n}=1 / 4$ e $\gamma_{n}=1 / 2$ a Equação 3.72 e Equação 3.73 resultam nas equações do movimento uniformemente variado, com velocidade que varia ao longo do tempo, porém a aceleração é constante e diferente de zero. Ademais, no caso de $2 \beta_{n} \geq \gamma_{n} \geq 1 / 2$, menciona-se que a convêrgencia da solução é incondicionalmente estável para problemas lineares ${ }^{11}$ [229].

Combinando a Equação 3.72, Equação 3.73 e Equação 3.70 e, recordando da Equação 3.55 e Equação 3.59 resulta a Equação 3.76.

11 Em problemas não lineares a estabilidade nem sempre é garantida [228]. 


$$
\vec{g}\left(\mathbf{Z}_{s+1}\right)=\mathbf{F}^{(i n t)}\left(\mathbf{Z}_{s+1}\right)+\frac{\mathbf{M} \cdot \mathbf{Z}_{s+1}}{\beta_{n} \Delta t^{2}}-\mathbf{M} \cdot \mathbf{Q}_{s}+\frac{\gamma_{n} \mathbf{C} \cdot \mathbf{Z}_{s+1}}{\beta_{n} \Delta t}+\mathbf{C} \cdot \mathbf{R}_{s}-\gamma_{n} \Delta t \mathbf{C} \cdot \mathbf{Q}_{s}-\mathbf{F}_{s+1}^{(e x t)}(t)=\overrightarrow{0}
$$

Uma expansão em série de Taylor da Equação 3.76 truncada em primeira ordem, para uma posição tentativa $\mathbf{Z}_{s+1}^{0}$ implica em:

$$
\vec{g}\left(\mathbf{Z}_{s+1}\right) \cong \vec{g}\left(\mathbf{Z}_{s+1}^{0}\right)+\nabla \vec{g}\left(\mathbf{Z}_{s+1}^{0}\right) \cdot \Delta \mathbf{Z}=\vec{g}\left(\mathbf{Z}_{s+1}^{0}\right)+\mathbf{H} \cdot \Delta \mathbf{Z}=\overrightarrow{0}
$$

sendo $\mathbf{H}$ a matriz Hessiana e $\Delta \mathbf{Z}$ o vetor de correções das posições no instante considerado. Uma vez que a Equação 3.77 é não linear, emprega-se o procedimento iterativo de Newton-Raphson para a sua solução. O processo iterativo ocorre até a tolerância $(t o l)$ ser:

$$
\frac{\|\Delta \mathbf{Z}\|}{\|\mathbf{X}\|} \leq \text { tol } \quad \text { ou } \quad \frac{\left\|\vec{g}\left(\mathbf{Z}_{s+1}\right)\right\|}{\left\|\mathbf{F}^{(\text {ext })}\right\|} \leq \text { tol }
$$

em que,

$$
\Delta \mathbf{Z}=-\mathbf{H}^{-1} \cdot \vec{g}\left(\mathbf{Z}_{s+1}^{0}\right)
$$

Consequentemente, a solução tentativa é então melhorada fazendo-se:

$$
\mathbf{Z}_{s+1}=\mathbf{Z}_{s+1}^{0}+\Delta \mathbf{Z}
$$

Por conseguinte, em cada iteração a velocidade e a aceleração são corrigidas pela Equação 3.72 e Equação 3.73, respectivamente. Note que na Equação 3.74 e Equação $3.75 \mathbf{Q}_{s} \mathrm{e}$ $\mathbf{R}_{s}$ permanecem constantes durante as iterações. Isso porque os valores do passado são somente atualizados após a convergência em um determinado passo de tempo [201]. No primeiro passo de tempo do início da análise, a aceleração deve ser calculada pela Equação 3.70 e resulta na Equação 3.81 .

$$
\ddot{\mathbf{Z}}_{0}=\mathbf{M}^{-1}\left[\mathbf{F}^{(\text {ext })}(0)-\mathbf{F}^{(\text {int })}\left(\mathbf{Z}_{0}\right)-\mathbf{F}^{(\text {amort })}\left(\dot{\mathbf{Z}}_{0}\right)\right] .
$$

Desenvolvendo a matriz Hessiana, obtém-se [201]:

$$
\mathbf{H}=\frac{\partial^{2} \Pi}{\partial \mathbf{Z} \otimes \partial \mathbf{Z}}=\nabla \vec{g}\left(\mathbf{Z}_{s+1}^{0}\right)=\mathbf{H}^{(e s t)}+\frac{\mathbf{M}}{\beta_{n} \Delta t^{2}}+\frac{\gamma_{n} \mathbf{C}}{\beta_{n} \Delta t}
$$

sendo $\mathbf{H}^{(\text {est })}$ a matriz Hessiana estática, que para forças externas conservativas resulta na Equação 3.83 [201].

$$
\mathbf{H}^{(e s t)}=\frac{\partial^{2} U}{\partial \mathbf{Z} \otimes \mathbf{Z}}
$$

A matriz $\mathbf{H}^{(e s t)}$ para um elemento finito de treliça genérico $j$ é determinado pela Equação 3.84 . 


$$
\left(H_{k i}^{\alpha \beta}\right)^{j}=\frac{\partial^{2} U^{j}}{\partial Z_{k}^{\alpha} \partial Z_{i}^{\beta}}=\frac{\partial}{\partial Z_{k}^{\alpha}}\left(A_{0}^{(j)} l_{0}^{(j)} \frac{\partial \Psi^{j}}{\partial \varepsilon_{l n}} \frac{\partial \varepsilon_{l n}}{\partial Z_{i}^{\beta}}\right)=A_{0}^{(j)} l_{0}^{(j)}\left(\frac{\partial^{2} \Psi^{j}}{\partial Z_{k}^{\alpha} \partial \varepsilon_{l n}} \frac{\partial \varepsilon_{l n}}{\partial Z_{i}^{\beta}}+\frac{\partial \Psi^{j}}{\partial \varepsilon_{l n}} \frac{\partial^{2} \varepsilon_{l n}}{\partial Z_{k}^{\alpha} \partial Z_{i}^{\beta}}\right)
$$

Aplicando a regra da cadeia no primeiro termo do último parêntese, obtém-se a matriz Hessiana estática do elemento, como segue:

$$
\left(H_{k i}^{\alpha \beta}\right)^{j}=\frac{A_{0}^{(j)} l_{0}^{(j)}(-1)^{\alpha}(-1)^{\beta}}{l^{4}}\left\{\frac{\partial^{2} \Psi^{j}}{\partial^{2} \varepsilon_{l n}}\left(Z_{k}^{2}-Z_{k}^{1}\right)\left(Z_{i}^{2}-Z_{i}^{1}\right)+\frac{\partial \Psi^{j}}{\partial \varepsilon_{l n}}\left[l^{2}-2\left(Z_{(k)}^{2}-Z_{(k)}^{1}\right)^{2}\right] \delta_{k i}\right\}
$$

em que, $\alpha=1,2$ e $\beta=1,2$ são os nós dos elementos, $i=1,2$ e $k=1,2$ ou $i=1,2,3$ e $k=1,2,3$ são as direções para uma treliça $2 D$ e $3 D$, respectivamente, e $\delta_{k i}$ é o Delta de Kronecker.

Pelo princípio do conjugado energético [194], a derivada do potencial de energia livre de Helmholtz com relação a medida de deformação logarítmica é a tensão de Kirchhoff ${ }^{12}$, que é dada pela Equação 3.19. Consequentemente, a segunda derivada do potencial de energia livre de Helmholtz, em termos da deformação logarítmica, resulta no módulo tangente ${ }^{13}\left(E_{t}\right)$, i.e.:

$$
E_{t}=\frac{\partial^{2} \Psi}{\partial^{2} \varepsilon_{l n}}
$$

Rearranjando os termos da Equação 3.85, obtém-se a Equação 3.87.

$$
\left(H_{k i}^{\alpha \beta}\right)^{j}=\frac{A_{0}^{(j)} l_{0}^{(j)}(-1)^{\alpha}(-1)^{\beta}}{l^{4}}\left\{E_{t}^{j}\left(Z_{k}^{2}-Z_{k}^{1}\right)\left(Z_{i}^{2}-Z_{i}^{1}\right)+\tau^{j}\left[l^{2}-2\left(Z_{(k)}^{2}-Z_{(k)}^{1}\right)^{2}\right] \delta_{k i}\right\}
$$

Dessa forma, no procedimento de Newton-Raphson, as variáveis $\tau$ e $E_{t}$ devem ser atualizadas a cada iteração. Enquanto o limite de dano inicial não é atingido (Equação 3.43), as variáveis $\tau$ e $E_{t}$ são atualizadas somente pela plasticidade. Por outro lado, quando o limite de dano inicial é atingido, as variáveis $\tau$ e $E_{t}$ são atualizadas pela abordagem acoplada de dano à plasticidade proposta. Ademais, $\varepsilon_{l n}^{p}$ e $\varpi$ são atualizadas seguindo o algoritmo de mapeamento de retorno proposto por Simo \& Hughes [60].

Usando a correspondência entre a direção do nó e graus de liberdade, a matriz Hessiana global da treliça, relaciona-se com a matriz Hessiana local de um elemento $j$ por acumulação, de acordo com a Equação 3.88 [201].

$$
\left\{\begin{array}{l}
\left(H_{n m}\right)^{\text {global }}=\left(H_{n m}\right)^{\text {global }}+\left(H_{k i}^{\alpha \beta}\right)^{j} \\
n=\operatorname{dim}[\operatorname{inc}(j, \alpha)-1]+k \\
m=\operatorname{dim}[\operatorname{inc}(j, \beta)-1]+i
\end{array}\right.
$$

12 No caso multiaxial, a Equação 3.19 é o tensor de tensão de Kirchhoff.

13 É a Hessiana da energia específica de deformação, que expressa a rigidez do material para cada nível de deformação medido [201]. Outrossim, no caso multiaxial, a Equação 3.86 é um tensor constitutivo de quarta ordem. 
O algoritmo de solução para a formulação proposta é apresentada na Figura 3.6.

Figura 3.6 - Algoritmo de solução.

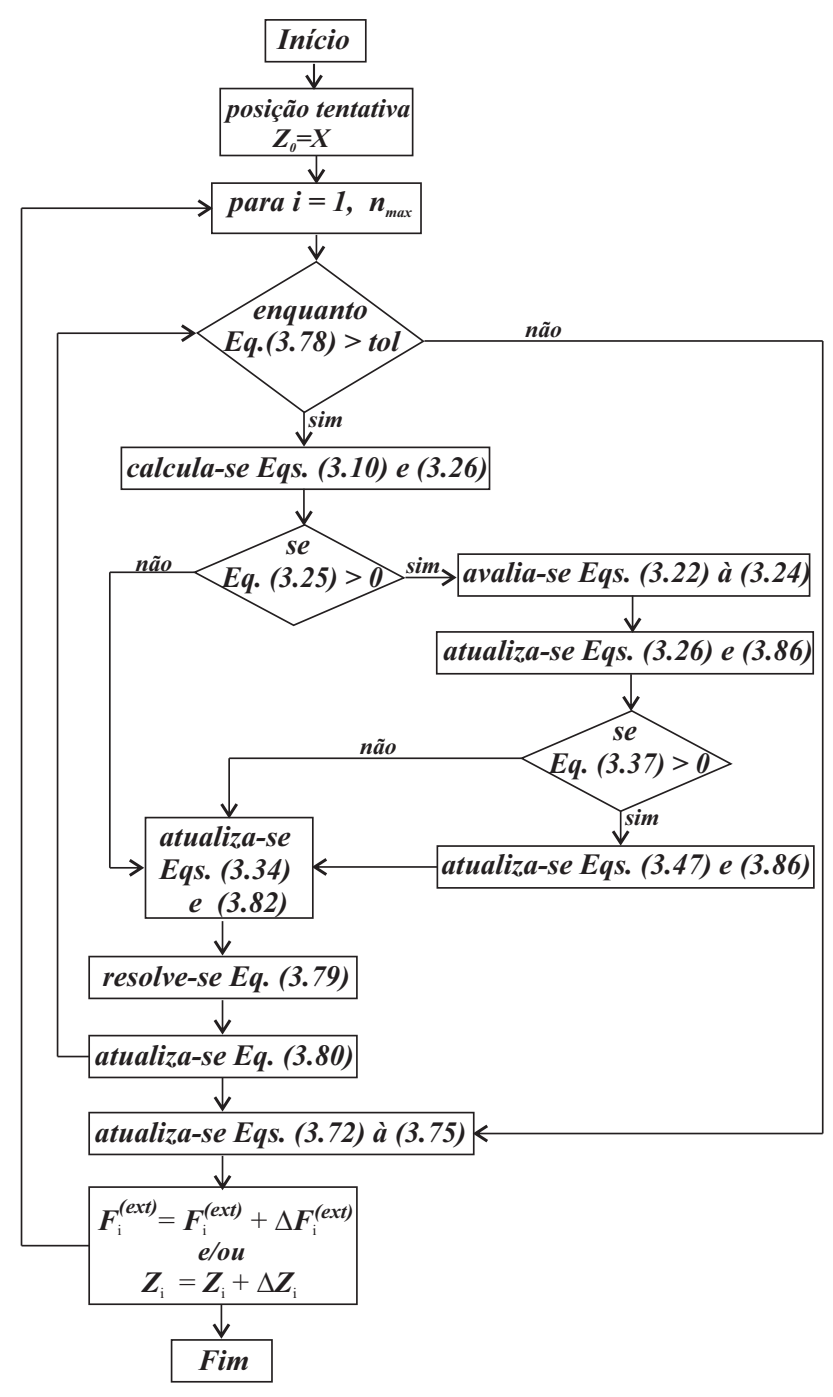

Fonte: Autor.

\subsection{Conclusão do Capítulo}

Neste capítulo, um abrangente modelo de dano dúctil foi proposto para a análise não linear de estruturas treliçadas sujeitas a grandes deslocamentos e grandes deformações. Esse modelo foi acoplado a uma formulação em Elementos Finitos Posicional usando a medida de deformação logarítmica. Tal modelo captura a degradação em termos de variação de porosidade devido ao crescimento e coalescência de microcavidades no material. Dessa forma, representa com precisão a curva tensão vs. deformação, registrando o encruamento, o amolecimento e a falha do material. Para a sua validação o Capítulo 4 apresenta vários resultados experimentais com diferentes materiais que são utilizados na Engenharia Civil. 
CAPÍtULO

\section{4}

4

\section{VALIDAÇÃO DO MODELO MECÂNICO: ANÁLISE ESTÁTICA}

\subsection{Aplicações}

A formulação proposta é empregada primeiramente para descrever as respostas de distintos materiais dúcteis não lineares em ensaios monotônicos de tração/compressão. Os resultados numéricos são confrontados com as curvas experimentais de tensão $v s$. deformação desses materiais. Em seguida, para comprovar a abrangência do modelo de dano dúctil proposto, esse é empregado para analisar a relação constitutiva obtida via ensaio experimental para os seguintes materiais: material frágil (ferro fundido), material quasi-frágil (madeira e concreto) e material pseudo-plástico (Ultra-High Performance Fiber-Reinforced Concrete).

Com relação ao concreto, a formulação proposta ainda é comparada com o modelo de Mazars [230] e o modelo de Lee \& Fenves [231]. O primeiro assume o comportamento elástico na evolução do dano, enquanto o segundo adota o comportamento elastoplástico para o concreto. Esses são os modelos mais usados pela comunidade científica para representar o processo de degradação mecânica desse material. Posteriormente, a formulação é utilizada na análise de uma treliça 2D de concreto com três barras. A escolha desse problema é para exemplificar de modo simplista o comportamento não linear do concreto sob tração em um sistema de redundância ativa. Nessa análise o modelo proposto também é checado com referência aos resultados obtidos pelos modelos citados acima. Finalmente, é avaliada a trajetória de equilíbrio de duas estruturas treliçadas 3D sob colapso progressivo.

\subsubsection{Exemplos experimentais}

Nesta seção, onze espécimes de materiais com diferentes comportamentos mecânicos são avaliados, seguindo a Tabela 4.1. O módulo de Young e a tensão de escoamento são apresentados 
na Tabela 4.2. Em todos os casos, são realizadas análises numéricas com apenas um elemento finito de treliça. Quatrocentos passos de carga são aplicados. As condições de contorno são as seguintes: deslocamento axial uniforme imposto em uma extremidade e extremidade oposta fixa. Os parâmetros do modelo de dano dúctil proposto para as onze espécimes testadas também são apresentados na Tabela 4.2 e no Apêndice A.

Tabela 4.1 - Espécimes e dados geométricos do corpo de prova.

\begin{tabular}{cccccc}
\hline Espécime & Material & Ensaio & $l_{0}(\mathrm{~mm})$ & $A_{0}\left(\mathrm{~mm}^{2}\right)$ & Ref. \\
\hline \hline Aço doce & dúctil & tração & 50,80 & 126,60 & {$[217]$} \\
\hline Aço de alta resistência & dúctil & tração & 50,80 & 126,60 & {$[217]$} \\
\hline Cobre (99\%) & dúctil & tração & 50,00 & 36,00 & {$[36]$} \\
\hline Aço ASTM A36 & dúctil & tração & 50,00 & 93,75 & {$[232]$} \\
\hline Madeira & quasi-frágil & compressão & 60,00 & 477,40 & Autor \\
\hline Alumínio & dúctil & tração & 50,80 & 126,60 & {$[217]$} \\
\hline Ferro fundido & frágil & compressão & 50,00 & 36,00 & {$[217]$} \\
\hline Concreto convencional & quasi-frágil & tração & 200,00 & 7850,00 & {$[231]$} \\
\hline Concreto convencional & quasi-frágil & compressão & 200,00 & 7850,00 & {$[231]$} \\
\hline UHPFRC & pseudo-plástico & tração & 80,00 & 900,00 & {$[233]$} \\
\hline UHPFRC & pseudo-plástico & compressão & 100,00 & 1962,50 & {$[233]$} \\
\hline \hline
\end{tabular}

Fonte - Autor.

Nota $-l_{0}=$ comprimento inicial do corpo de prova; $A_{0}=$ área da seção transversal inicial do corpo de prova; UHPFRC = Ultra-High Performance Fiber-Reinforced Concrete .

Tabela 4.2 - Dados dos materiais obtidos via curva experimental.

\begin{tabular}{cccccccc}
\hline Espécime & $E(\mathrm{MPa})$ & $\sigma_{y}(\mathrm{MPa})$ & $\varepsilon_{l n, d}^{p}$ & $\alpha_{1}^{p}$ & $\alpha_{2}^{p}$ & $\alpha_{3}^{p}$ & $D_{\text {crit }}$ \\
\hline \hline Aço doce & 200000 & 240 & $6,277 \cdot 10^{-2}$ & 70,532 & $-0,5851$ & 0,0020 & 0,250 \\
\hline Aço de alta resistência & 260800 & 435 & $4,180 \cdot 10^{-2}$ & 0,0 & 2,715 & 0,0 & 0,0930 \\
\hline Cobre (99\%) & 99000 & 200 & $1,706 \cdot 10^{-1}$ & 1,468 & 0,3003 & $-0,0071$ & 0,0750 \\
\hline Aço ASTM A36 & 200000 & 250 & $7,833 \cdot 10^{-2}$ & 143,623 & $-0,6390$ & 0,0008 & 0,0478 \\
\hline Madeira & 9513 & 37 & $3,912 \cdot 10^{-4}$ & 0,0 & 37,616 & $-0,0089$ & 0,038 \\
\hline Alumínio & 79772 & 300 & 0,0 & 0,0 & 0,0 & 0,0 & 0,0 \\
\hline Ferro fundido & 95445 & 300 & 0,0 & 0,0 & 0,0 & 0,0 & 0,0 \\
\hline Concreto (tração) & 32000 & 3,3 & $3,989 \cdot 10^{-6}$ & $-2 \cdot 10^{7}$ & 7107,632 & 0,2860 & 0,9290 \\
\hline Concreto (compressão) & 32000 & 12,7 & $3,724 \cdot 10^{-4}$ & 143844,897 & 297,571 & $-0,0216$ & 0,4410 \\
\hline UHPFRC (tração) & 43400 & 6,5 & $5,592 \cdot 10^{-4}$ & $-2902,337$ & 111,683 & $-0,1515$ & 0,9050 \\
\hline UHPFRC (compressão) & 43400 & 147 & $2,124 \cdot 10^{-4}$ & $-18142,261$ & 210,989 & 0,1137 & 0,7433 \\
\hline Fonte Autor.
\end{tabular}

Fonte - Autor. 
Figura 4.1 - Curva tensão vs. deformação do aço doce [217].

(a) ensaio de tração

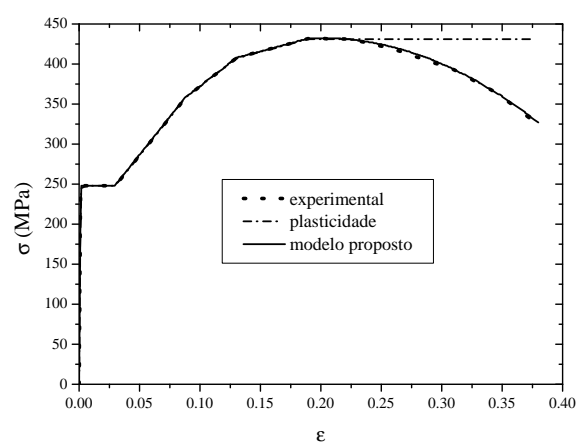

(b) módulo tangente

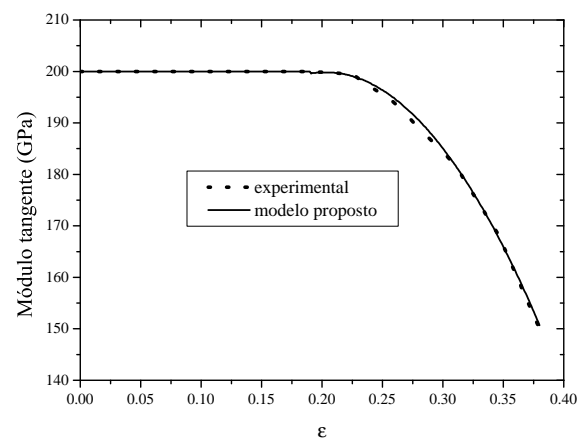

Fonte: Autor.

Figura 4.2 - Curva tensão vs. deformação do aço de alta resistência [217].

(a) ensaio de tração

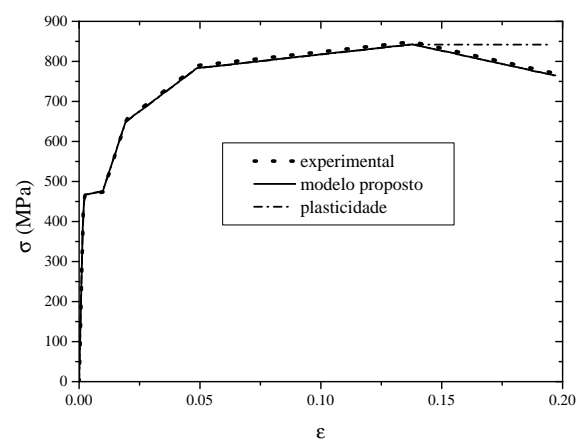

(b) módulo tangente

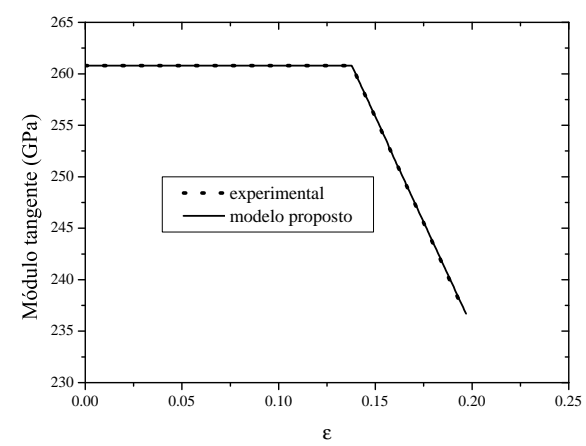

Fonte: Autor.

Figura 4.3 - Curva tensão vs. deformação do cobre (99\%) [36].

(a) ensaio de tração

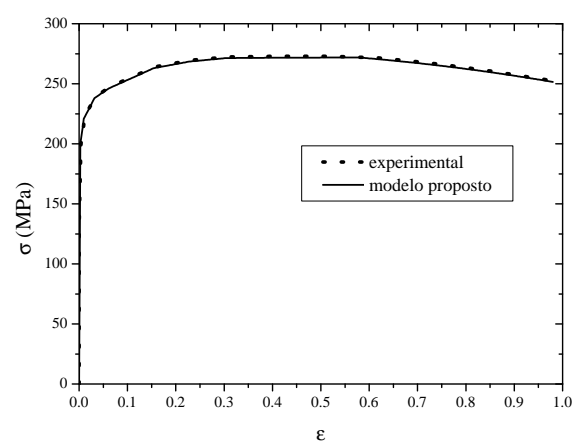

(b) módulo tangente

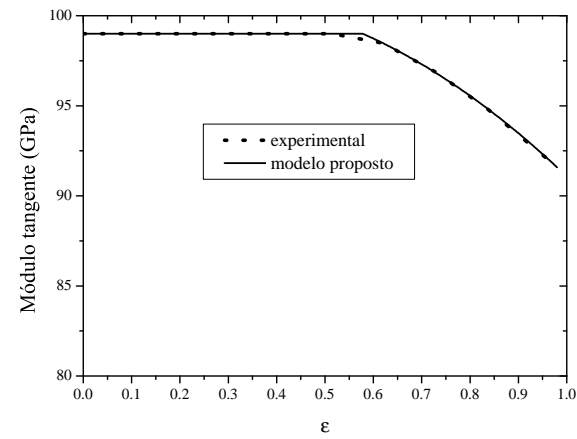

Fonte: Autor. 
Figura 4.4 - Curva tensão vs. deformação do aço ASTM A36 [232].

(a) ensaio de tração

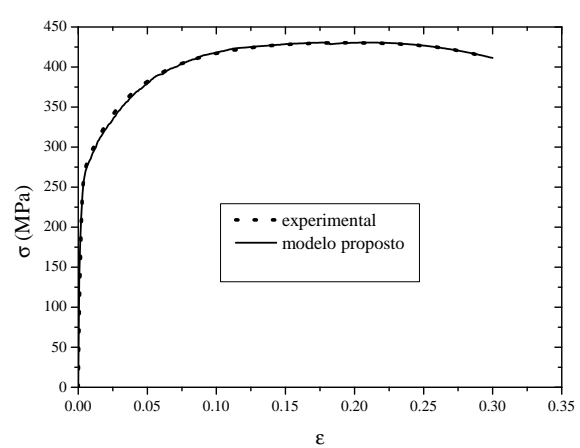

(b) módulo tangente

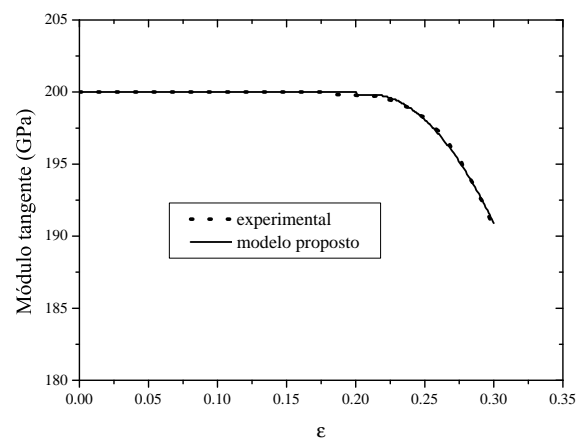

Fonte: Autor.

Figura 4.5 - Curva tensão vs. deformação da madeira espécie Simarouba amara.

(a) ensaio de compressão

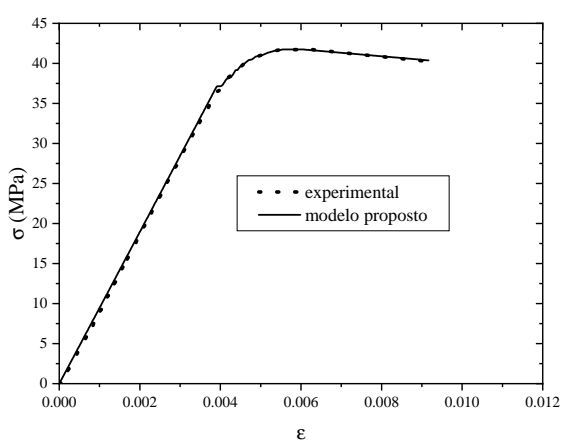

(b) módulo tangente

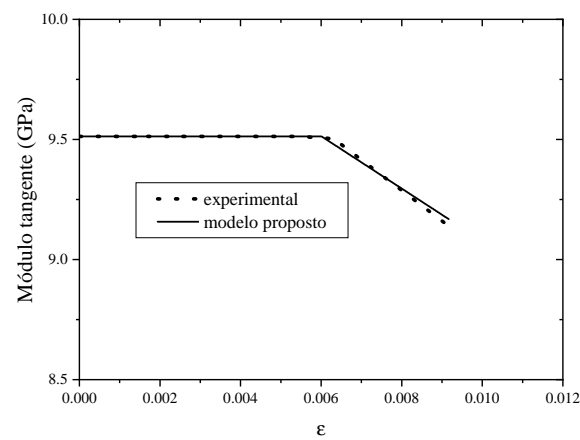

Fonte: Autor.

Figura 4.6 - Curva tenão vs. deformação do alumínio e do ferro fundido [217].

(a) ensaio de tração do alumínio

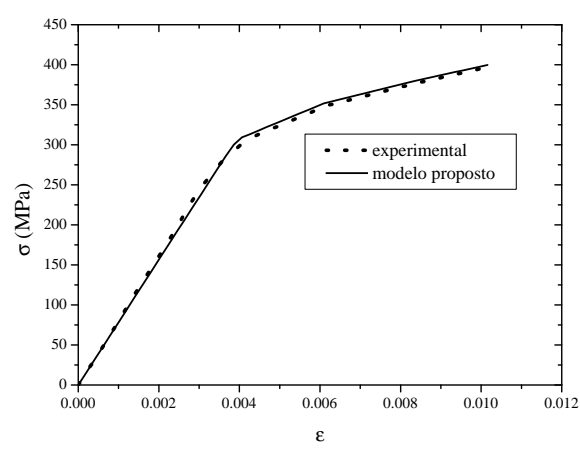

(b) ensaio de compressão do ferro fundido

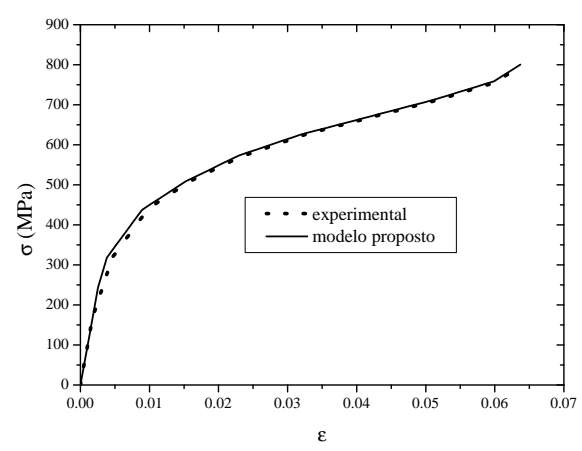

Fonte: Autor. 
Nas Figura 4.1-a, Figura 4.2-a, Figura 4.3-a e Figura 4.4-a são expostas as curvas experimentais e numéricas de tensão $v s$. deformação para o aço doce, aço de alta resistência, cobre e aço ASTM A36, respectivamente. Os resultados numéricos para o aço doce e o aço de alta resistência são calculados usando o modelo elastoplástico e o abrangente modelo elastoplástico com dano. Nas Figura 4.1-a e Figura 4.2-a, observa-se que apenas a consideração da plasticidade não é suficiente para representar o comportamento material. Quando o dano é desconsiderado, o material escoa sob níveis constantes de tensão e o comportamento de amolecimento não é capturado. No entanto, o acoplamento de dano proporcionado pela formulação proposta permite um excelente ajuste das curvas experimentais.

A Figura 4.5-a ilustra a resposta experimental e numérica da madeira de espécie Simarouba amara em ensaio monotônico de compressão axial paralela às fibras. Essa madeira é muito empregada na construção civil e naval, pois proporciona peças com pouco ou mesmo sem nenhum defeito que afete a sua resistência mecânica [234]. O ensaio foi realizado com dois corpos de provas de pequenas dimensões $(b=21,8 ; h=21,9 ; l=60$, ambas em $m m$ ), isentos de defeitos, conforme recomendação da norma [235]. Nota-se que a resposta numérica está em conformidade com a resposta experimental. Além disso, observa-se que o mecanismo de ruptura dessa madeira ocorreu com amolecimento para níveis de deformações moderadas. Devido à orientação das fibras, a madeira é um material anisotrópico. Esse efeito não é avaliado pelo modelo proposto. Porém, como o ensaio foi executado com a carga aplicada paralela às fibras, nessa direção não há variação das propriedades elásticas. Sendo assim, conclui-se que o modelo proposto pode ser aplicado para a análise da madeira, admitindo-se na direção considerada propriedades elásticas constantes.

Com relação aos módulos tangentes dos referidos materiais, verifica-se uma boa conformidade com os resultados obtidos experimentalmente, segundo a Figura 4.1-b, Figura 4.2-b, Figura 4.3-b, Figura 4.4-b e Figura 4.5-b . Nota-se que para valores de $\varepsilon_{l n, d}^{p} \approx 10^{-3}$, de acordo com a Tabela 4.2, a formulação proposta endereça adequadamente o módulo tangente desses materiais.

As Figura 4.6-a e Figura 4.6-b exibem a relação constitutiva do alumínio e ferro fundido, respectivamente, em testes de tração e compressão. Torna-se evidente que esses materiais não apresentam o regime de amolecimento. Portanto, caracterizam-se pela manifestação do dano frágil, onde a ruptura ocorre sem deformações plásticas significantes. Consequentemente, não ocorre variação de porosidade durante o processo de carregamento, pois não acontece variação volumétrica do meio. Esse fenômeno é conhecido na literatura como incompressibilidade plástica [195, 236]. Dessa forma, apenas a utilização da teoria da plasticidade representa com boa acurácia a resposta desses materiais. 
Figura 4.7 - Curva tensão vs. deformação do concreto a tração [231].

(a) ensaio de tração

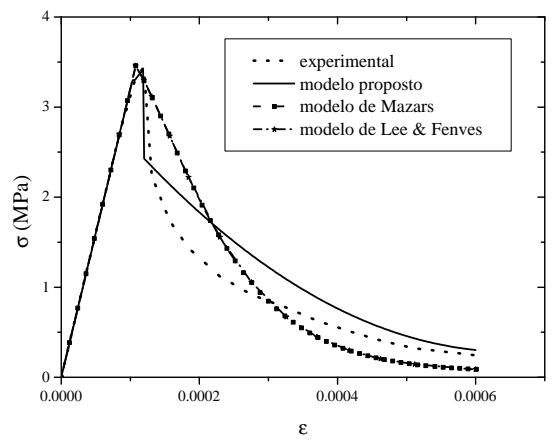

(b) módulo tangente

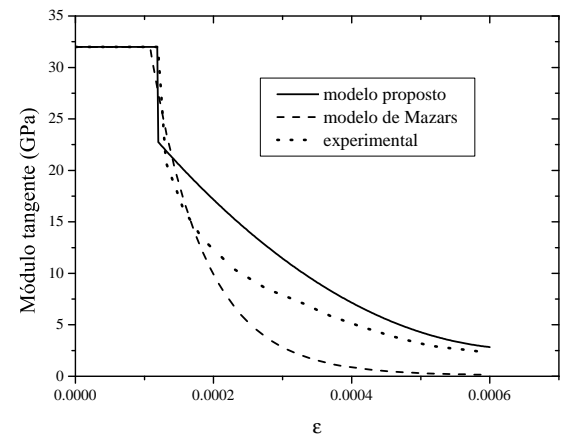

Fonte: Autor.

Figura 4.8 - Curva tensão vs. deformação do concreto a compressão [231].

(a) ensaio de compressão

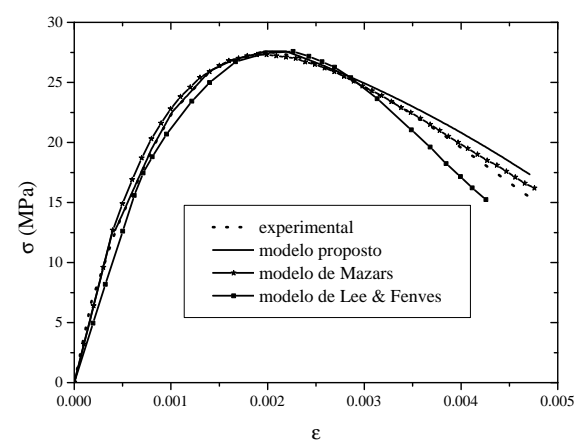

(b) módulo tangente

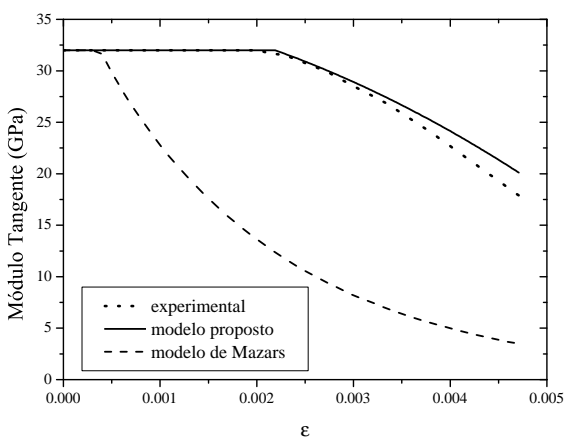

Fonte: Autor.

Figura 4.9 - Evolução do dano no concreto.

(a) tração

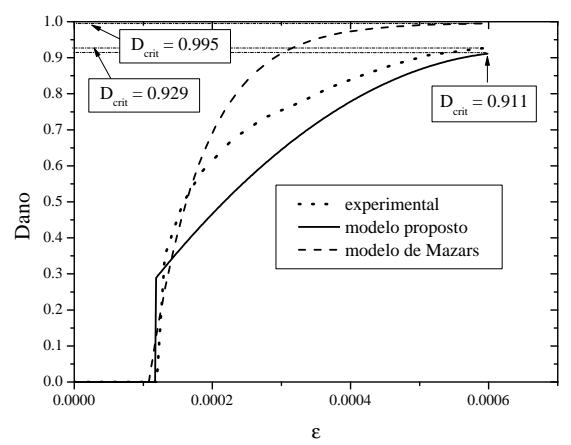

(b) compressão

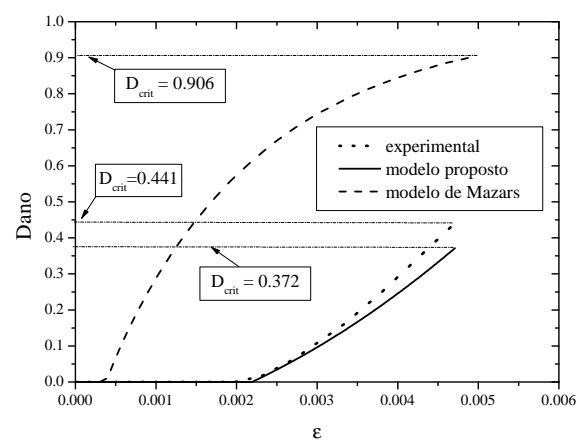

Fonte: Autor. 
As Figura 4.7-a e Figura 4.8-a apresentam a relação constitutiva do concreto em testes de tração e compressão, respectivamente. A abrangente formulação de dano dúctil proposta é comparada com os resultados numéricos oferecidos via modelo de Mazars [230] e pelo modelo Lee \& Fenves [231]. A formulação proposta descreve toda a curva tensão vs. deformação, como pode ser observado. Para o ensaio de tração (Figura 4.7-a), o modelo proposto fornece um ajuste mais próximo, no regime de amolecimento do concreto, em comparação com os modelos de Mazars [230] e Lee \& Fenves [231]. De fato, na tração o início da coalescência de fissuras na zona de transição é acompanhada de sensível variação de volume, o que implica numa pequena variação de porosidade na sua ruptura. Logo, o modelo proposto consegue capturar essa pequena variação. No que concerne ao ensaio de compressão (Figura 4.8-a), ambos os modelos tendem para a resposta experimental. Consequentemente, verifica-se que mesmo para valores de deformações plásticas pequenas, a formulação proposta endereça a resposta do concreto.

Nas Figura 4.7-b e Figura 4.8-b confrontam-se, respectivamente, a degradação do módulo de Young no ensaio de tração e compressão durante o acúmulo de dano, usando a formulação proposta e o modelo de Mazars [230]. O modelo de Mazars [230] não considera a perda de rigidez causada pelas deformações plásticas. Portanto, durante o amolecimento, o modelo de Mazars [230] penaliza a rigidez do material de maneira mais forte do que o observado nos resultados experimentais. No modelo proposto, a evolução do dano é induzida pelo crescimento de microcavidades e coalescência de fissuras, o que resulta em perda de rigidez que aproxima-se dos resultados experimentais.

Fisicamente o material não pode se degenerar. Todavia, a utilização do modelo de Mazars [230] conduz a valor de módulo tangente que tende a zero no ensaio de tração. Por conseguinte, uma formulação numérica que use esse modelo vai apresentar instabilidade na matriz Hessiana, pois esta torna-se singular. Por outro lado, a utilização do modelo proposto não acarreta a instabilidade numérica, uma vez que o módulo tangente vai tender ao seu valor obtido via ensaio experimental.

Para esses testes monotônicos do concreto, o dano crítico é obtido por: $D_{c r i t}^{t}=1-\tau_{r} / \tau_{u}=$ $1-0,244 / 3,440=0,929$; e $D_{c r i t}^{c}=1-\tau_{r} / \tau_{u}=1-15,429 / 27,606=0,441$, sendo que o sobrescrito $t$ significa tração e $c$ compressão, enquanto $\tau_{r}$ e $\tau_{u}$ são, respectivamente, as tensões de ruptura e última.

A Figura 4.9 ilustra a evolução do dano em testes de tração e compressão de concreto, utilizando a formulação proposta e o modelo da Mazars [230]. Para o modelo de dano dúctil proposto, os danos crescem continuamente convergindo para o valor de $D_{\text {crit }}$. A evolução do dano via modelo de Mazars, por outro lado, aumenta os valores acima do dano crítico tendendo a unidade, além de ter uma maior taxa de crescimento. A evolução do dano dos resultados experimentais mostram que o dano crítico não atinge a unidade. Destarte, uma formulação de dano baseada na evolução da porosidade, como proposta aqui, é mais consistente com o problema físico. 
Figura 4.10 - Curva tensão vs. deformação do UHPFRC [233].

(a) ensaio de tração

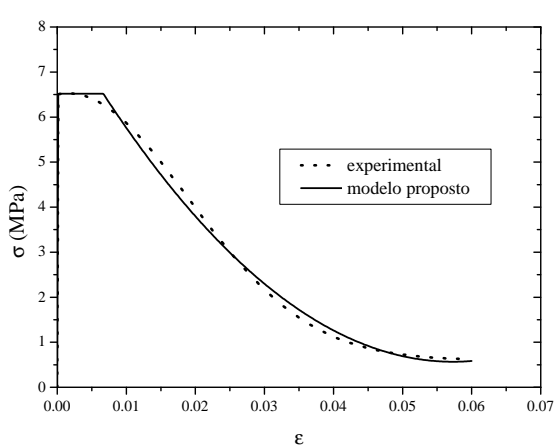

(b) módulo tangente

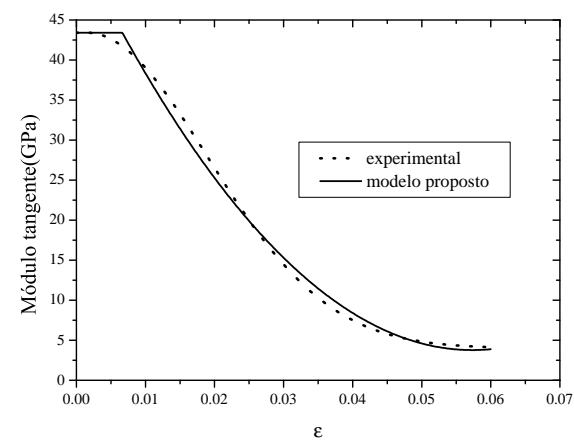

Fonte: Autor.

Figura 4.11 - Curva tensão vs. deformação do UHPFRC [233].

(a) ensaio de compressão

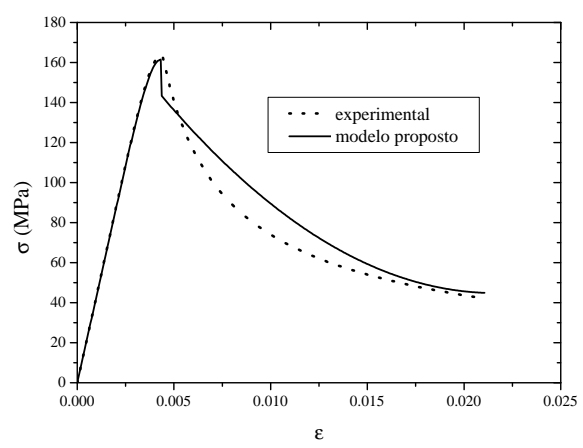

(b) módulo tangente

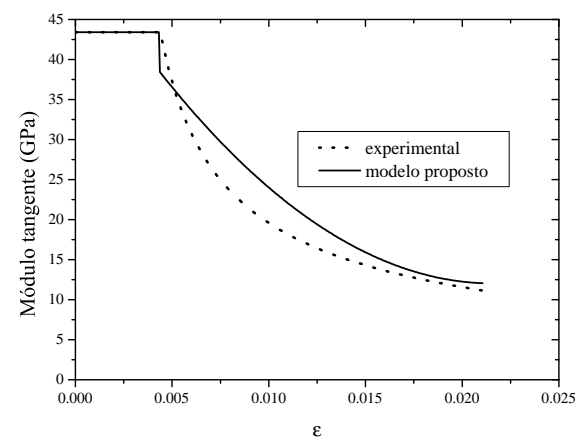

Fonte: Autor.

Figura 4.12 - Evolução do dano no UHPFRC.

(a) tração

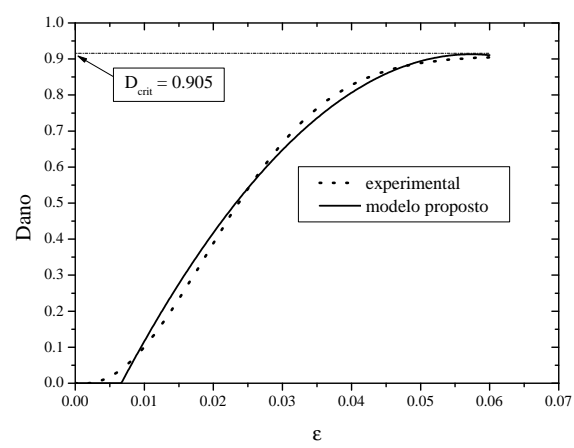

(b) compressão

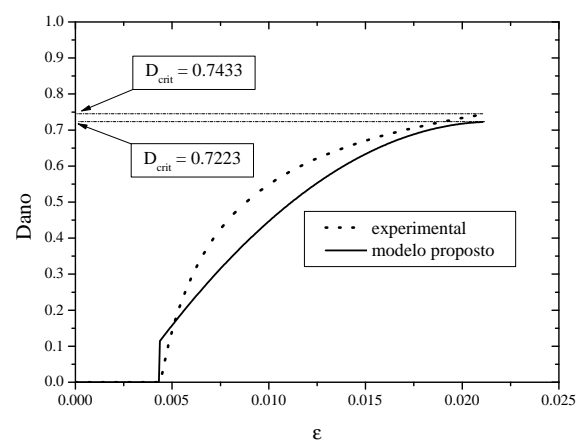


Nas Figura 4.10 e Figura 4.11 são apresentados a relação constitutiva e o módulo tangente do Ultra-High Performance Fiber-Reinforced Concrete (UHPFRC) com 2\% de fibras em ensaios de tração e compressão, respectivamente. Esse material, dependendo da eficiência de interação entre fibra/matriz, pode apresentar as características de ductilidade e capacidade de absorção de energia, exibindo um comportamento dúctil [237, 238]. A introdução das fibras retarda a propagação e coalescência de microfissuras durante o processo de carregamento. Dessa forma, diferentemente do concreto convencional que rompe de modo súbito na tração com pequenas deformações, quando a resistência a tração é atingida, conforme a Figura 4.7, o UHPFRC não rompe imediatamente, proporcionando um acentuado aumento da sua componente hidrostática de deformação plástica. Esse aumento é da ordem 100 vezes, conforme a Tabela 4.2. Isso conduz a uma melhor precisão numérica da Equação 3.44. Consequentemente, a curva tensão vs. deformação via modelo de dano dúctil proposto converge para a resposta experimental do UHPFRC a tração, como pode ser observado na Figura 4.10. No tocante ao módulo tangente, observa-se que a resposta numérica apresenta boa aproximação.

Sob compressão, o UHPFRC manifesta uma localização de deformação conduzida pela coalescência de microfissuras, a qual resulta em uma macrofissura para níveis de tensões próxima à tensão de pico [237, 239]. Esse fenômeno acarreta numa concentração de porosidade, fazendo com que o modelo proposto exiba uma inclinação mais acentuada no início do regime de amolecimento, conforme a Figura 4.11-a. Para deformações acima de 0,005 até 0,015 o modelo proposto evolui com uma taxa menor do que o exibido pela resposta experimental. Isso ocorre porque a formulação proposta não leva em consideração os mecanismos de degradação complementares que ocorrem no UHPFRC, como a perda de aderência entre fibra/matriz, o deslizamento e o arrancamento de fibras. Por outro lado, para deformações maiores que $0,015 \mathrm{o}$ resultado numérico converge para o experimental.

As Figura 4.12-a e Figura 4.12-b ilustram a evolução do dano durante o processo de carregamento do UHPFRC em ensaio de tração e compressão, respectivamente. Para esses testes monotônicos, o dano crítico é obtido por: $D_{\text {crit }}^{t}=1-\tau_{r} / \tau_{u}=1-0,622 / 6,526=0,905$; e $D_{c r i t}^{c}=1-\tau_{r} / \tau_{u}=1-42,1 / 164,01=0,7433$. Nota-se que na tração, a evolução do dano tende à resposta experimental. Já a evolução do dano na compressão do modelo proposto no intervalo de 0,005 até 0,015 proporciona um pequeno desvio em relação ao resultado experimental correspondendo às parcelas de degradação mecânica complementares do UHPFRC, conforme comentários feitos no parágrafo anterior.

\subsubsection{Exemplos numéricos}

Nesta seção, a formulação de dano dúctil proposta é empregada na análise de três problemas de aplicação: treliças 2D de concreto com três membros, uma cúpula em forma de estrela e uma treliça 3D. Os resultados são comparados com as soluções fornecidas pelos modelos de Mazars [230] e Lee \& Fenves [231]. Nessas aplicações, os efeitos conjuntos da 
não linearidade física e geométrica podem ser apreciados. Em todas as análises a tolerância de convergência adotada é igual a $10^{-6}$ em posição.

\subsubsection{Exemplo 1: treliça 2D}

A resposta mecânica do material e da mudança de configuração são consideradas para a estrutura de treliça 2D com três barras, conforme ilustrado na Figura 4.13. As barras são feitas de concreto com relação constitutiva dada pela Figura 4.7-a. O módulo de Young e a área da seção transversal de todas as barras são dados por $E=32000 \mathrm{~N} / \mathrm{mm}^{2}$ e $A=7850 \mathrm{~mm}^{2}$. A tensão de escoamento é $\sigma_{y}=3,3 \mathrm{~N} / \mathrm{mm}^{2}$. Cem passos de carga são aplicados para toda a análise.

Figura 4.13 - Geometria da treliça 2D.

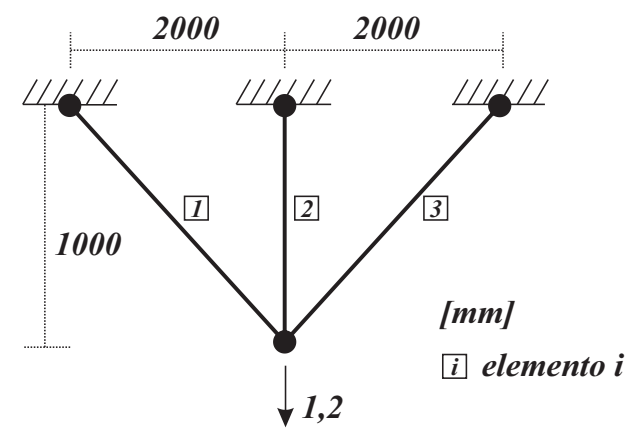

Fonte: Autor.

Figura 4.14 - Avaliação da treliça 2D de concreto.

(a) curva força $v s$. deslocamento vertical no nó livre.

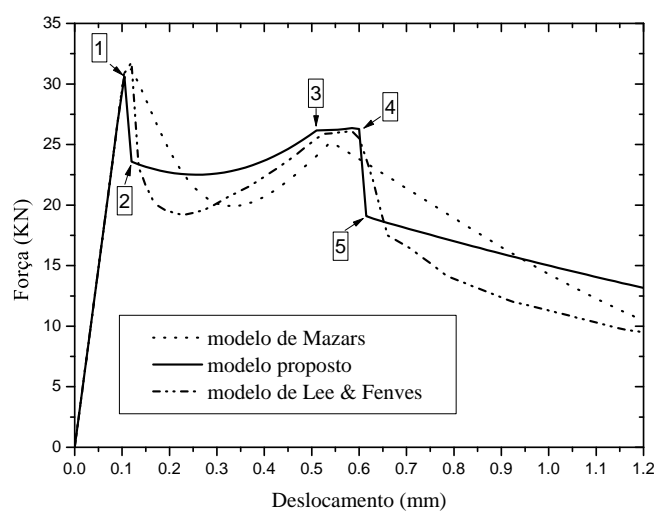

(b) evolução do dano nas barras. Nota: MP = modelo proposto; MZ = modelo de Mazars [230] e LF = modelo de Lee \& Fenves [231].

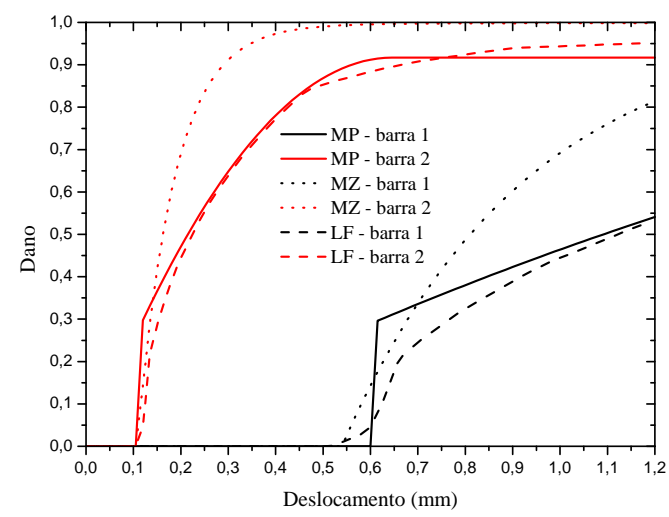

Fonte: Autor. 
A Figura 4.14 ilustra a curva força $v s$. deslocamento vertical do nó livre (inferior) e a evolução do dano nas barras. A solução obtida com a formulação de dano dúctil proposta pode ser dividida em cinco partes. No ponto 1, a barra 2 atinge o limite de dano inicial, resultando em microfissura e perda de rigidez local, veja a Figura 4.14-b. O comportamento é compatível com o observado para o ensaio de tração do concreto (Figura 4.7-a). O ponto 2 é a configuração da treliça após a perda de rigidez local para a barra 2. Como as barras 1 e 3 (por simetria) não atingiram o limite de dano inicial, conforme a Figura 4.14-b, a redistribuição de carga para essas barras ocorre entre pontos 2 e 3 . Observe que a inclinação das curvas aumenta entre esses pontos. Note que para deslocamentos entre 0,1 e 0,5 $\mathrm{mm}$, uma perda considerável de rigidez ocorre nos modelos de Mazars e Lee \& Fenves. Além disso, para deslocamentos em torno de $0,5 \mathrm{~mm}$, a barra 2 atinge o dano crítico, proporcionando na trajetória de equilíbrio um trecho aproximadamente constante em força entre os pontos 3 e 4 . No ponto 4, as barras 1 e 3 atingem o limite de dano inicial, conforme ilustrado na Figura 4.14-b, levando a uma perda brusca de rigidez para a treliça. O ponto 5 é a configuração da treliça após a barra 2 ter atingido dano crítico; e as barras 1 e 3 terem alcançado o limite de dano inicial. Após esse ponto, as barras 1 e 3 iniciam o processo de degradação mecânica, até atingirem o dano crítico, levando à completa falha da estrutura da treliça.

O modelo de Mazars [230] não aborda com precisão esse tipo de resposta. Esse modelo é baseado em um ajuste da curva de tensão vs. deformação do concreto e não levam em consideração o processo de degradação mecânica causado pelo crescimento e coalescência de microfissuras. Por conseguinte, esse modelo resulta em valores de módulos tangentes que não são compatíveis com o comportamento experimental, uma vez que acarretam valores de dano que tendem a unidade, de acordo com a Figura 4.14-b. Nesse problema, a resposta não linear geométrica é igual à solução linear, pois o nível de deformações é pequeno.

\subsubsection{Exemplo 2: cúpula em forma de estrela}

Esta última aplicação diz respeito à análise mecânica de uma estrutura de treliça 3D em forma de estrela ilustrada na Figura 4.15-a. Essa estrutura serviu como referência em diversos trabalhos sobre análise não linear $[12,30,41,42,54]$. A treliça é composta por 13 nós e 24 elementos. Os parâmetros do material são: $A=3,17 \mathrm{~cm}^{2}, E=30000 \mathrm{KN} / \mathrm{cm}^{2}$ e $\sigma_{y}=30$ $K N / \mathrm{cm}^{2}$. Os parâmetros de dano são avaliados a partir da curva de tensão $v s$. deformação apresentada na Figura 4.15-c: $\alpha_{1}^{p}=0,0 ; \alpha_{2}^{p}=750,0 ; \alpha_{3}^{p}=0,0 ; \varepsilon_{l n, d}^{p}=3,33 \cdot 10^{-4}$ e $D_{\text {crit }}=0,33$. A carga é aplicada em 100 passos, com magnitude de $0,05 \mathrm{~cm}$.

O problema é primeiramente analisado contabilizando apenas a não-linearidade geométrica. As respostas fornecidas pelo modelo proposto são comparadas com os resultados obtidos com o software ANSYS ${ }^{\circledR}$. Como observado na Figura 4.16, boa concordância é observada entre os resultados. Note que no ponto limite, para um deslocamento de $0,8 \mathrm{~cm}$, a força que leva o salto de posição (snap-through) é igual a $29,8 \mathrm{KN}$. Nesse ponto, o determinante da matriz 
hessiana é nulo. Portanto, o equilíbrio é indiferente. A força limite de 29,8 KN é a força máxima que a cúpula em forma de estrela resiste em um regime estável de equilíbrio estático. Por outro lado, observa-se que para o deslocamento de $0,8 \mathrm{~cm}$ a resposta linear é igual 70,1 KN. Por isso, estruturas desse tipo devem ser calculadas com modelos numéricos que avaliem o equilíbrio na configuração atual. Para deslocamentos maiores, entre 0,8 e 3,0 cm, o critério de convergência em força não pode ser empregado, porque o determinante da matriz hessiana é negativo (regime instável). Os resultados apresentados na Figura 4.16 são obtidos para o critério de convergência baseado em posição.

Figura 4.15 - Treliça 3D: a) visão de topo; b) visão lateral; c) lei constitutiva.
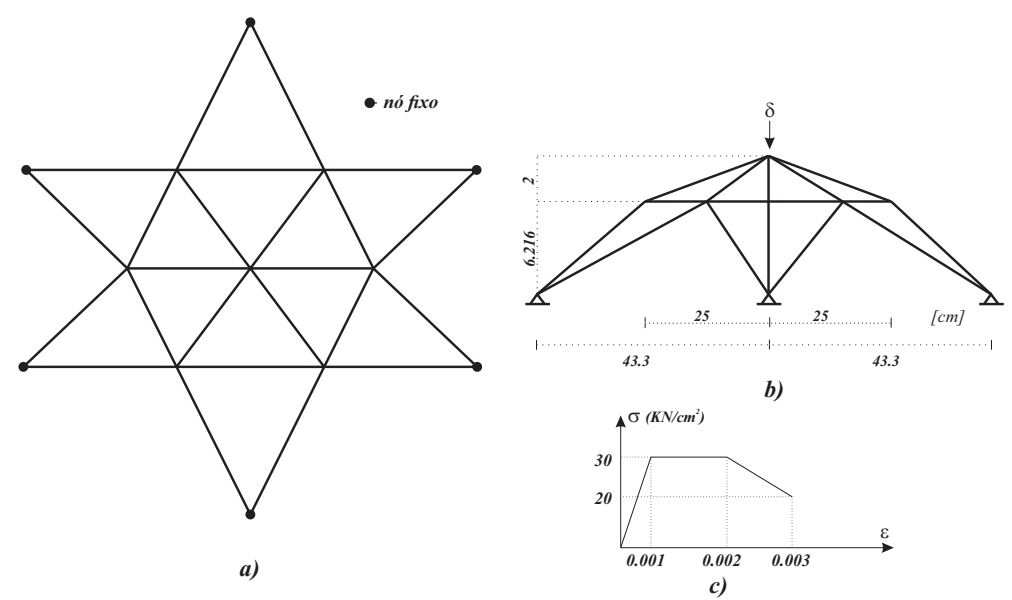

Fonte: Autor.

Figura 4.16 - Curva força vs. deslocamento vertical do nó central da treliça 3D.

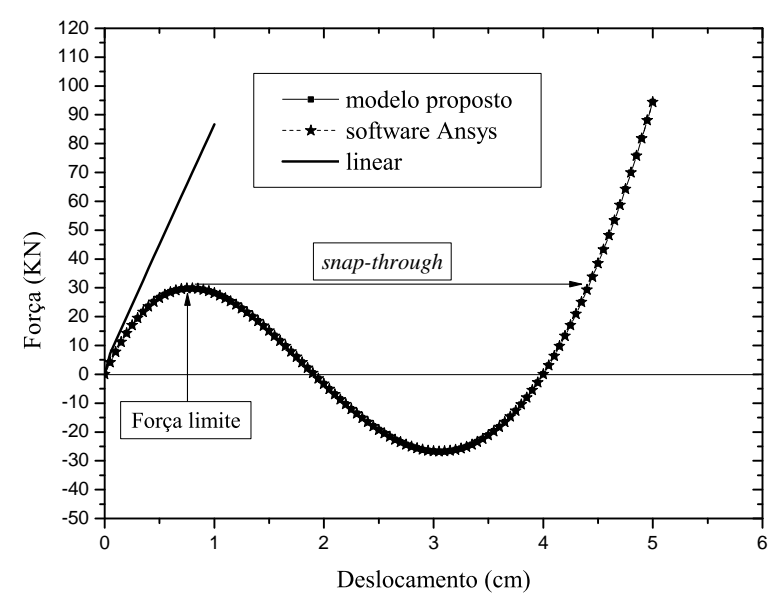

Fonte: Autor. 
A Figura 4.17 ilustra a curva força vs. deslocamento para o nó central da cúpula, contabilizando a não-linearidade física e geométrica. Observe como a inclinação das curvas mudam para os diferentes modelos. Como observado, considerar apenas a não linearidade geométrica, assumindo a resposta do material elástico linear, está longe de ser a resposta real para essa estrutura. A força limite $(28,7 \mathrm{KN})$ e seu respectivo deslocamento $(0,65 \mathrm{~cm})$ são menores para a solução plástica, comparada a solução elástica linear.

Figura 4.17 - Análise da trajetória de equilíbrio da treliça 3D.

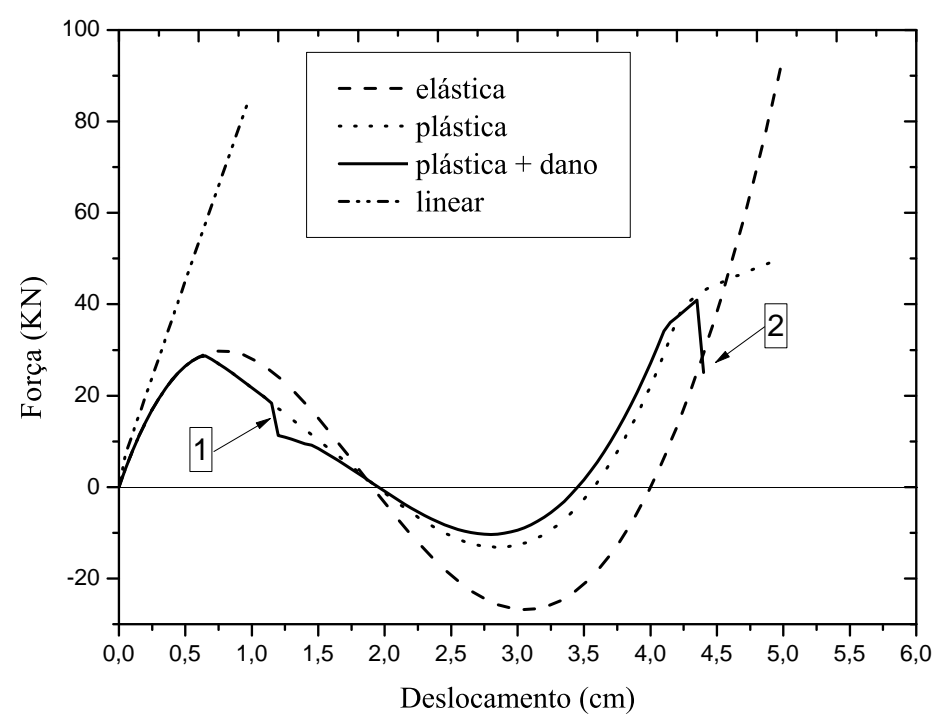

Fonte: Autor.

$\mathrm{Na}$ análise de placas e cascas moderadamente finas e muito finas, bem como cúpulas treliçadas, a análise não-linear geométrica é importante, mas o comportamento não linear do material tem um papel mais fundamental na trajetória de equilíbrio dessas estruturas.

Em relação à solução plástica não linear, observa-se a redução na rigidez devido às deformações plásticas. Quando a tensão nos elementos da coroa da cúpula atinge o limite de escoamento, há um deslocamento de cerca de 0,60 cm, esses elementos começam a escoar sob tensão constante, i.e., ocorrem deformações plásticas. A resposta, considerando apenas a plasticidade, produz um bom resultado até a tensão última do material ser atingida por todos os elementos da coroa da cúpula, para um nível de deslocamento de 1,15 cm. Além desse ponto, a solução plástica produz deformações cada vez maiores sob tensão constante, i.e., não pode modelar o amolecimento antes da ruptura.

Para o modelo abrangente de dano dúctil proposto, a solução não linear geométrica acoplada ao dano e plasticidade produz resultados consistentes. Perda significativa de rigidez ocorre quando os elementos da coroa da cúpula atingem o limite de dano inicial, no ponto 1 
(Figura 4.17), sob cargas compressivas. A segunda alteração da perda de rigidez, no ponto 2, ocorre sob esforços de tração, para o deslocamento prescrito de cerca de 4,30 cm. Essa perda de rigidez leva à falha da cúpula.

\subsubsection{Exemplo 3: treliça 3D com 12 barras}

Esta última aplicação estática envolve a análise mecânica de uma estrutura treliçada 3D, como ilustrado na Figura 4.18. Este exemplo foi usado como referência em vários trabalhos sobre análise não linear de treliça, por exemplo em [240, 241, 242]. A estrutura é formada por 9 nós e 12 elementos. As constantes são: $A=317 \mathrm{~mm}^{2} ; E=3 \cdot 10^{5} \mathrm{~N} / \mathrm{mm}^{2}$ e $\sigma_{y}=300$ $N / \mathrm{mm}^{2}$. Os parâmetros do modelo de dano são os seguintes: $\alpha_{1}^{p}=0,0 ; \alpha_{2}^{p}=750,0 ; \alpha_{3}^{p}=0,0$; $\varepsilon_{l n, d}^{p}=3,33 \cdot 10^{-4}$ e $D_{\text {crit }}=0,33$.

Figura 4.18 - Treliça 3D com 12 barras: (a) dados geométricos; (b) lei constitutiva.

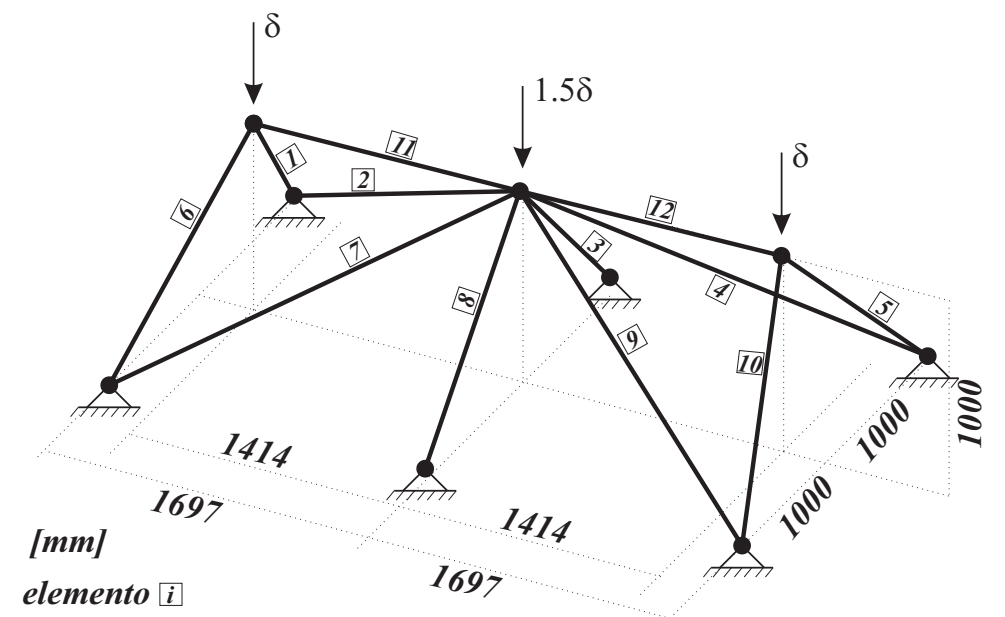

(a)

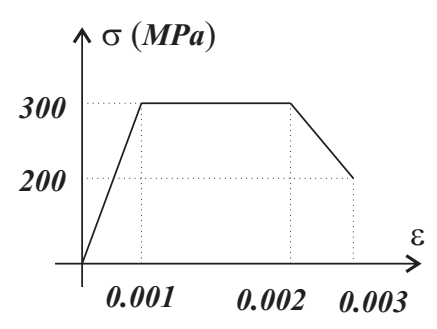

(b)

Fonte: Autor.

A Figura 4.19 mostra a solução não linear geométrica obtida pela formulação proposta e pelo software ANSYS ${ }^{\circledR}$ para um grande intervalo de deslocamentos presumindo o material com comportamento elástico linear. Observe a boa conformidade das respostas. Para um nível de deslocamento de $500 \mathrm{~mm}$ é nulo o determinante da matriz Hessiana (equilíbrio indiferente). Se o critério de convergência é em força, para o próximo passo de carga ocorre um salto em posição com força constante de 31,5 MN (snap-through). Em contrapartida, se o critério de convergência é em posição, o trecho do caminho de solução entre 500 até $2348 \mathrm{~mm}$, é calculado com o determinante da matriz Hessiana sendo negativo (equilíbrio instável).

A Figura 4.20 apresenta a curva força $v s$. deslocamento para o nó central para diferentes soluções, bem como a evolução do dano nos elementos. Note como a trajetória de equilíbrio se modifica para cada solução. Fica claro que a consideração da não linearidade geométrica 
assumindo o material com comportamento elástico linear não é suficiente para obter a trajetória de equilíbrio desse problema para deslocamentos acima de $2 \mathrm{~mm}$.

Figura 4.19 - Trajetória de equilíbrio para o comportamento do material elástico linear.

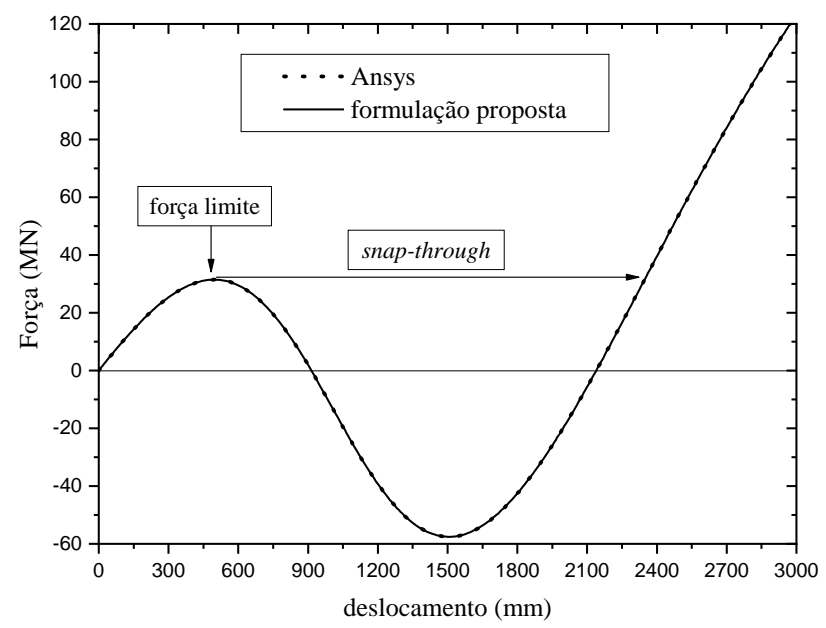

Fonte: Autor.

Figura 4.20 - Avaliação da Treliça 3D com 12 barras.

(a) curva força $v s$. deslocamento vertical no nó central.

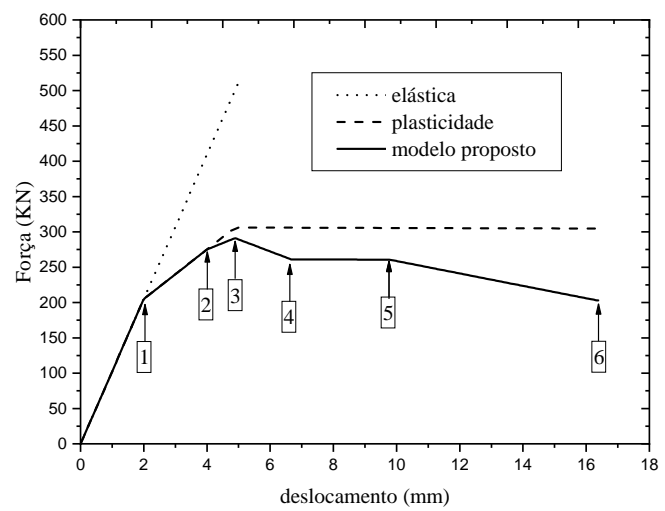

(b) evolução do dano nos elementos.

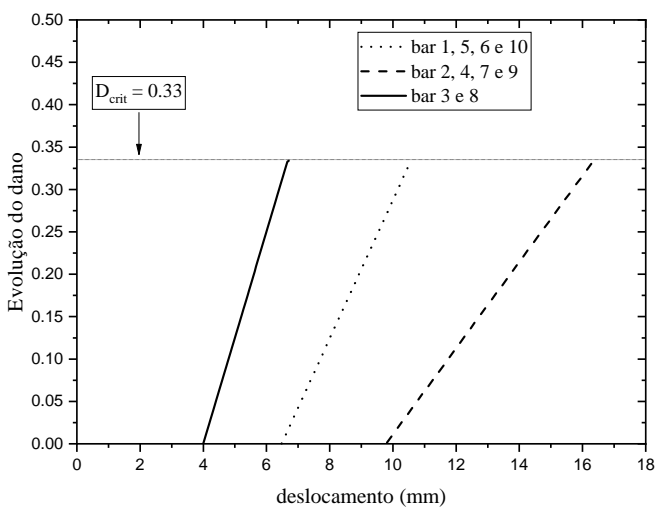

Fonte: Autor.

Em relação à solução plástica não linear, observa-se uma perda de rigidez devido o início da plastificação dos elementos 3 e 8 a partir do deslocamento de $2 \mathrm{~mm}$. Para um deslocamento igual a $5 \mathrm{~mm}$, os elementos de 1 a 10 começam a escoar sob tensão constante, por conseguinte, a curva força vs. deslocamento torna-se horizontal, de acordo com a Figura 4.20. Para essa configuração os elementos 11 e 12 ainda não atingiram a tensão de escoamento. 
No que diz respeito à formulação proposta, o acoplamento da plasticidade à mecânica do dano via modelo de dano proposto resulta em uma solução congruente. No ponto 1 , inicia-se a plastificação dos elementos 3 e 8 , o que leva à primeira perda de rigidez dessa estrutura. No ponto 2, esses elementos atingem o limite de dano inicial, consequentemente, começa o regime de amolecimento, entre os pontos 3 e 4 . Para um incremento de carga além do ponto 4, os elementos 3 e 8 alcançam o dano crítico, em concordância com a Figura 4.20-b, implicando na falha desses elementos. Entre os pontos 4 e 5 a estrutura sofre redistribuição de esforço normal, que acarreta as barras 1, 5, 6 e 10 atingirem o limite de dano inicial. No ponto 5 acontece a falha dessas barras, uma vez que elas alcançam o dano crítico. Além disso, observe a mudança na inclinação da curva após os elementos 2, 4, 7 e 9 iniciarem o regime de amolecimento a partir do ponto 5. Finalmente, no ponto 6 ocorre o colapso total dessa estrutura, devido todos os elementos falharem (exceto os elementos 11 e 12), conforme ilustrado na Figura 4.20-b.

\subsection{Conclusão do Capítulo}

Neste capítulo, a formulação abrangente de dano dúctil foi testada em todos os seus aspectos. Primeiramente, onze ensaios experimentais foram utilizados para validar essa formulação. Verificou-se que para materiais em regime de deformações moderadas e/ou grandes, o modelo proposto representou boa acurácia com relação a resposta experimental. No tocante a madeira, observou-se que para o ensaio de compressão paralela às fibras o modelo proposto também conseguiu simular a resposta experimental. No que concerne ao concreto, a presente formulação resultou em uma resposta mais coerente para o ensaio apresentado, em referência a resposta experimental, do que os modelos de dano de Mazars [230] e Lee \& Fenves [231]. Por fim, na avaliação das treliças $2 \mathrm{D}$ e $3 \mathrm{D}$, constatou-se a excelente conformidade da formulação na análise da trajetória de equilíbrio de estruturas treliçadas considerando a não linearidade física e geométrica. 
CAPÍtULO

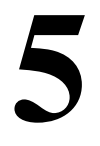

(1)

\section{VALIDAÇÃO DO MODELO MECÂNICO: ANÁLISE DINÂMICA}

\subsection{Aplicações}

Esta seção demonstra a capacidade da formulação proposta para simular estruturas sob efeitos dinâmicos. Inicialmente, é considerada uma treliça 2D com um grau de liberdade submetida a uma força dinâmica constante. A resposta numérica é comparada com a solução analítica exata desse problema. A análise é realizada com e sem amortecimento. Ademais, assume-se para o material a relação constitutiva elástica linear. Em seguida, essa treliça é avaliada sob ação do terremoto de Fukushima (2011). O intuito é verificar a resposta dessa estrutura quando o comportamento elastoplástico é assumido na análise. Posteriormente, uma torre de linha de transmissão é analisada presumindo que as forças nos cabos podem variar ao longo do tempo. Por fim, análises mais refinadas são concretizadas em torres metálicas 2D e 3D sob ação do terremoto El-Centro (1941).

\subsubsection{Treliça $2 D$ sob efeito dinâmico sem amortecimento}

A Figura 5.1 apresenta a geometria e a força dinâmica aplicada na treliça em avaliação. O módulo de elasticidade, a área da seção transversal, o comprimento e a densidade dessa estrutura são dados por $E=10^{4} \mathrm{~N} / \mathrm{m}^{2}, A=1 \mathrm{~m}^{2}, l=1 \mathrm{~m}$ e $\rho=1 \mathrm{Kg} / \mathrm{m}^{3}$, respectivamente. Os parâmetros de Newmark são $\beta_{n}=0,25 ; \gamma_{n}=0,50$ e $\Delta t=0,002 s$. A força externa $F^{(e x t)}$ é assumida unitária. Cem passos de tempo são aplicados para toda a análise. Este é um exemplo acadêmico.

A solução analítica exata desse problema pode ser calculada por meio da integral de Duhamel com condição de contorno $u(0)=\dot{u}(0)=0$, sendo $u$ e $\dot{u}$ o deslocamento e velocidade, nesta ordem. Para a treliça sem amortecimento, obtém-se [203]: 


$$
u(t)=\frac{F^{(e x t)}}{K}\left[1-\cos \left(\omega_{n} t\right)\right]
$$

em que $K$ é a rigidez da treliça, que é calculada por $K=(E \cdot A) / l ; \omega_{n}$ é a frequência fundamental e $t$ é o tempo. Para problemas de um grau de liberdade a frequência fundamental é avaliada por $\omega_{n}=(K / m)^{1 / 2}$, sendo $m$ a massa. Consequentemente, com os dados do problema, essas constantes são iguais $K=10^{4} \mathrm{~N} / \mathrm{m}$ e $\omega_{n}=141,42 \mathrm{~Hz}$. A frequência fundamental calculada pela formulação proposta é igual 141, $4214 \mathrm{~Hz}$.

Figura 5.1 - Treliça 2D: (a) geometria; (b) força dinâmica.
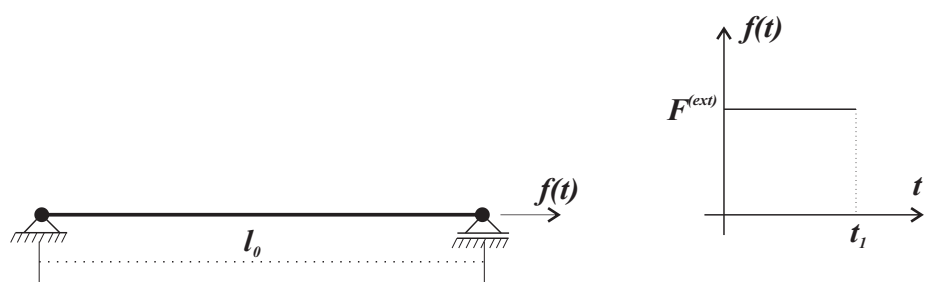

Fonte: Autor.

Figura 5.2 - Curva deslocamento vs. tempo: sistema conservativo.

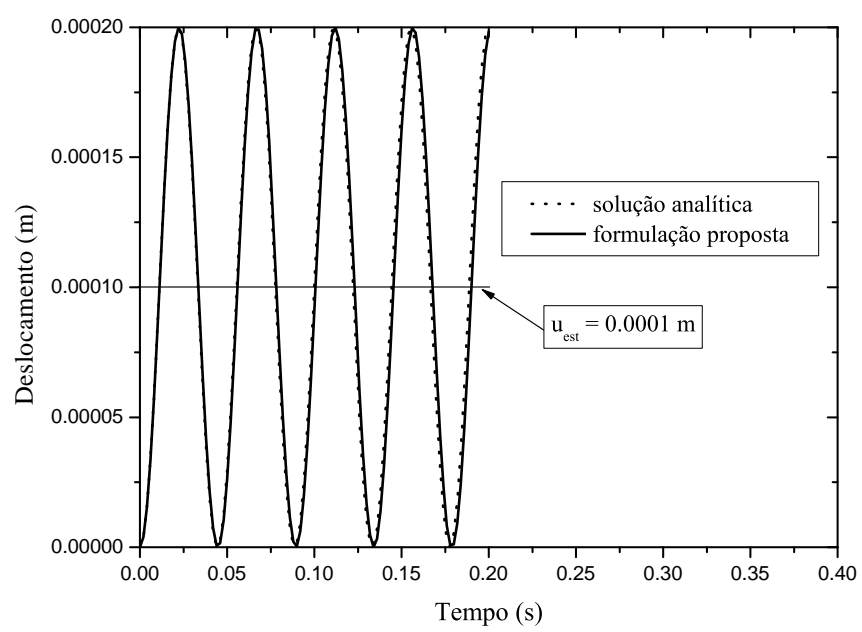

Fonte: Autor.

A Figura 5.2 mostra a comparação entre resposta numérica e analítica. Note que o resultado obtido pela formulação proposta é muito próximo da solução exata. A solução estática para o deslocamento dessa treliça é $u_{e s t}=0,0001 \mathrm{~m}$. Observe que a solução dinâmica vibra em torno da resposta estática, de acordo com a Figura 5.2. 


\subsubsection{Treliça $2 D$ sob efeito dinâmico com amortecimento}

Neste exemplo é usada a treliça ilustrada na Figura 5.1 para modelar um sistema dissipativo. A solução analítica exata desse problema pode ser determinada empregando a integral de Duhamel, o que implica [203]:

$$
u(t)=\frac{F^{(e x t)}}{K}\left\{1-e^{\left(-\xi \omega_{n} t\right)}\left[\cos \left(\omega_{d} t\right)+\frac{\xi \omega_{n}}{\omega_{d}} \operatorname{sen}\left(\omega_{d} t\right)\right]\right\}
$$

sendo $\xi$ o fator de amortecimento e $\omega_{d}$ a frequência de vibração amortecida, que é calculada pela Equação 5.3 [221].

$$
\omega_{d}=\omega_{n} \sqrt{1-\xi^{2}}
$$

Para executar esse problema, é assumido $\xi=0,1$ que implica em $\omega_{d}=140,71 \mathrm{~Hz}$. As outras constantes são iguais ao exemplo anterior. A Figura 5.3 apresenta a comparação entre solução numérica e analítica. Note a boa acurácia da formulação proposta para problemas com dissipação de energia.

Figura 5.3 - Curva deslocamento vs. tempo: sistema não conservativo.

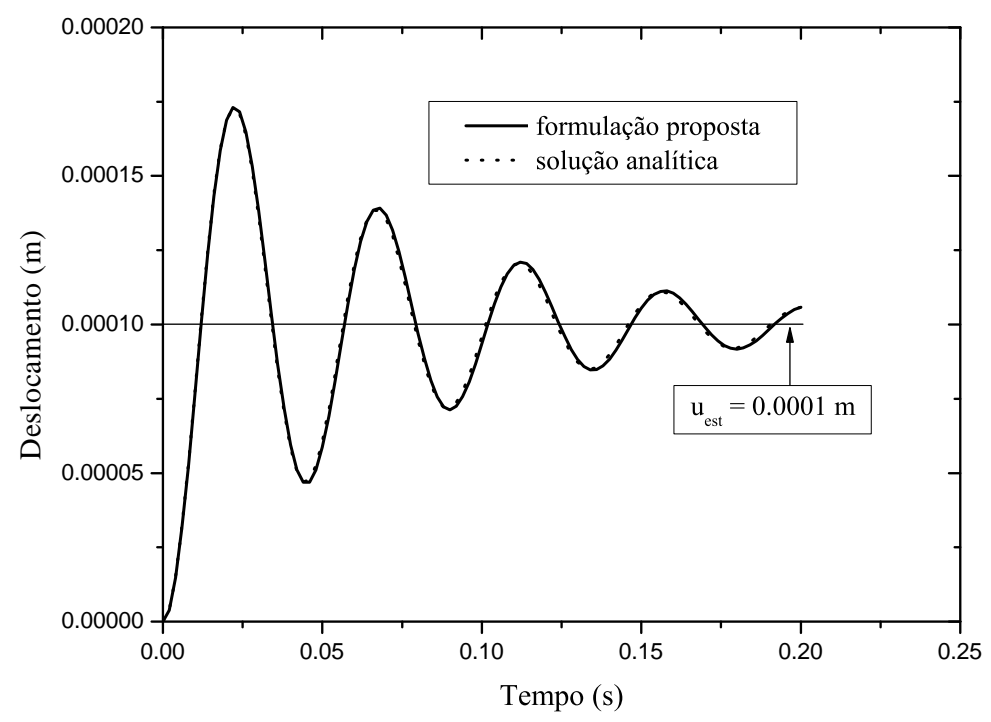

Fonte: Autor.

Conforme a Equação 5.3 o amortecimento diminui a frequência dessa treliça, consequentemente, aumenta o seu período em relação ao problema anterior. Na literatura, utiliza-se para as estruturas usuais da Engenharia Civil fator de amortecimento $\xi$ situado no intervalo 
de 0,01 a 0,1 [219]. Como $\xi$ exibe baixo valor, a frequência angular amortecida tenderá a frequência fundamental, em concordância com a Figura 5.4. Embora a frequência angular amortecida apresente uma pequena variação com o aumento do $\xi$, a taxa de atenuação dos picos de deslocamento tem um considerável aumento à medida que $\xi$ cresce, de acordo com a Figura 5.5. Além disso, valores baixos de $\xi$ têm influência acentuada na resposta de longa duração, veja a Figura 5.5.

Figura 5.4 - Razão entre frequências vs. $\xi$.

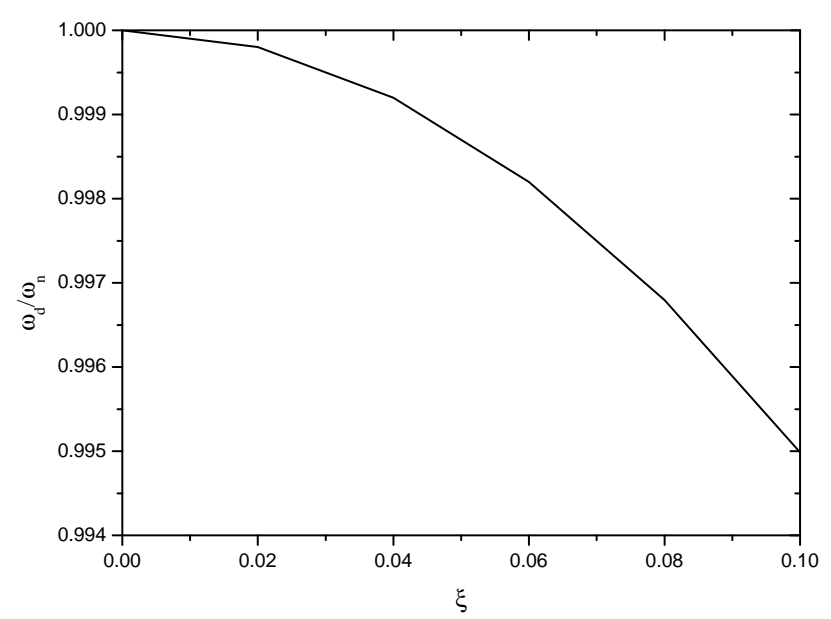

Fonte: Autor.

Figura 5.5 - Deslocamentos vs. tempo para diferentes $\xi$.

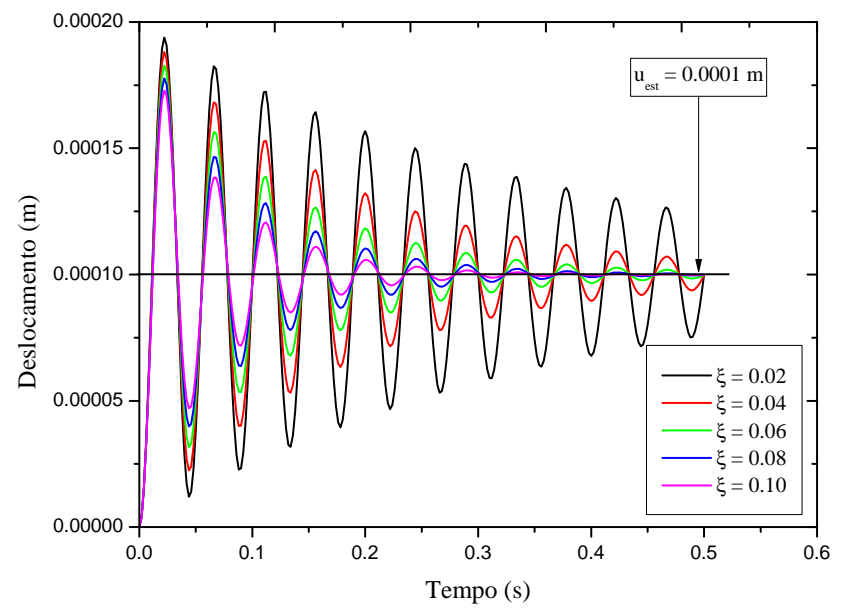

Fonte: Autor. 
O cálculo de $\omega_{n}$ foi concretizado no regime de pequenos deslocamentos, em que a rigidez da estrutura foi avaliada na configuração inicial. De fato, a mudança de configuração do corpo tem influência na determinação dessa grandeza, uma vez que a rigidez da estrutura modifica ao longo da trajetória de equilíbrio na análise não linear. Segundo [201], em regime de grandes deslocamentos é mais adequado falar em frequência $\omega$, ao invés de $\omega_{n}$. Isso porque $\omega$ vai depender do nível de deformação que a estrutura está submetida. A fim de ilustrar esse comportamento, a Figura 5.6 mostra a razão entre $\omega$ e $\omega_{n}$ com o aumento da deformação da treliça em análise. Note que o aumento das deformações do elemento dessa estrutura reduz $\omega$ em comparação a $\omega_{n}$. Portanto, a mudança de configuração altera a matriz Hessiana (rigidez tangente) durante o caminho de solução, o que leva uma diminuição da frequência da estrutura ${ }^{1}$.

Figura 5.6 - Razão entre frequências vs. deformações.

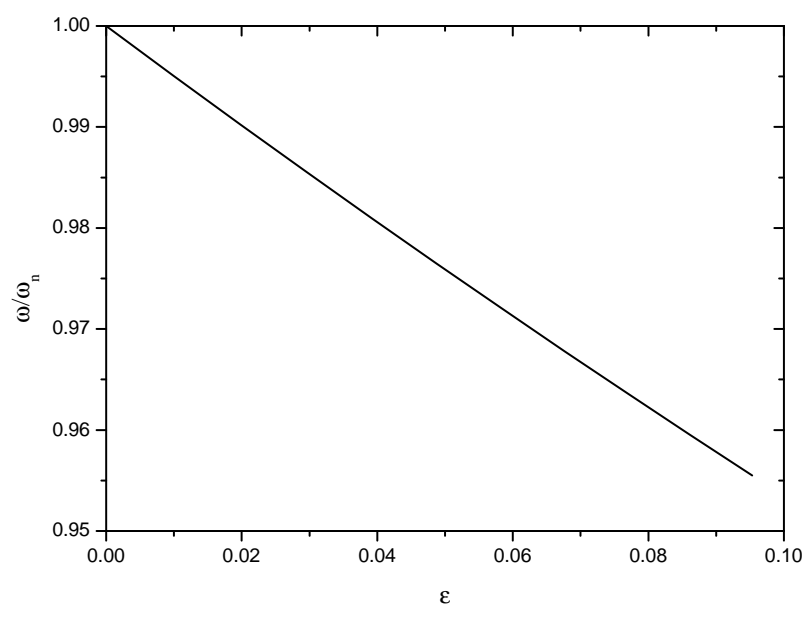

Fonte: Autor.

\subsubsection{Treliça $2 D$ sob ação de terremoto}

Neste exemplo é avaliado o efeito do escoamento do material na resposta da estrutura submetida a terremoto. Para tal, utiliza-se a treliça ilustrada na Figura 5.7 sob ação de um sismo com comportamento elastoplástico perfeito. São assumidos três valores para o coeficiente de redução da força sísmica $(R)$. O $R$ é definido como a razão entre o maior deslocamento gerado pelo sismo em uma análise dinâmica elástica linear pelo deslocamento que conduz o início do escoamento do material em uma análise dinâmica elastoplástica [203]. Todas as verificações são concretizadas para o terremoto de Fukushima que ocorreu no Japão em 2011. Outrossim, não é analisada aqui a influência da taxa de carregamento na relação constitutiva do material.

1 Para determinar $\omega$ em análise não linear, basta calcular a matriz Hessiana atual para uma posição de equilíbrio estático e resolver o problema de autovalores e autovetores da vibração livre em cada passo de carga no caminho de solução. 
Figura 5.7 - Treliça 2D: (a) geometria; (b) relação constitutiva do material.

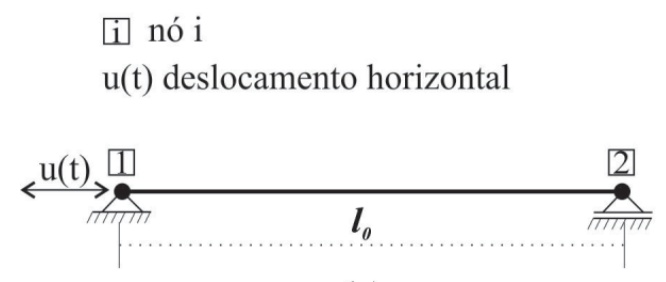

(a)

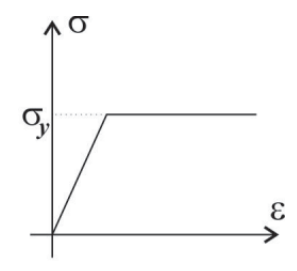

(b)

Fonte: Autor.

Figura 5.8 - Históricos de deslocamento do terremoto Fukushima.

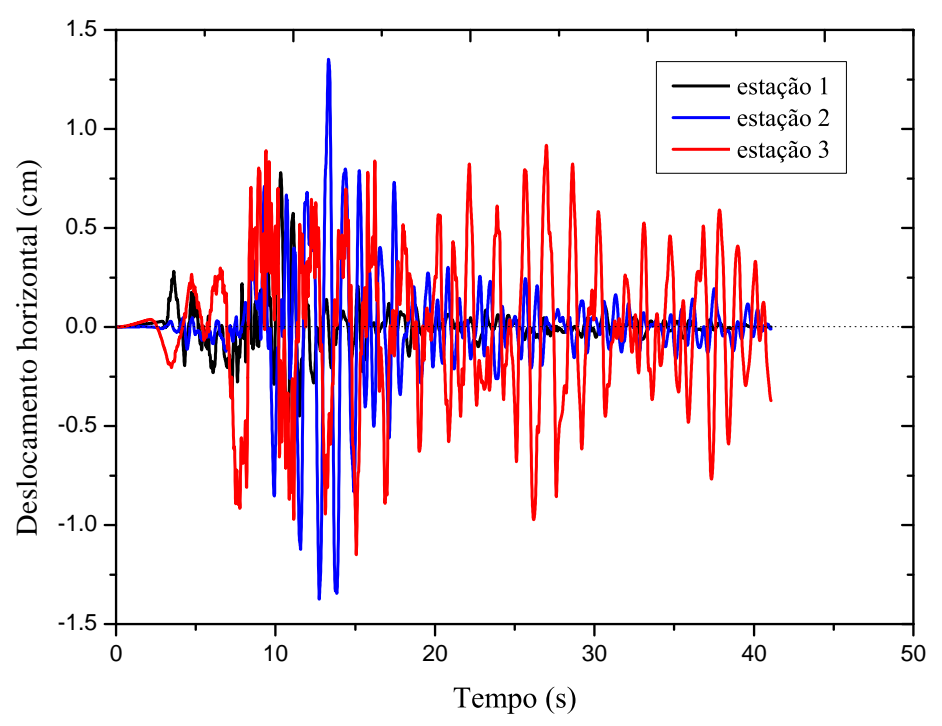

Fonte: [243].

O módulo de elasticidade, a tensão de escoamento, a área da seção transversal, o comprimento, a densidade, o fator de amortecimento e a frequência fundamental dessa estrutura são dados por $E=1,972 \cdot 10^{6} \mathrm{~N} / \mathrm{m}^{2}, \sigma_{y}=1,98 \cdot 10^{4} \mathrm{~N} / \mathrm{m}^{2}, A=10^{-4} \mathrm{~m}^{2}, l=1 \mathrm{~m}, \rho=1000$ $\mathrm{Kg} / \mathrm{m}^{3}, \xi=0,02$ e $\omega_{n}=62,8 \mathrm{~Hz}$, respectivamente. Os parâmetros de Newmark são $\beta_{n}=0,25$, $\gamma_{n}=0,50$ e $\Delta t=0,01 s$. Na Figura 5.8 são apresentados os históricos de deslocamento do terremoto Fukushima [243]. Para os resultados que seguem são empregado os registros da estação 3 .

A Figura 5.9 mostra os deslocamentos horizontais no nó 2 para $R=1, R=2$ e $R=4$. O valor de $R=1$ representa a resposta elástica linear. Por outro lado, $R=2$ e $R=4$ simula uma 
análise elastoplástica com tensão de escoamento igual a $50 \%$ e $25 \%$ de $\sigma_{y}$, respectivamente. Os valores $R=2$ e $R=4$ são frequentemente prescritos pelos códigos de projeto de terremoto [203].

Figura 5.9 - Deslocamento vs. tempo para $\mathrm{R}=1, \mathrm{R}=2$ e $\mathrm{R}=4$.

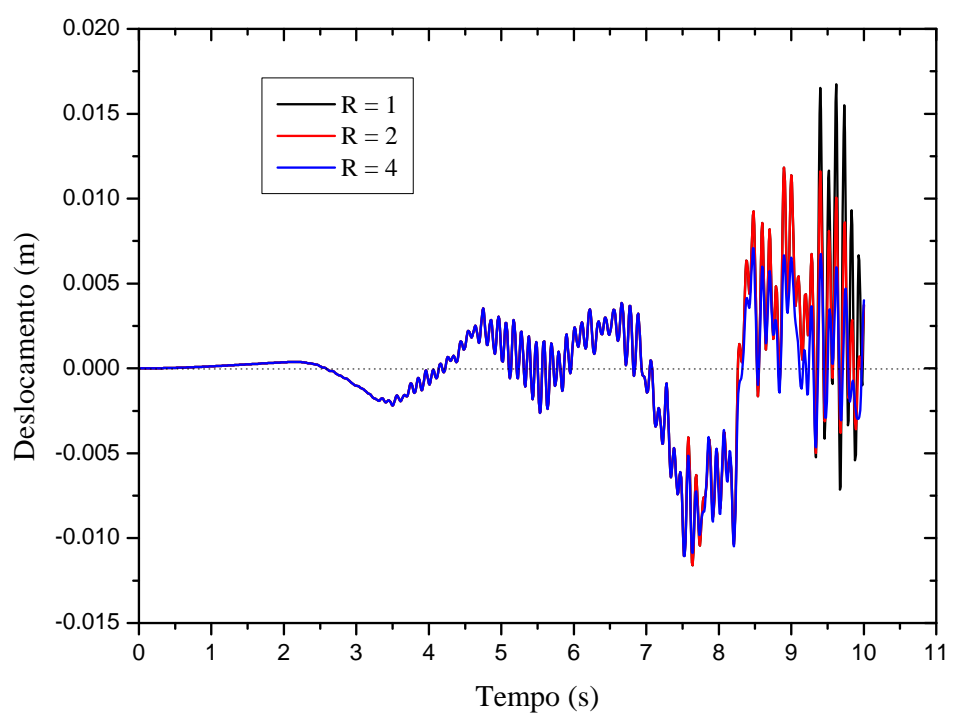

Fonte: Autor.

Como pode ser visto na Figura 5.9, os deslocamentos do nó 2 para $R=1$ apresenta valor máximo de 0,01673 $m$ em 9,62 $s$. Enquanto que as respostas para $R=2$ e $R=4$, exibem um desvio de deslocamento com valores máximos de 0,01182 $m$ em 8,9 $s$ e -0,01106 $m$ em 7,53 $s$, nesta ordem. Nota-se que os deslocamentos para a solução não linear dinâmica reduzem com o aumento do $R$. Isso porque, parte da energia interna é dissipada pelas deformações plásticas em forma de calor e atrito durante o terremoto.

A Figura 5.10 ilustra a evolução das deformações plásticas totais com o tempo. A plastificação inicia no tempo de 9,3 $s$ para $R=2$ e 7,53 $s$ para $R=4$. Observa-se que o aumento do $R$ antecipa o aparecimento das deformações plásticas. Além disso, as deformações plásticas totais crescem com o crescimento do $R$. A Figura 5.11 apresenta a evolução da força normal com o tempo. Como pode ser verificado a força normal no decorrer da análise reduz à medida que o $R$ cresce. Isso era esperado, em razão do nível de tensão na barra ficar constante após atingir a tensão de escoamento. 
Figura 5.10 - Evolução das deformações plásticas totais.

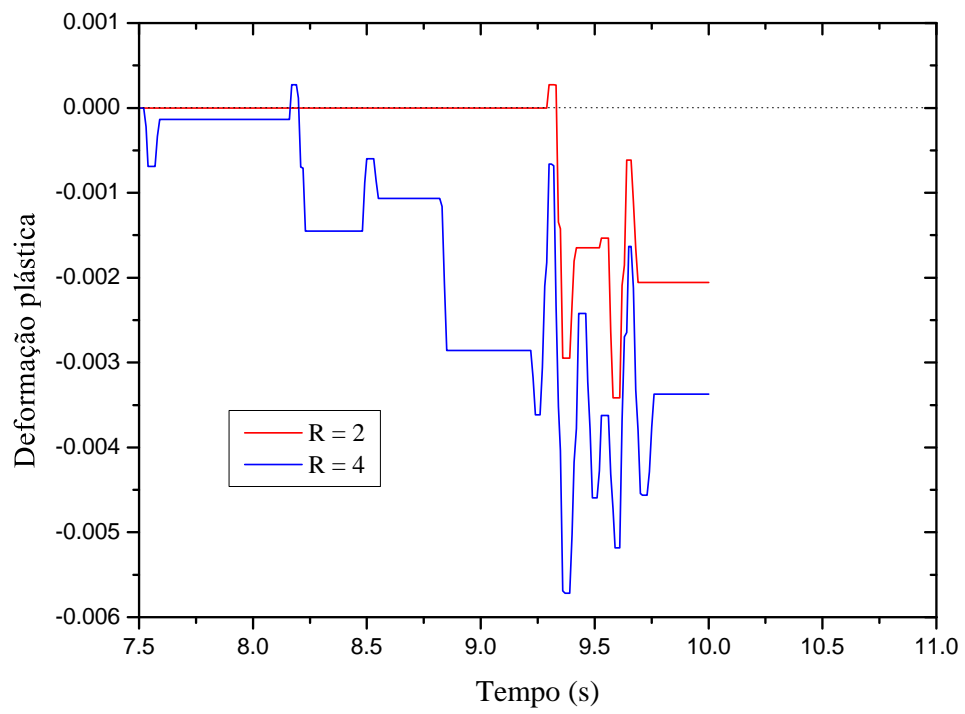

Fonte: Autor.

Figura 5.11 - Evolução da força normal.

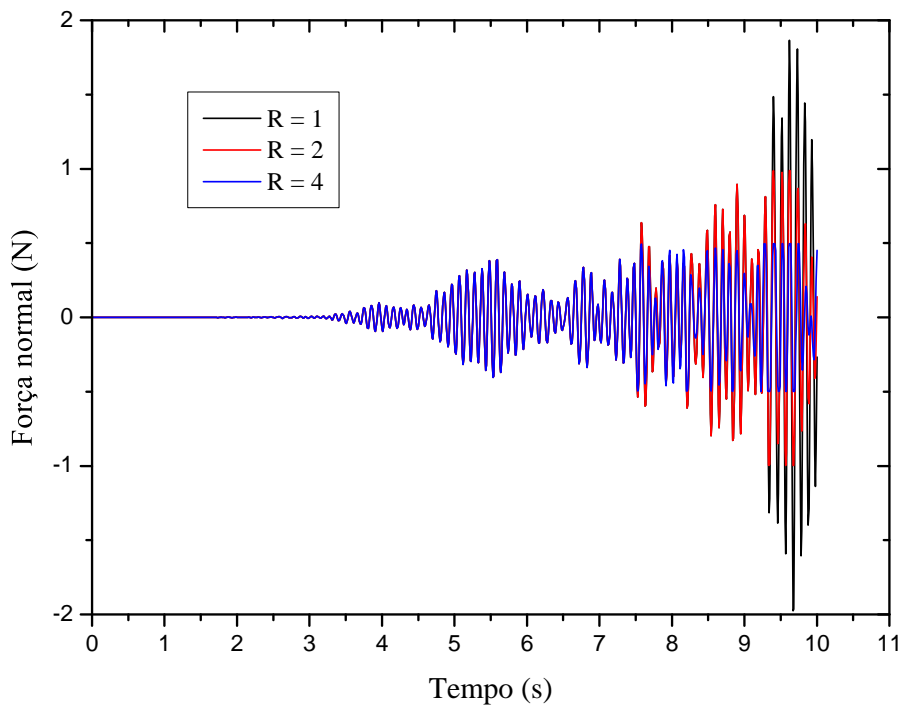

Fonte: Autor. 


\subsubsection{Torre de linhas de transmissão sob a ação dinâmica dos cabos}

Nesta seção é efetivada uma análise dinâmica não linear geométrica de uma torre autoportante tipo tronco-piramidal usada em linhas de transmissão. Essa estrutura foi avaliada por meio de uma análise estática por [244]. O referido autor analisou essa estrutura sob ação do vento. Os dados da geometria dessa torre podem ser vistos no trabalho do referido autor. A torre é discretizada em 233 elementos e 110 nós. Suas constantes são as seguintes: $E=2,1 \cdot 10^{11}$ $N / \mathrm{m}^{2}, A=1,5 \cdot 10^{-3} \mathrm{~m}^{2}$ e $\rho=7000 \mathrm{Kg} / \mathrm{m}^{3}$. Os parâmetros do integrador de Newmark são $\beta_{n}=0,25, \gamma_{n}=0,50$ e $\Delta t=0,0015 s$. As análises não lineares são concretizadas com e sem amortecimento, sendo para o último o fator de amortecimento igual a $\xi=0,02$. A Figura 5.12-a apresenta o posicionamento dos cabos. Devido a ação do vento esses cabos oscilam impondo um efeito dinâmico na torre, em conformidade com a Figura 5.12-b. A finalidade desse exemplo é avaliar a deslocabilidade da torre sob esse efeito.

Figura 5.12 - Torre metálica 2D: (a) posicionamento dos cabos; (b) intensidade da força dinâmica.

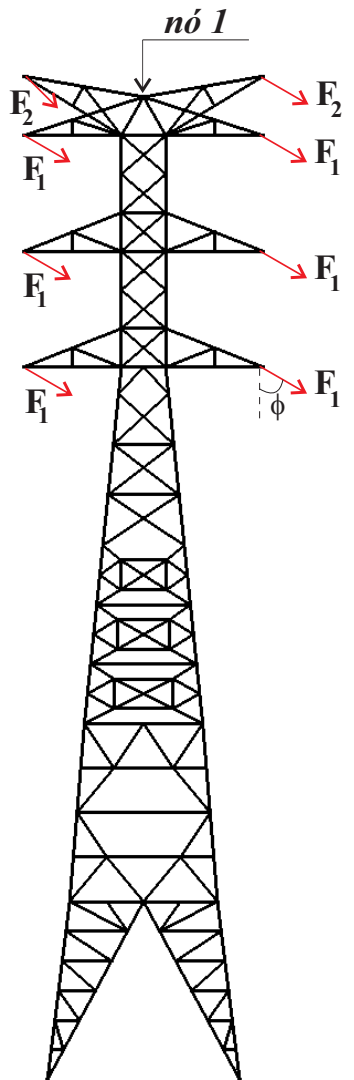

(a)

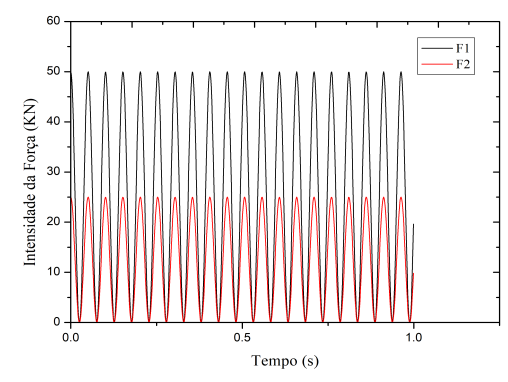

(b)

Fonte: Autor.

A força $F_{1}$ corresponde à força nos cabos condutores, enquanto $F_{2}$ representa a força no cabo de guarda (para-raios). As intensidades das forças $F_{1}$ e $F_{2}$ são descritas pela seguinte 
equações:

$$
\begin{array}{ll}
F_{1}=50 \cdot \cos ^{2}(62 \cdot t) & {[K N]} \\
F_{2}=25 \cdot \cos ^{2}(62 \cdot t) & {[K N]}
\end{array}
$$

$\operatorname{com} t$ em segundos. Essas forças são descompostas em componentes na direção $x$ e $y$ de acordo com o ângulo $\phi$. Este ângulo corresponde a inclinação dos cabos com relação a direção vertical. Nas análises que decorre é adotado $\phi=37^{\circ}$.

Figura 5.13 - Análise modal: (a) primeiro, (b) segundo e (c) terceiro modo de vibração.

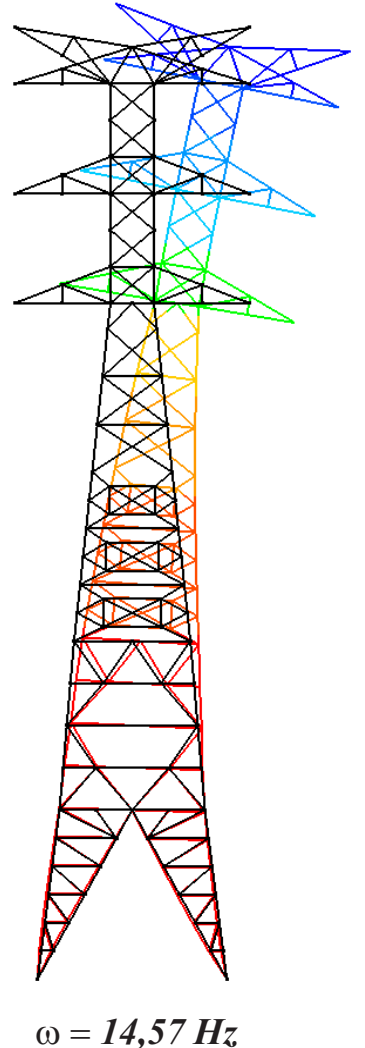

(a)

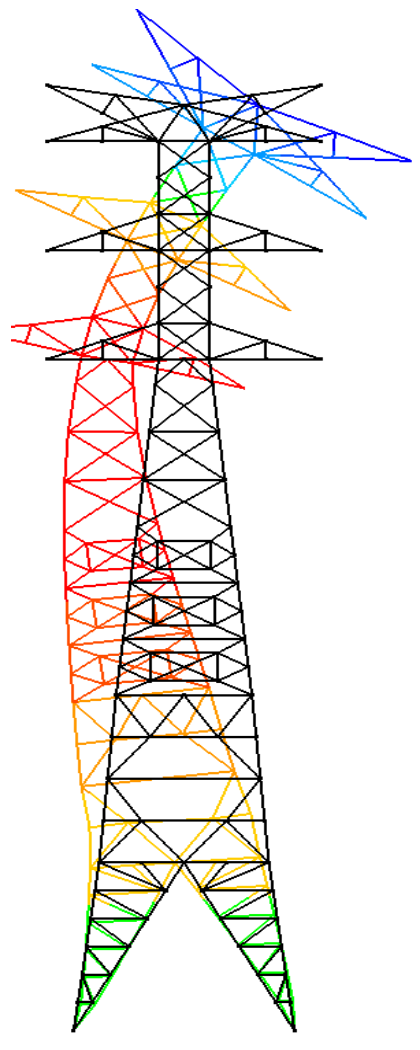

$\omega=56,24 \mathrm{~Hz}$

(b)

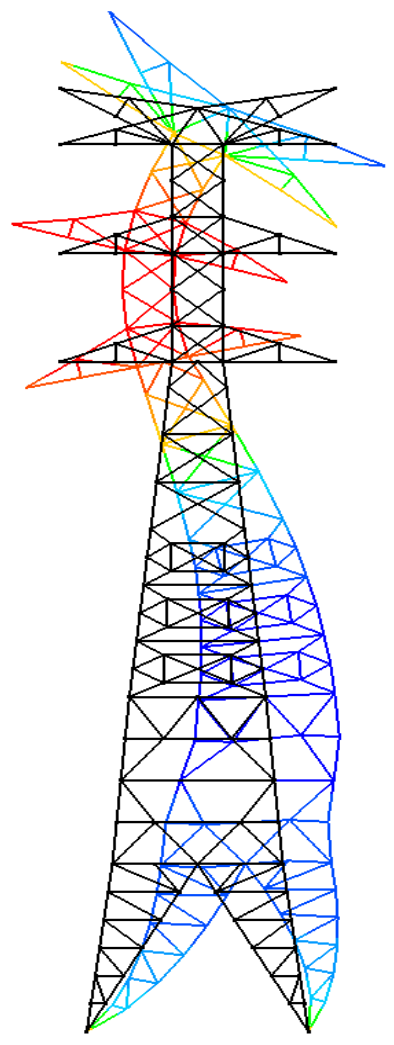

$\omega=116,61 \mathrm{~Hz}$

(c)

Fonte: Autor.

Na Figura 5.13 são ilustrados os três primeiros modos de vibração da torre. O pós processamento dessa estrutura foi concretizado no software AcadView. Nota-se que ambos são flexionais, sendo a frequência natural igual a $14,57 \mathrm{~Hz}$ para o primeiro; $56,24 \mathrm{~Hz}$ para o segundo e $116,61 \mathrm{~Hz}$ para o terceiro modo.

A Figura 5.14 apresenta o histórico de deslocamento do nó 1 para a análise sem amortecimento, sendo $x_{e s t}$ e $y_{\text {est }}$ os deslocamento estáticos, enquanto $x_{\text {din }}$ e $y_{\text {din }}$ os deslocamentos dinâmicos, respectivamente, na direção $x$ e $y$. Observa-se que os deslocamentos máximos 
dinâmicos $x_{\text {din }}$ e $y_{\text {din }}$ são aproximadamente 0,8 e 0,15 $m$, nesta ordem. Em contrapartida, os deslocamentos estáticos são $x_{e s t}=0,848 \mathrm{~m}$ e $y_{e s t}=-0,027 \mathrm{~m}$. Na análise dinâmica o deslocamento máximo em comparação a análise estática na direção $x$ reduziu 6\%, ao passo que em $y$ aumentou 555\%. Além disso, os deslocamentos na direção $x$ atingem o seu pico com período de 0,447 s. Embora os picos de deslocamentos passem por valores semelhantes, a forma da curva nunca se repete precisamente. Isso ocorre porque em análise não linear dinâmica a estrutura não tem exatamente um modo de vibrar. De fato, a cada passo de carga a torre muda de configuração, consequentemente, sua rigidez é penalizada, portanto, mudam seus modos de vibrar. Tais mudanças acarretam oposição de fase entre a estrutura e a força dinâmica que conduz à diminuição da amplitude nos deslocamentos $y_{\text {din }} \mathrm{e}$, no momento em que essa fase se ajusta, ocorre novo acréscimo da amplitude, conforme a Figura 5.14. Esse fenômeno ocorre quando a frequência da força dinâmica está muito próxima da frequência da estrutura (mas não igual), sendo conhecido na literatura como batimento [201]. O período de batimento definido como o tempo entre zeros sucessivos [203], é 1,76 s, em concordância com a Figura 5.14. Dessa forma, os deslocamentos $y_{\text {din }}$ retornam a zero com repetição do movimento a cada 1,76 s.

Figura 5.14 - Deslocamento vs. tempo para o nó $1 \mathrm{com} \xi=0$.

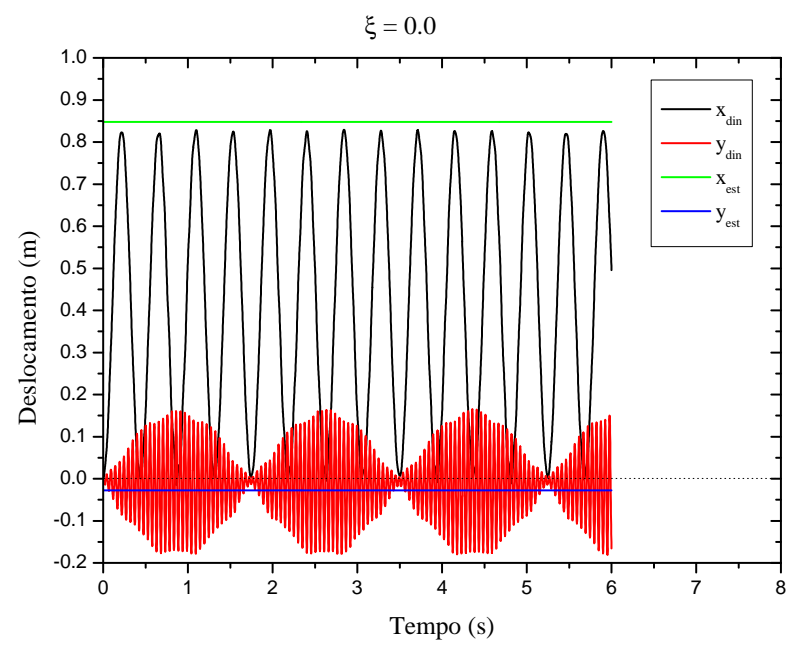

Fonte: Autor.

A Figura 5.15 mostra a solução do problema assumindo $\xi=0,02$. A dissipação de energia dada pelo amortecimento da estrutura atenua os deslocamentos $x_{\text {din }}$ e $y_{\text {din }}$ ao longo do tempo. Em contrapartida, os deslocamentos verticais $\left(y_{\text {din }}\right)$ entre 0 até 1,5 $s$ mantiveram comportamento semelhante ao sistema conservativo, porém não é mais notado o fenômeno do batimento. Portanto, como o amortecimento reduz a frequência da estrutura, esta se afasta da frequência da força dinâmica à medida que a torre muda de configuração, induzindo uma atenuação no fenômeno do batimento. 
Figura 5.15 - Deslocamento vs. tempo para o nó 1 com $\xi=0,02$.

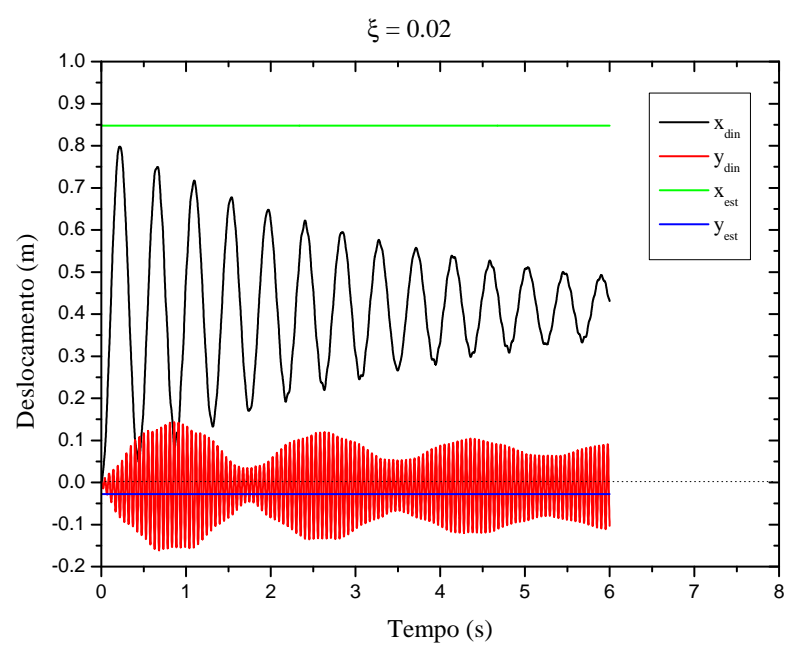

Fonte: Autor.

\subsubsection{Torre metálica $2 D$ sob ação de terremoto}

Este exemplo apresenta a análise de colapso progressivo de uma torre metálica 2D sujeita a um sismo. O terremoto selecionando é o de El-Centro (1941). O espectro de deslocamento desse terremoto é dado por [221]. Os deslocamentos horizontais são aplicados na base da torre. A torre é formada por 47 elementos e 22 nós, conforme ilustrado na Figura 5.16. O fator de amortecimento é igual a $\xi=0,02$. Os parâmetros de Newmark são $\beta_{n}=0,25, \gamma_{n}=0,50 \mathrm{e}$ $\Delta t=0,01 \mathrm{~s}$. As constantes são $E=2 \cdot 10^{11} \mathrm{~N} / \mathrm{m}^{2}, \sigma_{y}=2 \cdot 10^{8} \mathrm{~N} / \mathrm{m}^{2}, A=10^{-4} \mathrm{~m}^{2}$ e $\rho=7850$ $K g / m^{3}$. Os coeficientes do modelo de dano são $\alpha_{1}^{p}=0 ; \alpha_{2}^{p}=1000 ; \alpha_{3}^{p}=0 ; \varepsilon_{l n, d}^{p}=3,33 \cdot 10^{-4}$ e $D_{\text {crit }}=0,50$. O efeito dinâmico dos cabos não é considerado neste exemplo.

A Figura 5.17 ilustra os três primeiros modos de vibração da torre. Nota-se que o primeiro e o segundo são flexionais, ao passo que o terceiro é longitudinal. O primeiro modo de vibração mais o fator de amortecimento são empregados para o cálculo da matriz de amortecimento, conforme Equação 3.67.

A Figura 5.18 mostra a curva de deslocamento horizontal vs. tempo para o nó 1 dessa estrutura. Observe que os deslocamentos no nó 1 são diferentes para cada tipo de análise. $\mathrm{Na}$ análise elástica ocorre uma amplificação dos deslocamentos horizontais e verticais do topo dessa estrutura. Por outro lado, na análise plástica sucede uma redução dos deslocamentos no topo da torre tanto na horizontal (Figura 5.18-a) como na vertical (Figura 5.18-b). Isso acontece porque a plastificação dos elementos $E 1, E 2, E 3$ e $E 4$ conduz a uma mudança de configuração que implica na diminuição dos deslocamentos do topo da torre. Além disso, como comentado no exemplo da subseção 5.1.3, surgimento de deformações plásticas dissipa energia do sistema 
conduzindo menores valores de deslocamentos no topo dessa estrutura. Ademais, para um tempo acima de 2,5 $s$ os deslocamentos verticais no nó 1 são sempre positivos para a análise plástica, de acordo com a Figura 5.18.

Figura 5.16 - Torre metálica 2D: (a) geometria; (b) relação constitutiva do material.

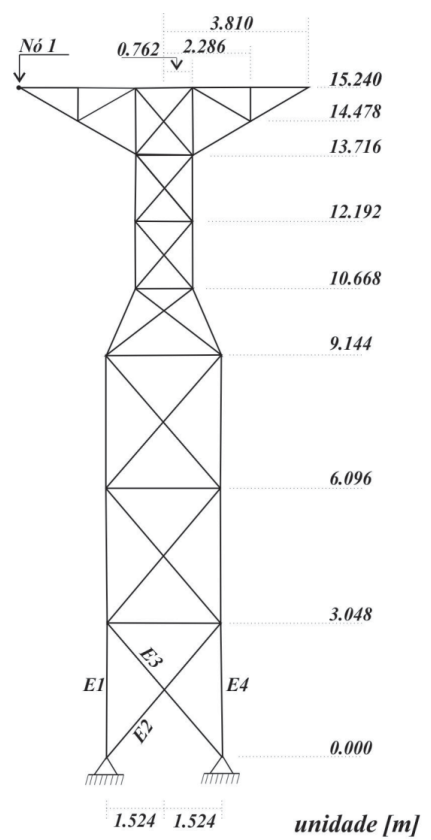

(a)

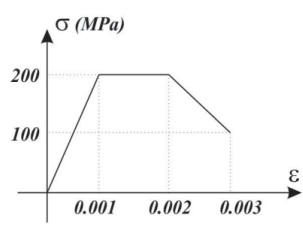

(b)

Fonte: Autor.

Figura 5.17 - Modo de vibração: (a) primeiro; (b) segundo e (c) terceiro.

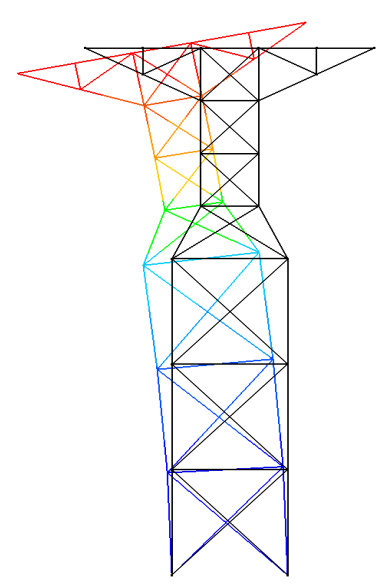

$\omega=45,67 \mathrm{~Hz}$

(a)

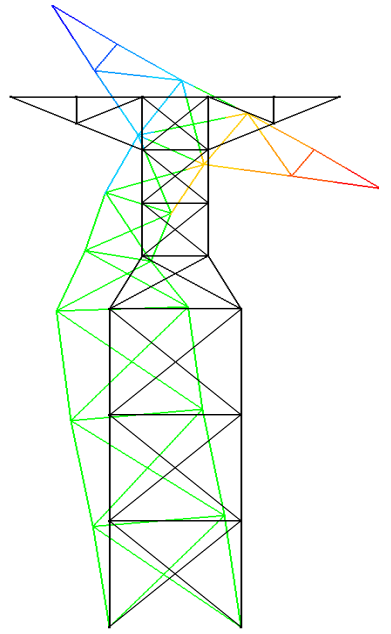

$\omega=170,66 \mathrm{~Hz}$

(b)

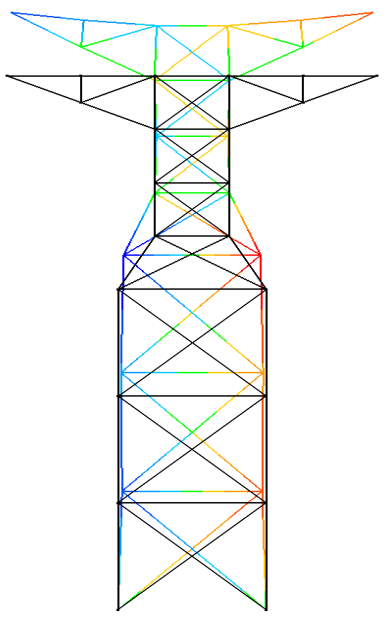

$\omega=262,06 \mathrm{~Hz}$

(c)

Fonte: Autor. 
Com relação à análise plástica mais dano, nota-se que quando o regime de amolecimento do material é introduzido, os elementos $E 2$ e $E 3$ atingem o dano crítico para o tempo de 0,56s. Esses elementos falham implicando no colapso progressivo dessa torre. Note que a falha de $E 2 \mathrm{e}$ E3 transforma essa estrutura em um mecanismo, pois a falha desses elementos acarreta a perda de instabilidade da torre.

Figura 5.18 - Deslocamento horizontal do nó 1 vs. tempo: (a) horizontal; (b) vertical.

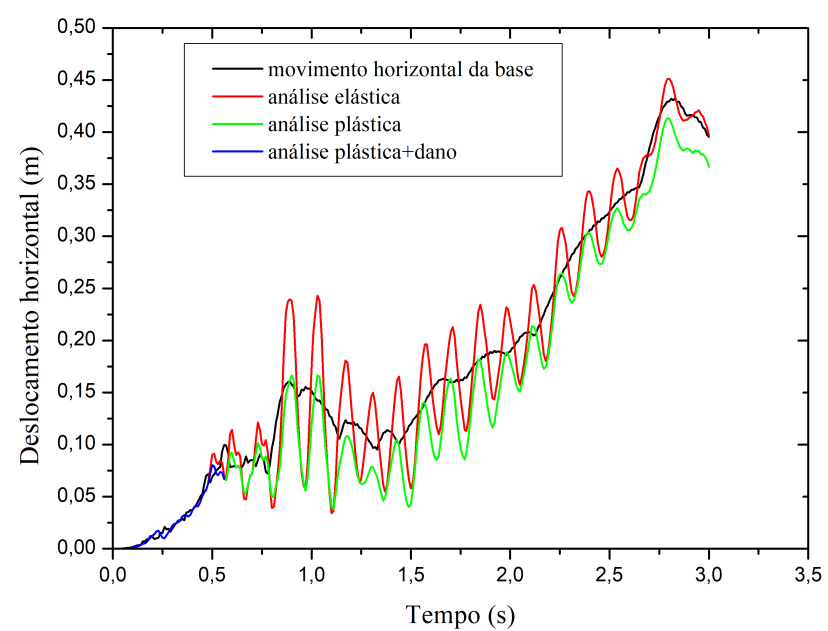

(a)

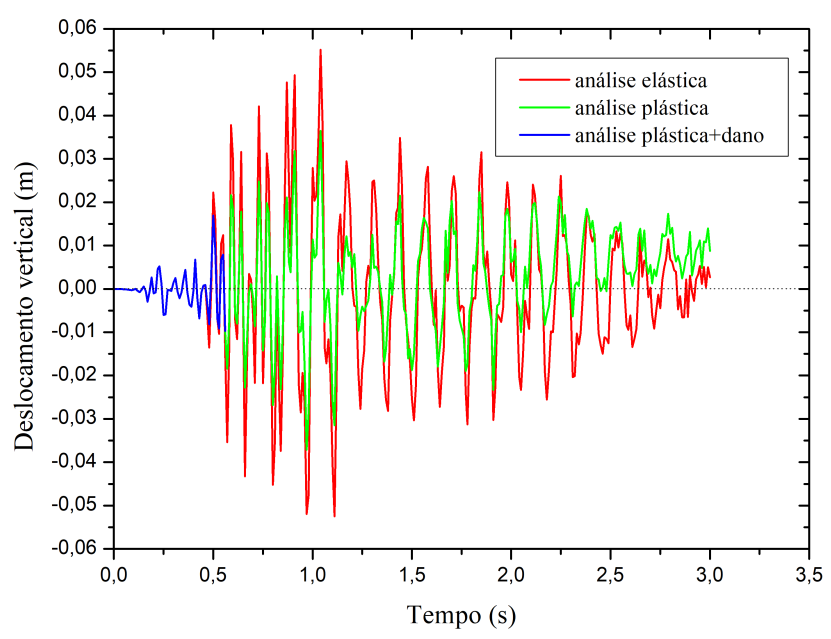

(b)

Fonte: Autor.

A Figura 5.19 apresenta a evolução do dano, enquanto que a Figura 5.20 mostra o histórico das deformações plásticas totais para os elementos $E 2$ e E3. A plastificação desses elementos inicia a partir de 0,45 s. No tempo de 0,47 $s$ essas barras atingem o limite de dano inicial, por conseguinte, inicia-se a degradação mecânica com valor de dano igual a 0,046. Para um intervalo de tempo de 0,48 até 0,49 s ocorre um descarregamento elástico, conforme ilustrado 
na Figura 5.21. Esse descarregamento causa inversão de esforço provocando tração na barra $E 2$ e compressão na barra E3. Como o critério de plastificação não é atingido entre os pontos 2 e 3 , isso conduz um valor constante para as deformações plásticas totais (Figura 5.20), dessa forma, para o dano desses elementos (Figura 5.19). Finalmente, a partir do ponto 3 as deformações plásticas começam a evoluir até os elementos E2 e E3 alcançarem o dano crítico levando o colapso da torre.

Figura 5.19 - Evolução do dano vs. tempo para os elementos E2 e E3.

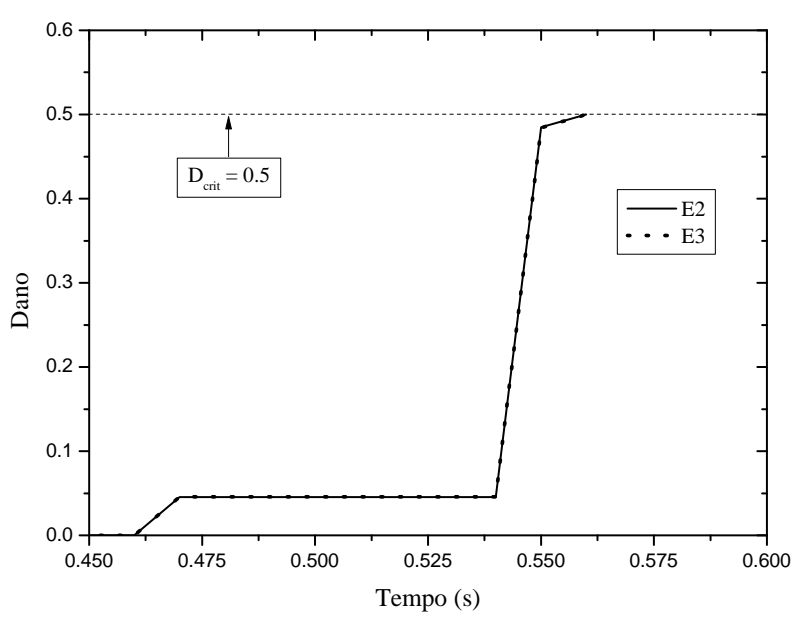

Fonte: Autor.

Figura 5.20 - Deformações plásticas totais vs. tempo.

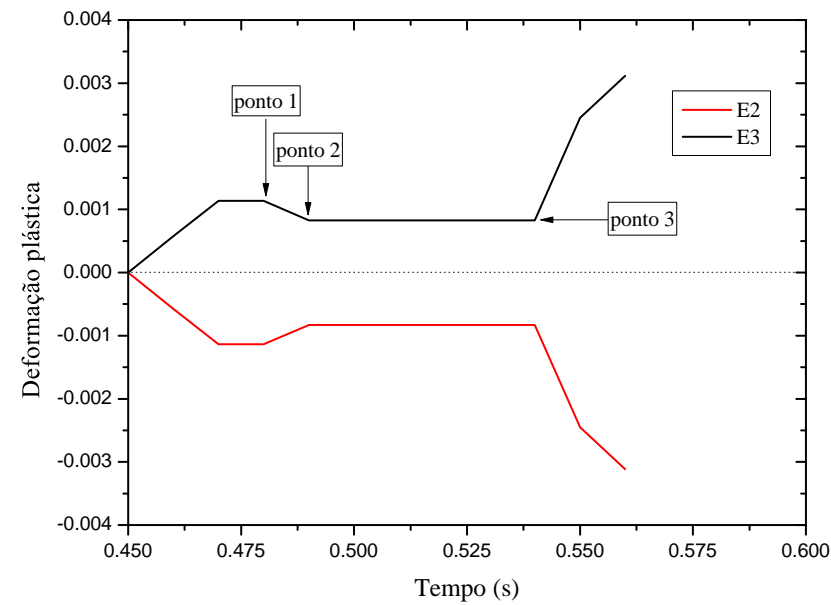

Fonte: Autor. 
Figura 5.21 - Trecho do espectro de deslocamento do terremoto.

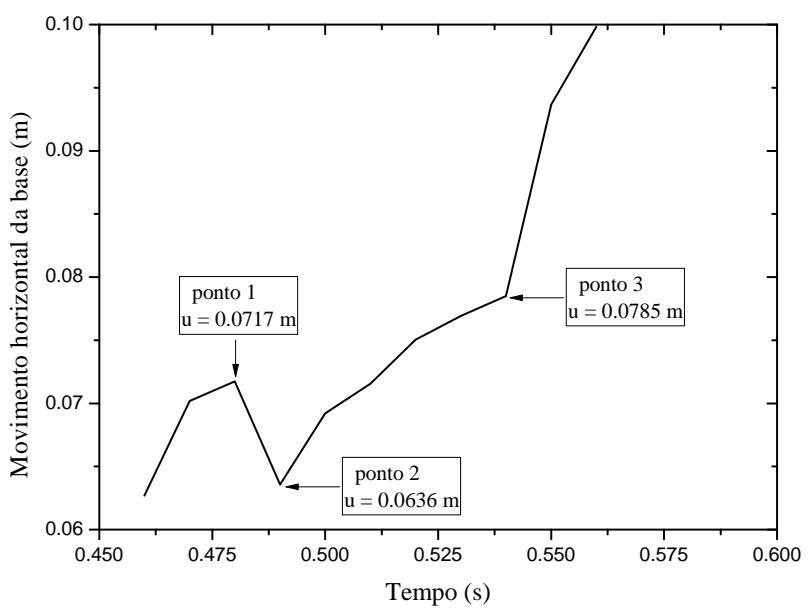

Fonte: Autor.

\subsubsection{Torre de telecomunicação submetida ao sismo de El-Centro}

Nesta seção, a formulação proposta é aplicada em um estudo de caso de uma torre metálica de telecomunicação sob excitação de terremoto. O terremoto usado na análise é o de El-Centro que ocorreu na Califórnia em 1941. Para tal, utiliza-se o espectro de deslocamento com fator de amortecimento igual $\xi=0,02$ e $\xi=0,05$ apresentado em [221]. Esse espectro é amplamente empregado pela comunidade científica nas validações dos seus modelos numéricos para a avaliação de sismo [203]. O espectro de deslocamento é aplicado na direção x. Ademais, a análise é concretizada no domínio do tempo.

A torre foi construída na cidade de Florianópolis/RS. Essa estrutura usa como base o projeto de uma torre autoportante, modelo TAB 050 1500L do fabricante BrasilSAT, constituída por perfis em aço ASTM A36. Os seus dados geométricos e a posição dos elementos adicionais (antenas) são fornecidos por [245]. Ela tem $50 \mathrm{~m}$ de altura sendo composta por um troco piramidal na sua base de 5,7 $\mathrm{m}$ de abertura e no topo um trecho reto com 1,5 $\mathrm{m}$ de abertura. Os montantes são formados por perfis de seção ômega e os elementos das diagonais e travamentos horizontais em perfis de seção cantoneira de abas iguais [245]. O seu dimensionamento foi efetivado com os esforços oriundos do peso próprio e força do vento.

A Figura 5.22 apresenta uma vista de perspectiva, bem como o posicionamento das antenas. Na vista de elevação (Figura 5.22-b), as letras ao longo da altura faz referência à cada módulo para a determinação das forças de vento. Ademais, mostra a relação constitutiva do aço ASTM A36 assumida no projeto original, assim como a curva experimental desse material. A resposta experimental foi obtida para uma espécime desse aço no Laboratório de Engenharia de 
Estruturas da EESC/USP por [232]. Nas análises que se seguem, a torre é avaliada utilizando a curva de projeto (modelo elastoplástico perfeito) e a curva experimental. O intuito é avaliar a capacidade resistente dessa torre (estrutura real) diante de uma ação considerada excepcional no Brasil.

Figura 5.22 - Torre metálica 3D: (a) vista de perspectiva; (b) elevação e posicionamento das antenas; (c) relação constitutiva do material empregado.

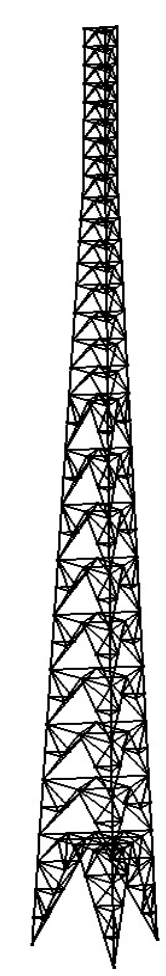

(a)

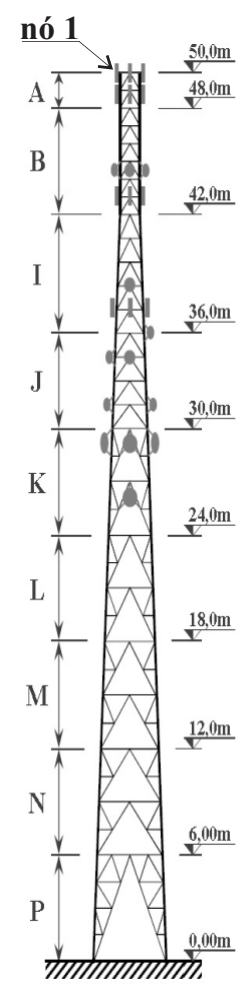

(b)

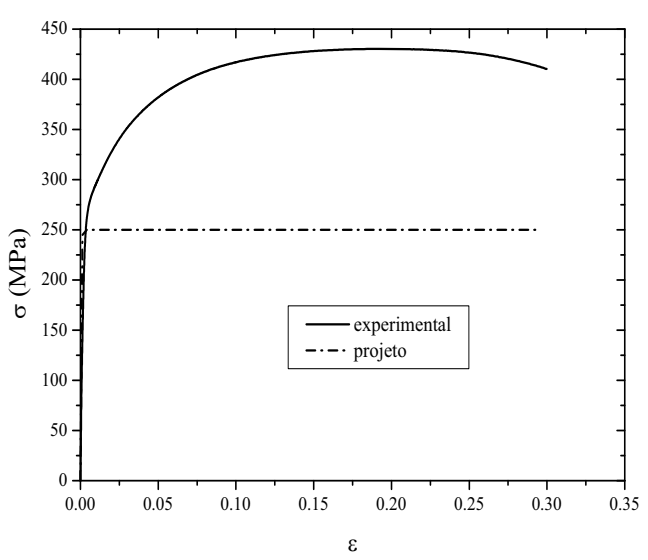

(c)

Fonte: Autor.

A torre é discretizada por 267 nós e 798 elementos, conforme ilustrado na Figura 5.22-a. São utilizados 13 seções transversais diferentes em conformidade com o projeto original. Para a análise os parâmetros de Newmark são: $\beta_{n}=0,25, \gamma_{n}=0,50$ e $\Delta t=0,001 s$. As propriedades do material são os seguintes: $E=200 \mathrm{GPa}, \sigma_{y}=250 \mathrm{MPa}$ e $\rho=7850 \mathrm{Kg} / \mathrm{m}^{3}$. Com relação aos parâmetros do modelo de dano, esses são apresentados na Tabela 4.2 para o aço ASTM A36, em conformidade com o ensaio de [232].

Inicialmente, realiza-se uma análise modal da torre para determinar sua frequência fundamental. Esse dado é importante para determinar a matriz de amortecimento proporcional à massa, conforme a Equação 3.67. A Figura 5.23 ilustra o primeiro e o terceiro modo de vibração da estrutura em avaliação. O pós-processamento foi efetivado no software AcadView. Note que o primeiro é flexional, enquanto que o terceiro é torcional. Devido à simetria dessa estrutura o segundo modo foi igual ao primeiro, mas com flexão em torno do eixo $x$, enquanto que o quarto 
modo foi igual ao terceiro, porém a torção ocorre com um giro anti-horário em torno do eixo $y$. Portanto, por definição, a frequência fundamental dessa torre é igual a 8,37 $\mathrm{Hz}$.

Figura 5.23 - Torre metálica 3D: (a) primeiro e (b) terceiro modo de vibração.

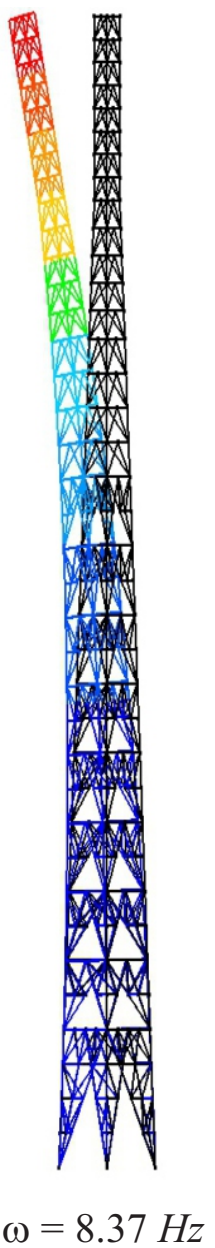

(a)

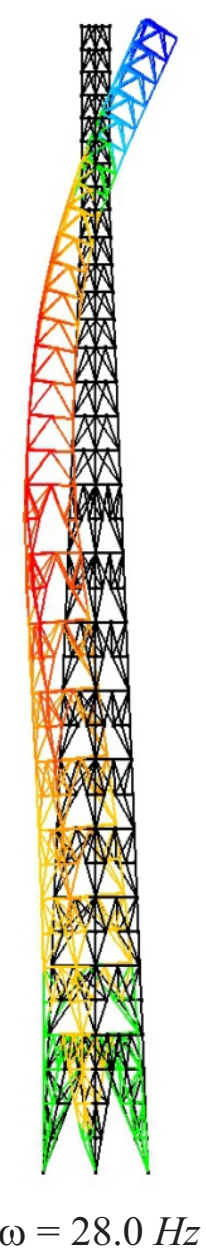

(b)

Fonte: Autor.

A Figura 5.24 mostra os deslocamentos do nó 1 para a relação constitutiva de projeto e experimental, usando o espectro de reposta $\operatorname{com} \xi=0,02$. Como pode ser visto os deslocamentos $x$ (Figura 5.22-a), $y$ (Figura 5.22-b) e $z$ (Figura 5.22-c) têm um aumento considerável quando assume-se a relação constitutiva de projeto em comparação à solução obtida pela curva experimental. Nota-se que até o intervalo de tempo de 0,66 $s$ as respostas se confundem, pois,o material está no regime elástico linear. Para o próximo passo de tempo, a tensão de escoamento é atingida para as barras da base (módulo P). Logo, inicia-se o processo de plastificação dessas barras. Como o aço exibe encruamento (curva experimental), a superfície de plastificação aumenta e conduz um acréscimo de resistência implicando em deslocamentos menores no que concerne a solução obtida via curva de projeto. 
Figura 5.24 - Deslocamento vs. tempo para o nó $1 \mathrm{com} \xi=0,02$.

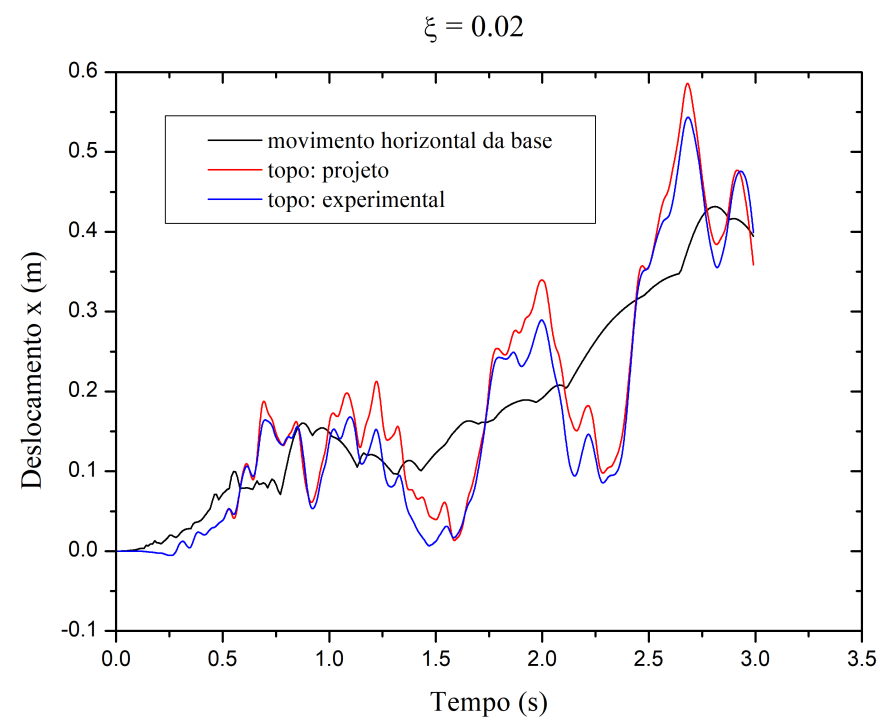

(a)

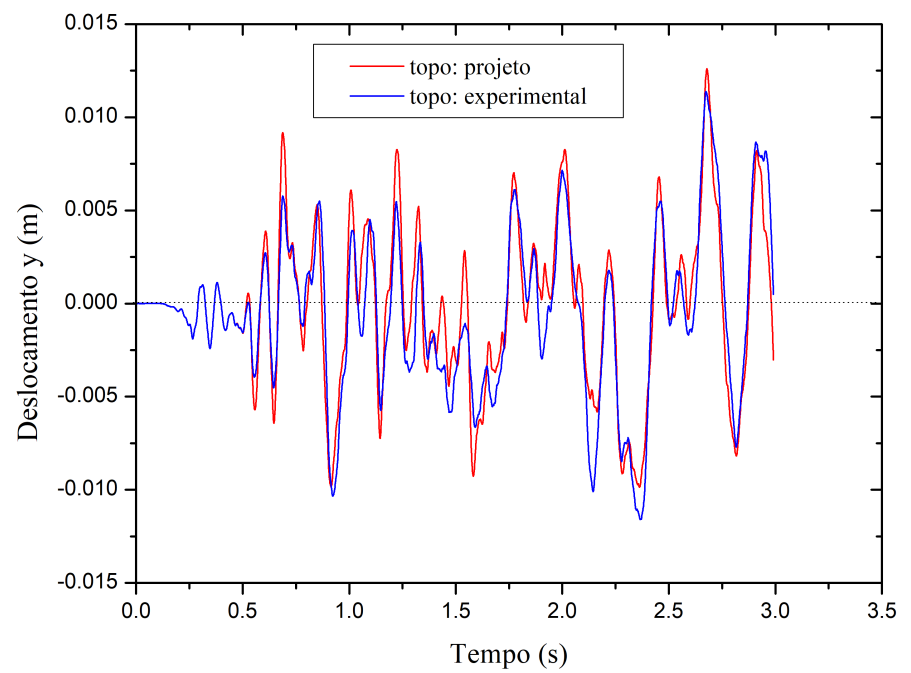

(b)

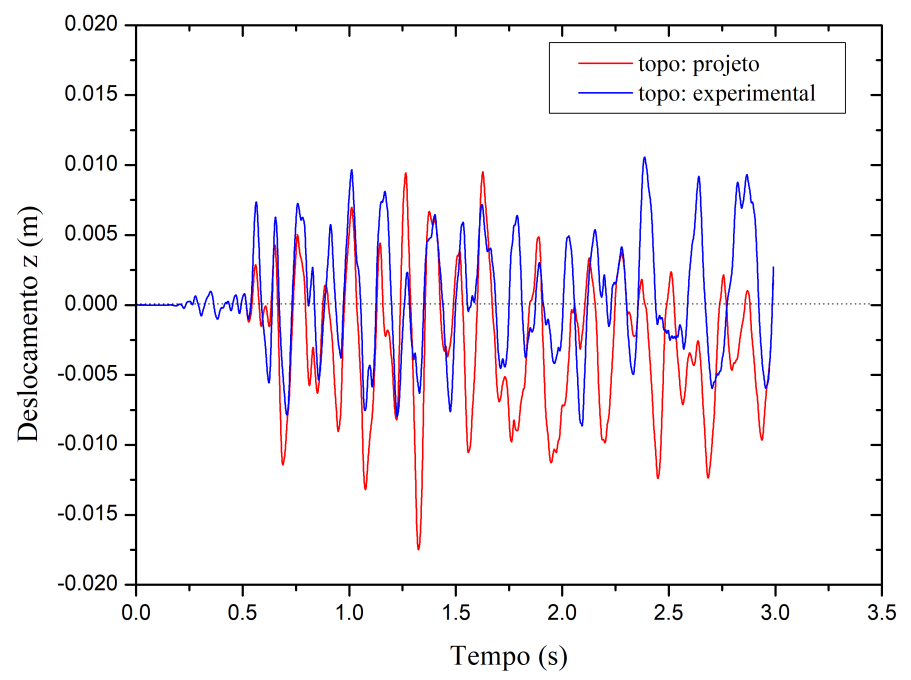

(c)

Fonte: Autor. 
Figura 5.25 - Deslocamento vs. tempo para o nó $1 \mathrm{com} \xi=0,05$.

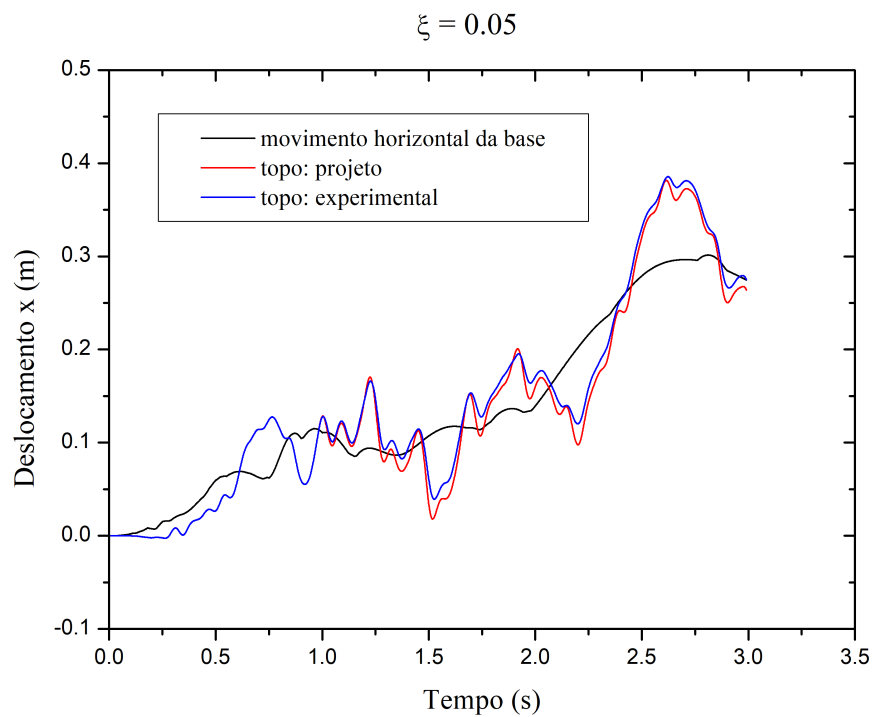

(a)

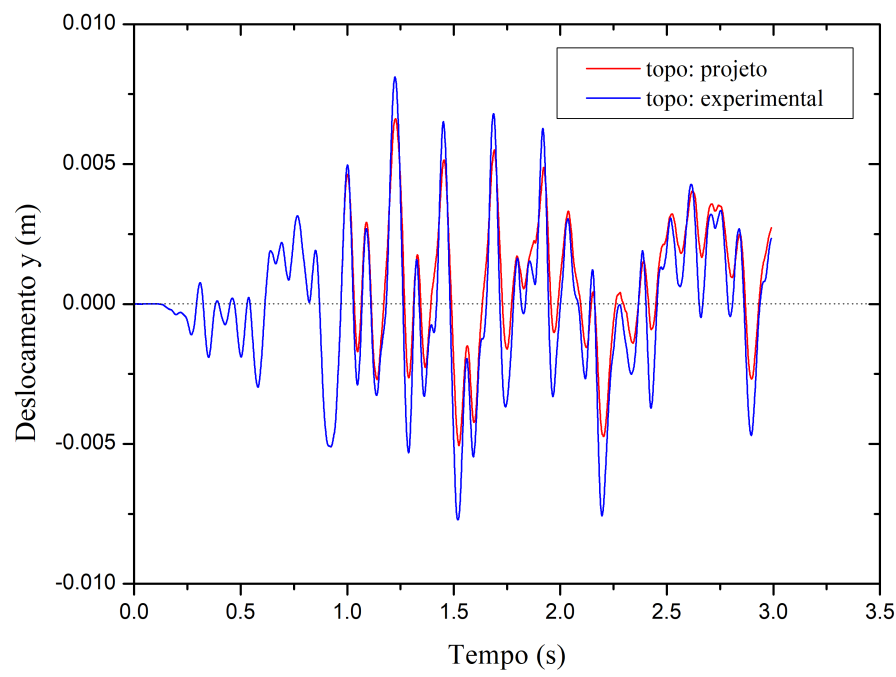

(b)

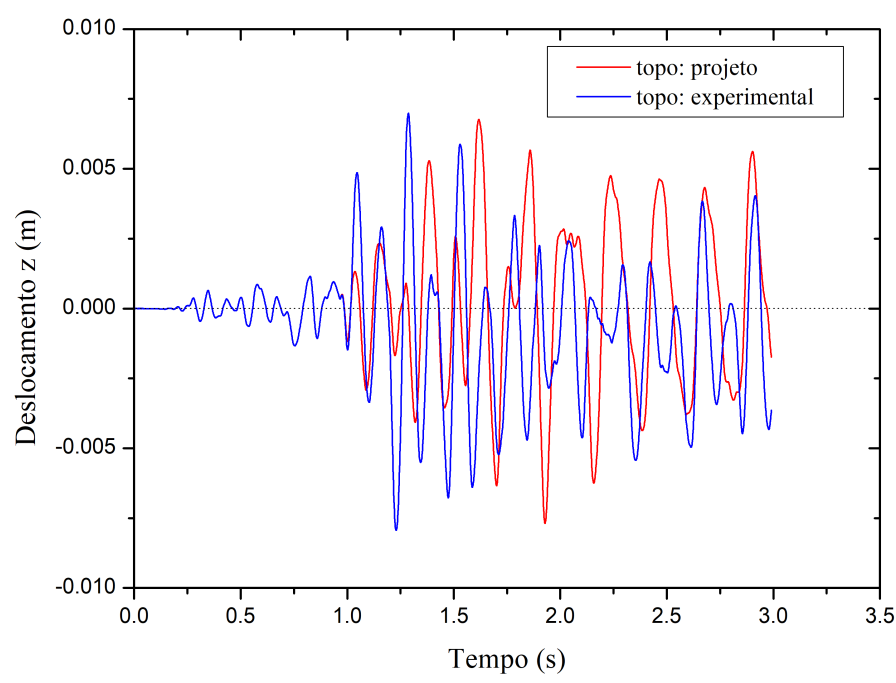

(c)

Fonte: Autor. 
A Figura 5.25 apresenta os deslocamentos para o espectro de resposta com fator de amortecimento igual a $\xi=0,05$. Observa-se que o aumento desse fator reduz os deslocamentos para ambas soluções. Isso era esperado, uma vez que a dissipação de energia pelo amortecimento é diretamente proporcional $\xi$. Ademais, o nível de tensão nas barras não alcançou o regime de amolecimento do material, consequentemente, a evolução da degradação mecânica foi nula. Vale ressaltar que o baixo peso e alta flexibilidade dessa torre suavizou a excitação do terremoto.

O projeto original da torre seguiu as recomendações da Prática 240-410-600 [246]. Para torres tipo TASL-C (modelo em análise), esse documento prescreve no item 3.08 que a deflexão máxima para garantir a segurança da estrutura em relação ao seu eixo vertical seja igual $1^{\circ} 40^{\prime} 00^{\prime \prime}$, que transformando esse valor em deslocamento horizontal para a torre em estudo resulta em 1,45 $m$. Esse valor seria o deslocamento lateral que induz a perda de instabilidade da estrutura devido à força do vento. $\mathrm{O}$ máximo deslocamento ocorrido na direção do sismo foi aproximadamente $0,6 m$ para $\xi=0,02$. Essa estrutura possui resistência suficiente para suportar a excitação do terremoto El-Centro sem a ocorrência de colapso progressivo. Contudo, o nível de deformações permanentes da ordem de $10^{-2}$ nos elementos da base, após cessar a excitação, aliada a sua posição atual provoca uma mudança de configuração que prejudica sua funcionalidade, de acordo com a Figura 5.26.

Figura 5.26 - Mudança de configuração da torre: (a) inicial; (b) final (aumentado 25 vezes).

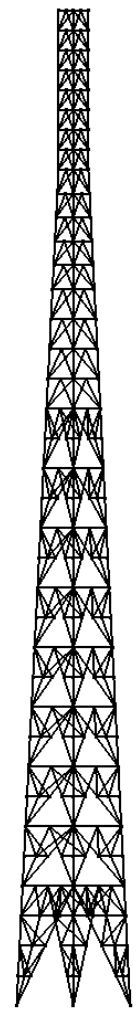

(a)

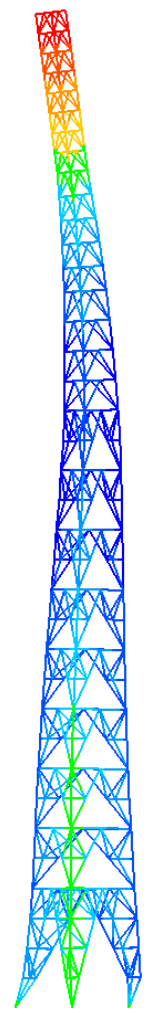

(b)

Fonte: Autor. 


\subsection{Conclusão do Capítulo}

Neste capítulo, a formulação proposta foi validada em aplicações dinâmicas. No tocante a avaliação de sistemas com um grau de liberdade, verificou-se a boa acurácia da formulação proposta em comparação à solução analítica para problemas com e sem dissipação de energia. No que concerne a análise transiente de estruturas treliçadas 2D e 3D, observou-se uma excelente convergência da solução numérica. Com relação às análises não lineares dinâmicas plásticas, averiguou-se que a introdução do comportamento elastoplástico reduziu os deslocamentos das estruturas analisadas sob ação de sismo. 
CAPÍTULO

\section{6}

10

\section{MODELO PROBABILÍSTICO}

\subsection{Generalidades}

Os modelos de engenharia são desenvolvidos com base nos fundamentos da física e da matemática sob hipóteses estabelecidas, que implicam em incertezas associadas às suas variáveis [247]. Tais modelos podem ser empregados para realizar análises determinísticas e/ou probabilísticas. Nas análises determinísticas, as incertezas nas variáveis dos modelos são desprezadas, enquanto que nas análises probabilísticas, a maioria das variáveis ou todas elas são descritas como variáveis aleatórias, gerando para elas valores de probabilidade. Nesse sentido, como as incertezas são levadas em consideração nas análises, o desenvolvimento de um modelo de engenharia utilizando análise probabilística torna-se mais apropriado [247].

A teoria de confiabilidade estrutural surgiu como uma ferramenta para manipular as incertezas de forma racional. Os documentos normativos de projeto têm sido calibrados com os fundamentos dessa teoria. Nesse contexto, os projetistas consideram implicitamente as incertezas nas variáveis de projeto através dos coeficientes parciais de segurança. Por outro lado, sob o ponto de vista de pesquisa, atualmente o que se busca é a utilização da análise de confiabilidade explicitamente nas aplicações dos procedimentos de projeto [247].

O problema fundamental da teoria de confiabilidade estrutural é a mensuração da probabilidade de falha $\left(P_{f}\right)$ definida por $[58,59]$ :

$$
P_{f}=P[g(\mathbf{v}) \leq 0]=\int_{\Omega_{f}} f_{\mathbf{v}}(\mathbf{v}) d \mathbf{v}
$$

em que, $\mathbf{v}$ é o vetor das variáveis aleatórias, que representam as incertezas, tais como, carregamentos, fatores ambientais, propriedades dos materiais, etc. As funções $g(\mathbf{v})$ e $f_{\mathbf{v}}(\mathbf{v})$ são a equação de estado limite e função conjunta de densidade de probabilidade, respectivamente, de v. 
Cada $g(\mathbf{v})$ constitui um modo de falha e representa um estado indesejável em um modelo de engenharia. A $g(\mathbf{v})$ determina a fronteira entre os domínios de falha $\left(\Omega_{f}\right)$ e não falha $\left(\Omega_{s}\right)$, conforme a Equação 6.2 [248, 249].

$$
\begin{aligned}
\Omega_{f} & =\{\mathbf{v} \mid g(\mathbf{v}) \leq 0\} \\
\Omega_{s} & =\{\mathbf{v} \mid g(\mathbf{v})>0\}
\end{aligned}
$$

Devido à dificuldade da integração multi-dimensional, a Equação 6.1 não pode ser determinada analiticamente, apenas para alguns casos individuais [58]. Nesse sentido, duas abordagens surgiram: os métodos de simulação e os métodos de transformação [59]. Dentre os métodos de simulação, são amplamente utilizados o método de simulação de Monte Carlo e o Weighted Average Simulation Method. Com relação aos métodos de transformação, o mais empregado é o First Order Reliability Method. Para maiores detalhes desses métodos recomendase os trabalhos de [58, 59, 248, 249].

\subsection{Simulação de Monte Carlo (SMC)}

A SMC é baseada na geração de números aleatórios por meio da $f_{\mathbf{v}}(\mathbf{v})$. Para cada número gerado, $g(\mathbf{v})$ é avaliado e, se $g(\mathbf{v}) \leq 0$, uma falha é contada. Portanto, introduzindo uma função indicadora $I(\mathbf{v})$, tal que $I(\mathbf{v})=1$ se $\mathbf{v} \in \Omega_{f}$, e $I(\mathbf{v})=0$ se $\mathbf{v} \in \Omega_{s}$, a Equação 6.1 é reescrita pela Equação 6.3, sendo $\Omega$ todo o domínio do problema, i.e., $\Omega=\Omega_{s}+\Omega_{f}$.

$$
P_{f}=P[g(\mathbf{v}) \leq 0]=\int_{\Omega} I(\mathbf{v}) f_{\mathbf{v}}(\mathbf{v}) d \mathbf{v} \equiv E[I(\mathbf{v})]
$$

$\mathrm{Na}$ Equação 6.3 o termo $E[I(\mathbf{v})]$ é o valor médio ou esperado da função indicadora. Como resultado, $E[I(\mathbf{v})]$ pode ser estimado por amostras de tamanho finito de números aleatórios $\left(n_{a}\right)$ [58, 59], como segue:

$$
E[I(\mathbf{v})]=P_{f} \approx \sum_{j=1}^{n_{a}} \frac{I\left(v_{j}\right)}{n_{a}}=\frac{n_{f}}{n_{a}}
$$

sendo $n_{f}$ o número de pontos pertencentes ao domínio de falha.

\subsection{Weighted Average Simulation Method (WASM)}

Em relação ao WASM, esta abordagem utiliza o conceito de índice de peso para avaliar a Equação 6.1 [248, 249]. A primeira etapa no WASM é medir os intervalos apropriados. Rashki et al. [248] apresentam dois procedimentos para selecionar esses intervalos. Em seguida, a função de distribuição uniforme de probabilidade é empregada para a geração dos números 
aleatórios para cada variável aleatória desses intervalos. Depois, o índice de peso das amostras para variáveis aleatórias estatisticamente independentes é calculado da seguinte forma:

$$
w(k)=\prod_{j=1}^{n_{v a}} f_{j}(k)
$$

sendo $w(k)$ o índice de peso das $k$ amostras, $n_{v a}$ o número de variáveis aleatórias e $f_{j}$ a função de densidade de probabilidade (PDF) da variável aleatória. Finalmente, a $P_{f}$ é determinado por:

$$
P_{f} \approx \frac{\sum_{k=1}^{n_{a}} I(k) w(k)}{\sum_{k=1}^{n_{a}} w(k)}
$$

em que $I(k)$ é a função indicadora das $k$ amostras.

\subsection{First Order Reliability Method (FORM)}

O FORM é um dos métodos de análise de confiabilidade amplamente empregados para aproximar a Equação 6.1 [58, 59]. Essa abordagem consiste em linearizar a função de estado limite em torno do ponto mais provável, também denominado de ponto de projeto. Esse é o ponto sobre o domínio de falha mais próximo à origem do espaço normal padrão. Consequentemente, a $P_{f}$ é calculada pela seguinte expressão:

$$
P_{f} \approx \Phi[-\beta]
$$

em que, $\Phi[\cdot]$ é a distribuição acumulativa normal padrão e $\beta$ o índice de confiabilidade. Torna-se evidente que o $\beta$ é uma medida geométrica da $P_{f}$, sendo definido por [58, 59]:

$$
\left\{\begin{array}{l}
\beta=\min \left[\left\|\mathbf{v}_{n p}\right\|\right]=\min \left[\sqrt{\mathbf{v}_{n p}^{t} \cdot \mathbf{v}_{n p}}\right] \\
\text { Sujeito a } g\left(\mathbf{v}_{n p}\right)=0
\end{array}\right.
$$

sendo $\mathbf{v}_{n p}$ o vetor com as variáveis no espaço normal padrão. Como se trata de um problema de otimização com restrição, a Equação 6.8 pode ser avaliada pelo algoritmo HLRF proposto por $[250,251]$.

\subsection{Validação do Modelo Probabilístico}

Nesta seção é realizada a validação do modelo probabilístico. Para tal, é utilizado o problema fundamental de confiabilidade para variáveis normais e log-normais. Ademais, é apresentada a análise de confiabilidade da treliça de von Mises considerando a não-linearidade 
física e geométrica. Em todas as análises, as soluções obtidas pelos métodos citados anteriormente são confrontadas.

\subsubsection{Problema fundamental de confiabilidade para variáveis aleatórias nor- mais}

O problema fundamental de confiabilidade para variáveis normais estatisticamente independentes e equação de estado limite linear pode ser resolvido analiticamente pela seguinte expressão:

$$
\beta=\frac{\mu_{R}-\mu_{S}}{\sqrt{\sigma_{R}^{2}+\sigma_{S}^{2}}}
$$

sendo, $\mu_{R}$ e $\mu_{S}$ a média, enquanto que $\sigma_{R}$ e $\sigma_{R}$ o desvio padrão, respectivamente, da variável de resistência $(R)$ e solicitação $(S)$.

Seja um problema com $R \sim N(4 ; 0,5)$ e $S \sim N(3 ; 0,6)$, logo, o índice de confiabilidade e a probabilidade de falha resulta:

$$
\begin{gathered}
\beta=\frac{4-3}{\sqrt{0,5^{2}+0,6^{2}}}=1,2804 \\
P_{f}=\Phi[-\beta]=\Phi[-1,2804]=0,1002 .
\end{gathered}
$$

Na Tabela 6.1 são apresentados o valor do índice de confiabilidade e probabilidade de falha para as diferentes análises. Nota-se que o resultado via FORM é exato para esse problema. Isso era esperado visto que a equação de estado limite é linear. No que diz respeito às soluções via simulação, as abordagens WASM e SMC tende à solução exata à medida que o número de simulações aumenta.

Tabela 6.1 - Comparação das soluções: variáveis normais.

\begin{tabular}{cccccc}
\hline$\ddots$ & FORM & WASM $\left(n_{a}=10^{5}\right)$ & $\operatorname{WASM}\left(n_{a}=10^{6}\right)$ & $\operatorname{SMC}\left(n_{a}=10^{5}\right)$ & $\operatorname{SMC}\left(n_{a}=10^{6}\right)$ \\
\hline \hline$\beta$ & 1,2804 & 1,2816 & 1,2809 & 1,2763 & 1,2773 \\
\hline$P_{f}$ & 0,1002 & 0,0999 & 0,1001 & 0,1009 & 0,1007 \\
\hline \multicolumn{7}{r}{ Fonte - Autor. } & & &
\end{tabular}

Empregando o software StRAnD (Structural Risk Analisys and Design) ${ }^{1}$, determina-se o valor de $\beta$ via FORM e SMC $\left(n_{a}=10^{5}\right)$. Para o FORM o $\beta=1,2804$, enquanto que para a SMC o $\beta=1,2779$. Torna-se evidente que a resposta do StRAnD por meio do FORM é igual a solução mostrada na Tabela 6.1. No que concerne a resposta do StRAnD mediante a SMC, 
observa-se uma diferença de $0,125 \%$ em comparação com a solução apresentada na Tabela 6.1 para $n_{a}=10^{5}$. Isso era previsto, em razão da geração dos números aleatórios, que depende do gerador utilizado na análise. Como o gerador usado neste trabalho é diferente do empregado no $S t R A n D$, a afirmativa anterior é verificada.

\subsubsection{Problema fundamental de confiabilidade para variáveis aleatórias log- normais}

Uma solução analítica equivalente a Equação 6.9 pode ser determinada para as variáveis $R$ e $S$ com distribuição log-normal, de acordo com a Equação 6.10 [59].

$$
\beta=\frac{\lambda_{R}-\lambda_{S}}{\sqrt{\xi_{R}^{2}+\xi_{S}^{2}}}
$$

onde, $\lambda$ e $\xi$ são os parâmetros da distribuição lognormal. Esses parâmetros são mensurados pelas seguintes equações:

$$
\begin{gathered}
\xi=\sqrt{\ln \left[1+\left(\frac{\sigma}{\mu}\right)\right]} \\
\lambda=\ln (\mu)-0,5 \cdot \xi^{2}
\end{gathered}
$$

sendo, $\mu$ e $\sigma$ a média e o desvio padrão da variável, respectivamente. Partindo das estatísticas de $R$ e $S$ do exemplo acima, obtém-se: $\lambda_{R}=1,3785 ; \xi_{R}=0,1245 ; \lambda_{S}=1,0790$ e $\xi_{S}=0,1980$. Por conseguinte, tem-se:

$$
\begin{aligned}
\beta & =\frac{1,3785-1,0790}{\sqrt{0,1245^{2}+0,1980^{2}}}=1,2805 \\
P_{f} & =\Phi[-\beta]=\Phi[-1,2805]=0,1002
\end{aligned}
$$

Na Tabela 6.2 são confrontadas as soluções do problema em estudo. Observa-se que o FORM convergiu novamente para a solução analítica. Com relação às abordagens ditas de simulação, essas também se aproximam da resposta exata. Esses exemplos demonstram que a implementação dos algoritmos desses métodos foi realizada corretamente.

Tabela 6.2 - Comparação das soluções: variáveis log-normais.

\begin{tabular}{cccccc}
\hline$\ddots$ & FORM & WASM $\left(n_{a}=10^{5}\right)$ & WASM $\left(n_{a}=10^{6}\right)$ & $\operatorname{SMC}\left(n_{a}=10^{5}\right)$ & $\operatorname{SMC}\left(n_{a}=10^{6}\right)$ \\
\hline \hline$\beta$ & 1,2805 & 1,2888 & 1,2859 & 1,2797 & 1,2763 \\
\hline$P_{f}$ & 0,1002 & 0,0987 & 0,0992 & 0,1003 & 0,1009 \\
\hline \multicolumn{7}{l}{ Fonte - Autor. } & & &
\end{tabular}




\subsubsection{Treliça de von Mises: solução analítica linear elástica}

A Figura 6.1 mostra a treliça de von Mises. As barras são constituídas de aço com seção transversal circular com raio $(r)$ igual a $5 \mathrm{~cm}$. O módulo de Young e a área da seção transversal de todas as barras são dadas por $E=20500 \mathrm{KN} / \mathrm{cm}^{2}$ e $A=78,5 \mathrm{~cm}^{2}$. As constantes são: $l_{0}=200,25 \mathrm{~cm}, x_{0}=200 \mathrm{~cm}$ e $y_{0}=10 \mathrm{~cm}$.

Figura 6.1 - Treliça de von Mises: (a) geometria; (b) relação constitutiva.

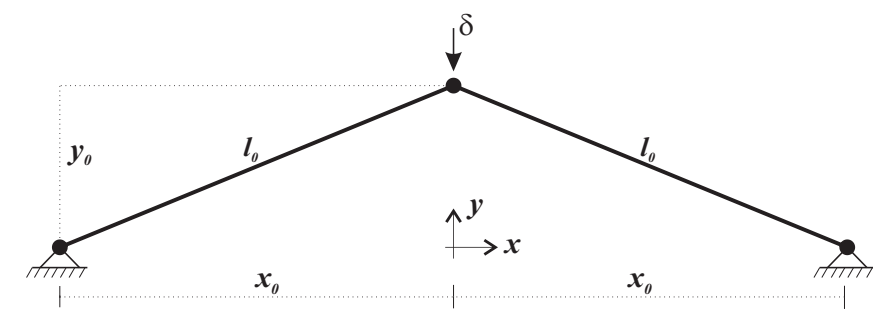

(a)

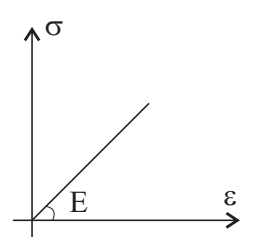

(b)

Fonte: Autor.

A solução analítica para este exemplo, geometricamente linear, é obtida pelo equilíbrio na configuração inicial. Por conseguinte, a força normal nas barras $(N)$, assumindo o comportamento do material elástico linear, é dada por:

$$
N=-\frac{\delta E A}{l_{0}} \operatorname{sen}\left[\tan ^{-1}\left(\frac{y_{0}}{x_{0}}\right)\right]
$$

sendo $\delta$ o deslocamento aplicado no nó central da treliça.

Como o comportamento do material é linearmente elástico, e as barras estão sob compressão, o estado limite nessa treliça é a carga de flambagem de Euler, como segue:

$$
g\left(E, A, r, l_{0}, x_{0}, y_{0}\right)=\frac{\pi^{3} E r^{4}}{4 l_{0}^{2}}-\frac{\delta E A}{l_{0}} \operatorname{sen}\left[\tan ^{-1}\left(\frac{y_{0}}{x_{0}}\right)\right]
$$

A Tabela 6.3 apresenta as estatísticas para a análise de confiabilidade. A Figura 6.2 mostra a curva $P_{f} v s$. deslocamento obtida mediante o FORM, SMC e WASM. O índice $n_{a}$ indica o tamanho da amostra utilizado nos métodos de simulação. 
Tabela 6.3 - Estatísticas das variáveis aleatórias da treliça de von Mises.

\begin{tabular}{ccccc}
\hline variável & média & coeficiente de variação & PDF & referência \\
\hline \hline$E$ & $1,00 E$ & 0,03 & lognormal & {$[252]$} \\
\hline$\sigma_{y}$ & $1,00 \sigma_{y}$ & 0,07 & lognormal & {$[252]$} \\
\hline$A$ & $1,01 A$ & 0,04 & normal & {$[252]$} \\
\hline$l_{0}$ & $1,00 l_{0}$ & 0,02 & normal & {$[253]$} \\
\hline$r$ & $1,00 r$ & 0,02 & normal & {$[253]$} \\
\hline$x_{0}$ & $1,00 x_{0}$ & 0,02 & normal & {$[253]$} \\
\hline$y_{0}$ & $1,00 y_{0}$ & 0,02 & normal & {$[253]$} \\
\hline
\end{tabular}

Fonte - Autor.

Observe que usar o WASM com $n_{a}$ igual a $10^{4}$ ou $10^{5}$, a solução vibra em torno dos resultados atingidos pelo FORM e SMC, de acordo com a Figura 6.2. Portanto, a premissa de que o WASM pode ser usado com poucas amostras não é verificada nesse exemplo. Por outro lado, o WASM consegue avaliar pequenos valores de $P_{f}$. Nota-se que, para um deslocamento aproximadamente igual a $6 \mathrm{~cm}$, a treliça de von Mises apresenta uma $P_{f}=0,50$, que é um valor muito alto. Considerando custo relativo normal para as medidas de segurança e consequências moderadas de falha, o valor da confiabilidade alvo para o estado limite último é igual a 4,2 $\left(P_{f} \approx 10^{-5}\right)$ conforme [252]. Por conseguinte, assumindo esse valor de confiabilidade alvo, observa-se que o deslocamento máximo que a treliça de von Mises resiste em uma análise elástica linear é igual a $4 \mathrm{~cm}$, em conformidade com a Figura 6.2.

Figura 6.2 - Curva $P_{f} v s$. deslocamento vertical do nó central: solução linear elástica.

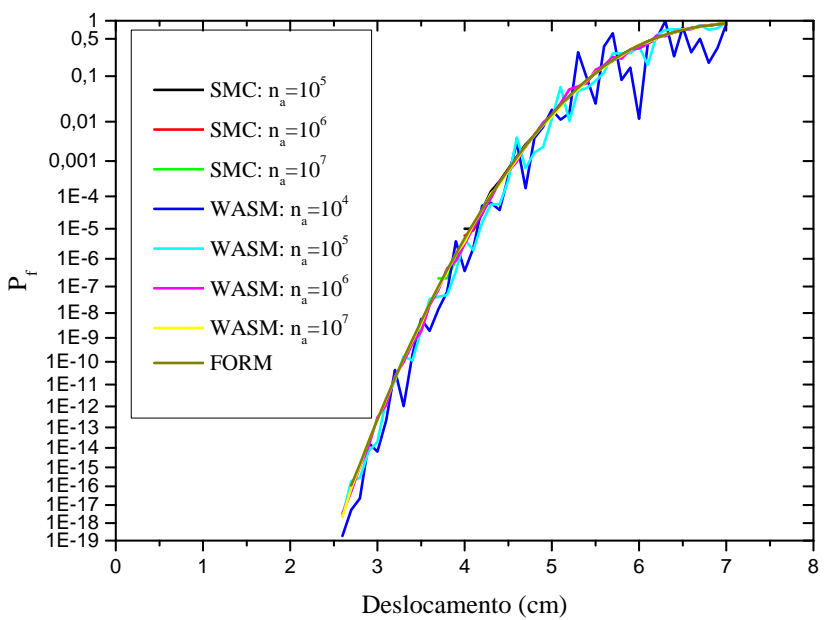

Fonte: Autor. 


\subsubsection{Treliça de von Mises: solução analítica não linear elástica}

Nesta seção é avaliada apenas a não linearidade geométrica. O comportamento do material é assumido como elástico linear, conforme ilustrado na Figura 6.3. Os dados de entrada de geometria e material são iguais ao exemplo anterior. Cem passos de carga de 0,22 cm são aplicados no nó central.

A solução analítica para esse exemplo é encontrada pelo equilíbrio na configuração atual, que é dada pela Equação 6.15.

$$
N=-2 E A\left\{1-\frac{\cos \left[\tan ^{-1}\left(\frac{y_{0}}{x_{0}}\right)\right]}{\cos \left[\tan ^{-1}\left(\frac{y_{0}-\delta}{x_{0}}\right)\right]}\right\} \operatorname{sen}\left[\tan ^{-1}\left(\frac{y_{0}-\delta}{x_{0}}\right)\right]
$$

A Figura 6.3 mostra a solução analítica e numérica para a treliça de von Mises. Observe que a resposta numérica via formulação proposta é muito próxima da solução analítica exata.

Figura 6.3 - Curva força vs. deslocamento vertical do nó central da treliça.

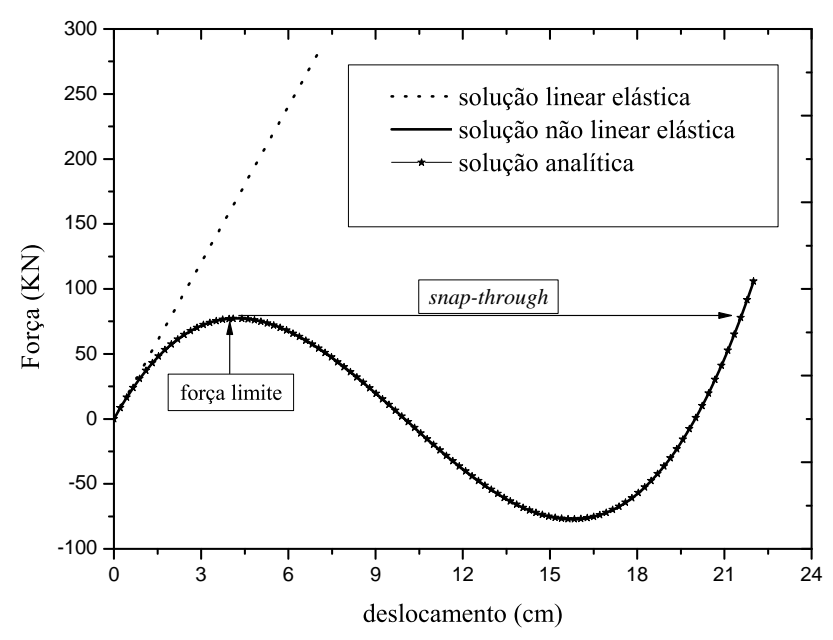

Fonte: Autor.

Para a solução elástica não linear, a força máxima que a treliça de von Mises suporta em um regime estável de equilíbrio estático é igual a 77,17 KN, de acordo com a Figura 6.3. Para essa força, o determinante da matriz Hessiana (Equação 3.82) é nulo. Consequentemente, a função do estado limite pode ser escrita pela Equação 6.16.

$$
g\left(E, A, x_{0}, y_{0}\right)=77,17-2 E A\left\{1-\frac{\cos \left[\tan ^{-1}\left(\frac{y_{0}}{x_{0}}\right)\right]}{\cos \left[\tan ^{-1}\left(\frac{y_{0}-\delta}{x_{0}}\right)\right]}\right\} \operatorname{sen}\left[\tan ^{-1}\left(\frac{y_{0}-\delta}{x_{0}}\right)\right]
$$


Para a análise de confiabilidade, as estatísticas estão representadas na Tabela 6.3. A Figura 6.4 apresenta a curva $P_{f} v s$. deslocamento para a solução elástica não linear. Note que o WASM com $n_{a}=10^{4}$ também mostra uma vibração em torno das respostas obtidas via FORM e SMC. Observe que para um nível de deslocamento igual a $4 \mathrm{~cm}$ a $P_{f}=0,5$. Este valor de $P_{f}$ em uma solução elástica linear é alcançado apenas para um deslocamento igual a $6 \mathrm{~cm}$, conforme ilustrado na Figura 6.2. Torna-se evidente que a análise geometricamente não linear é importante porque captura a força limite que leva à falha da treliça de von Mises. Assim, considerando o valor de confiabilidade alvo de acordo com o [252], o deslocamento máximo que pode ser aplicado a treliça de von Mises em solução elástica não linear é igual a 1,8 cm, conforme ilustrado na Figura 6.4.

Figura 6.4 - Curva $P_{f} v s$. deslocamento vertical do nó central: solução não linear elástica.

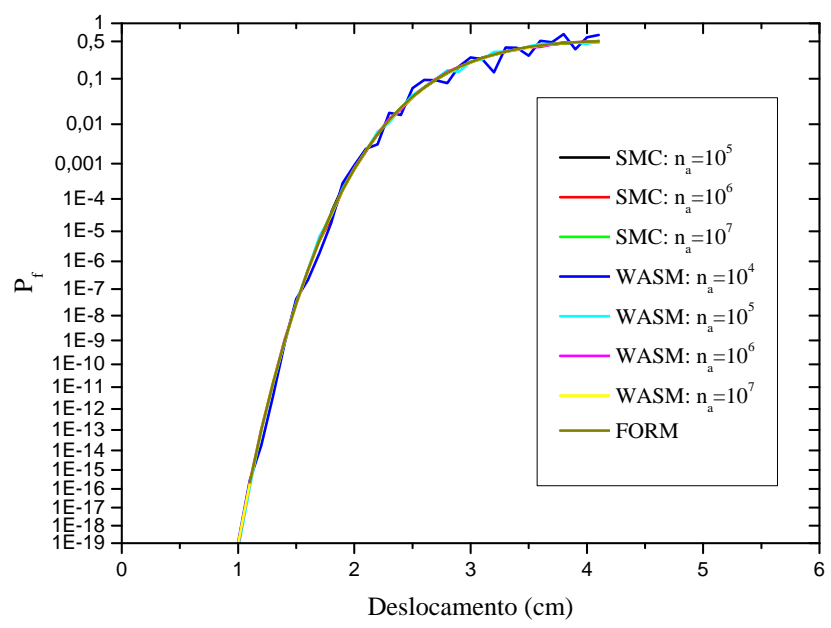

Fonte: Autor.

\subsubsection{Treliça de von Mises: solução analítica não linear plástica}

Este exemplo apresenta a solução plástica não linear da treliça de von Mises. Os dados de entrada de geometria e material são apresentados na Figura 6.5. Para cada barra as constantes são: $E=20500 \mathrm{KN} / \mathrm{cm}^{2}, A=78,5 \mathrm{~cm}^{2}$ e $\sigma_{y}=10 \mathrm{KN} / \mathrm{cm}^{2}$. Quatrocentos passos de carga de $0,055 \mathrm{~cm}$ são aplicados no nó central.

A Figura 6.6 ilustra a solução numérica obtida a partir da formulação proposta em relação à não linearidade geométrica e física. Veja como a inclinação das curvas se altera para as diferentes soluções. A força limite agora é igual a $61,21 \mathrm{KN}$. Este valor é $26 \%$ menor do que a força limite calculada pela solução elástica não linear. 
Figura 6.5 - Treliça de von Mises: (a) geometria; (b) relação constitutiva.

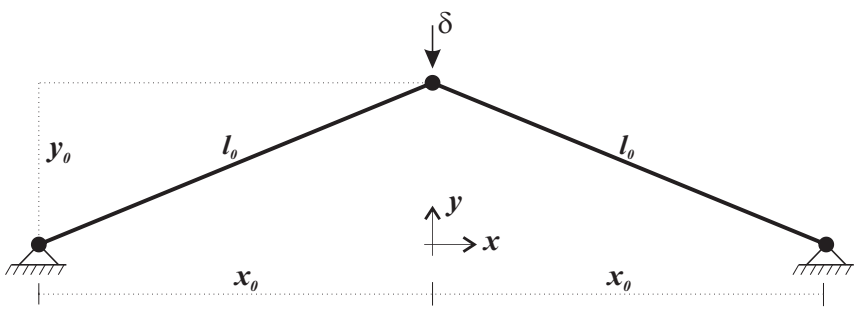

(a)

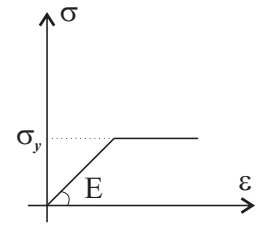

(b)

Fonte: Autor.

Figura 6.6 - Curva força vs. deslocamento vertical do nó central da treliça.

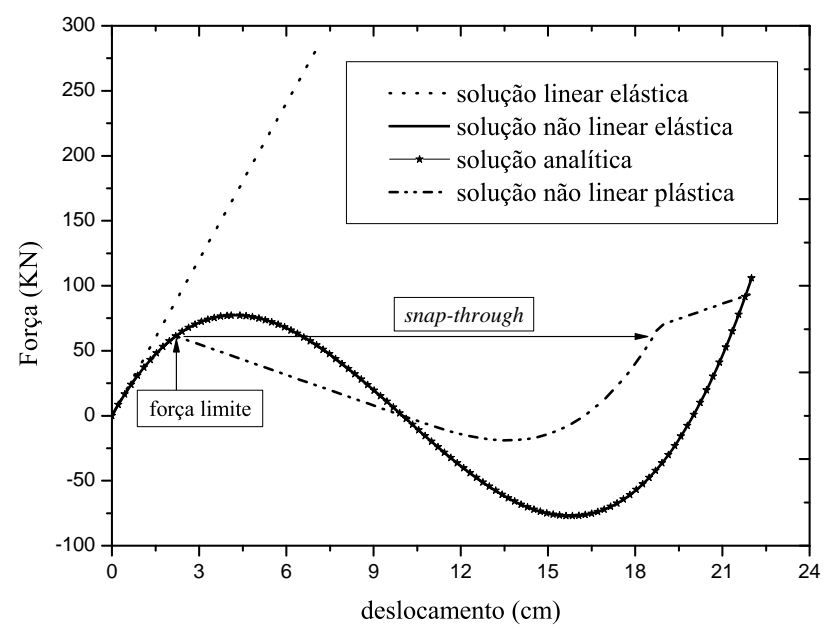

Fonte: Autor.

A função de estado limite é dada agora pela Equação 6.17.

$$
g\left(E, A, x_{0}, y_{0}\right)=61,21-2 E A\left\{1-\frac{\cos \left[\tan ^{-1}\left(\frac{y_{0}}{x_{0}}\right)\right]}{\cos \left[\tan ^{-1}\left(\frac{y_{0}-\delta}{x_{0}}\right)\right]}\right\} \operatorname{sen}\left[\tan ^{-1}\left(\frac{y_{0}-\delta}{x_{0}}\right)\right]
$$

Para caminhar com este exemplo, as estatísticas são mostradas na Tabela 6.3. A Figura 6.7 mostra a curva $P_{f} v s$. deslocamento para a solução plástica não linear. Como observado assumindo o comportamento do material como sendo elastoplástico ocorre o aumento da $P_{f}$. Note que para o mesmo valor de $P_{f}$, o deslocamento aplicado é menor que a resposta elástica não linear. Para um nível de deslocamento igual a $2,2 \mathrm{~cm}$ a $P_{f}=0,5$. Além disso, para o valor 
de confiabilidade alvo de acordo com o [252], o deslocamento máximo que pode ser aplicado nessa treliça é igual a $1,25 \mathrm{~cm}$.

Figura 6.7 - Curva $P_{f} v s$. deslocamento vertical do nó central: solução não linear plástica.

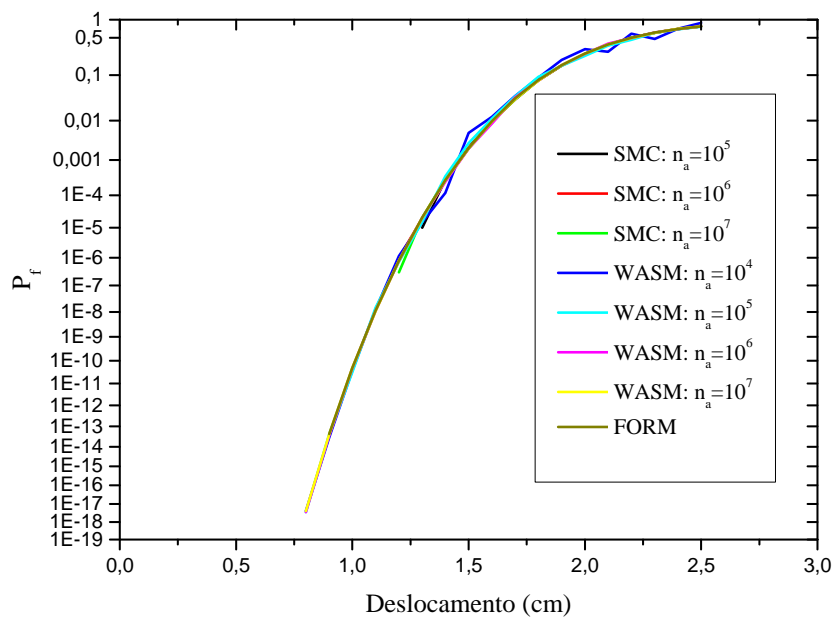

Fonte: Autor.

Figura 6.8 - Comparativos das soluções via FORM.

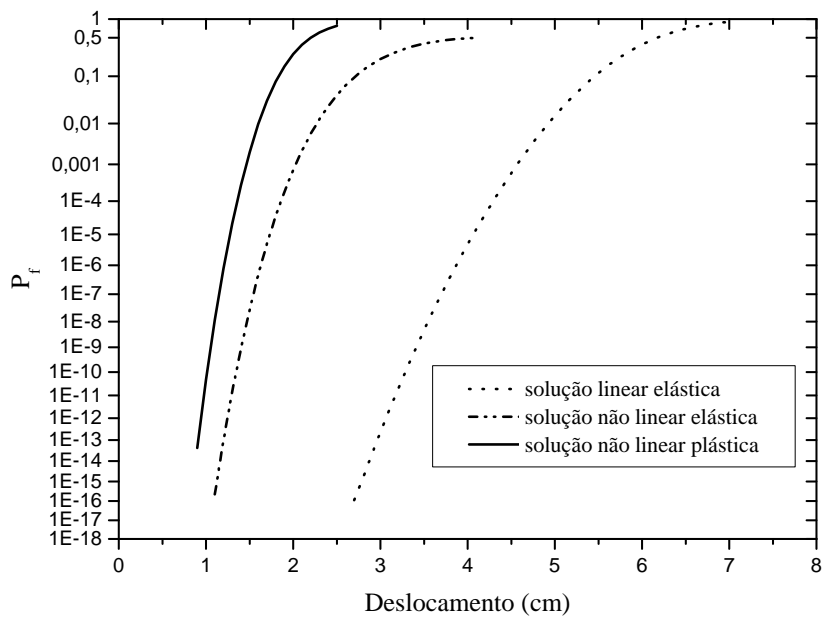

Fonte: Autor.

A Figura 6.8 resume a convergência das soluções pelo FORM. Observe a modificação da inclinação das curvas. Ademais, a taxa de crescimento da solução plástica não linear é maior do 
que as outras soluções. Como observado a linearidade física e geométrica está longe de ser a resposta real para a treliça de von Mises.

\subsection{Conclusão do Capítulo}

Neste capítulo, o modelo probabilístico foi validado. Verificou-se que para o problema fundamental de confiabilidade com variáveis normais ou lognormais, a solução via FORM converge para a solução analítica exata. No que concerne à análise de confiabilidade da treliça de von Mises, foi verificada em todos os seus aspectos: análise elástica linear, análise elástica não linear e análise plástica não linear. Essas análises foram realizadas empregando o FORM, SMC e WASM. Observou-se que o WASM para um pequeno número de simulação vibra em torno das respostas obtidas utilizando o FORM e SMC. Finalmente, verificou-se que a probabilidade de falha aumentou à medida que a solução da treliça de von Mises foi refinada por meio da consideração da não-linearidade física e geométrica. A Figura 6.9 apresenta o algoritmo do modelo mecano-probabístico que será empregado no Capítulo 7.

Figura 6.9 - Algoritmo do modelo mecano-probabilístico.

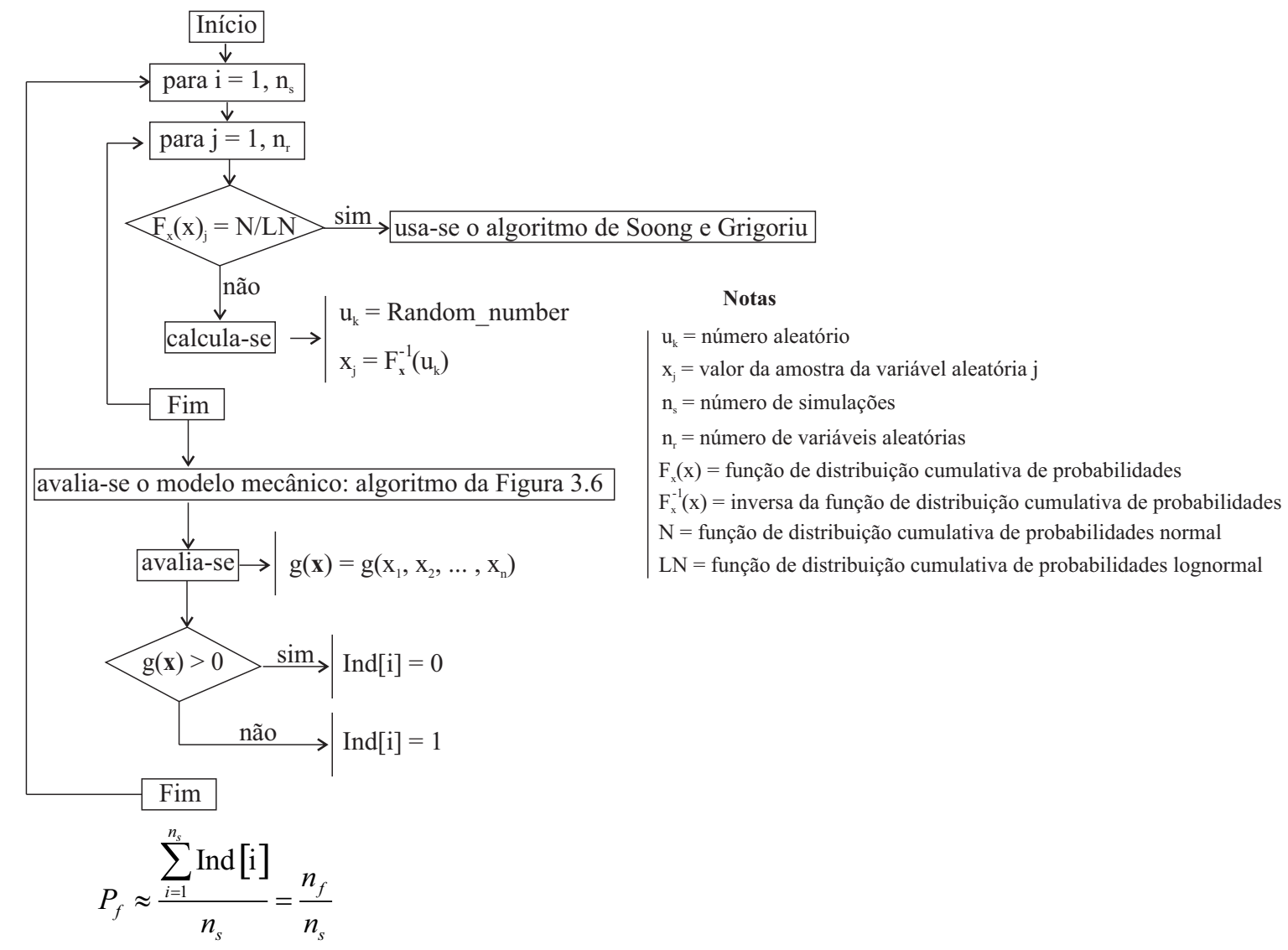

Fonte: Autor. 
CAPÍTULO

\section{7}

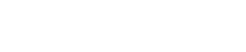

\section{VALIDAÇÃO DO MODELO MECANO-PROBABILÍSTICO}

\subsection{Aplicações}

Neste capítulo é realizada a validação do modelo mecano-probabilístico. Para tal, o modelo mecânico proposto é acoplado ao modelo probabilístico. Nas análises de confiabilidade que seguem, emprega-se o método de Simulação de Monte Carlo (SMC) com $10^{6}$ amostras e as estatísticas apresentadas na Tabela 6.3. Inicialmente, é concretizada a avaliação da treliça de von Mises com as variáveis aleatórias independentes do tempo. A solução numérica é confrontada com a solução analítica apresentada no Capítulo 6. Em seguida, é analisado um problema Load-path dependency. Por fim, é avaliado um problema dinâmico não linear com a solicitação definida por meio de um processo estocástico.

\subsection{Avaliação da Treliça de von Mises para Análise de Confi- abilidade Independente do Tempo}

Para demonstrar a acurácia da formulação proposta, a treliça de von Mises é avaliada numericamente. Dessa forma, a equação de estado limite para a solução linear elástica é dada pela carga crítica de Euler, de acordo com a seguinte expressão:

$$
g\left(E, x_{0}, y_{0}, r, \boldsymbol{\delta}\right)=\frac{\pi^{3} E r^{4}}{4\left(x_{0}^{2}+y_{0}^{2}\right)}-N_{\text {num }}\left(E, x_{0}, y_{0}, r, \boldsymbol{\delta}\right)
$$

onde $N_{\text {num }}$ é a força normal nas barras calculada pela formulação proposta, sendo função das variáveis aleatórias do problema, bem como do nível de deslocamento imposto $(\delta)$.

Na Figura 7.1 é apresentada a curva $P_{f} v s$. deslocamento para a análise linear elástica. 
Note que a solução numérica converge para a solução analítica. Como o modo de falha dessa análise é a carga crítica de Euler, que é determinada na configuração inicial, a força normal via resposta numérica é igual a força normal calculada pela resposta analítica. Por consequência, a $P_{f}$ é idêntica em ambas as soluções.

Figura $7.1-P_{f} v s$. deslocamento: comparativo entre as soluções pelo SMC, análise linear elástica.

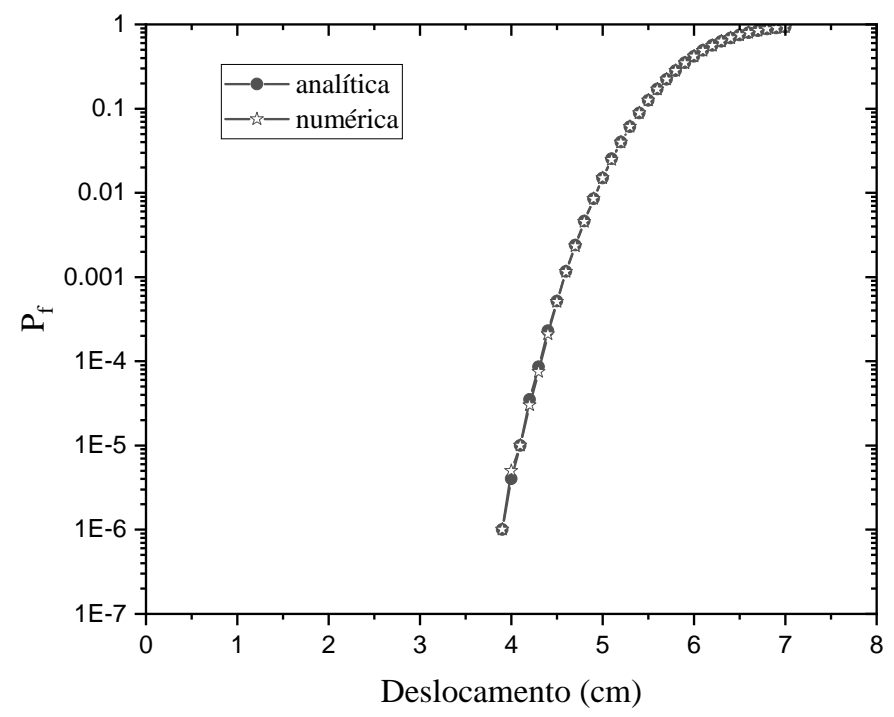

Fonte: Autor.

Para a solução não linear elástica a equação de estado limite calculada via formulação proposta é escrita conforme a Equação 7.2:

$$
g\left(E, x_{0}, y_{0}, r, \boldsymbol{\delta}\right)=F_{\text {lim }}-N_{\text {num }}\left(E, x_{0}, y_{0}, r, \boldsymbol{\delta}\right)
$$

onde $F_{\text {lim }}$ é a força limite, que conduz a perda de instabilidade da estrutura, sendo avaliada na mudança de configuração que leva o determinante da matriz Hessiana ser igual a zero.

Na Figura 7.2 mostra-se a curva $P_{f} v s$. deslocamento para a análise não linear elástica. Observa-se que a resposta numérica converge para a resposta analítica até o deslocamento de 3,5 $\mathrm{cm}$. No intervalo entre 3,5 até 4,1 $\mathrm{cm}$ houve um aumento de $1 \%$ na $P_{f}$ da solução numérica em relação a solução analítica. Isso ocorreu porque a medida de deformação utilizada na formulação proposta é a logarítmica, também denominada de real. Por outro lado, a medida de deformação empregada na solução analítica é a longitudinal de engenharia. Como essas medidas divergem no regime de deslocamentos moderados e/ou grandes, acarreta valor de força normal diferente. Como resultado, a $P_{f}$ é distinta para essas soluções. 
Figura $7.2-P_{f} v s$. deslocamento: comparativo entre as soluções pelo SMC, análise não linear elástica.

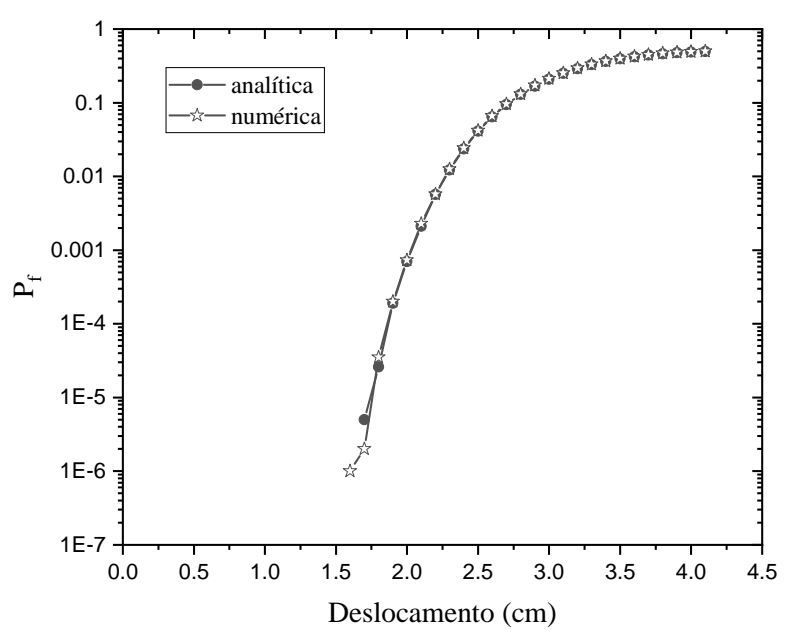

Fonte: Autor.

Uma outra forma de avaliar esse problema é escrever a Equação 7.2 em função do deslocamento, que resulta:

$$
g(\vec{X})=\delta_{\text {lim }}-\delta_{\text {num }}(\vec{X})=1-\frac{\delta_{\text {num }}(\vec{X})}{\delta_{\text {lim }}}
$$

sendo $\delta_{\text {lim }}$ o deslocamento limite que conduz o snap-through da estrutura e $\delta_{\text {num }}$ o deslocamento no nó obtido numericamente na direção considerada.

A Figura 7.3 mostra uma análise comparativa entre as soluções para os diferentes modos de falhas que podem ocorrer na treliça de von Mises: (i) carga crítica de Euler (Equação 7.1), (ii) força limite (Equação 7.2) e (iii) deslocamento limite (Equação 7.3). Ademais, a equação de estado limite do sistema foi definida como sendo o mínimo das outras equações. Esta hipótese é confirmada uma vez que a estrutura é isostática, configurando um sistema em série. Note que o modo de falha da carga crítica de Euler para esse nível de deslocamento não influencia essa estrutura, pois durante o processo de carregamento a probabilidade de falha é nula. A solução via Equação 7.3 é contra a segurança, porque não captura os valores de probabilidade em regime de pequenos deslocamentos, de acordo com a Figura 7.3. Para um nível de deslocamento igual a 3,5 cm ocorre o colapso da treliça de von Mises, visto que a probabilidade de falha é aproximadamente igual a unidade. 
Figura $7.3-P_{f} v s$. deslocamento: comparativo entre os modos de falha pelo SMC.

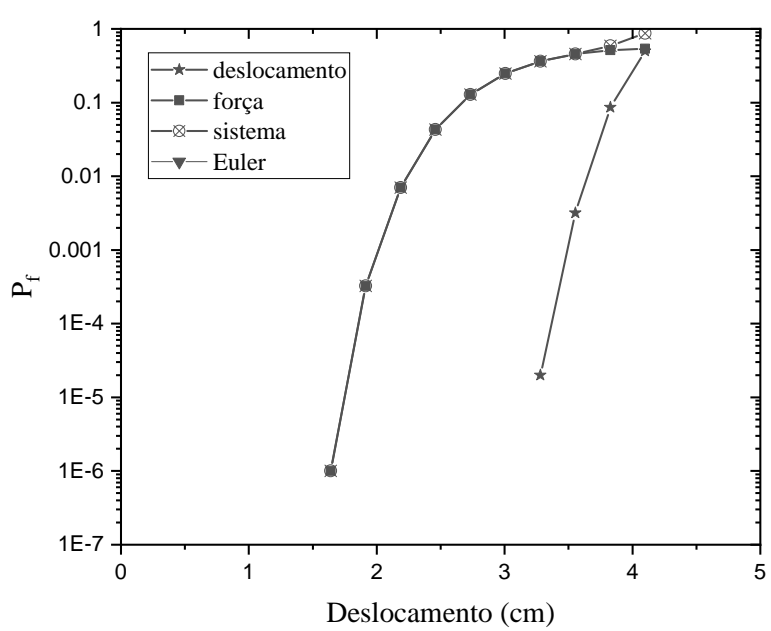

Fonte: Autor.

No que concerne a solução não linear plástica, empregando a Equação 7.2, a solução numérica é apresentada na Figura 7.4. Torna-se evidente a boa convergência da solução numérica em comparação à resposta analítica.

Figura $7.4-P_{f} v s$. deslocamento: comparativo entre as soluções pelo SMC, análise não linear plástica.

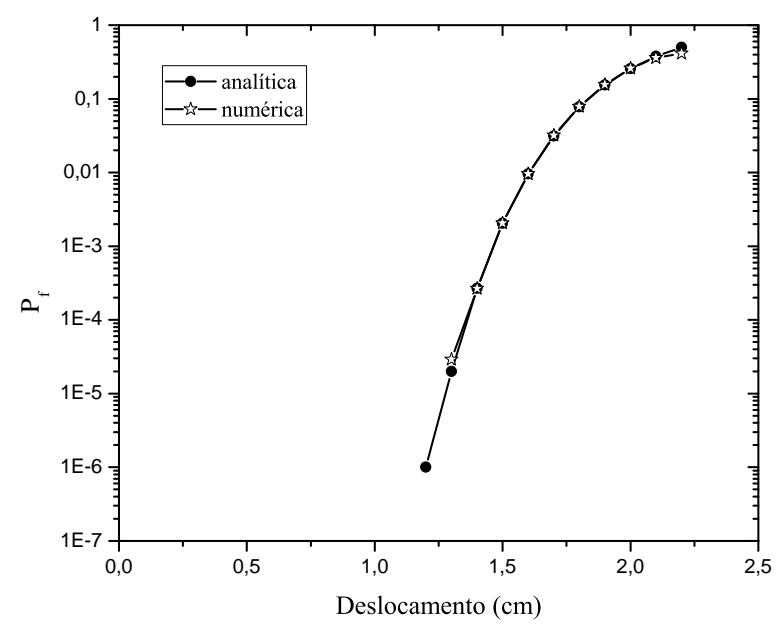

Fonte: Autor.

Com relação às deformações plásticas, a equação de estado limite pode ser escrita 
conforme a seguinte expressão:

$$
g(\vec{X})=\varepsilon_{y}-\varepsilon_{l n}(\vec{X})=1-\frac{\varepsilon_{l n}(\vec{X})}{\varepsilon_{y}}
$$

onde $\varepsilon_{y}$ é a deformação de escoamento, enquanto $\varepsilon_{l n}$ a deformação logarítmica calculada pela formulação proposta.

A Figura 7.5 resume as soluções dos diferentes modos de falhas. Quatro equações de estado limite foram avaliadas: $(i)$ deslocamento limite; (ii) força limite; (iii) deformação plástica; e $(i v)$ confiabilidade do sistema. Esta foi definida como o valor mínimo das outras. Para um nível de deslocamento de $1,32 \mathrm{~cm}$ a probabilidade de falha para esses modos de falha é respectivamente, $7 \cdot 10^{-6} ; 6,1 \cdot 10^{-5} ; 0 ;$ e $6,8 \cdot 10^{-5}$. Como o critério de plastificação não foi atingido, logo, não aparece deformação plástica nos elementos, por conseguinte, a probabilidade de falha por deformação plástica é nula. Por outro lado, o nível de esforço normal aproxima-se da força limite. Isso implica em um valor de probabilidade de falha da ordem de grandeza que conduz consequências moderadas de falha para a estrutura, de acordo com as prescrições do JCSS [252]. Quando o processo de carregamento atinge o deslocamento de 1,76 cm o critério de plastificação é atingido, consequentemente, a probabilidade de falha devido a deformação plástica é igual a $8 \cdot 10^{-6}$. Em contrapartida, a probabilidade de falha do deslocamento limite, força limite e confiabilidade do sistema é 0,014, 0,070 e 0,084, nesta ordem. Nesse nível de deslocamento a estrutura está na iminência do colapso, pois uma pequena variação no deslocamento aplicado conduz um salto da probabilidade de falha para 50\%. Neste exemplo, o modo de falha de deformação plástica não teve contribuição significativa na probabilidade de falha do sistema.

Figura $7.5-P_{f} v s$. deslocamento: comparativo entre os modos de falha pelo SMC.

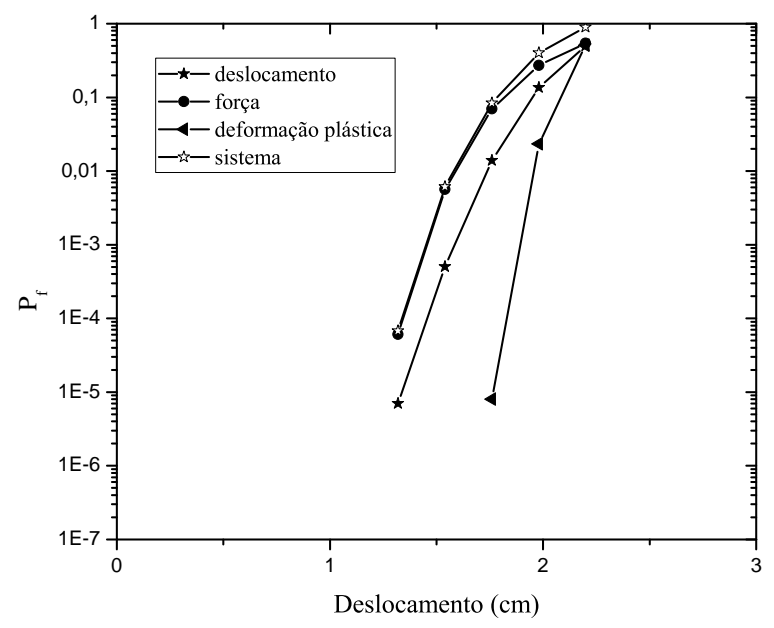

Fonte: Autor. 


\subsection{Validação da SMC para Análise de Confiabilidade De- pendente do Tempo}

Nesta seção é apresentada, a análise de uma estrutura hipotética sujeita a um carregamento estocástico. O intuito é validar a implementação da Simulação de Monte Carlo (SMC) na avaliação de problemas em que a solicitação é descrita por um processo estocástico. Essa abordagem será aplicada nas estruturas analisadas nas seções a seguir. Maiores detalhes sobre processos estocásticos, confiabilidade dependente do tempo e SMC podem ser vistos nos trabalhos de Melchers \& Beck [58] e Beck [59].

A solução analítica desse exemplo é discutida no livro de Beck [59]. O problema consiste em uma estrutura submetida a uma sequência de pulsos independentes descritos por meio do Processo de Borges. A análise é realizada com discretização a cada ano. A variável de resistência $(R)$ possui distribuição normal com os seguintes parâmetros $N\left(\mu_{R} ; \sigma_{R}\right)=N(5 ; 0,5)$, enquanto a solicitação $(S)$ segue uma distribuição normal com $N\left(\mu_{S} ; \sigma_{S}\right)=N(1 ; 1)$.

Figura 7.6 - Evolução da probabilidade de falha com o tempo.

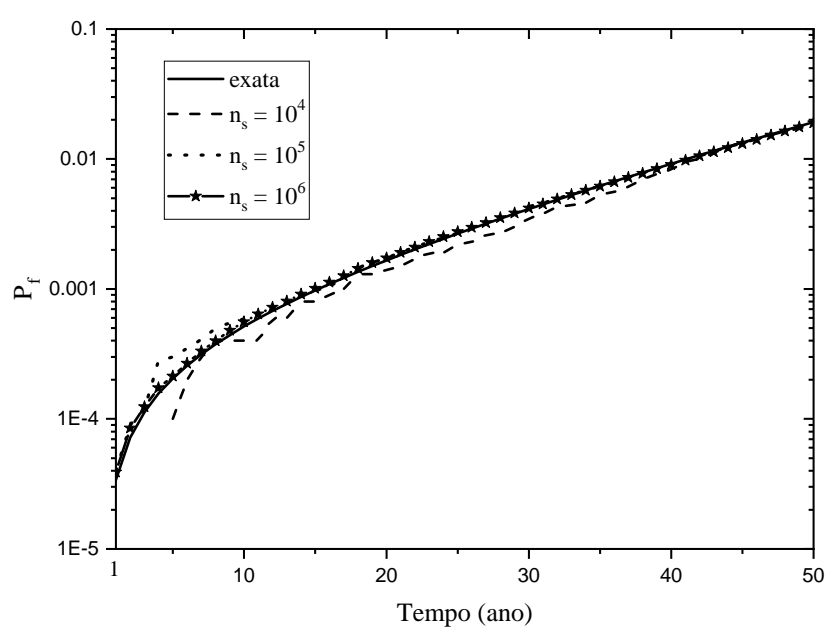

Fonte: Autor.

A Figura 7.6 apresenta a evolução da probabilidade de falha com o tempo. A avaliação foi concretizada para uma vida de projeto de 50 anos. Para o número de simulação $\left(n_{s}\right)$ igual a $10^{4}$, nota-se que a solução numérica não captura a $P_{f}$ nos primeiros quatro anos. Ademais, no intervalo de 10 até 40 anos o resultado da resposta numérica sofre uma pequena discrepância em comparação a solução analítica exata. Infere-se que para $n_{s}=10^{6}$ a resposta numérica converge para a solução analítica. Como a SMC depende do $n_{s}$, consequentemente, a medida que $n_{s}$ aumenta a solução tende a resposta analítica, conforme observa-se na Figura 7.6. 


\subsection{Dependência do Caminho dos Carregamentos}

Nesta seção é avaliado um problema com dependência do caminho de carregamento. Para tal, a treliça de von Mises é submetida a dois processos estocásticos. As barras têm comprimento $l_{0}=1 \mathrm{~m}$, seção transversal com raio $r_{1}=4,3 \mathrm{~mm}$ e $r_{2}=8,6 \mathrm{~mm}$, respectivamente para a barra 1 e barra 2, conforme ilustrado na Figura 6.1. As forças $H(t)$ e $V(t)$ são aplicadas no nó central, sendo a primeira aplicada na direção positivo do eixo $x$, enquanto a segunda na direção negativa do eixo $y$. Essas forças são descritas por um processo Gaussiano com coeficiente de variação (cov) de 0,2 e média $H(t)=2000 \mathrm{~N}$ e $V(t)=1000 \mathrm{~N}$. O processo estocástico é gerado por meio do Processo de Borges, com discretização do tempo a cada ano.

No que concerne as variáveis de resistência, são consideradas independentes do tempo e são descritas por uma distribuição normal com as seguintes estatísticas: módulo de elasticidade $E=70 \mathrm{GPa}$ e $\operatorname{cov}_{E}=0,03$ e tensão de ruptura $\sigma_{u}=24,56 \mathrm{MPa}$ e $\operatorname{cov}_{\sigma_{u}}=0,10$. Três modos de falhas são assumidos: $(i)$ ruptura por tração da barra 1; (ii) carga crítica de Euler da barra 1; e (iii) carga crítica de Euler da barra 2. As equações de estado limite dos referidos modos de falha são expressos pela Equação 7.5, Equação 7.6 e Equação 7.7, nesta ordem. A probabilidade de falha do sistema é avaliada pela Equação 7.8.

$$
\begin{gathered}
g_{\text {ruptura }}(\vec{X}, t)=A \sigma_{u}-\frac{\sqrt{2}}{2}[H(t)-V(t)] \\
g_{\text {Euler } 1}(\vec{X}, t)=\frac{\pi^{3} E r_{1}^{4}}{4\left(x_{0}^{2}+y_{0}^{2}\right)}-\frac{\sqrt{2}}{2}[-H(t)+V(t)] \\
g_{\text {Euler } 2}(\vec{X}, t)=\frac{\pi^{3} E r_{2}^{4}}{4\left(x_{0}^{2}+y_{0}^{2}\right)}-\frac{\sqrt{2}}{2}[H(t)+V(t)] \\
g_{\text {sistema }}(\vec{X}, t)=\min \left[g_{\text {ruptura }}(\vec{X}), g_{\text {Euler } 1}(\vec{X}), g_{\text {Euler } 2}(\vec{X})\right]
\end{gathered}
$$

A Figura 7.7 ilustra três caminhos de falhas dessa treliça. Considere que no instante $t$ as forças $H(t)$ e $V(t)$ estão no ponto A e em um instante $t+\Delta t$, estão no ponto B. Se as forças seguem a trajetória $\mathrm{ABC}$ (caminho 1), a treliça colapsa por instabilidade da barra 2. Caso as forças percorram a trajetória $\mathrm{ADC}$ (caminho 2), a estrutura colapsa por ruptura da barra 1. Em contrapartida, na hipótese das forças percorrerem o caminho 3, o ponto B é alcançado com segurança. Nota-se que a treliça pode colapsar por meio de modos de falhas distintos em intervalos de tempo diferentes. Esse fenômeno é conhecido na literatura de confiabilidade estrutural por load-path dependency [58]. A Figura 7.8 resume a evolução da probabilidade de falha com o tempo. Constata-se que a carga crítica de Euler é o modo de falha dominante para essa estrutura. Isso era esperado, pois a análise foi concretizada no regime elástico linear. 
Todavia, na análise não linear, o modo de falha preponderante é o snap-through, conforme será demonstrado na seção a seguir.

Figura 7.7 - Caminhos de carregamentos.

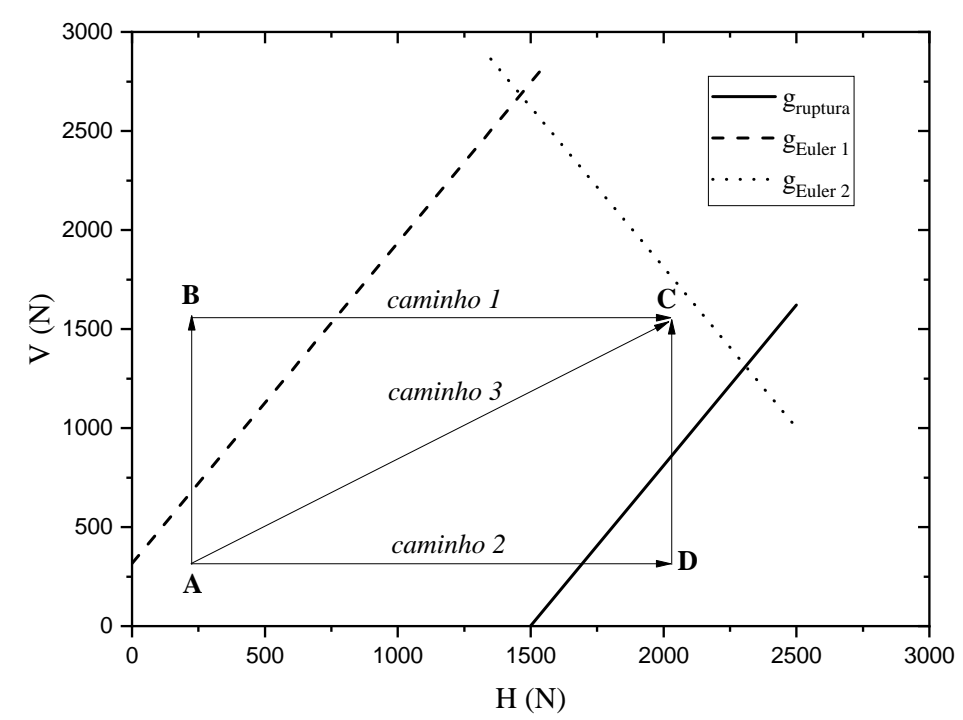

Fonte: Autor.

Figura 7.8 - Evolução da $P_{f}$ com o tempo.

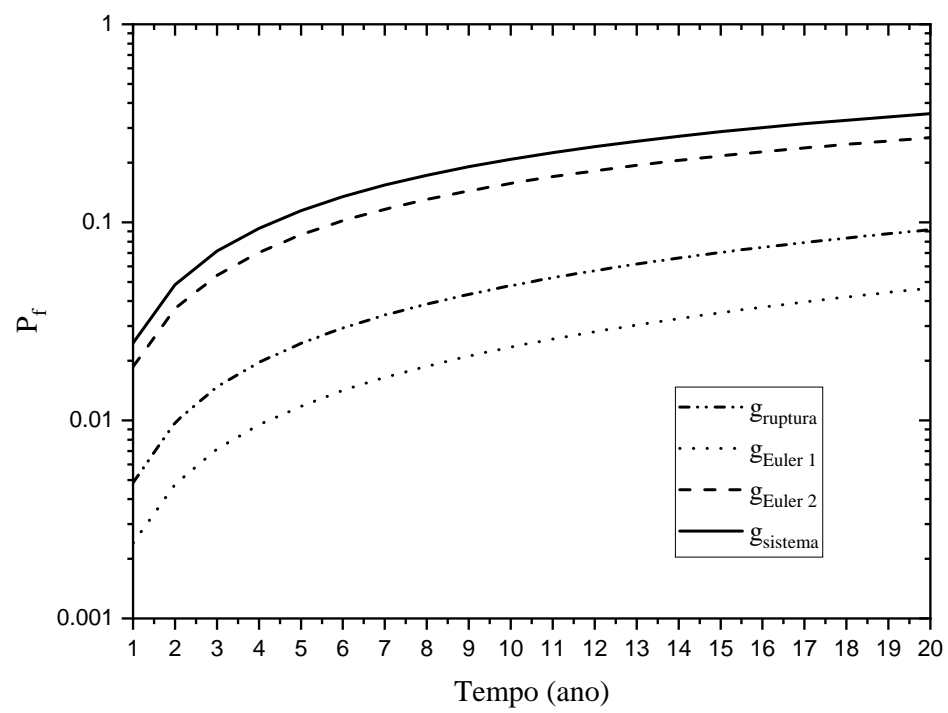

Fonte: Autor. 


\subsection{Análise Dinâmica não Linear da Treliça de von Mises com Solicitação Dependente do Tempo}

A Figura 7.9 ilustra a treliça de von Mises sob dois processos de carregamento estocásticos. A estrutura é dimensionada de acordo com as prescrições da ABNT NBR 8800 [144] a partir de um deslocamento de projeto $\left(\boldsymbol{\delta}_{\text {projeto }}\right)$ no regime elástico linear, em concordância com a Figura 7.10. As barras são compostas de aço ASTM A36 com módulo de elasticidade $(E)$ igual $20500 \mathrm{KN} / \mathrm{cm}^{2}$ e tensão de escoamento $\left(\sigma_{y}\right)$ igual a $25 \mathrm{kN} / \mathrm{cm}^{2}$. A seção transversal dos elementos estruturais é circular com raio $(r)$ de $5 \mathrm{~cm}$. As constantes são: $l_{0}=200,25 \mathrm{~cm}$; $x_{0}=200 \mathrm{~cm} ; y_{0}=10 \mathrm{~cm} ; \xi=0,01 ; \omega_{n}=180,2 \mathrm{~Hz} ; \beta_{n}=0,25 ; \gamma_{n}=0,50$ e $\Delta t=0,007 \mathrm{~s}$. A Tabela 6.3 apresenta as estatísticas dessas variáveis aleatórias. Os deslocamentos $\delta_{h o r}(t)$ e $\delta_{v e r}(t)$ são definidos por uma distribuição de Gumbel tipo 1 com $\operatorname{cov}=0,1$ e média igual a 0,1 e 1 $\mathrm{cm}$, respectivamente. Seus parâmetros são avaliados em concordância com a teoria de valores extremos. Tal teoria é empregada para calcular o máximo característico a cada passo de tempo no decorrer da análise, conforme a metodologia proposta por Tessari [245]. Neste exemplo a não linearidade física e geométrica são consideradas.

Figura 7.9 - Geometria e lei constitutiva da treliça.

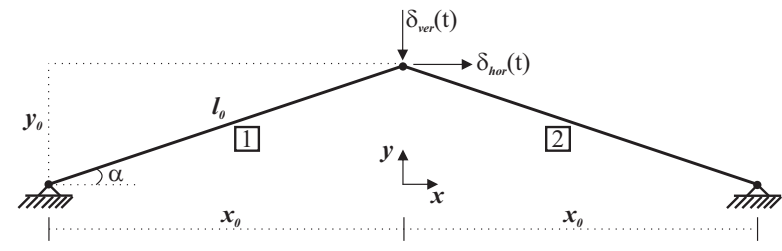

(a)

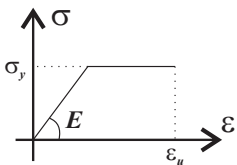

(b)

Fonte: Autor.

Figura 7.10 - Curva Força vs. deslocamento do nó central.

(a) deslocamento vertical

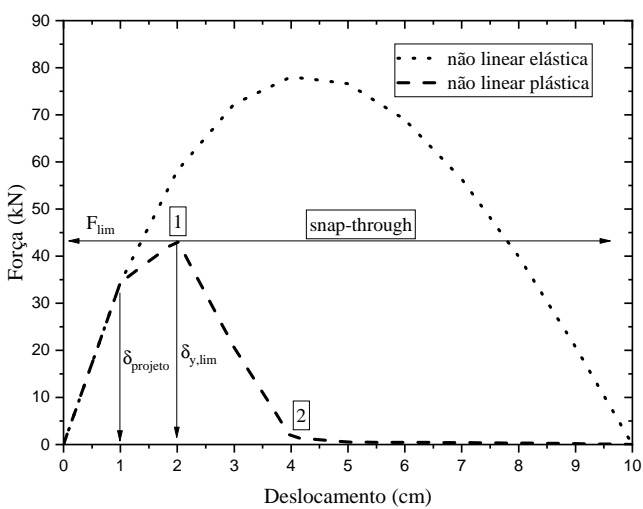

(b) deslocamento horizontal

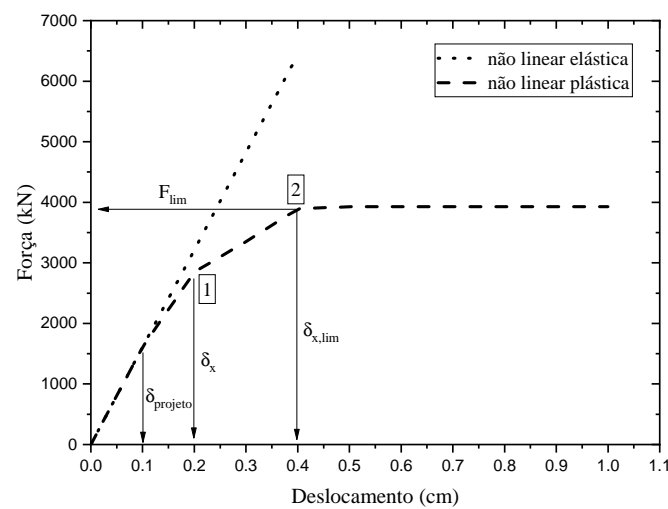


A Figura 7.10 apresenta a solução da estrutura assumindo o comportamento do material e a análise na configuração atual. Nota-se que o comportamento do material começa a influenciar a resposta a partir do $\delta_{\text {projeto }}$, uma vez que ocorre uma perda de rigidez da estrutura em comparação a sua solução não linear elástica. Essa penalização da rigidez é mais pronunciada entre o ponto 1 e 2 . Observa-se que quando a estrutura é submetida a um deslocamento vertical de $2 \mathrm{~cm}$ combinado com um deslocamento horizontal de $0,2 \mathrm{~cm}$ conduz ao seu colapso. Isso porque qualquer incremento de carregamento a partir desse nível de deslocamento acarreta uma queda brusca de rigidez, até o nível em que é nula. Ademais, pode ocorrer um salto de posição (snap - through) para o mesmo nível de força aplicada. Verifica-se que o colapso da treliça ocorre com um nível de deslocamento horizontal $\delta_{x}$ duas vezes menor do que o $\delta_{x, \text { lim }}$. Por conseguinte, na análise de confiabilidade esse efeito deve ser levando em consideração.

No que concerne a análise de confiabilidade, os modos de falhas da estrutura são definidos como sendo: $(i)$ deslocamento na direção $x$; (ii) snap - through; (iii) ruptura do material; e (iv) carga crítica de Euler na barra 2. Para cada modo de falha sua respectiva equação de estado limite é expressa por:

$$
\begin{gathered}
g_{1}(\vec{X}, t)=1-\frac{\delta_{x}(\vec{X}, t)}{\delta_{x}} \\
g_{2}(\vec{X}, t)=1-\frac{\delta_{y}(\vec{X}, t)}{\delta_{y, l i m}} \\
g_{3, i}(\vec{X}, t)=1-\frac{\varepsilon(\vec{X}, t)}{\varepsilon_{u}} \quad i=1,2 \text { é a barra avaliada } \\
g_{4}(\vec{X}, t)=\frac{\pi^{3} E r^{4}}{4\left(x_{0}^{2}+y_{0}^{2}\right)}-N_{\text {num }}(\vec{X}, t) \\
g_{\text {sistema }}(\vec{X}, t)=\min \left[g_{1}(\vec{X}), g_{2}(\vec{X}), g_{3, i}(\vec{X}), g_{4}(\vec{X})\right]
\end{gathered}
$$

sendo $\varepsilon_{u}$ a deformação última do aço, definida por uma distribuição lognormal com média igual 0,2 e coeficiente de variação de 0,06 [252]. Inicialmente, as equações acima são analisadas com o modelo mecânico estático. Em seguida, são avaliadas com o modelo mecânico dinâmico. $\mathrm{O}$ intuito é verificar o comportamento da $P_{f}$ em cada análise.

A Figura 7.11 mostra a evolução da $P_{f}$ com o tempo para a análise quasi-estática ${ }^{1}$. Infere-se que a ruptura do material não contribui na $P_{f}$ do sistema, pois a $P_{f}$ desse estado limite é nula. Em relação ao modo de falha de snap-through, verifica-se que nos primeiros cinco anos a sua $P_{f}$ proporciona um valor maior do que os outros modos de falha. No que diz respeito ao deslocamento $x$, constata-se que sua $P_{f}$ exibe valor muito próximo a $P_{f}$ do snap-through.

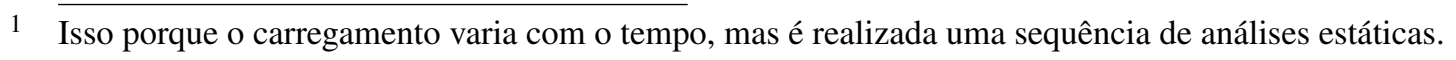


Figura 7.11 - Evolução da $P_{f}$ com o tempo: análise quasi-estática.

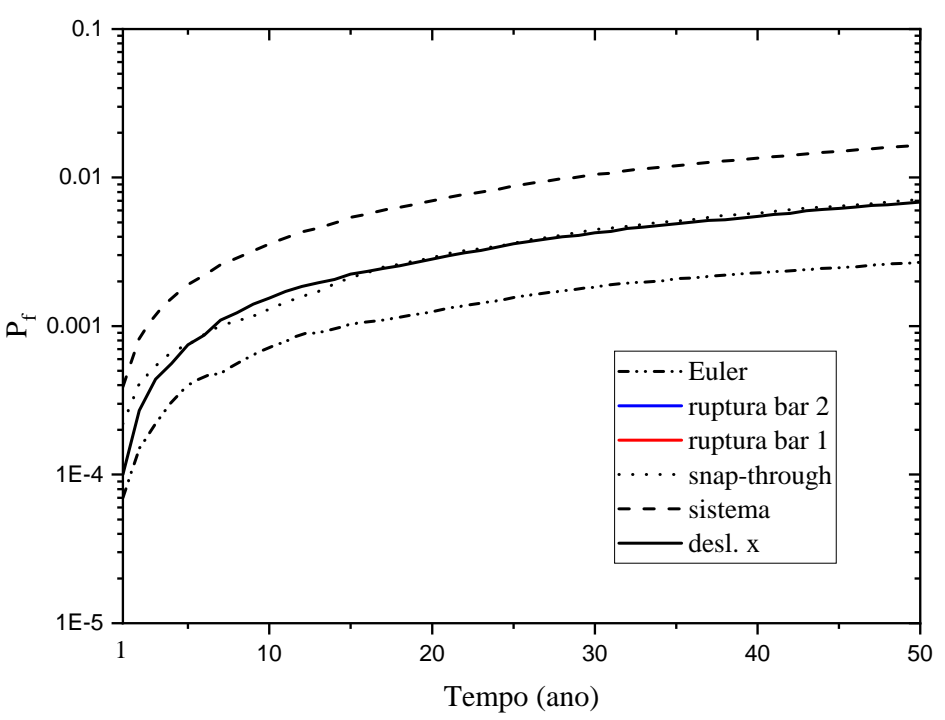

Fonte: Autor.

Figura 7.12 - Evolução da $P_{f}$ com o tempo: análise dinâmica.

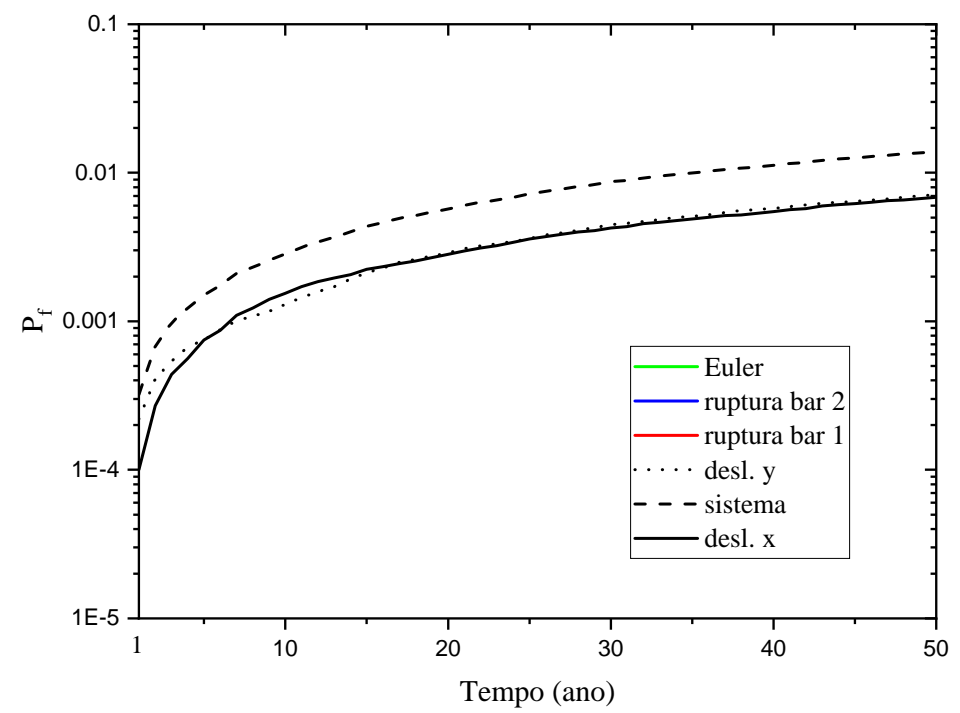

Fonte: Autor.

A Figura 7.12 apresenta a evolução da $P_{f}$ com o tempo para a análise dinâmica. Constata- 
se que os modos de falha, carga crítica de Euler e a ruptura do material, não são ativados durante o processo de carregamento. Ademais, a $P_{f}$ do sistema reduz de $20 \%$ em comparação a análise estática, em concordância com a Figura 7.13. Essa redução ocorre por causa da dissipação de energia do amortecimento e das deformações plásticas.

Figura $7.13-P_{f}$ do sistema $v s$. tempo: comparação entre a análise quasi-estática e dinâmica.

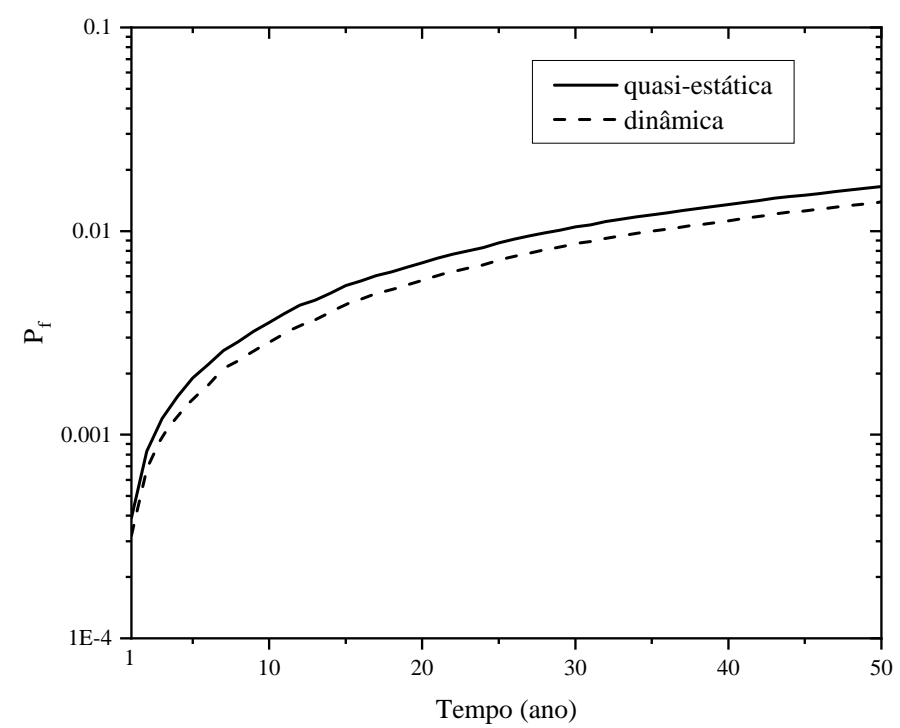

Fonte: Autor.

\subsection{Conclusão do Capítulo}

Neste capítulo, o modelo mecano-probabilístico foi apresentado. Verificou-se a boa acurácia da formulação proposta na análise de confiabilidade no que diz respeito à solução numérica em comparação à solução analítica. Constatou-se que na análise de confiabilidade de sistemas, quando envolvendo processos estocásticos de carregamento, pode ocorrer o chamado load-path dependency. Tal fenômeno deve ser avaliado com atenção pelos projetistas. Isso porque modos de falhas que inicialmente não são relevantes na contribuição da probabilidade de falha da estrutura, podem se mostrar relevantes, por exemplo, devido ao acúmulo de dano plástico. 


\section{CONCLUSÕES}

Neste trabalho, um abrangente modelo de dano dúctil foi deduzido para a análise não linear estática e dinâmica de estruturas treliçadas. O modelo foi acoplado a uma formulação em Elementos Finitos Posicional (MEF Posicional) usando a medida de deformação logarítmica para lidar com grandes deslocamentos e grandes deformações.

O modelo proposto representou com precisão as curvas de tensão vs. deformação para onze materiais diferentes, registrando o encruamento, o amolecimento e a falha do material. Nas aplicações ao concreto, esse modelo resultou em uma melhor aproximação para o resultado experimental analisado, em comparação com os modelos de Mazars [230] e Lee \& Fenves [231]. No que diz respeito à madeira, verificou-se que tal modelo também conseguiu simular sua resposta experimental para o ensaio de compressão paralela às fibras. No tocante ao UHPFRC, observou-se também sua boa acurácia na avaliação das suas respostas experimentais nos ensaios de tração e compressão.

A curva estiramento de Cauchy-Green por deformação logarítmica, apresenta comportamento não simétrico tanto para o alongamento quanto para o encurtamento. Esse efeito é mais bem caracterizado em regime de grandes deformações. Por conseguinte a deformação logarítmica não consegue representar os materiais que apresentem o mesmo comportamento à tração e à compressão. Neste caso, a formulação proposta deve ser deduzida empregando a medida de deformação longitudinal de engenharia (deformação de Biot), uma vez que essa apresenta comportamento simétrico. Em contrapartida, a deformação de Biot diverge em comparação à deformação logarítmica em regime de grandes deformações com valores de deformação acima de $20 \%$. Outrossim, permite jacobiano negativo para níveis finitos de tensão.

Uma das melhores características do modelo proposto é que a lei de evolução de dano é escrita em termos de porosidade, que é o resultado do crescimento e coalescência das microcavidades e microfissuras no material. A variação da porosidade é o principal fenômeno na degradação mecânica de materiais ductéis. Usando o modelo proposto, a evolução do dano cresce continuamente até o dano crítico, em concordância a pressuposição de Lemaitre \& Desmorat [205]. Isso implica que, em aplicações numéricas, a utilização do modelo proposto não acarreta instabilidade numérica na matriz Hessiana, uma vez que o módulo tangente vai tender ao seu valor obtido via curva experimental, diferentemente dos modelos apresentados na literatura, que conduzem a valores de módulo tangente que tendem a zero.

A formulação proposta pode ser estendida para elementos sólidos. No entanto, uma aproximação cinemática e um mapeamento posicional são necessários, além de computar a 
variável de dano nos pontos de integração de cada elemento. Em princípio, as ideias aqui exploradas podem ser empregadas para qualquer material sujeito à evolução da componente hidrostática das deformações plásticas para carregamento monotonicamente crescente.

O modelo mecânico proposto apresentou uma boa convergência nos resultados na análise estática e dinâmica da trajetória de equilíbrio de estruturas treliçadas, sob colapso progressivo considerando a não linearidade física e geométrica.

No que concerne ao modelo mecano-probabilístico, constatou-se que nas análises de confiabilidade a solução numérica exibiu uma excelente convergência em comparação à solução analítica. Verificou-se que o fenômeno load-path dependency conduz ao colapso progressivo da estrutura por meio de modos de falhas que inicialmente apresentavam baixa contribuição na probabilidade de falha do sistema. Por fim, constatou-se que na análise dinâmica da treliça de von Mises, a probabilidade de falha foi $20 \%$ menor do que o valor obtido via análise estática.

\section{Recomendações para Trabalhos Futuros}

a) avaliar a acurácia do modelo de dano proposto em aplicações a outros tipos de materiais;

b) acoplar o modelo de dano proposto à formulação do MEF posicional para elementos sólidos (3D e 2D), casca e pórtico, a fim de análises mais robustas da trajetória de equilíbrio das estruturas sob colapso progressivo avaliadas com esses elementos;

c) utilizar o modelo mecânico em análises de otimização, com o intuito de verificar a configuração ótima das estruturas treliçadas para mitigar a ocorrência do colapso progressivo;

d) acoplar a formulação proposta a metodologia Systematic Reliability-based Approach to Progressive Collapse para analisar as estruturas treliçadas submetidas ao colapso progressivo

e) verificar a influência do dano na mensuração da matriz de amortecimento;

f) analisar a influência do comportamento não simétrico da deformação logarítmica em materiais que apresenta mesmo comportamento em ensaio de tração e compressão. 
[1] SALEM, H.; HELMY, H. Numerical investigation of collapse of the minnesota i-35w bridge. Engineering Structures, Elsevier, v. 59, p. 635-645, 2014.

[2] MIYACHI, K.; NAKAMURA, S.; MANDA, A. Progressive collapse analysis of steel truss bridges and evaluation of ductility. Journal of Constructional Steel Research, Elsevier, v. 78, p. 192-200, 2012.

[3] SUBRAMANIAN, N. I-35w mississippi river bridge failure-is it a wake up call? The Indian Concrete Journal, v. 19, n. 9, p. 29-38, 2008.

[4] ASTANEH-ASL, A. Progressive collapse of steel truss bridges, the case of i-35w collapse. In: Proceedings of 7th International Conference on Steel Bridges, Guimarăes, Portugal. [S.1.: s.n.], 2008.

[5] NATIONAL TRANSPORTATION SAFETY BOARD. Highway accident report interstate 35W collapse over the Mississipi River Minneapolis, Minnesota, August 1, 2007. Washington, DC, 2008.

[6] HAO, S. I-35w bridge collapse. Journal of Bridge Engineering, American Society of Civil Engineers, v. 15, n. 5, p. 608-614, 2009.

[7] LIAO, M. et al. Nonlinear finite-element analysis of critical gusset plates in the i-35w bridge in minnesota. Journal of Structural Engineering, American Society of Civil Engineers, v. 137, n. 1, p. 59-68, 2010.

[8] ODEN, J. T. Finite elements nonlinear continua. New York: Dover, 2006. 432 p.

[9] CRISFIELD, M. A. Non-linear finite element analysis of solids and structures - advanced topics. Chichester, England: John Wiley \& Sons, 1997. v. 2. 345 p.

[10] BONET, J.; WOOD, R. D. Nonlinear continuum mechanics for finite element analysis. 2. ed. Cambridge: Cambridge University Press, 2008. 409 p.

[11] CRISFIELD, M. A. Non-linear finite element analysis of solids and structures - essentials. Chichester, England: John Wiley \& Sons, 1991. v. 1. 362 p.

[12] KRISHNAMOORTHY, C.; RAMESH, G.; DINESH, K. Post-buckling analysis of structures by three-parameter constrained solution techniques. Finite elements in analysis and design, Elsevier, v. 22, n. 2, p. 109-142, 1996. 
[13] CODA, H.; GRECO, M. A simple fem formulation for large deflection 2d frame analysis based on position description. Computer methods in applied mechanics and engineering, Elsevier, v. 193, n. 33-35, p. 3541-3557, 2004.

[14] BONET, J. et al. Finite element analysis of air supported membrane structures. Computer methods in applied mechanics and engineering, Elsevier, v. 190, n. 5-7, p. 579-595, 2000.

[15] MEEK, J.; TAN, H. S. Geometrically nonlinear analysis of space frames by an incremental iterative technique. Computer methods in applied mechanics and engineering, Elsevier, v. 47, n. 3, p. 261-282, 1984.

[16] ORAN, C.; KASSIMALI, A. Large deformations of framed structures under static and dynamic loads. Computers \& structures, Elsevier, v. 6, n. 6, p. 539-547, 1976.

[17] TORKAMANI, M. A.; SHIEH, J.-H. Higher-order stiffness matrices in nonlinear finite element analysis of plane truss structures. Engineering Structures, Elsevier, v. 33, n. 12, p. 3516-3526, 2011.

[18] CRISFIELD, M. A. A consistent co-rotational formulation for non-linear, threedimensional, beam-elements. Computer methods in applied mechanics and engineering, Elsevier, v. 81, n. 2, p. 131-150, 1990.

[19] CRISFIELD, M.; MOITA, G. A unified co-rotational framework for solids, shells and beams. International Journal of Solids and Structures, Elsevier, v. 33, n. 20-22, p. 2969-2992, 1996.

[20] CODA, H. B.; PACCOLA, R. R. et al. A positional fem formulation for geometrical nonlinear analysis of shells. Latin American Journal of Solids and Structures, Latin Amer. J. Solids Structures, v. 5, n. 3, p. 205-223, 2008.

[21] CODA, H. B.; PACCOLA, R. R. An alternative positional fem formulation for geometrically non-linear analysis of shells: curved triangular isoparametric elements. Computational Mechanics, Springer, v. 40, n. 1, p. 185-200, 2007.

[22] CODA, H. B.; PACCOLA, R. R.; SAMPAIO, M. d. S. M. Positional description applied to the solution of geometrically non-linear plates and shells. Finite Elements in Analysis and Design, Elsevier, v. 67, p. 66-75, 2013.

[23] CODA, H. B. A solid-like fem for geometrically non-linear 3d frames. Computer methods in applied mechanics and engineering, Elsevier, v. 198, n. 47-48, p. 3712-3722, 2009.

[24] NOGUEIRA, G. V.; PACCOLA, R. R.; CODA, H. B. A positional unconstrained vector layerwise (uvlwt) fem formulation for laminated frame element modeling. Composite Structures, Elsevier, v. 148, p. 97-112, 2016. 
[25] CODA, H. B.; PACCOLA, R. R. A fem procedure based on positions and unconstrained vectors applied to non-linear dynamic of 3d frames. Finite Elements in Analysis and Design, Elsevier, v. 47, n. 4, p. 319-333, 2011.

[26] GRECO, M.; CODA, H. Positional fem formulation for flexible multi-body dynamic analysis. Journal of Sound and vibration, Elsevier, v. 290, n. 3-5, p. 1141-1174, 2006.

[27] CODA, H. B.; PACCOLA, R. R. A total-lagrangian position-based fem applied to physical and geometrical nonlinear dynamics of plane frames including semi-rigid connections and progressive collapse. Finite Elements in Analysis and Design, Elsevier, v. 91, p. 1-15, 2014.

[28] SIQUEIRA, T. M.; CODA, H. B. Total lagrangian fem formulation for nonlinear dynamics of sliding connections in viscoelastic plane structures and mechanisms. Finite Elements in Analysis and Design, Elsevier, v. 129, p. 63-77, 2017.

[29] CARRAZEDO, R.; CODA, H. B. Triangular based prismatic finite element for the analysis of orthotropic laminated beams, plates and shells. Composite Structures, Elsevier, v. 168, p. 234-246, 2017.

[30] GRECO, M. et al. Nonlinear positional formulation for space truss analysis. Finite elements in analysis and design, Elsevier, v. 42, n. 12, p. 1079-1086, 2006.

[31] GRECO, M.; FERREIRA, I. P. Logarithmic strain measure applied to the nonlinear positional formulation for space truss analysis. Finite elements in analysis and design, Elsevier, v. 45, n. 10, p. 632-639, 2009.

[32] GRECO, M.; COSTA, L. J. R. da. Discussion on "the logarithmic strain measure applied to the nonlinear positional formulation for space truss analysis"[finite element in analysis and design 45 (2009) 632-639] and "nonlinear positional formulation for space truss analysis"[finite element in analysis and design 42 (2006) 1079-1086]. Finite Elements in Analysis and Design, Elsevier, v. 52, p. 93-95, 2012.

[33] LUBLINER, J. Plasticity theory. New York: Courier Corporation, 2008. 517 p.

[34] CHEN, W.-F.; HAN, D.-J. Plasticity for structural engineers. New York: Springer - Verlag, 1988. $601 \mathrm{p}$.

[35] FLOREZ-LOPEZ, J.; MARANTE, M. E.; PICON, R. Fracture and Damage Mechanics for Structural Engineering of Frames: State-of-the-Art Industrial Applications: State-of-the-Art Industrial Applications. Hershey, PA: IGI Global, 2015.

[36] LEMAITRE, J. A course on damage mechanics. New York: Springer Science \& Business Media, 1992. 207 p. 
[37] PEREIRA, L.; WEERHEIJM, J.; SLUYS, L. A new effective rate dependent damage model for dynamic tensile failure of concrete. Engineering Fracture Mechanics, Elsevier, v. 176, p. 281-299, 2017.

[38] ZHANG, J.; LI, J.; JU, J. W. 3d elastoplastic damage model for concrete based on novel decomposition of stress. International Journal of Solids and Structures, Elsevier, v. 94, p. 125-137, 2016.

[39] FENG, D.; REN, X.; LI, J. Stochastic damage hysteretic model for concrete based on micromechanical approach. International Journal of Non-Linear Mechanics, Elsevier, v. 83, p. 15-25, 2016.

[40] THAI, H.-T.; KIM, S.-E. Large deflection inelastic analysis of space trusses using generalized displacement control method. Journal of Constructional Steel Research, Elsevier, v. 65, n. 10-11, p. 1987-1994, 2009.

[41] BLANDFORD, G. E. Review of progressive failure analyses for truss structures. Journal of Structural Engineering, American Society of Civil Engineers, v. 123, n. 2, p. 122-129, 1997.

[42] BLANDFORD, G. E. Large deformation analysis of inelastic space truss structures. Journal of Structural Engineering, American Society of Civil Engineers, v. 122, n. 4, p. 407-415, 1996.

[43] KARAMCHANDANI, A.; CORNELL, C. An event-to-event strategy for nonlinear analysis of truss structures. i. Journal of Structural Engineering, American Society of Civil Engineers, v. 118, n. 4, p. 895-909, 1992.

[44] HILL, C. D.; BLANDFORD, G. E.; WANG, S. T. Post-buckling analysis of steel space trusses. Journal of Structural Engineering, American Society of Civil Engineers, v. 115, n. 4, p. 900-919, 1989.

[45] MURTHA-SMITH, E. Alternate path analysis of space trusses for progressive collapse. Journal of Structural Engineering, American Society of Civil Engineers, v. 114, n. 9, p. 1978-1999, 1988.

[46] SMITH, E. A. Space truss nonlinear analysis. Journal of Structural Engineering, American Society of Civil Engineers, v. 110, n. 4, p. 688-705, 1984.

[47] WU, J.-Y.; CERVERA, M. A thermodynamically consistent plastic-damage framework for localized failure in quasi-brittle solids: Material model and strain localization analysis. International Journal of Solids and Structures, Elsevier, v. 88, p. 227-247, 2016.

[48] LIBERATI, E. A. et al. Nonlinear formulation based on fem, mazars damage criterion and fick's law applied to failure assessment of reinforced concrete structures subjected to 
chloride ingress and reinforcements corrosion. Engineering Failure Analysis, Elsevier, v. 46, p. 247-268, 2014.

[49] WU, J.-Y.; XU, S.-L. An augmented multicrack elastoplastic damage model for tensile cracking. International Journal of Solids and Structures, Elsevier, v. 48, n. 18, p. 2511-2528, 2011.

[50] MATALLAH, M.; BORDERIE, C. L. Inelasticity-damage-based model for numerical modeling of concrete cracking. Engineering Fracture Mechanics, Elsevier, v. 76, n. 8, p. 1087-1108, 2009.

[51] LI, J.; REN, X. Stochastic damage model for concrete based on energy equivalent strain. International Journal of Solids and Structures, Elsevier, v. 46, n. 11-12, p. 2407-2419, 2009.

[52] DESMORAT, R.; GATUINGT, F.; RAGUENEAU, F. Nonlocal anisotropic damage model and related computational aspects for quasi-brittle materials. Engineering Fracture Mechanics, Elsevier, v. 74, n. 10, p. 1539-1560, 2007.

[53] SHAO, J.-F. et al. A coupled elastoplastic damage model for semi-brittle materials and extension to unsaturated conditions. Mechanics of materials, Elsevier, v. 38, n. 3, p. 218-232, 2006.

[54] DRIEMEIER, L.; PROENCA, S. P. B.; ALVES, M. A contribution to the numerical nonlinear analysis of three-dimensional truss systems considering large strains, damage and plasticity. Communications in nonlinear science and numerical simulation, Elsevier, v. 10, n. 5, p. 515-535, 2005.

[55] SALARI, M. et al. A coupled elastoplastic damage model for geomaterials. Computer methods in applied mechanics and engineering, Elsevier, v. 193, n. 27-29, p. 2625-2643, 2004.

[56] LEMAITRE, J. How to use damage mechanics. Nuclear engineering and design, Elsevier, v. 80, n. 2 , p. 233-245, 1984.

[57] FELIPE, T. R. C. Novo método para a avaliação do risco de colapso progressivo em edifícios de alvenaria estrutural. Dissertação (Mestrado) - Escola de Engenharia de São Carlos, Universidade de São Paulo, São Carlos, 2017.

[58] MELCHERS, R. E.; BECK, A. T. Structural reliability analysis and prediction. Hoboken, NJ: John Wiley \& Sons, 2018.

[59] BECK, A. T. Confiabilidade e segurança das estruturas. Rio de Janeiro: Elsevier Campus, 2019.

[60] SIMO, J. C.; HUGHES, T. J. Computational inelasticity. New York: Springer, 1998. v. 7. $392 \mathrm{p}$. 
[61] BAKER, J. F.; WILLIAMS, E. L.; LAX, D. The design of framed buildings against highexplosive bombs. In: THOMAS TELFORD LTD. The civil engineer in war: A symposium of papers on war-time engineering problems. [S.1.], 1948. p. 3-80.

[62] SMITH, P.; B YFIELD, M.; GOODE, D. Building robustness research during world war ii. Journal of Performance of Constructed Facilities, American Society of Civil Engineers, v. 24, n. 6, p. 529-535, 2010.

[63] ELLINGWOOD, B. R.; LEYENDECKER, E. Approaches for design against progressive collapse. Journal of the Structural Division, ASCE, v. 104, n. 3, p. 413-423, 1978.

[64] ELLINGWOOD, B.; LEYENDECKER, E.; YAO, J. T. Probability of failure from abnormal load. Journal of Structural Engineering, American Society of Civil Engineers, v. 109, n. 4, p. 875-890, 1983.

[65] CORLEY, W. G. et al. The oklahoma city bombing: Summary and recommendations for multihazard mitigation. Journal of Performance of Constructed Facilities, American Society of Civil Engineers, v. 12, n. 3, p. 100-112, 1998.

[66] OSTERAAS, J. D. Murrah building bombing revisited: A qualitative assessment of blast damage and collapse patterns. Journal of Performance of Constructed Facilities, American Society of Civil Engineers, v. 20, n. 4, p. 330-335, 2006.

[67] SEFFEN, K. A. Progressive collapse of the world trade center: simple analysis. Journal of engineering mechanics, American Society of Civil Engineers, v. 134, n. 2, p. 125-132, 2008.

[68] BAŽANT, Z. P.; VERDURE, M. Mechanics of progressive collapse: Learning from world trade center and building demolitions. Journal of Engineering Mechanics, American Society of Civil Engineers, v. 133, n. 3, p. 308-319, 2007.

[69] ELLINGWOOD, B. R. Mitigating risk from abnormal loads and progressive collapse. Journal of Performance of Constructed Facilities, American Society of Civil Engineers, v. 20, n. 4, p. 315-323, 2006.

[70] ALLEN, D. E.; SCHRIEVER, W. Progressive collapse, abnormal loads, and building codes. In: ASCE. Structural failures: Modes, causes, responsibilities. [S.1.], 1972. p. 21-47.

[71] GROSS, J. L.; MCGUIRE, W. Progressive collapse resistant design. Journal of Structural engineering, American Society of Civil Engineers, v. 109, n. 1, p. 1-15, 1983.

[72] AGARWAL, J.; ENGLAND, J. Recent developments in robustness and relation with risk. Proceedings of the Institution of Civil Engineers-Structures and Buildings, Thomas Telford Ltd, v. 161, n. 4, p. 183-188, 2008. 
[73] STAROSSEK, U.; HABERLAND, M. Disproportionate collapse: terminology and procedures. Journal of performance of constructed facilities, American Society of Civil Engineers, v. 24, n. 6, p. 519-528, 2010.

[74] PARISI, F.; AUGENTI, N. Influence of seismic design criteria on blast resistance of rc framed buildings: A case study. Engineering Structures, Elsevier, v. 44, p. 78-93, 2012.

[75] ADAM, J. M. et al. Research and practice on progressive collapse and robustness of building structures in the 21st century. Engineering Structures, Elsevier, v. 173, p. 122-149, 2018.

[76] STAROSSEK, U. Typology of progressive collapse. Engineering Structures, Elsevier, v. 29, n. 9, p. 2302-2307, 2007.

[77] BYFIELD, M. et al. A review of progressive collapse research and regulations. Proceedings of the ICE-Structures and Buildings, v. 167, n. 8, p. 447-456, 2014.

[78] NATIONAL INSTITUTE OF STANDARD AND TECHNOLOGY. NISTIR 7396: Best practices for reducing the potential for progressive collapse in buildings, technology administration. Gaithersburg, MD, 2007.

[79] AGENCY, F. E. M. World trade center building performance study: Data collection, preliminary observations, and recommendations. FEMA403, T. McAllister, ed., FEMA 403, Washington, DC, 2002.

[80] QIAN, K.; LI, B. Research advances in design of structures to resist progressive collapse. Journal of Performance of Constructed Facilities, American Society of Civil Engineers, v. 29, n. 5, p. B4014007, 2014.

[81] EL-TAWIL, S.; LI, H.; KUNNATH, S. Computational simulation of gravity-induced progressive collapse of steel-frame buildings: Current trends and future research needs. Journal of Structural Engineering, American Society of Civil Engineers, v. 140, n. 8, p. A2513001, 2013.

[82] DEPARTMENT OF DEFENSE. UFC 4-023-03: Design of buildings to resist progressive collapse. Washington, DC, 2009.

[83] STO. STO 008-02495342: Prevention progressive collapse of reiforced concrete monolithic structures of buildings. Moscow, 2009.

[84] AMERICAN SOCIETY OF CIVIL ENGINEERS. ASCE/SEI 7-10: Mininum design loads for buildings and other structures. Reston, VA, 2010.

[85] GENERAL SERVICES ADMINISTRATION. GSA: Progressive collapse analysis and design guidelines for new federal buildings and major modernization projects. Washington, DC, 2003. 
[86] STAROSSEK, U. Progressive collapse of structures. London: Thomas Telford Limited, 2018.

[87] STAROSSEK, U.; HABERLAND, M. Disproportionate collapse: terminology and procedures. Journal of Performance of Constructed Facilities, American Society of Civil Engineers, v. 24, n. 6, p. 519-528, 2010.

[88] STEVENS, D. et al. Dod research and criteria for the design of buildings to resist progressive collapse. Journal of Structural Engineering, American Society of Civil Engineers, v. 137, n. 9, p. 870-880, 2011.

[89] STEVENS, D. et al. Unified progressive collapse design requirements for dod and gsa. In: Structures Congress 2008: Crossing Borders. [S.1.: s.n.], 2008. p. 1-10.

[90] ELLINGWOOD, B. R.; DUSENBERRY, D. O. Building design for abnormal loads and progressive collapse. Computer-Aided Civil and Infrastructure Engineering, Wiley Online Library, v. 20, n. 3, p. 194-205, 2005.

[91] SMITH, J. W. Structural robustness analysis and the fast fracture analogy. Structural Engineering International, Taylor \& Francis, v. 16, n. 2, p. 118-123, 2006.

[92] JIHONG, Y.; LIQIANG, J. Collapse mechanism analysis of a steel moment frame based on structural vulnerability theory. Archives of Civil and Mechanical Engineering, Elsevier, v. 18, n. 3, p. 833-843, 2018.

[93] WOLIŃSKI, S. Robustness and vulnerability of flat slab structures. Procedia engineering, Elsevier, v. 193, p. 88-95, 2017.

[94] ANDRE, J.; BEALE, R.; BAPTISTA, A. New indices of structural robustness and structural fragility. Struct Eng Mech, v. 56, p. 1063-1093, 2015.

[95] GIULIANI, L. Structural safety in case of extreme actions. International Journal of Lifecycle Performance Engineering, Inderscience Publishers Ltd, v. 1, n. 1, p. 22-40, 2012.

[96] BIONDINI, F.; FRANGOPOL, D. M.; RESTELLI, S. On structural robustness, redundancy, and static indeterminacy. In: Structures Congress 2008: Crossing Borders. [S.1.: s.n.], 2008. p. $1-10$.

[97] PHAM, A. T.; TAN, K. H.; YU, J. Numerical investigations on static and dynamic responses of reinforced concrete sub-assemblages under progressive collapse. Engineering Structures, Elsevier, v. 149, p. 2-20, 2017.

[98] LU, X. et al. Experimental investigation of rc beam-slab substructures against progressive collapse subject to an edge-column-removal scenario. Engineering Structures, Elsevier, v. 149, p. 91-103, 2017. 
[99] QIAN, K.; LI, B.; MA, J.-X. Load-carrying mechanism to resist progressive collapse of rc buildings. Journal of Structural Engineering, American Society of Civil Engineers, v. 141, n. 2, p. 04014107, 2014.

[100] DAT, P. X.; HAI, T. K.; JUN, Y. A simplified approach to assess progressive collapse resistance of reinforced concrete framed structures. Engineering Structures, Elsevier, v. 101, p. 45-57, 2015.

[101] SLOTINE, J.-J. E.; LI, W. et al. Applied nonlinear control. New Jersey: Prentice hall Englewood Cliffs, 1991. v. 199.

[102] BONTEMPI, F.; GIULIANI, L.; GKOUMAS, K. Handling the exceptions: robustness assessment of a complex structural system. In: Proceedings of the 3rd International Conference on Structural Engineering, Mechanics and Computation (SEMC 2007), Cape Town, South Africa. [S.1.: s.n.], 2007. p. 10-12.

[103] VROUWENVELDER, T. Treatment of risk and reliability in the eurocodes. Proceedings of the Institution of Civil Engineers-Structures and Buildings, Thomas Telford Ltd, v. 161, n. 4, p. 209-214, 2008.

[104] FÉDÉRATION INTERNATIONALE DU BÉTON (FIB). Model code for concrete structures 2010. Lausanne, 2012.

[105] JOINT COMMITTEE OF STRUCTURAL SAFETY (JCSS). Risk assesment in engineering - principles, system representation and risk criteria. Zurich, 2008.

[106] MCGILL, W.; AYYUB, B. The meaning of vulnerability in the context of critical infrastructure protection. Critical infrastructure protection: Elements of risk, School of Laws, George Mason Univ. Arlington, VA, p. 25-48, 2007.

[107] CHEN, Y.-L. et al. Assessment of structural robustness under different events according to vulnerability. Journal of Performance of Constructed Facilities, American Society of Civil Engineers, v. 30, n. 5, p. 04016004, 2016.

[108] MAHMOUD, B. et al. Calculation of seismic vulnerability index for steel structures. Energy Procedia, Elsevier, v. 139, p. 558-564, 2017.

[109] OVETT, M. et al. Vulnerability to failure of cable-stayed bridges for beyond-design basis wind events. Engineering Failure Analysis, Elsevier, v. 91, p. 182-200, 2018.

[110] WENG, J. et al. Damage assessment for reinforced concrete frames subject to progressive collapse. Engineering Structures, Elsevier, v. 149, p. 147-160, 2017.

[111] SU, H. et al. A systematic framework of vulnerability analysis of a natural gas pipeline network. Reliability Engineering \& System Safety, Elsevier, v. 175, p. 79-91, 2018. 
[112] FELIPE, T. R. C.; HAACH, V. G.; BECK, A. T. Systematic reliability-based approach to progressive collapse. ASCE-ASME Journal of Risk and Uncertainty in Engineering Systems, Part A: Civil Engineering, American Society of Civil Engineers, v. 4, n. 4, p. 04018039-9, 2018.

[113] NAFDAY, A. M. Consequence-based structural design approach for black swan events. Structural Safety, Elsevier, v. 33, n. 1, p. 108-114, 2011.

[114] FRANGOPOL, D. M.; CURLEY, J. P. Effects of damage and redundancy on structural reliability. Journal of structural engineering, American Society of Civil Engineers, v. 113, n. 7, p. 1533-1549, 1987.

[115] FU, G.; FRANGOPOL, D. M. Balancing weight, system reliability and redundancy in a multiobjective optimization framework. Structural Safety, Elsevier, v. 7, n. 2-4, p. 165-175, 1990.

[116] LIND, N. C. A measure of vulnerability and damage tolerance. Reliability Engineering \& System Safety, Elsevier, v. 48, n. 1, p. 1-6, 1995.

[117] MAES, M. A.; FRITZSONS, K. E.; GLOWIENKA, S. Structural robustness in the light of risk and consequence analysis. Structural engineering international, International Association for Bridge and Structural Engineering, v. 16, n. 2, p. 101-107, 2006.

[118] SØRENSEN, J. D. Framework for robustness assessment of timber structures. Engineering Structures, Elsevier, v. 33, n. 11, p. 3087-3092, 2011.

[119] BAKER, J. W.; SCHUBERT, M.; FABER, M. H. On the assessment of robustness. Structural Safety, Elsevier, v. 30, n. 3, p. 253-267, 2008.

[120] ELLINGWOOD, B. R. et al. Best practices for reducing the potential for progressive collapse in buildings. [S.1.], 2007.

[121] FELIPE, T. R. C.; HAACH, V. G. Discussion about progressive collapse of masonry buildings. Revista IBRACON de Estruturas e Materiais, SciELO Brasil, v. 12, n. 3, p. 479$485,2019$.

[122] MAYS, G.; SMITH, P. D.; SMITH, P. D. Blast effects on buildings: Design of buildings to optimize resistance to blast loading. London: Thomas Telford, 1995.

[123] BYFIELD, M.; PARAMASIVAM, S. Catenary action in steel-framed buildings. Proceedings of the Institution of Civil Engineers-Structures and Buildings, Thomas Telford Ltd, v. 160, n. 5, p. 247-257, 2007.

[124] LI, Y. et al. An improved tie force method for progressive collapse resistance design of reinforced concrete frame structures. Engineering Structures, Elsevier, v. 33, n. 10, p. 2931-2942, 2011. 
[125] SAGASETA, J.; ULAETO, N.; RUSSELL, J. Structural robustness of concrete flat slab structures. Special Publication, v. 315, p. 273-298, 2017.

[126] ARUP. Review of international research on structural robustness and disproportionate collapse. [S.1.]: Dept. for Communities and Local Government, DCLG Publications London, 2011.

[127] EUROPEAN STANDARD. Eurocode 1: Actions on structures. part 1-7: General actions — accidental actions. Brussels, 2003.

[128] DEPARTMENT OF COMMUNITIES AND LOCAL GOVERNMENT. The buildings regulats 2010 - structure. UK, 2010.

[129] BRITISH STANDARDS INSTITUTION. BS 5628-1: Code of practice for use of masonry — part 1. London, 1992.

[130] INSTITUTION OF STRUCTURAL ENGINEERS (ISTRUCTE). Manual for the systematic risk assessment of high-risk structures against disproportionate collapse. London, 2013.

[131] ELLINGWOOD, B. R. Strategies for mitigating risk to buildings from abnormal load events. International Journal of Risk Assessment and Management, Inderscience Publishers, v. 7, n. 6-7, p. 828-845, 2007.

[132] ELLINGWOOD, B. R.; DUSENBERRY, D. O. Building design for abnormal loads and progressive collapse. Computer-Aided Civil and Infrastructure Engineering, Wiley Online Library, v. 20, n. 3, p. 194-205, 2005.

[133] PATÉ-CORNELL, M. E. Quantitative safety goals for risk management of industrial facilities. Structural Safety, Elsevier, v. 13, n. 3, p. 145-157, 1994.

[134] NATIONAL RESEARCH COUNCIL OF CANADA. Canadian Commission on Building and Fire Codes. Ottawa, 1995.

[135] GENERAL SERVICES ADMINISTRATION. GSA: Alternate path analysis \& design guidelines for progressive collapse resistance. Washington, DC, 2013.

[136] AUSTRALIAN BUILDING CODES BOARD. National construction code. Sydney, 2016.

[137] CHINA ASSOCIATION FOR ENGINEERING CONSTRUCTION STANDARDIZATION. CECS: Code for anti-collapse design of building structures, cecs 392. Beijing, China, 2014.

[138] ASSOCIAÇÃO BRASILEIRA DE NORMAS TÉCNICAS. NBR 15812: Alvenaria estrutural - blocos cerâmicos parte 1: Projeto. Rio de Janeiro, 2010. 
[139] ASSOCIAÇÃO BRASILEIRA DE NORMAS TÉCNICAS. NBR 15961: Alvenaria estrutural - blocos de concreto parte 1: Projeto. Rio de Janeiro, 2011.

[140] ASSOCIAÇÃO BRASILEIRA DE NORMAS TÉCNICAS. NBR 6118: Projeto e execução de obras de concreto armado - procedimentos. Rio de Janeiro, 2014.

[141] ASSOCIAÇÃO BRASILEIRA DE NORMAS TÉCNICAS. NBR 9062: Projeto e execuc c ao de estruturas de concreto pré-moldado. Rio de Janeiro, 2006.

[142] ASSOCIAÇÃO BRASILEIRA DE NORMAS TÉCNICAS. NBR 16055: Parede de concreto moldada no local para a construc $\mathrm{c}$ ao de edificac $\mathrm{c}$ oes - requisitos e procendimentos. Rio de Janeiro, 2012.

[143] ASSOCIAÇÃO BRASILEIRA DE NORMAS TÉCNICAS. NBR 7190: Projeto de estruturas de madeira. Rio de Janeiro, 1997.

[144] ASSOCIAÇÃO BRASILEIRA DE NORMAS TÉCNICAS. NBR 8800: Projeto de estruturas de aço e de estruturas mistas de aço e concreto de edifícios. Rio de Janeiro, 2008.

[145] WANG, W. et al. Performance of practical beam-to-shs column connections against progressive collapse. Engineering Structures, Elsevier, v. 106, p. 332-347, 2016.

[146] GONG, Y. Test, modeling and design of bolted-angle connections subjected to column removal. Journal of Constructional Steel Research, Elsevier, v. 139, p. 315-326, 2017.

[147] DINU, F.; MARGINEAN, I.; DUBLINA, D. Experimental testing and numerical modelling of steel moment-frame connections under column loss. Engineering Structures, Elsevier, v. 151, p. 861-878, 2017.

[148] WEIGAND, J. M.; BERMAN, J. W. Integrity of bolted angle connections subjected to simulated column removal. Journal of Structural Engineering, American Society of Civil Engineers, v. 142, n. 3, p. 04015165, 2015.

[149] QIN, X. et al. Experimental study of through diaphragm connection types under a column removal scenario. Journal of Constructional Steel Research, Elsevier, v. 112, p. 293-304, 2015.

[150] LIU, C.; TAN, K. H.; FUNG, T. C. Investigations of nonlinear dynamic performance of top-and-seat with web angle connections subjected to sudden column removal. Engineering Structures, Elsevier, v. 99, p. 449-461, 2015.

[151] LI, L.-L. et al. Analysis of robustness of steel frames against progressive collapse. Journal of Constructional Steel Research, Elsevier, v. 143, p. 264-278, 2018. 
[152] PARTHASARATHI, N. et al. Nonlinear analysis of the progressive collapse for twodimensional steel frame under fire conditions. Materials Today: Proceedings, Elsevier, v. 5, n. 2, p. 8718-8726, 2018.

[153] LOU, G. et al. Fire tests on full-scale steel portal frames against progressive collapse. Journal of Constructional Steel Research, Elsevier, v. 145, p. 137-152, 2018.

[154] JIANG, J. et al. Quantitative evaluation of progressive collapse process of steel portal frames in fire. Journal of Constructional Steel Research, Elsevier, v. 150, p. 277-287, 2018.

[155] REZAZADEH, P.; SHEIDAII, M. R.; SALMASI, A. Assessment of progressive collapse behaviour of moment frames strengthened with knee elements. International Journal of Steel Structures, Springer, p. 1-13, 2018.

[156] HUANG, H. et al. Experimental study and numerical analysis on the progressive collapse resistance of scms. International Journal of Steel Structures, Springer, p. 1-18, 2018.

[157] SZYNISZEWSKI, S.; KRAUTHAMMER, T. Energy flow in progressive collapse of steel framed buildings. Engineering Structures, Elsevier, v. 42, p. 142-153, 2012.

[158] GERASIMIDIS, S.; SIDERI, J. A new partial-distributed damage method for progressive collapse analysis of steel frames. Journal of Constructional Steel Research, Elsevier, v. 119, p. 233-245, 2016.

[159] YU, J.; TAN, K. H. Structural behavior of reinforced concrete frames subjected to progressive collapse. ACI Structural Journal, v. 114, n. 1, 2017.

[160] FORQUIN, P.; CHEN, W. An experimental investigation of the progressive collapse resistance of beam-column rc sub-assemblages. Construction and Building Materials, Elsevier, v. 152 , p. 1068-1084, 2017.

[161] REN, P. et al. Experimental investigation of progressive collapse resistance of oneway reinforced concrete beam-slab substructures under a middle-column-removal scenario. Engineering Structures, Elsevier, v. 118, p. 28-40, 2016.

[162] LU, X. et al. Experimental investigation of rc beam-slab substructures against progressive collapse subject to an edge-column-removal scenario. Engineering Structures, Elsevier, v. 149, p. 91-103, 2017.

[163] KANG, S. B.; TAN, K. H.; YANG, E. H. Progressive collapse resistance of precast beam-column sub-assemblages with engineered cementitious composites. Engineering Structures, Elsevier, v. 98, p. 186-200, 2015.

[164] ELSANADEDY, H. M. et al. Investigation of precast rc beam-column assemblies under column-loss scenario. Construction and Building Materials, Elsevier, v. 142, p. 552-571, 2017. 
[165] LIM, N. S.; TAN, K.; LEE, C. A simplified model for alternate load path assessment in rc structures. Engineering Structures, Elsevier, v. 171, p. 696-711, 2018.

[166] GOWTHAM, S. et al. 2d-linear static and non-linear dynamic progressive collapse analysis of reinforced concrete building. Materials Today: Proceedings, Elsevier, v. 5, n. 2, p. 87758783, 2018.

[167] ZHANG, J.-Z.; LI, G.-Q. Collapse resistance of steel beam-concrete slab composite substructures subjected to middle column loss. Journal of Constructional Steel Research, Elsevier, v. 145, p. 471-488, 2018.

[168] LI, G.-Q.; ZHANG, J.-Z.; JIANG, J. Analytical modeling on collapse resistance of steel beam-concrete slab composite substructures subjected to side column loss. Engineering Structures, Elsevier, v. 169, p. 238-255, 2018.

[169] BREDEAN, L.; BOTEZ, M. The influence of beams design and the slabs effect on the progressive collapse resisting mechanisms development for rc framed structures. Engineering Failure Analysis, Elsevier, v. 91, p. 527-542, 2018.

[170] AL-SALLOUM, Y. et al. Progressive collapse analysis of a typical rc high-rise tower. Journal of King Saud University-Engineering Sciences, Elsevier, v. 29, n. 4, p. 313-320, 2017.

[171] AL-SALLOUM, Y. A. et al. Strengthening of precast rc beam-column connections for progressive collapse mitigation using bolted steel plates. Engineering Structures, Elsevier, v. 161, p. 146-160, 2018.

[172] FENG, D.-C.; WU, G.; LU, Y. Numerical investigation on the progressive collapse behavior of precast reinforced concrete frame subassemblages. Journal of Performance of Constructed Facilities, American Society of Civil Engineers, v. 32, n. 3, p. 04018027, 2018.

[173] FENG, D.; REN, X.; LI, J. Stochastic damage hysteretic model for concrete based on micromechanical approach. International Journal of Non-Linear Mechanics, Elsevier, v. 83, p. $15-25,2016$.

[174] LI, S. et al. Experimental and numerical study on progressive collapse process of rc frames with full-height infill walls. Engineering Failure Analysis, Elsevier, v. 59, p. 57-68, 2016.

[175] QIAN, K.; LI, B. Effects of masonry infill wall on the performance of rc frames to resist progressive collapse. Journal of Structural Engineering, American Society of Civil Engineers, v. 143, n. 9, p. 04017118, 2017.

[176] GUO, L.; GAO, S.; FU, F. Structural performance of semi-rigid composite frame under column loss. Engineering Structures, Elsevier, v. 95, p. 112-126, 2015.

[177] SHAN, S. et al. Experimental study on the progressive collapse performance of rc frames with infill walls. Engineering Structures, Elsevier, v. 111, p. 80-92, 2016. 
[178] LIU, J. et al. Resistance of flat-plate buildings against progressive collapse. i: Modeling of slab-column connections. Journal of Structural Engineering, American Society of Civil Engineers, v. 141, n. 12, p. 04015053, 2015.

[179] OLMATI, P. et al. Simplified reliability analysis of punching in reinforced concrete flat slab buildings under accidental actions. Engineering Structures, Elsevier, v. 130, p. 83-98, 2017.

[180] WANG, W.; LI, H.; WANG, J. Progressive collapse analysis of concrete-filled steel tubular column to steel beam connections using multi-scale model. In: ELSEVIER. Structures. [S.1.], 2017. v. 9, p. 123-133.

[181] YANKELEVSKY, D. Z. et al. Final state of damage in buildings subjected to extreme loading. Proceedings of XL2003, Response of Structures to Extreme Loading, Elsevier, 2006.

[182] SMITH, J. W. Energy approach to assessing corrosion damaged structures. Proceedings of the Institution of Civil Engineers-Structures and Buildings, Thomas Telford Ltd, v. 156, n. 2, p. 121-130, 2003.

[183] STRUGATSKY, J. M. Strength ensuring of large-panel buildings on local failure of their bearing structures. In: Investigation of bearing concrete and reinforced concrete structures of multistory precast buidings, 1980.

[184] SMITH, J. W. Structural robustness analysis and the fast fracture analogy. Structural Engineering International, International Association for Bridge and Structural Engineering, v. 16, n. 2, p. 118-123, 2006.

[185] ASGARIAN, B.; REZVANI, F. H. Progressive collapse analysis of concentrically braced frames through epca algorithm. Journal of Constructional Steel Research, Elsevier, v. 70, p. 127-136, 2012.

[186] LIU, M. Progressive collapse design of seismic steel frames using structural optimization. Journal of Constructional Steel Research, Elsevier, v. 67, n. 3, p. 322-332, 2011.

[187] KIM, H.-S.; KIM, J.; AN, D.-W. Development of integrated system for progressive collapse analysis of building structures considering dynamic effects. Advances in Engineering Software, Elsevier, v. 40, n. 1, p. 1-8, 2009.

[188] KAEWKULCHAI, G.; WILLIAMSON, E. B. Beam element formulation and solution procedure for dynamic progressive collapse analysis. Computers \& Structures, Elsevier, v. 82, n. 7-8, p. 639-651, 2004.

[189] FELIPE, T. R. et al. A comprehensive ductile damage model for 3d truss structures. International Journal of Non-Linear Mechanics, Elsevier, v. 112, p. 13-24, 2019. 
[190] TIPLER, P. A.; MOSCA, G. Physics for scientists and engineers. New York: Macmillan, 2007.

[191] NUSSENZVEIG, H. M. Curso de física básica. Rio de Janeiro: Blucher, 1997.

[192] HALLIDAY, D.; RESNICK, R. Fundamentals of physics. New York: John Wiley \& Sons, 1981.

[193] LANCZOS, C. The variational principles of mechanics. 4. ed. New York: Dover, 1970. $409 \mathrm{p}$.

[194] OGDEN, R. W. Non-linear elastic deformations. New York: Dover, 1984. 526 p.

[195] LEMAITRE, J.; CHABOCHE, J. L. Mechanics of solid materils. Cambridge: Cambridge University Press, 2000. 550 p.

[196] NETO, E. A. de S.; PERIC, D.; OWEN, D. R. Computational methods for plasticity: theory and applications. Chichester, England: John Wiley \& Sons, 2011. 783 p.

[197] HENANN, D. L.; ANAND, L. A large deformation theory for rate-dependent elasticplastic materials with combined isotropic and kinematic hardening. International Journal of Plasticity, Elsevier, v. 25, n. 10, p. 1833-1878, 2009.

[198] GARINO, C. G.; OLIVER, J. Un modelo constitutivo para el análisis de sólidos elastoplásticos sometidos a grandes deformaciones. Revista internacional de métodos numéricos para cálculo y diseño en ingeniería, v. 11, n. 1, p. 105-122, 1995.

[199] NEMAT-NASSER, S. On finite deformation elasto-plasticity. International Journal of Solids and Structures, Elsevier, v. 18, n. 10, p. 857-872, 1982.

[200] LEE, E. H. Elastic-plastic deformation at finite strains. Journal of applied mechanics, American Society of Mechanical Engineers, v. 36, n. 1, p. 1-6, 1969.

[201] CODA, H. B. O método dos elementos finitos posicional: sólidos e estruturas - não linearidade geométrica e dinâmica. São Carlos: EESC-USP, 2018. 248 p.

[202] CLOUGH, R. W.; PENZIEN, J. Dynamics of structures. Tokyo: McGraw-Hill, 1975. $629 \mathrm{p}$.

[203] PAULTRE, P. Dynamics of structures. London: ISTE and Wiley, 2011. 802 p.

[204] ARGYRIS, J.; MLEJNEK, H. P. Dynamics of structures. New York: Elsevier, 1991. v. 5. $593 \mathrm{p}$.

[205] LEMAITRE, J.; DESMORAT, R. Engineering damage mechanics: ductile, creep, fatigue and brittle failures. New York: Springer Science \& Business Media, 2005. 380 p. 
[206] LEMAITRE, J.; CHABOCHE, J.-L. Mechanics of solid materials. Cambridge: Cambridge university press, 1994. $550 \mathrm{p}$.

[207] LEMAITRE, J. A continuous damage mechanics model for ductile fracture. Journal of engineering materials and technology, American Society of Mechanical Engineers, v. 107, n. 1, p. $83-89,1985$.

[208] RIGOBELLO, R.; CODA, H. B.; NETO, J. M. A 3d solid-like frame finite element applied to steel structures under high temperatures. Finite Elements in Analysis and Design, Elsevier, v. 91, p. 68-83, 2014.

[209] BOTTA, A. et al. A discussion on volume change in the plastic phase. International Journal for Numerical Methods in Biomedical Engineering, Wiley Online Library, v. 24, n. 11, p. 1149-1162, 2008.

[210] DUNNE, F.; PETRINIC, N. Introduction to computational plasticity. London: Oxford University Press, 2005. 241 p.

[211] JIRÁSEK, M.; BAZANT, Z. P. Inelastic analysis of structures. Chichester, West Sussex: John Wiley \& Sons, 2002. 719 p.

[212] SANCHES, R. A. K.; CODA, H. B. Flexible multibody dynamics finite element formulation applied to structural progressive collapse analysis. Latin American Journal of Solids and Structures, SciELO Brasil, v. 14, n. 1, p. 52-71, 2017.

[213] GURSON, A. L. Plastic flow and fracture behaviour of ductile materials incorporating nucleation, growth and coalescence. Tese (Doutorado) - Brown University, 1975.

[214] NEEDLEMAN, A.; TVERGAARD, V. An analysis of ductile rupture modes at a crack tip. Journal of the Mechanics and Physics of Solids, Elsevier, v. 35, n. 2, p. 151-183, 1987.

[215] KOPLIK, J.; NEEDLEMAN, A. Void growth and coalescence in porous plastic solids. Tese (Doutorado) — Brown University, 1988.

[216] ZHANG, Z.; THAULOW, C.; ØDEGÅRD, J. A complete gurson model approach for ductile fracture. Engineering Fracture Mechanics, Elsevier, v. 67, n. 2, p. 155-168, 2000.

[217] HIBBLER, R. C. Resistência dos materiais. São Paulo: Pearson Prentice Hall, 2010.

[218] CRAIG, R. R. Structural dynamics - an introduction to computer methods. New York: Jonh Wiley \& Sons, 1981. 527 p.

[219] SORIANO, H. L. Introdução a dinâmica das estruturas. Rio de Janeiro: Elsevier, 2014. $459 \mathrm{p}$. 
[220] BACHMANN, H. et al. Vibration problems in structures: practical guidelines. Zurich: Birkhäuser, 2012. 231 p.

[221] CHOPRA, A. K. Dynamics of structures - theory and applications to earthquake engineering. New York: Prentice-Hall, 2007. v. 3. 876 p.

[222] CAUGHEY, T.; O'KELLY, M. E. Classical normal modes in damped linear dynamic systems. Journal of Applied Mechanics, American Society of Mechanical Engineers, v. 32, n. 3, p. 583-588, 1965.

[223] RAYLEIGH, J. W. S. L. Theory of sound. New York: Dover Publications, 1945. v. 2. $476 \mathrm{p}$.

[224] CODA, H. B.; PACCOLA, R. R. Unconstrained finite element for geometrical nonlinear dynamics of shells. Mathematical problems in engineering, Hindawi, v. 2009, 2009.

[225] ENGINEERS, A. S. of C. Seismic rehabilitation of existing buildings. [S.1.]: ASCE Publications, 2007. v. 41.

[226] NEWMARK, N.; HALL, W. Earthquake spectra and design: Engineering monographs on earthquake criteria, structural design, and strong motion records. Earthquake Engineering Research Institute Monograph, Berkeley, CA, 1982.

[227] NEWMARK, N. M. A method of computation for structural dynamics. Journal of the engineering mechanics division, ASCE, v. 85, n. 3, p. 67-94, 1959.

[228] GÉRADIN, M.; CARDONA, A. Flexible multibody dynamics: a finite element approach. [S.1.]: John Wiley Chichester, England; New York, USA, 2001.

[229] PROENÇA, S. P. B. Análise não-linear de estruturas (Notas de aulas). São Carlos: EESC-USP, 2016.

[230] MAZARS, J. A description of micro-and macroscale damage of concrete structures. Engineering Fracture Mechanics, Elsevier, v. 25, n. 5-6, p. 729-737, 1986.

[231] LEE, J.; FENVES, G. L. Plastic-damage model for cyclic loading of concrete structures. Journal of engineering mechanics, American Society of Civil Engineers, v. 124, n. 8, p. 892-900, 1998.

[232] PRADO, L. P. Ensaio experimental do aço ASTM A36. São Carlos: Departamento de Engenharia de Estruturas da Escola de Engenharia de São Carlos, Universidade de São Paulo, 2014.

[233] KRAHL, P. A.; GIDRÃO, G. d. M. S.; CARRAZEDO, R. Compressive behavior of uhpfrc under quasi-static and seismic strain rates considering the effect of fiber content. Construction and Building Materials, Elsevier, v. 188, p. 633-644, 2018. 
[234] BARBOSA, A. P. et al. Estudo do crescimento e qualidade de mudas de marupá (simarouba amara aubl.) em viveiro. Acta Amazonica, 2010.

[235] ASSOCIAÇÃO BRASILEIRA DE NORMAS TÉCNICAS. NBR 7190: Projeto de esruturas de madeira. Rio de Janeiro, 1997.

[236] PROENÇA, S. P. B. Introdução às mecânicas do dano e da fratura (Notas de aulas). São Carlos: EESC-USP, 2008.

[237] KRAHL, P. A.; CARRAZEDO, R.; EL-DEBS, M. K. Mechanical damage evolution in uhpfrc: Experimental and numerical investigation. Engineering Structures, Elsevier, v. 170, p. 63-77, 2018.

[238] WILLE, K.; EL-TAWIL, S.; NAAMAN, A. Properties of strain hardening ultra high performance fiber reinforced concrete (uhp-frc) under direct tensile loading. Cement and Concrete Composites, Elsevier, v. 48, p. 53-66, 2014.

[239] OESCH, T. S. Investigation of fiber and cracking behavior for conventional and ultra-high performance concretes using $x$-ray computed tomography. Tese (Doutorado) - University of Illinois at Urbana-Champaign, 2015.

[240] KRENK, S. Non-linear modeling and analysis of solids and structures. [S.1.]: Cambridge University Press, 2009.

[241] KRENK, S.; HEDEDAL, O. A dual orthogonality procedure for non-linear finite element equations. Computer Methods in Applied Mechanics and Engineering, Elsevier, v. 123, n. 1-4, p. 95-107, 1995.

[242] YANG, Y.-B.; LEU, L.-J. Constitutive laws and force recovery procedures in nonlinear analysis of trusses. Computer Methods in Applied Mechanics and Engineering, Elsevier, v. 92, n. 1, p. 121-131, 1991.

[243] PEER. PEER ground motion database. Berkeley: University of California, 2011.

[244] SINGH, K. S. Análise estática de torres meálicas treliçadas autoportantes para linhas de transmissão. Dissertação (Mestrado) — Faculdade de Tecnologia, Universidade de Brasília, Brasília, 2009.

[245] TESSARI, R. K. Projeto baseado em desempenho de torres metálicas sujeitas à ação do vento. Dissertação (Mestrado) — Escola de Engenharia de São Carlos, Universidade de São Paulo, São Carlos, 2016.

[246] TELEBRÁS. Procedimentos de projeto para torres metálicas auto-suportadas, estaiadas e postes metálicos. Rio de Janeiro, 1997. 
[247] PUTCHA, C.; TIWARI, B. Interdisciplinary applications of reliability analysis, risk analysis and optimization. ASCE-ASME Journal of Risk and Uncertainty in Engineering Systems, Part A: Civil Engineering, American Society of Civil Engineers, v. 4, n. 1, p. $02017003,2018$.

[248] RASHKI, M.; MIRI, M.; MOGHADDAM, M. A. A new efficient simulation method to approximate the probability of failure and most probable point. Structural Safety, Elsevier, v. 39, p. 22-29, 2012.

[249] OKASHA, N. M. An improved weighted average simulation approach for solving reliability-based analysis and design optimization problems. Structural Safety, Elsevier, v. 60, p. 47-55, 2016.

[250] HASOFER, A. M.; LIND, N. C. Exact and invariant second-moment code format. Journal of the Engineering Mechanics division, ASCE, v. 100, n. 1, p. 111-121, 1974.

[251] FIESSLER, B.; RACKWITZ, R. Structural reliability under combined random load sequences. Comput Struct, v. 9, n. 5, p. 489-94, 1978.

[252] JOINT COMMITEE ON STRUCTURAL SAFET. Probabilistic model code: part 1 basis of design. Denmark, 2001.

[253] HAUKAAS, T.; SCOTT, M. H. Shape sensitivities in the reliability analysis of nonlinear frame structures. Computers \& structures, Elsevier, v. 84, n. 15-16, p. 964-977, 2006. 
APÊNDICE

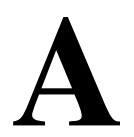

DETERMINAÇÃO DOS PARÂMETROS DO

MODELO PROPOSTO

\section{A.1 Algoritmo de Solução}

Figura A.1 - Algoritmo em linguagem Fortran para a determinação de $D$ e $E_{t}$ via curva experimental.

$$
\begin{aligned}
& \text { do } \mathrm{i}=1, \mathrm{n} \\
& \varepsilon_{i}^{e}=\frac{\sigma_{i}}{E} \\
& \varepsilon_{i}^{p}=\varepsilon_{i}-\frac{\sigma_{i}}{E} \\
& \varepsilon_{H, i}^{p}=\frac{\varepsilon_{i}^{p}}{3} \\
& \text { if }\left(\sigma_{i}=\sigma_{u}\right) \text { then } \\
& \varepsilon_{\mathrm{ln}, d}^{p}=\varepsilon_{H, u}^{p}=\frac{\varepsilon_{u}^{p}}{3} \\
& \text { endif } \\
& \text { if }\left(\sigma \leq \sigma_{u}\right) \text { then } \\
& \bar{\varepsilon}_{i}^{p}=\varepsilon_{i}-\frac{\sigma_{i}}{E} \\
& \text { else } \\
& \bar{\varepsilon}_{i}^{p}=\varepsilon_{i}-\frac{\sigma_{u}}{E} \\
& \text { endif } \\
& \varepsilon_{i}^{d}=\varepsilon_{i}^{p}-\bar{\varepsilon}_{i}^{p} \\
& D_{i}=\frac{\varepsilon_{i}^{d}}{\varepsilon_{i}^{d}+\varepsilon_{i}^{e}} \\
& E_{t, i}=E\left(1-D_{i}\right) \\
& \text { enddo }
\end{aligned}
$$

Fonte: Autor.

Nota $-\varepsilon$ e $\sigma$ são os pontos (deformação $v s$. tensão) da curva experimental do material em análise. Recorde que $\varepsilon=\lambda-1$, logo, $\lambda=1+\varepsilon$. Consequentemente, $\varepsilon_{l n}$ e $\tau$, resulta: $\varepsilon_{l n}=\ln (1+\varepsilon)$ e $\tau=\sigma(1+\varepsilon)$. Plota-se a curva $\left(\varepsilon_{H}^{p}-\varepsilon_{l n, d}^{p}\right)$ vs. $D$ e, determina-se $\alpha_{1}^{p}, \alpha_{2}^{p}$ e $\alpha_{3}^{p}$, por meio de um ajuste polinomial (polinômio do segundo grau). 


\section{A.2 Determinação de $\alpha_{1}^{p}, \alpha_{2}^{p}$ e $\alpha_{3}^{p}$ para o Aço Doce}

Figura A.2 - Fit da evolução do dano para o aço doce.

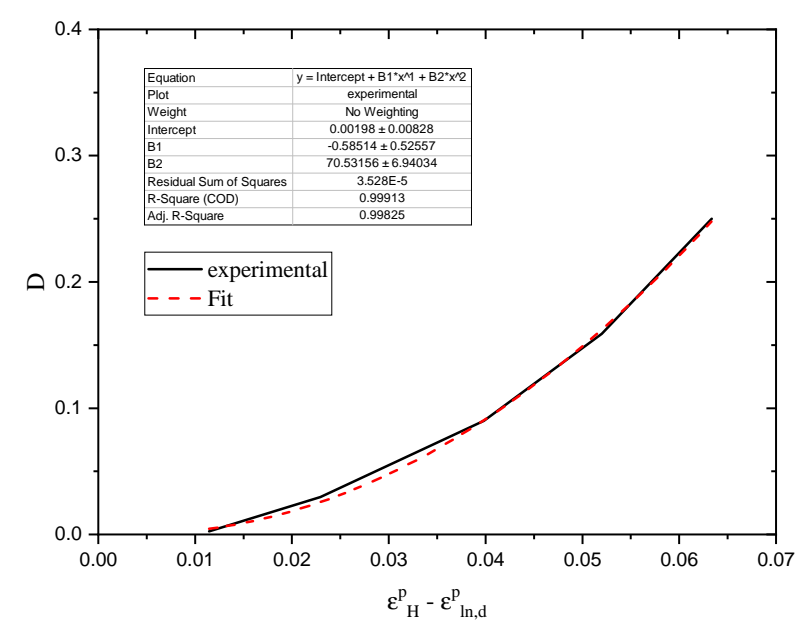

Fonte: Autor.

\section{A.3 Determinação de $\alpha_{1}^{p}, \alpha_{2}^{p}$ e $\alpha_{3}^{p}$ para o Aço de Alta Resis- tência}

Figura A.3 - Fit da evolução do dano para o aço alta resistência.

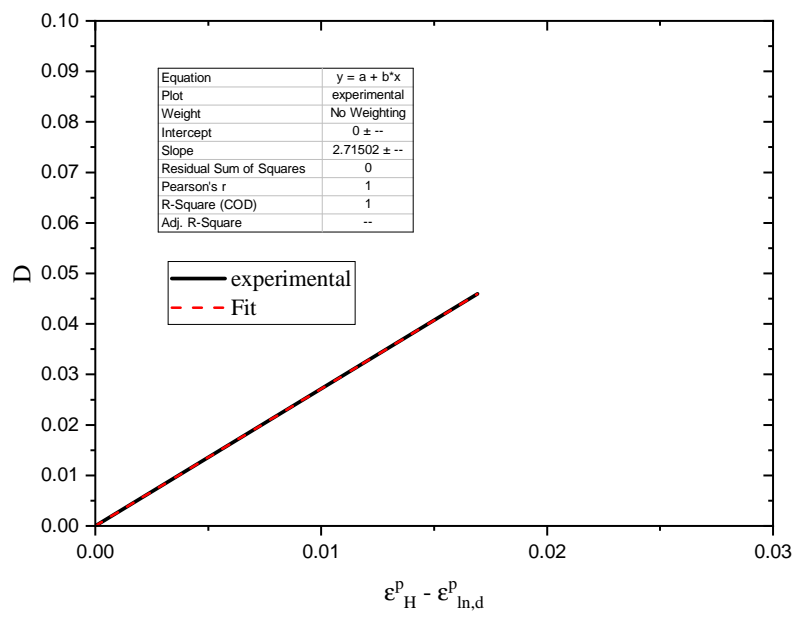

Fonte: Autor. 


\section{A.4 Determinação de $\alpha_{1}^{p}, \alpha_{2}^{p}$ e $\alpha_{3}^{p}$ para o Cobre (99\%)}

Figura A.4 - Fit da evolução do dano para o cobre (99\%).

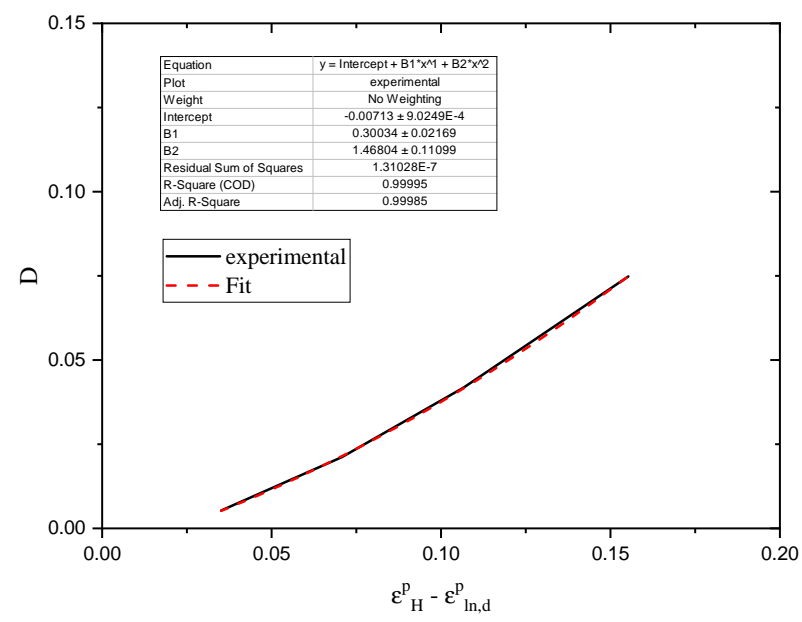

Fonte: Autor.

\section{A.5 Determinação de $\alpha_{1}^{p}, \alpha_{2}^{p}$ e $\alpha_{3}^{p}$ para o aço ASTM A36}

Figura A.5 - Fit da evolução do dano para o Aço ASTM A36.

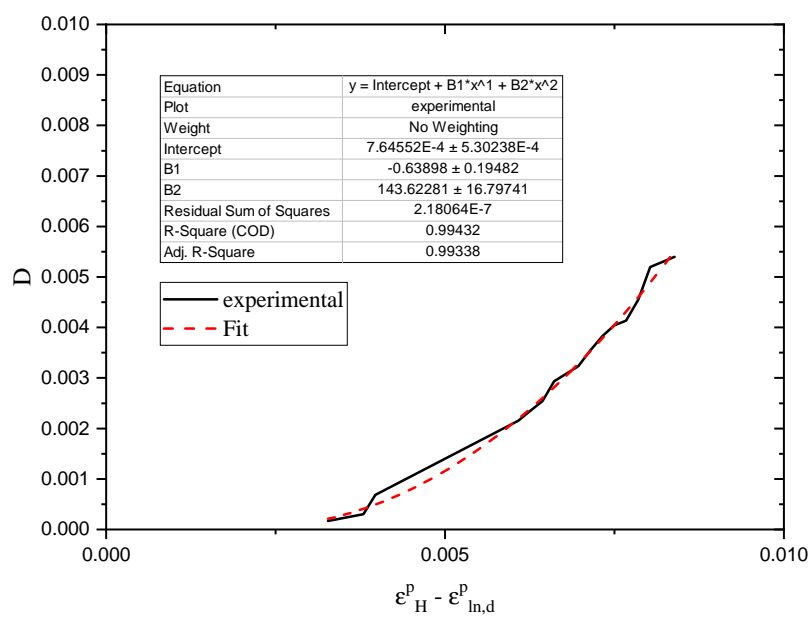

Fonte: Autor. 


\section{A.6 Determinação de $\alpha_{1}^{p}$, $\alpha_{2}^{p}$ e $\alpha_{3}^{p}$ para a Madeira Espécie Simarouba amara em Ensaio de Compressão}

Figura A.6 - Fit da evolução do dano para a madeira espécie Simarouba amara.

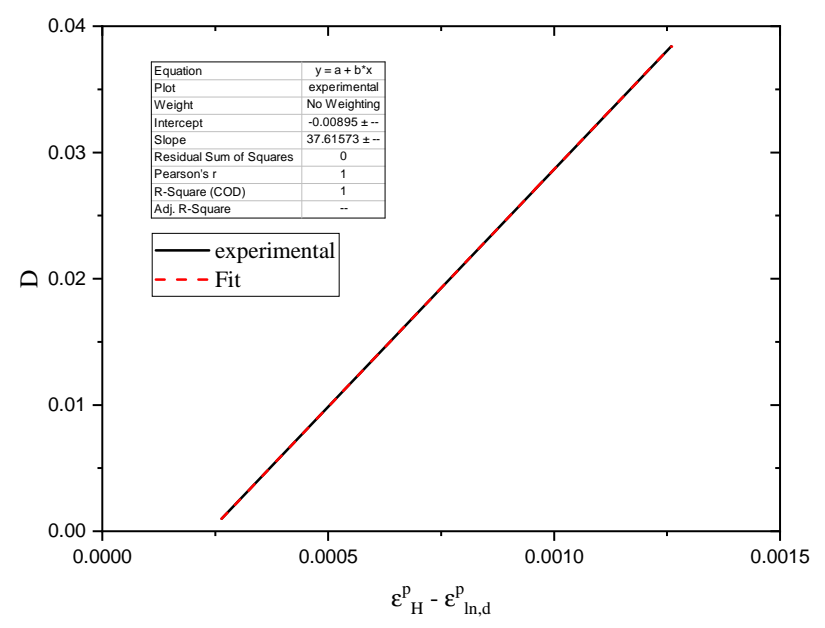

Fonte: Autor.

\section{A.7 Determinação de $\alpha_{1}^{p}, \alpha_{2}^{p}$ e $\alpha_{3}^{p}$ para o Concreto a Tração}

Figura A.7 - Fit da evolução do dano para o concreto a tração.

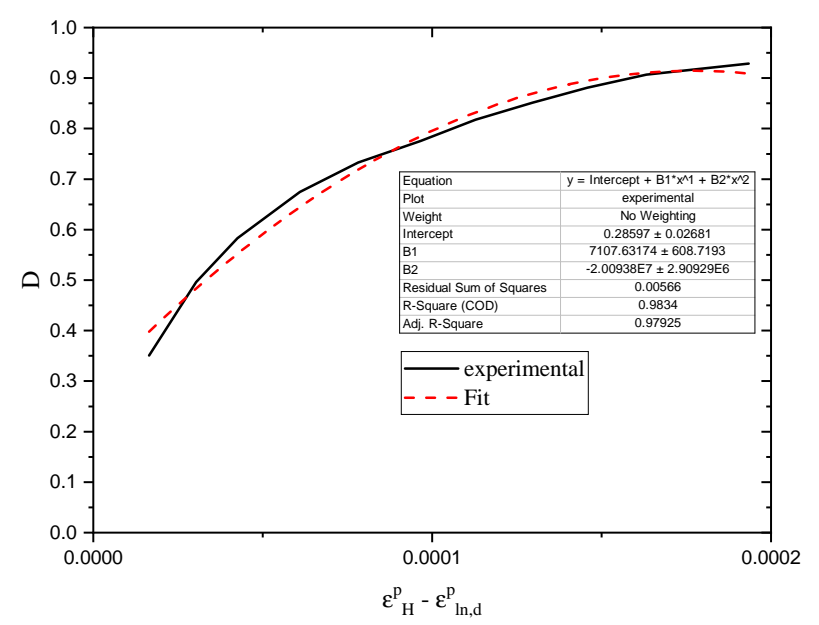

Fonte: Autor. 
A.8 Determinação de $\alpha_{1}^{p}, \alpha_{2}^{p}$ e $\alpha_{3}^{p}$ para o Concreto a Compressão

Figura A.8 - Fit da evolução do dano para o concreto a compressão.

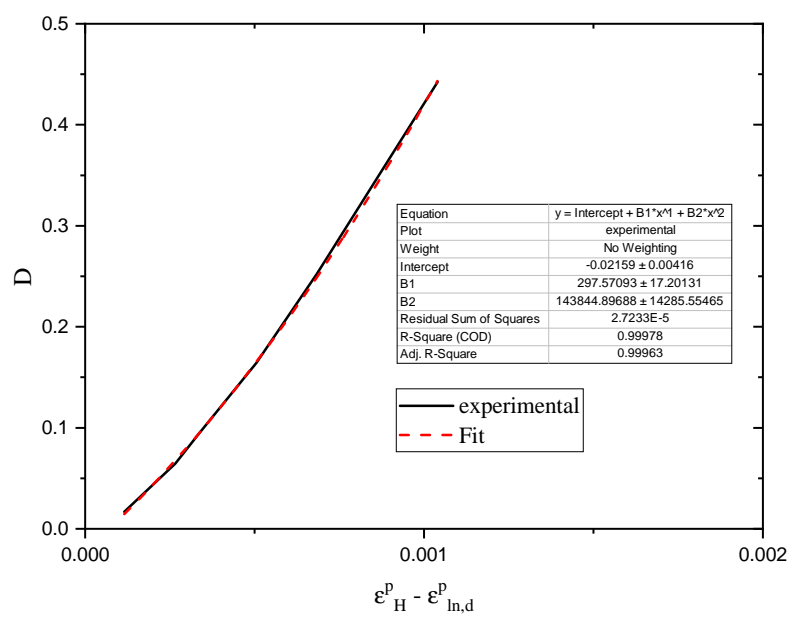

Fonte: Autor.

\section{A.9 Determinação de $\alpha_{1}^{p}, \alpha_{2}^{p}$ e $\alpha_{3}^{p}$ para o UHPFRC a Tração}

Figura A.9 - Fit da evolução do dano para o UHPFRC a tração.

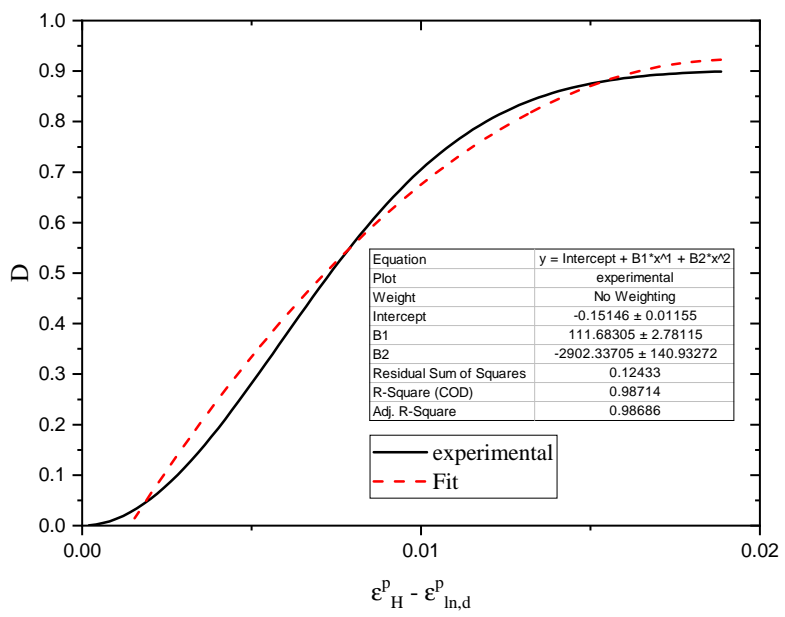

Fonte: Autor. 


\section{A.10 Determinação de $\alpha_{1}^{p}, \alpha_{2}^{p}$ e $\alpha_{3}^{p}$ para o UHPFRC a Com- pressão}

Figura A.10 - Fit da evolução do dano para o UHPFRC a compressão.

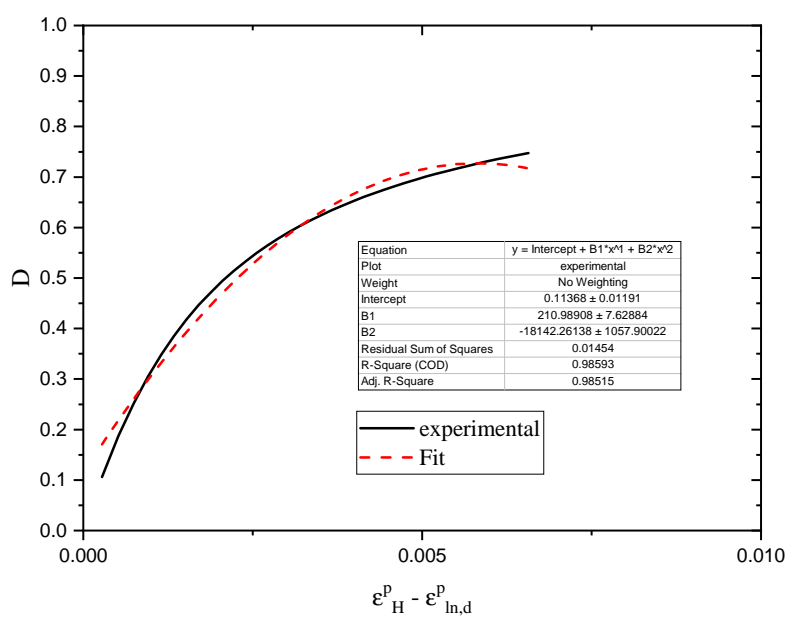

Fonte: Autor. 